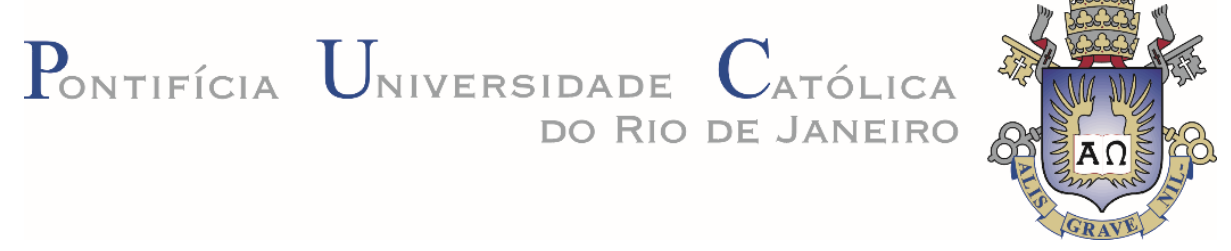

Fernando Aparecido de Assis

\title{
Algoritmo Metaheurístico Construtivo para Solução do Problema de Planejamento da Expansão da Transmissão
}

Tese de Doutorado

Tese apresentada ao Programa de Pós-Graduação em Engenharia Elétrica da PUC-Rio como requisito parcial para obtenção do grau de Doutor em Engenharia Elétrica.

Orientador: Prof. Armando Martins Leite da Silva Coorientador: Prof. Luiz Antônio da Fonseca Manso 
Fernando Aparecido de Assis

\begin{abstract}
Algoritmo Metaheurístico Construtivo para Solução do Problema de Planejamento da Expansão da Transmissão
\end{abstract}

Tese apresentada como requisito parcial para obtenção do grau de Doutor pelo Programa de Pós-Graduação em Engenharia Elétrica da PUC-Rio. Aprovada pela Comissão Examinadora abaixo assinada.

Prof. Armando Martins Leite da Silva Orientador Departamento de Engenharia Elétrica - PUC-Rio

Prof. Luiz Antônio da Fonseca Manso Coorientador UFSJ

Prof. Djalma Mosqueira Falcão UFRJ

Prof. Leonardo de Mello Honório UFJF

Prof. Leonidas Chaves de Resende UFSJ

Prof. Edimar José de Oliveira UFJF

Prof. Márcio da Silveira Carvalho Coordenador Setorial do Centro Técnico Científico - PUC-Rio 
Todos os direitos reservados. É proibida a reprodução total ou parcial do trabalho sem autorização da universidade, do autor e do orientador.

\section{Fernando Aparecido de Assis}

Graduou-se em Engenharia Elétrica pela Universidade Federal de São João del-Rei (UFSJ) em 2012. Obteve o título de mestre em Engenharia Elétrica em 2014 pelo Programa de Pós-Graduação em Engenharia Elétrica, associação ampla entre a Universidade Federal de São João del-Rei (UFSJ) e o Centro Federal de Educação Tecnológica de Minas Gerais (CEFET-MG). É professor do Ensino Básico, Técnico e Tecnológico do Instituto Federal de Educação, Ciência e Tecnologia de Minas Gerais (IFMG), Campus Avançado Itabirito.

Ficha Catalográfica

Assis, Fernando Aparecido de

Algoritmo metaheurístico construtivo para solução do problema de planejamento da expansão da transmissão / Fernando Aparecido de Assis; orientador: Armando Martins Leite da Silva; coorientador: Luiz Antônio da Fonseca Manso 2018.

172 f: il. color. ; $30 \mathrm{~cm}$

Tese (doutorado) - Pontifícia Universidade Católica do Rio de Janeiro, Departamento de Engenharia Elétrica, 2018.

Inclui bibliografia

1. Engenharia Elétrica - Teses. 2. Algoritmo metaheurístico construtivo. 3. Critérios de segurança. 4. Planejamento da expansão da transmissão. 5. Planejamento de sistemas de potência. I. Silva, Armando M. Leite da. II. Manso, Luiz Antônio da Fonseca. III. Pontifícia Universidade Católica do Rio de Janeiro. Departamento de Engenharia Elétrica. IV. Título. 
Dedico esta tese aos meus pais: Aparecida Enita e Joaquim Aristeu. 


\section{Agradecimentos}

Ao término de mais essa importante etapa em minha vida, não poderia deixar de expressar meus sinceros agradecimentos a todos que de alguma forma contribuíram para realização deste trabalho.

Primeiramente, agradeço a Deus pelo dom da vida e por me abençoar sempre, colocando grandes oportunidades em meu caminho.

Aos meus orientadores desse trabalho, Armando M. Leite da Silva e Luiz A. F. Manso, gostaria de expressar minha enorme gratidão pelos ensinamentos, pela paciência e pela confiança. Espero exercer minha carreira de educador com a mesma seriedade, dedicação e empenho que praticam em suas carreiras.

Agradeço aos meus pais, Aparecida Enita e Joaquim Aristeu, por todo amor, carinho e dedicação oferecidos a mim. Se um dia eu puder ser para meus filhos a metade do que representam para mim, estarei satisfeito e orgulhoso.

Agradeço ao meu irmão Antônio Erivaldo pelo apoio incondicional em minha formação pessoal e profissional. Sua importante presença em minha vida sempre transmitiu grande força e segurança.

Tenho enorme gratidão à Fernanda Santos, companheira admirável de todos os momentos. Obrigado por sempre me ajudar a enxergar as coisas de um ponto de vista diferente. Seu amor me engrandece.

Agradeço, ainda, aos amigos que conviveram comigo durante esse tempo de formação, amigos da PUC-Rio, da UFSJ e do IFMG. Em especial, agradeço a quatro grandes companheiros pelas suas valiosas discussões e contribuições para este trabalho: José Filho, Kleber Mazione, Luiz Olmes e Muriell Freire.

Por fim, agradeço à PUC-Rio, ao CNPq e à CAPES pela oportunidade e apoio financeiro. 


\section{Resumo}

Assis, Fernando Aparecido de; Leite da Silva, Armando Martins; Manso, Luiz Antônio da Fonseca. Algoritmo Metaheurístico Construtivo para Solução do Problema de Planejamento da Expansão da Transmissão. Rio de Janeiro, 2018. 172p. Tese de Doutorado - Departamento de Engenharia Elétrica, Pontifícia Universidade Católica do Rio de Janeiro.

O planejamento da expansão da transmissão (PET) visa identificar reforços para a rede a fim de permitir uma adequada interligação entre a demanda e a geração de energia elétrica, ambas previstas para um determinado horizonte futuro de planejamento. Um bom plano de expansão deve garantir o adequado equilíbrio entre o custo de investimento e o custo de operação, mantendo ainda um nível satisfatório de confiabilidade no fornecimento da energia. Entretanto, a identificação de bons planos de expansão para a rede de transmissão tem se tornado uma tarefa cada vez mais difícil. Isso se deve, principalmente, às características e dimensões dos sistemas atuais e, ainda, às incertezas inerentes ao problema. Dessa forma, torna-se necessário o desenvolvimento de ferramentas cada vez mais elaboradas para auxílio dos planejadores. Neste sentido, é proposto nesta tese de doutorado um algoritmo metaheurístico construtivo, denominado AMC-PET, o qual realiza um processo gradual e concomitante de construção de soluções viáveis (planos de expansão). Por meio de mecanismos baseados principalmente em índices de sensibilidade para avaliação dos reforços candidatos e na troca de informações entre as soluções correntes, o processo construtivo proposto é conduzido, parcimoniosamente, na direção de planos de excelente qualidade. Para validação da metodologia proposta, é utilizado o problema PET estático de longo prazo, considerando o critério de segurança "N-1" para a rede de transmissão. Um modelo linearizado de rede com a inclusão de perdas ôhmicas é utilizado para análise das configurações obtidas. Dois sistemas teste, comumente utilizados neste tópico de pesquisa e, também, um sistema real de grande porte, que corresponde à rede elétrica do sul do Brasil, são empregados na validação.

\section{Palavras-Chave}

Algoritmo metaheurístico construtivo; Critérios de segurança; Planejamento da expansão da transmissão; Planejamento de sistemas de potência. 


\section{Abstract}

Assis, Fernando Aparecido de; Leite da Silva, Armando Martins (Advisor); Manso, Luiz Antônio da Fonseca (Co-advisor). Constructive Metaheuristic Algorithm for Solving Transmission Expansion Planning Problems. Rio de Janeiro, 2018. 172p. Tese de Doutorado - Departamento de Engenharia Elétrica, Pontifícia Universidade Católica do Rio de Janeiro.

The transmission expansion planning (TEP) aims to identify reinforcements for the network in order to allow an adequate interconnection between load and electric power generation, both foreseen for a given future planning horizon. A good expansion plan must ensure the proper balance between investment and operating costs, while preserving a satisfactory reliability level in the energy supply. However, identifying good expansion plans for the transmission network has become an increasingly difficult task. This is mainly due to the characteristics and dimensions of current power systems and also to the uncertainties inherent to the problem. Thus, it becomes necessary to develop even more elaborate tools to assist system planners. This doctoral thesis proposes a new optimization tool named constructive metaheuristic algorithm (CMA-TEP). The proposed CMA-TEP tool performs a gradual and parallel process of building feasible solutions (expansion plans). By means of mechanisms mainly based on sensitivity indices for the evaluation of candidate reinforcements and on the information exchange among current solutions, the proposed constructive process is parsimoniously conducted towards high quality plans. To verify the performance of the proposed methodology, the long-term static PET problem considering the "N-1" security criterion for the transmission network is solved. A linearized network model with the inclusion of ohmic losses is used to analyze the obtained configurations. Two test systems, commonly utilized in this research area, and also a real large network, which corresponds to the electric grid of Southern Brazil, are used to validate the proposed method.

\section{Keywords}

Constructive metaheuristic algorithm; Security criteria; Transmission expansion planning; Power system planning. 


\section{Sumário}

$\begin{array}{ll}1 . \text { Introdução } & 17\end{array}$

1.1. Considerações Gerais 17

1.2. Objetivos 21

1.2.1. Objetivo Geral 21

1.2.2. Objetivos Específicos 22

1.3. Estrutura da Tese 22

2. Planejamento da Expansão da Transmissão 24

2.1. Introdução 24

2.2. Modelagem do Problema PET 24

2.3. Técnicas de Solução 28

2.3.1. Otimização Clássica 28

2.3.2. Otimização Heurística 30

2.3.3. Otimização Metaheurística 32

2.4. Critérios de Planejamento 42

2.4.1. Planejamento via Abordagem Determinística 43

2.4.2. Planejamento via Abordagem Probabilística 45

$\begin{array}{ll}\text { 2.5. Conclusões } & 48\end{array}$

3. Algoritmo Metaheurístico Construtivo 49

3.1. Introdução 49

3.2. Representação das Soluções 49

3.3. Mecanismos Construtivos $\quad 50$

3.3.1. Índices de Sensibilidade 51

3.3.2. Mecanismo de Adição 53

3.3.3. Mecanismo de Cruzamento 54

3.3.4. Mecanismo de Mutação 55

3.3.5. Mecanismo de Seleção 56

3.3.6. Mecanismo de Depuração 57

3.3.7. Mecanismo de Refinamento 58 
3.4. Fluxograma do AMC-PET 58

3.5. Parâmetros do AMC-PET 61

3.6. Análise da Dinâmica do Processo Construtivo 63

3.7. AMC-PET Aplicado ao Problema Estático 66

3.7.1. Subproblema de Investimento $\quad 67$

3.7.2. Subproblema de Operação 68

3.7.3. Perdas Ôhmicas na Transmissão 70

3.8. Conclusões 70

4. Aplicações em Sistemas de Pequeno Porte 72

4.1. Introdução 72

4.2. Índices de Desempenho 72

4.3. Resultados - IEEE-RTS 73

4.4. Resultados - SSB 78

4.4.1. Testes Iniciais $\quad 79$

4.4.2. Testes com Ampliação de $n_{p}$ e Variação de $n_{r}$

4.5. Análise Geral dos Parâmetros Utilizados $\quad 87$

4.6. Mecanismo de Seleção com Estratégia de Diversidade 89

4.7. Conclusões 91

5. Aplicação em um Sistema de Grande Porte 92

5.1. Introdução 92

5.2. Definição do SGSB 93

5.2.1. Considerações Iniciais 93

5.2.2. Topologia Base da Rede 94

5.2.3. Lista de Ramos Candidatos ao Reforço 95

5.2.4. Cenários de Carga e de Geração 99

5.2.5. Despacho de Geração e Lista de Contingências 100

5.3. Ajuste do AMC-PET para Sistema de Grande Porte 101

5.4. Resultados - SGSB 103

5.4.1. Cenário Norte Seco 104

5.4.2. Cenário Norte Úmido 107

5.4.3. Cenários Norte Seco e Norte Úmido - Soluções Globais 112

5.5. Análise de Desempenho: AMC-PET versus GA 115 
5.5.1. Populações Iniciais

5.5.2. Resultados - GA 118

5.6. Análise Complementar de Desempenho do AMC-PET 123

5.7. Conclusões

6. Conclusões e Trabalhos Futuros 126

6.1. Conclusões 126

$\begin{array}{lr}\text { 6.2. Propostas de Trabalhos Futuros } & 128\end{array}$

$\begin{array}{ll}7 . \text { Referências bibliográficas } & 130\end{array}$

Apêndice A. Dados dos sistemas de pequeno porte 137

$\begin{array}{lr}\text { A.1. IEEE-RTS } & 137\end{array}$

$\begin{array}{lr}\text { A.2. SSB } & 140\end{array}$

Apêndice B. Dados do sistema de grande porte (SGSB) 144

Apêndice C. Caso tutorial - Sistema Garver 163

C.1. Sistema Garver 163

$\begin{array}{ll}\text { C.2. Execução do AMC-PET } & 167\end{array}$

C.2.1. Primeiro Nível Construtivo 167

C.2.2. Demais Níveis Construtivos 168

C.2.3. Refinamento das Soluções Finais 170

$\begin{array}{ll}\text { C.3. Considerações Finais } & 171\end{array}$ 


\section{Lista de figuras}

Figura 1.1 - Incertezas versus detalhamento do sistema no horizonte de planejamento.

Figura 3.1 - Geração de novos indivíduos: passo (ii) do MA.

Figura 3.2 - Fluxograma representativo do AMC-PET. 59

Figura 3.3 - Dinâmica de evolução do AMC-PET. 64

Figura 4.1 - Evolução do processo construtivo - Execução 1 do Teste A.1.

Figura 4.2 - Comportamento do índice $\mathrm{T}_{\mathrm{M}}$ com variação de $n_{\mathrm{MA}} \mathrm{e}$ $n_{\mathrm{MCM}}$.

Figura 5.1 - Sistema Interligado Nacional (SIN) - Sistema de Transmissão - Horizonte de 2017 [80].

Figura A.1 - Diagrama do IEEE-RTS [74].

Figura A.2 - Diagrama do SSB [43]. 140

Figura C.1 - Diagrama do Sistema Garver [23]. 163

Figura C.2 - Diagrama do Sistema Garver com plano AMC-G.1. 172 


\section{Lista de tabelas}

Tabela 4.1 - Resultados com variação de $n_{\mathrm{MA}}$ e $n_{\mathrm{MCM}}$ - IEEE-RTS. $\quad 75$

Tabela 4.2 - Resultados em função do valor e composição de $n_{r}-$ IEEE-RTS.

Tabela 4.3 - Resultados com variação de $n_{\mathrm{MA}}$ e $n_{\mathrm{MCM}}$ - SSB. $\quad 79$

Tabela 4.4 - Os 10 melhores planos de expansão identificados SSB.

Tabela 4.5 - Resultados impondo maior estagnação $\left(n_{p}=12\right)$ - SSB. 82

Tabela 4.6 - Resultados em função do valor e composição de $n_{r}-$ SSB.

Tabela 4.7 - Índices de decisão - SSB. 86

Tabela 4.8 - Resultados com estratégia de diversidade no MS IEEE-RTS.

Tabela 4.9 - Resultados com estratégia de diversidade no MS - SSB. 90

Tabela 5.1 - Custos dos cabos para construção de LTs. 96

Tabela 5.2 - Parâmetros típicos de LTs por comprimento. 97

Tabela 5.3 - Melhor solução - SGSB - Cenário Norte Seco. 104

Tabela 5.4 - Melhores soluções - SGSB - Cenário Norte Seco. 105

Tabela 5.5 - Resultados do AMC-PET - SGSB - Cenário Norte Seco. 105

Tabela 5.6 - Testes C.1 a C.12: informações adicionais - SGSB -

Cenário Norte Seco.

Tabela 5.7 - Melhor solução - SGSB - Cenário Norte Úmido. 108

Tabela 5.8 - Melhores soluções - SGSB - Cenário Norte Úmido. 108

Tabela 5.9 - Resultados do AMC-PET - SGSB - Cenário Norte Úmido.

Tabela 5.10 - Testes D.1 a D.12: informações adicionais - SGSB Cenário Norte Úmido.

Tabela 5.11 - Resultados do AMC-PET com parâmetros reduzidos SGSB - Cenário Norte Úmido. 
Tabela 5.12 - Melhores soluções globais - SGSB.

Tabela 5.13 - Solução AMC-SG.1 - SGSB. 114

Tabela 5.14 - Resultados do GA - SGSB - Cenário Norte Seco. 119

Tabela 5.15 - Melhores soluções do GA - SGSB - Cenário Norte Seco.

Tabela 5.16 - Melhores soluções do GA com MR - SGSB - Cenário Norte Seco.

Tabela 5.17 - Resultados do GA - SGSB - Cenário Norte Úmido.

Tabela 5.18 - Análise de desempenho - Sistemas IEEE-RTS, SSB e SGSB.

Tabela A.1 - Dados de barra - IEEE-RTS.

Tabela A.2 - Dados de ramos candidatos - IEEE-RTS.

Tabela A.3 - Dados de barra - SSB.

Tabela A.4 - Dados de ramos candidatos - SSB.

Tabela B.1 - Dados de barra - SGSB.

Tabela B.2 - Dados de ramos existentes - SGSB.

Tabela B.3 - Lista de ramos candidatos - SGSB.

Tabela C.1 - Dados de barra - Sistema Garver.

Tabela C.2 - Dados de ramos candidatos - Sistema Garver.

Tabela C.3 - Fluxos de potência - Topologia base - Sistema Garver. 165

Tabela C.4 - Sobrecargas resultantes do estudo de contingências -

Sistema Garver.

Tabela C.5 - Evolução do processo construtivo - AMC-PET Sistema Garver.

Tabela C.6 - Melhores soluções com execução única do AMC-PET Sistema Garver.

Tabela C.7 - Melhores soluções identificadas - Sistema Garver. 


\section{Lista de siglas}

ACO - $\quad$ Otimização por Colônia de Formigas (Ant Colony Optimization)

ACS - $\quad$ Sistemas de Colônia de Formigas (Ant Colony Systems)

AHC - $\quad$ Algoritmo Heurístico Construtivo

AIS - $\quad$ Sistema Imunológico Artificial (Artificial Immune System)

AMC-PET - Algoritmo metaheurístico construtivo proposto para solução do problema PET

EENS - $\quad$ Valor esperado de energia não suprida (Expected Energy Not-Supplied)

EPE - $\quad$ Empresa de Pesquisa Energética

ES - $\quad$ Estratégia de Evolução (Evolutionary Strategy)

GA - $\quad$ Algoritmo Genético (Genetic Algorithm)

GRASP - Procedimento de Busca Adaptativa Aleatória Gulosa (Greedy Randomized Adaptive Search Procedure)

LOLC - $\quad$ Custo de corte de carga (Loss of Load Cost)

LOLE - $\quad$ Expectativa de perda de carga (Loss of Load Expectation)

LT - $\quad$ Linha de transmissão

MA - Mecanismo de adição

MC - Mecanismo de cruzamento

MD - Mecanismo de depuração

MM - Mecanismo de mutação

MR - $\quad$ Mecanismo de refinamento

MS - Mecanismo de seleção

OO - $\quad$ Otimização Ordinal (Ordinal Optimization)

PET - Planejamento da expansão da transmissão

PSO - O Otimização por Enxame de Partículas (Particle Swarm Optimization)

SA - $\quad$ Recozimento Simulado (Simulated Annealing)

SMCNS - Simulação Monte Carlo Não Sequencial

SMCS - S Simulação Monte Carlo Sequencial 
SIN - $\quad$ Sistema Interligado Nacional

SGSB - Sistema Geoelétrico Sul do Brasil

SSB - $\quad$ Sistema Sul Brasileiro

TS - $\quad$ Busca Tabu (Tabu Search) 


\section{Lista de símbolos}

$\operatorname{Ind}_{c h-i j}-\quad$ Índice de atratividade/efetividade para verificação do carregamento hipotético do ramo $i-j$ na condição " $\mathrm{N}-0$ "

Ind $d_{s c-i j}^{\text {outros }}$ - Índice de atratividade para verificação da sobrecarga e do corte de carga causados pelo ramo $i-j$ na condição "N-1"

Ind ${ }_{s c-i j}^{\text {própro }}$ - Índice de atratividade para verificação da sobrecarga sofrida pelo ramo $i-j$ na condição " $\mathrm{N}-1$ "

"N-0" - Condição de rede intacta do sistema

"N-1" - Condição de contingência simples da rede do sistema

$n_{\mathrm{V}}-\quad$ Tamanho do conjunto $\Omega_{\mathrm{V}}$, de indivíduos viáveis

$n_{\mathrm{MA}}-\quad$ Tamanho do conjunto $\Omega_{\mathrm{MA}}$, de indivíduos obtidos pelo mecanismo de adição (MA)

$n_{\mathrm{MCM}}-\quad$ Tamanho do conjunto $\Omega_{\mathrm{MCM}}$, de indivíduos obtidos, de forma conjunta, pelos mecanismos de cruzamento (MC) e de mutação (MM)

$n_{p}-\quad$ Critério de convergência do algoritmo metaheurístico construtivo (AMC-PET)

$n_{p-G A}-\quad$ Critério de convergência da metaheurística Algoritmo Genético (GA)

$N_{\text {Pop }}-\quad$ Tamanho da população de indivíduos da metaheurística Algoritmo Genético (GA)

$n_{r}-$

Número de ramos selecionados a partir dos índices de sensibilidade no emprego do mecanismo de adição (MA)

$n_{r c}-\quad$ Número de ramos candidatos ao reforço

$\Omega_{\mathrm{V}}-\quad$ Conjunto de indivíduos viáveis

$\Omega_{\mathrm{MA}}-\quad$ Conjunto de indivíduos obtidos pelo mecanismo de adição (MA)

$\Omega_{\mathrm{MCM}}-\quad$ Conjunto de indivíduos obtidos, de forma conjunta, pelos mecanismos de cruzamento (MC) e de mutação (MM)

$\Omega_{\mathrm{MD}}-\quad$ Conjunto de indivíduos obtidos pelo mecanismo de depuração (MD) 


\section{1. Introdução}

\section{1.}

\section{Considerações Gerais}

Solucionar o problema de Planejamento da Expansão da Transmissão (PET) consiste em definir reforços a serem instalados/construídos na rede, a fim de prover a continuidade do atendimento frente ao crescimento da demanda e da geração de energia elétrica. A adição de novos reforços na transmissão implica em um crescimento da capacidade de transporte de energia, o que, consequentemente, aumenta a capacidade de sua negociação e os níveis de confiabilidade em seu fornecimento. Porém, geralmente os investimentos necessários são elevados. Dessa forma, boas alternativas de expansão devem ser capazes de garantir um compromisso entre os custos de investimento e de operação, mantendo-se um nível adequado de qualidade no fornecimento da energia e maximizando o uso dos recursos atuais disponíveis.

A busca por boas alternativas de expansão para o problema PET tem se tornado uma tarefa cada vez mais difícil. As grandes dimensões dos sistemas de transmissão atuais, a natureza discreta das decisões de investimento e as incertezas associadas ao crescimento da carga e à disponibilidade de fontes energéticas são alguns dos principais fatores que dificultam essa busca. De forma geral, o planejamento da expansão da transmissão pode ser definido como um problema combinatório, estocástico e de grande complexidade, classificado como problema de programação não linear inteira mista [1]. Diversos trabalhos presentes na literatura vêm sendo publicados, apresentando diferentes formas de abordagem e métodos de solução [2], [3], [4], [5] e [6].

O horizonte temporal relativo ao estudo do PET influencia diretamente na forma como o problema deve ser tratado. Geralmente, o horizonte de planejamento é divido em longo, médio e curto prazo, como representado na Figura 1.1. Quanto mais distante é o horizonte de análise, maior atenção deve ser dispensada à consideração das incertezas associadas ao problema (e.g., disponibilidade dos 
equipamentos da rede, projeções da carga e da geração e restrições ambientais e de mercado), e um menor esforço pode ser considerado em relação ao nível de detalhamento na modelagem do sistema. Em contrapartida, para um período mais curto do horizonte de planejamento, já com um nível menor de incertezas envolvidas, maior é o detalhamento do sistema a ser considerado no modelo. De forma geral, os planos de expansão identificados nos primeiros estágios do estudo de planejamento vão sendo reavaliados a partir de modelos cada vez mais completos e adaptados até a data de início das obras de instalação/construção [7].

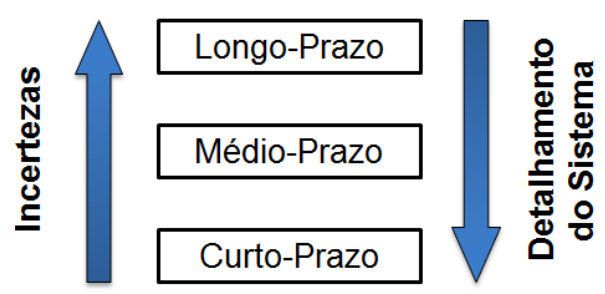

Figura 1.1 - Incertezas versus detalhamento do sistema no horizonte de planejamento.

No estudo de planejamento da expansão para o horizonte de longo prazo, foco do estudo proposto nesta tese, a representação da rede elétrica é comumente realizada por meio de modelos baseados na linearização das equações de fluxo de potência (e.g., modelo de transportes, modelo DC, modelo disjuntivo e modelo híbrido) [8]. Poucos são os trabalhos publicados com base em equações de fluxo de potência $\mathrm{AC}$ [9]. Isso se deve, principalmente, às características da rede e ao maior nível de incertezas associadas ao problema para este estágio. Com o intuito de melhorar a qualidade dos resultados nas avaliações dos planos de expansão obtidos a partir do modelo DC, trabalhos mais recentes vêm incorporando a representação das perdas ôhmicas da transmissão. Alguns exemplos podem ser verificados em [10], [11], [12], [13] e [14].

De acordo com a divisão do horizonte de planejamento em períodos de investimento, o problema PET pode ainda ser considerado como de abordagem estática ou multiestágio, também denominado dinâmico por alguns autores [3]. Uma abordagem estática determina a localização e o número de reforços necessários para expansão da transmissão para apenas um único estágio dentro do horizonte de estudo. Nesta abordagem, o planejador não está interessado em saber quando os reforços devem ser instalados, mas sim o estado final da rede. A grande maioria dos trabalhos relacionados à solução do problema PET é destinada a esta abor- 
dagem [5]. Já no planejamento multiestágio, não somente a localização e o número de reforços são necessários, mas também a evolução temporal destas decisões é objeto do estudo. O horizonte de planejamento é separado em vários períodos, sendo que os investimentos devem ser realizados no início de cada um deles (e.g., [12], [14], [15], [16] e [17]). Nesta abordagem, o tamanho e o nível de complexidade dos sistemas proporcionam um número muito grande de variáveis e restrições a serem consideradas, exigindo um maior esforço computacional para a obtenção dos melhores planos. Apesar da abordagem estática para solução do problema PET ser mais simplificada que a abordagem multiestágio, ela se apresenta como uma excelente opção para estudos iniciais no planejamento da expansão, sendo adotada para o desenvolvimento da metodologia proposta neste documento.

De acordo com o procedimento de otimização utilizado para identificação do plano de expansão, as técnicas de solução do problema PET podem ser classificadas como métodos clássicos, heurísticos e metaheurísticos. Vantagens e desvantagens podem ser verificadas na utilização de cada uma delas [3], [4].

Nas técnicas classificadas como de otimização clássica o planejamento da transmissão é tratado como um problema de otimização contendo uma função objetivo, normalmente relacionada à minimização de custos e sujeita a algumas restrições, que geralmente são associadas a critérios técnicos, econômicos e de qualidade e confiabilidade no fornecimento da energia. Apesar de, geralmente, os métodos clássicos garantirem a solução ótima para o problema PET, no planejamento de longo prazo é impossível modelar todos os aspectos relacionados aos critérios citados. Portanto, a solução identificada é ótima apenas sob as restrições inseridas no modelo, devendo ainda ser verificada e aperfeiçoada em relação aos aspectos e critérios (e.g., sociais e ambientais) não considerados. Ademais, a característica discreta das variáveis envolvidas no problema e a não linearidade das relações matemáticas entre essas variáveis representam grandes obstáculos na identificação do plano ótimo de expansão quando da utilização destas técnicas.

Assim sendo, uma alternativa para solução do problema PET, que vem apresentando uma crescente aplicação e aceitação na literatura atual, é o emprego de técnicas heurísticas e metaheurísticas. Isto se deve, principalmente, pela capacidade destes métodos em trabalhar com variáveis mistas (discretas e contínuas) e problemas não lineares, pela baixa complexidade de implementação de seus algoritmos e pelo menor nível de complexidade envolvido no tratamento de incertezas 
com a utilização das mesmas. Apesar de não garantirem a identificação da solução ótima para o problema, estes métodos podem fornecer soluções de alta qualidade com tempos de processamento aceitáveis, até mesmo para sistemas de grande porte [16].

Em relação à interação do planejador com o processo de solução do problema PET, de acordo com a modelagem e técnica de otimização adotadas, a abordagem pode ser classificada como interativa ou automática [1]. Em uma abordagem interativa, o planejador interfere no processo de planejamento tomando decisões pontuais baseadas em sua experiência e em estudos complementares realizados. Nesta abordagem, os ajustes realizados ao longo do planejamento interferem diretamente no resultado final (plano de expansão) obtido. Já em uma abordagem automática, depois de definidas as informações iniciais do problema, não há mais interferência do planejador orientando e tomando decisões durante sua solução.

Outro importante aspecto pertinente à identificação de boas soluções para o problema PET está relacionado à avaliação do desempenho do sistema após falha/saída de equipamentos [12], [18]. Durante sua operação é preciso que o sistema esteja preparado para tais situações. Quando da consideração de critérios de segurança ${ }^{1}$ relacionados ao desempenho do sistema no atendimento à demanda, o PET pode ser classificado como de abordagem determinística ou de abordagem probabilística. De forma geral, planos de expansão que atendam a esses critérios exigem maiores níveis de investimento se comparados aos planos obtidos apenas para o atendimento da rede intacta do sistema.

$\mathrm{Na}$ abordagem determinística, são considerados critérios tais como "N-1" e "N-2" (contingências simples ou duplas). Para o critério "N-1", durante a operação do sistema deve ser garantido o total atendimento da carga, sem que os equipamentos sejam sobrecarregados, mesmo para o caso de perda simples de qualquer componente da rede. Para o critério determinístico "N-2", a continuidade do atendimento à carga deve ser garantida também para o caso de perda combinada de quaisquer dois equipamentos do sistema. Já nos estudos de planejamento com abordagem probabilística, a qualidade do sistema é avaliada a partir de índices de confiabilidade (e.g., Loss of Load Expectation - LOLE, Expected Energy not-

\footnotetext{
${ }^{1}$ Nesta tese, assim como considerado em vários trabalhos da literatura relacionada, o termo "critério de segurança" é utilizado sob o ponto de vista da adequação estática, de acordo com a continuidade do atendimento à demanda frente à falha/saída de componentes do sistema.
} 
Supplied - EENS e Loss of Load Cost - LOLC) obtidos a partir de informações de disponibilidade de equipamentos do sistema [19]. A dificuldade de se utilizar este tipo de abordagem reside no alto custo computacional necessário para avaliação dos planos candidatos, principalmente para redes de elevadas dimensões, e na ausência de definições claras de quão confiável um sistema precisa ser em termos dos índices avaliados [12].

Devido ao esforço computacional necessário, poucos trabalhos da literatura atual consideram algum tipo de critério de segurança durante a solução do problema PET. Alguns trabalhos, por outro lado, consideram a avaliação do critério de segurança apenas para o conjunto final de soluções, as quais apresentam os menores investimentos para a situação de rede intacta (e.g., [11] e [20]). Neste caso, são preservadas apenas as soluções finais do processo de otimização que permitem a operação dos equipamentos dentro de seus limites técnicos e garantem o atendimento total da carga, ou que estejam dentro de certos limites estabelecidos quanto aos índices de confiabilidade. Entretanto, os custos de investimento correspondentes são mais elevados se comparados aos das soluções obtidas quando o critério de segurança é observado durante o processo de busca [21], [22].

Dessa forma, faz-se necessária a utilização de ferramentas de otimização mais eficientes (i.e., que garantam um melhor balanço entre exatidão e custo computacional) no processo de identificação de soluções de boa qualidade, que simultaneamente garantam o critério de segurança pré-definido. No estudo apresentado nesta tese, para solução do problema PET é considerado o critério determinístico de segurança "N-1", aplicado à falha de equipamentos da rede de transmissão. Informações acerca de eventuais sobrecargas e cortes de carga por ilhamento, resultantes do estudo de contingência, são utilizadas como indicadores para o reforço da rede.

\section{2.}

\section{Objetivos}

\subsection{1.}

\section{Objetivo Geral}

Tendo em vista a complexidade inerente à tarefa de se planejar a expansão das redes de transmissão de energia elétrica, esta tese de doutorado tem como ob- 
jetivo geral contribuir para o desenvolvimento de novas ferramentas, que sejam capazes de auxiliar o planejador de forma adequada e eficiente na solução do problema PET.

Para tanto, é proposto um algoritmo metaheurístico construtivo, denominado AMC-PET. A partir desta técnica, soluções viáveis de boa qualidade são paralela e automaticamente construídas partindo da topologia base da rede (solução vazia). O processo construtivo se dá pela adição gradual de reforços mais atrativos, indicados por índices de sensibilidade relacionados ao comportamento operativo da rede. Mecanismos de recombinação e perturbação, comumente utilizados por outras classes de metaheurísticas, são também integrados, visando inserir maior diversidade ao processo. Dois outros mecanismos, seleção e depuração, têm por objetivo permitir a condução do algoritmo na direção de soluções de boa qualidade. Ao final do processo construtivo, visando aprimorar ainda mais o conjunto final das melhores soluções (planos de expansão), é empregado um mecanismo de refinamento.

\subsection{2.}

\section{Objetivos Específicos}

Como objetivos específicos a serem cumpridos, destacam-se:

- investigar o desempenho/comportamento do AMC-PET frente a diferentes problemas, com diferentes dimensões e características;

- propor um sistema/problema real de grande porte para realização de testes de validação relacionados ao problema PET;

- verificar o desempenho do AMC-PET em comparação com o desempenho de ferramentas usualmente empregadas para solução do problema PET.

\section{3.}

\section{Estrutura da Tese}

No presente capítulo são apresentados conceitos gerais relacionados ao problema PET, principalmente no que se referem às linhas de abordagem de interesse para o estudo deste trabalho. São também apresentados neste capítulo os principais objetivos a serem alcançados com o desenvolvimento desta pesquisa. 
Posteriormente, no Capítulo 2, é apresentada uma revisão de diversos trabalhos da literatura. São apontados nesta revisão os principais modelos adotados para o PET e as técnicas de otimização comumente utilizadas em sua solução. Também faz parte deste capítulo uma discussão relacionada à consideração de critérios determinísticos ou probabilísticos na decisão de reforços para a rede de transmissão.

No Capítulo 3 é apresentado o algoritmo metaheurístico construtivo (AMCPET) proposto como ferramenta de solução do problema PET estático para o horizonte de longo prazo. Os mecanismos de construção empregados, assim como o algoritmo do processo construtivo, são detalhadamente descritos. A formulação considerada nesta tese para o problema PET, a qual se baseia no modelo DC com perdas, e os índices de sensibilidade utilizados neste trabalho durante o processo construtivo do AMC-PET são também apresentados neste capítulo.

A avaliação e ajuste dos parâmetros da metodologia proposta são realizados no Capítulo 4, onde o problema PET, considerando o critério de segurança "N-1" para a rede de transmissão, é solucionado para o Sistema IEEE-RTS de 24 barras e o Sistema Sul Brasileiro (SSB) de 46 barras.

O desempenho da metodologia proposta (AMC-PET) frente a um problema real de grande porte é avaliado no Capítulo 5. Neste capítulo são apresentadas todas as premissas consideradas para obtenção do sistema real utilizado, denominado Sistema Geoelétrico Sul do Brasil (SGSB), bem como para definição do problema PET para este sistema. Resultados obtidos na solução do PET, para dois diferentes cenários de carga e de geração, são apresentados e analisados. São ainda apresentadas neste capítulo três diferentes versões da metaheurística Algoritmo Genético (Genetic Algorithm - GA) implementadas e também empregadas na solução do PET para o sistema real de grande porte definido. Os resultados apresentados pelo GA são utilizados para validação do AMC-PET.

Finalmente, no Capítulo 6 são expostas as principais conclusões do trabalho desenvolvido nesta tese de doutorado. São apresentadas também neste capítulo, propostas de continuidade do estudo para realização de trabalhos futuros. 


\section{2. \\ Planejamento da Expansão da Transmissão}

\section{1. Introdução}

Neste capítulo é apresentada uma revisão bibliográfica dos principais conceitos referentes ao problema PET levantados no Capítulo 1, com ênfase para as questões associadas à sua formulação e solução. As principais abordagens do problema PET, presentes em diversos trabalhos da área que serviram de base e motivação para o desenvolvimento desta tese de doutorado, são exibidas e discutidas ao longo de alguns temas principais, tais como a modelagem do problema, as técnicas de otimização comumente utilizadas e os critérios de planejamento adotados na identificação dos planos de expansão.

\section{2. \\ Modelagem do Problema PET}

No estudo tradicional de planejamento da expansão da transmissão, busca-se definir os melhores reforços a serem adicionados à topologia corrente da rede a fim de garantir o adequado funcionamento do sistema em um cenário futuro. Os primeiros estudos acerca do planejamento da expansão de sistemas elétricos de potência tratavam de problemas com poucas alternativas de expansão, o que tornava o trabalho do planejador uma tarefa relativamente simples. Para realização dos estudos, ferramentas de análise de redes, tais como cálculos de fluxo de potência e estudos de estabilidade e de curto-circuito, se faziam suficientes. Entretanto, com o crescimento das dimensões destes sistemas, surgiu a necessidade de estudos mais elaborados acerca do problema de planejamento da expansão de sistemas elétricos de potência.

Já no início da década de 70, com uma maior disponibilidade de ferramentas computacionais, houve uma intensificação na proposta e utilização de modelos matemáticos e técnicas de otimização para solução do problema PET, visando identificar bons planos de reforços para a rede de transmissão [3]. Neste sentido, 
um dos primeiros trabalhos publicados para solução do problema PET foi desenvolvido por Garver [23]. Outros trabalhos de grande importância da época, também baseados em técnicas de otimização e abordagens mais automatizadas para solução do problema de planejamento da expansão, podem ainda ser citados: [2], [24], [25] e [26].

De uma forma geral, o modelo de um problema de otimização é composto por uma função objetivo, a qual se deseja minimizar ou maximizar, e um conjunto de restrições, ambos relacionados às variáveis de decisão do problema. Os valores possíveis para as variáveis de decisão, os quais são delimitados pelas restrições, formam um conjunto (finito ou não) de soluções factíveis. A solução que apresenta o melhor valor para a função objetivo é chamada de ótimo global. Em relação à fase de modelagem, pode-se dizer que uma solução ótima será tanto melhor para um problema quanto mais detalhadamente forem representadas todas as suas características.

Em relação ao problema PET para o horizonte de longo prazo, modelos clássicos de otimização mais simplificados são comumente utilizados para representar a rede elétrica do sistema. Nesta fase do planejamento, existe um elevado nível de incertezas associadas ao problema, tais como as incertezas relativas ao crescimento da carga e à disponibilidade de energia no cenário futuro. Somado a este fato, a rede de transmissão normalmente apresenta uma configuração não conexa para este período, o que dificulta sua solução com a utilização, por exemplo, de relações matemáticas de fluxo de potência AC.

Dessa forma, os modelos mais frequentemente utilizados na abordagem de longo prazo do problema PET são os baseados nas equações de fluxo de potência linearizado $^{2}$ [8], [27]. O modelo de transportes, por exemplo, primeiramente utilizado em [23], é o mais simples entre eles. Este modelo não considera a lei de Kirchhoff das tensões em sua formulação e, portanto, apresenta apenas equações lineares em suas restrições. Dessa maneira, torna-se possível a utilização de técnicas de programação linear como elemento básico de otimização. Entretanto, soluções obtidas com este modelo apresentam qualidade reduzida (i.e., distantes das soluções encontradas por meio de modelos mais completos). Além disso, planos

\footnotetext{
${ }^{2}$ Diversas referências da literatura utilizam o termo "modelos lineares" para denominação de formulações do PET baseadas nas equações de fluxo de potência linearizado. É importante que um cuidado especial seja considerado na utilização de tais termos, tendo em vista que o modelo DC implica em não linearidade para o problema PET.
} 
de expansão identificados a partir do modelo de transportes, em geral, não se mantêm factíveis em uma avaliação considerando a segunda lei de Kirchhoff e, portanto, necessitam de reforços adicionais. Exemplos de utilização do modelo de transportes para o PET podem também ser encontrados em [27] e [28].

O modelo considerado como ideal pelos planejadores na realização dos trabalhos de planejamento da expansão para horizontes de longo prazo é conhecido como modelo DC. Neste modelo, as condições de operação do sistema devem satisfazer às duas leis de Kirchhoff, das tensões e das correntes. Soluções identificadas por meio deste modelo, sobretudo quando as perdas ôhmicas são consideradas, apresentam menor necessidade de reforços adicionais quando avaliadas por ferramentas baseadas nas equações de fluxo de potência AC. Apesar das simplificações decorrentes da utilização do fluxo de carga linearizado, o modelo DC ainda representa um problema de programação não linear inteira mista. Exemplos da aplicação do modelo DC para solução do PET podem ser verificados em [29], [30] e [31].

O modelo híbrido, decorrente da combinação dos modelos DC e de transportes, é outro exemplo de modelo baseado nas equações de fluxo de potência linearizado. Este modelo permite encontrar soluções mais próximas da solução ótima do modelo DC, enquanto flexibiliza a questão da não linearidade. No modelo híbrido, proposto inicialmente em [26], a segunda lei de Kirchhoff é considerada apenas para a rede original existente no sistema. Já as restrições lineares de balanço de fluxo nas barras e a capacidade de transmissão nas linhas são consideradas para todos os ramos do sistema. Um exemplo recente do emprego do modelo híbrido pode ser encontrado em [32].

Outro modelo muito difundido, também derivado da formulação do modelo DC, é o modelo disjuntivo. Em sua essência, este modelo transforma o problema não linear em um problema equivalente linearizado por meio da incorporação de um parâmetro $M$ de valor suficientemente elevado e pela consideração de variáveis binárias. A qualidade das soluções obtidas por este modelo é mantida em relação à qualidade das soluções decorrentes do modelo DC. Um fator complicador é a determinação do parâmetro $M$. Entretanto, existem trabalhos que adotam estratégias para determinação de valores mínimos para esse parâmetro, como em [33], por exemplo. Outras aplicações do modelo disjuntivo para solução do problema PET podem ser encontradas em, [34], [35] e [36]. 
Existem ainda na literatura trabalhos que consideram a combinação de mais de um modelo durante o processo de solução do problema PET. Em fases iniciais do estudo são utilizados modelos mais simplificados e, com a evolução da solução, modelos mais completos vão sendo considerados. Em [27], por exemplo, o algoritmo proposto é dividido em três fases principais, as quais utilizam o modelo de transportes, o modelo híbrido e, por fim, o modelo DC. Neste trabalho, somente na terceira fase do algoritmo, quando é utilizado o modelo DC, a natureza discreta de investimento é considerada. Nas demais fases, as adições de reforços são representadas por variáveis contínuas.

Com o intuito de melhorar a qualidade das soluções identificadas pelos modelos baseados na simplificação das equações de fluxo de potência, e consequentemente a operação futura do sistema, alguns trabalhos, como [10], [11], [12], [13], [14], [29] e [31], consideram ainda a estimação das perdas ôhmicas nos circuitos do sistema.

Em [12], por exemplo, o custo relativo às perdas ôhmicas é considerado na função objetivo do problema PET multiestágio, a qual se deseja minimizar. Cada plano de expansão identificado é avaliado por meio de um problema de operação baseado no modelo de fluxo DC. O cálculo das perdas é realizado para cada circuito do sistema utilizando as informações obtidas a partir da solução do problema de programação linear. Em seguida, as perdas são distribuídas como cargas entre as barras terminais de cada circuito. A fim de melhorar a precisão dos resultados, o problema de programação linear é novamente resolvido e as perdas são novamente calculadas. O mesmo procedimento de cálculo das perdas é também utilizado em [29] e [31]. Já em [10], é proposta uma técnica baseada em programação linear inteira mista para solução do problema PET, incluindo uma linearização por partes para a representação das perdas. Apesar de fornecer soluções mais caras, a consideração de perdas pode fornecer alternativas de reforços mais consistentes, reduzindo os gastos com os futuros ajustes do plano de expansão [1].

Apesar das dificuldades mencionadas em relação à utilização de modelos baseados em equações de fluxo de potência AC dedicados à solução do problema PET para horizontes de longo prazo, alguns trabalhos da literatura podem ser citados. Em [37], por exemplo, é proposto um modelo não linear que inclui limites para a magnitude de tensão nas barras. Já no trabalho [9] é apresentado um algoritmo heurístico construtivo simples para solução do problema PET, no qual é 
considerado um modelo AC para alocação de potência reativa. Mais recentemente, em [20] e [38], a modelagem AC do fluxo de potência é utilizada para solução do problema de planejamento da subtransmissão de energia elétrica. Nestes dois últimos trabalhos, as metodologias propostas são empregadas a dois sistemas reais da Cemig Distribuição, sendo alcançados bons resultados para o problema de planejamento.

\section{3. \\ Técnicas de Solução}

Após definir a adequada formulação do problema de otimização, o próximo passo na solução do PET é encontrar o plano ótimo, ou quase ótimo, de expansão, o que é realizado por meio de procedimentos matemáticos de otimização. Normalmente, quanto mais completo é o modelo de otimização, mais complexa é a solução do problema. Portanto, é necessário que exista, a depender do problema em estudo, um compromisso entre o detalhamento do modelo e a técnica de solução adotada.

Neste sentido, diversos estudos vêm sendo publicados, explorando diversificadas técnicas de solução para o problema PET [3], [4], [5] e [6]. Estes estudos objetivam, além de melhorar a qualidade das soluções, diminuir o esforço computacional envolvido na obtenção dos planos de expansão.

De acordo com a metodologia adotada para solução do problema, basicamente as técnicas de otimização podem ser agrupadas nas categorias dos métodos clássicos, heurísticos e metaheurísticos [3]. A seguir são apresentadas características gerais dos métodos de otimização utilizados na solução do problema PET.

\subsection{1.}

\section{Otimização Clássica}

Na otimização clássica, o PET é formulado como um problema de otimização com uma determinada função objetivo, normalmente relacionada à minimização de custos, e um conjunto de restrições operativas, econômicas, ambientais e/ou de confiabilidade. Diversas são as técnicas de otimização clássica já empregadas para solução do problema PET. Como exemplo, podem ser citadas as técnicas de programação linear (e.g., [23] e [26]), de programação dinâmica (e.g., [24]), de programação não linear (e.g., [9], [13] e [39]), de programação inteira 
mista (e.g., [10], [34], [40] e [41]) e baseadas em decomposição hierárquica ou de Benders (e.g., [27], [33], [36] e [42]).

Métodos de programação linear, tais como o método simplex e o método de pontos interiores, são comumente utilizados para solução de subproblemas gerados pela análise direta do planejador ou pela utilização de técnicas diversas de otimização. Os problemas formulados de acordo com os modelos de transporte e híbrido, por exemplo, são usualmente solucionados por técnicas de programação linear. Neste sentido, em [23], a cada fase do algoritmo construtivo proposto são gerados subproblemas no formato do modelo de transportes, os quais são solucionados por meio de algoritmos de programação linear, tornando possível a análise da rede. Em [26], o método de programação linear é utilizado para identificar as necessidades de reforços para a rede de transmissão, o que é feito por meio da estimação dos fluxos em uma rede artificial.

Uma técnica de otimização clássica comumente utilizada para solução de problemas de otimização formado por variáveis de decisão mistas (discretas e contínuas) é o algoritmo branch-and-bound. Este algoritmo, basicamente trabalha criando uma árvore de enumeração de soluções de forma inteligente e iterativa. A cada iteração são resolvidos subproblemas de programação linear com variáveis contínuas. O algoritmo branch-and-bound é utilizado em [34] para solução do problema de programação linear inteira mista, referente ao modelo disjuntivo para o problema PET. Neste trabalho, uma função gulosa é utilizada para evolução do processo de solução. Um algoritmo branch-and-bound para solução de problemas de programação não linear inteira mista, referente ao PET de longo prazo e considerando as perdas ôhmicas na transmissão, é proposto em [13].

No tratamento hierárquico proposto em [27] é possível verificar um exemplo de aplicação do método de decomposição de Benders, onde o problema principal é dividido em dois subproblemas: investimento (subproblema "mestre") e operação (subproblema "escravo"). No subproblema "mestre", são definidas as decisões de investimento, as quais são informadas ao subproblema "escravo". No subproblema "escravo", são representadas as equações de fluxo de potência, onde é considerada a minimização do corte de carga. As informações de corte de carga são retornadas ao subproblema de investimento e funcionam como indicativos das necessidades operativas da rede. Os subproblemas gerados a cada nível hierárquico são resolvidos a partir dos métodos de programação linear e de programação 
linear inteira, a depender do modelo resultante. Os mesmos autores utilizaram em [42] um algoritmo especializado de enumeração implícita para resolver o subproblema de investimento decorrente da terceira fase do algoritmo de decomposição hierárquica de Benders.

O problema PET, na forma do modelo de transportes, é também tratado em [43] utilizando a decomposição hierárquica de Benders, sendo o problema decomposto nos subproblemas de investimento (mestre) e de operação (escravo). O subproblema de investimento é solucionado por meio da técnica branch-and-bound, e o subproblema de operação é solucionado utilizando um programa linear especializado.

\subsection{2.}

\section{Otimização Heurística}

Levando-se em consideração a complexidade relativa à modelagem do PET e o explosivo número de combinações de alternativas de expansão, as técnicas aproximadas de otimização têm recebido cada vez mais a atenção dos pesquisadores na solução do problema de planejamento da transmissão.

Técnicas heurísticas são ferramentas aproximadas de otimização cujo processo de construção de soluções é guiado por regras lógicas ou empíricas associadas ao tipo de problema que se pretende resolver. Na utilização destas técnicas não se pode garantir a identificação da solução ótima global para o problema, principalmente na presença de grande número de ótimos locais dentro do conjunto factível de soluções, característica peculiar do PET. Entretanto, soluções tecnicamente viáveis e economicamente competitivas podem ser obtidas em tempos de processamento computacional reduzidos, até mesmo para problemas de grandes dimensões [3].

Na solução do problema PET, um procedimento usual é a realização de adições de reforços a partir de análises de sensibilidade e do comportamento do sistema durante a operação, à medida que sua configuração vai sendo modificada. Funções de variáveis do problema são utilizadas para classificar e selecionar os melhores reforços a serem adicionados a cada etapa do processo de construção da solução. Neste sentido, podem ser observadas, por exemplo, as sobrecargas em equipamentos de transmissão [23], a distribuição dos fluxos de potência na rede [25] e os cortes de carga na operação do sistema [44], entre outros. 
Uma estratégia comum é a utilização de algoritmos iterativos baseados em heurísticas para construção de soluções. O primeiro Algoritmo Heurístico Construtivo (AHC) aplicado ao PET [23] realiza a seleção de novos circuitos a serem adicionados ao sistema com base no carregamento estimado da rede. Este carregamento é obtido por meio de soluções do modelo de transportes.

O AHC apresentado em [23] foi também utilizado e adaptado por [25]. Na identificação de novos reforços para a rede de transmissão, durante o processo iterativo, é observado o critério de mínimo esforço (distribuição dos fluxos nos ramos). Em [25], um passo adicional foi ainda inserido ao algoritmo a fim de remover reforços desnecessários da solução final identificada. Foi observado que alguns circuitos selecionados, que representavam grande importância no início do processo de construção, poderiam ser removidos da solução final obtida sem torná-la infactível. Esta estratégia foi também empregada por diversos outros trabalhos na literatura, inclusive na ferramenta apresentada nesta tese de doutorado. Em [28], foi sugerida ainda uma extensão do AHC apresentado por [23] para a abordagem multiestágio do problema PET. Em [30], é também proposto um AHC baseado no trabalho de [23].

Normalmente, quando os AHCs são utilizados, apenas um plano de expansão é fornecido como solução final do problema PET. Entretanto, proporcionar ao planejador do sistema mais de uma opção de expansão para a rede de transmissão pode se tornar uma estratégia de grande importância, tendo em vista as incertezas que não foram consideradas na modelagem do problema.

Em [20], por exemplo, um AHC paralelizado, baseado em uma árvore de expansão e na minimização de perdas ôhmicas e do custo de investimento, é proposto para solução do problema de planejamento da expansão do sistema de subtransmissão de energia elétrica. Neste exemplo, é realizada uma construção em árvore, que fornece não apenas um, mas um conjunto de planos de expansão como solução final do algoritmo. A atratividade de novos ramos a serem selecionados para reforçar a rede a cada nível da árvore é medida por meio de índices calculados a partir dos resultados de análise de fluxo de potência AC e de dados dos circuitos. No cálculo destes índices, são observados o comprimento e informações relacionadas às barras terminais dos ramos, como abertura angular e diferença modular das tensões. Ações de poda são também empregadas neste trabalho a fim de evitar o crescimento exagerado da árvore de expansão. 
Já em [17], um algoritmo heurístico construtivo em árvore é empregado para solução do problema PET multiestágio. As soluções construídas por meio deste algoritmo são ainda utilizadas como população inicial para a metaheurística Algoritmo Genético, a qual é empregada em uma etapa final, destinada à inserção do critério determinístico de segurança "N-1".

\subsection{3.}

\section{Otimização Metaheurística}

Técnicas de otimização baseadas em metaheurísticas são aplicáveis a uma gama diversificada de problemas de otimização. O número de trabalhos na literatura cuja solução do problema PET se baseia na utilização dessas técnicas tem aumentado cada vez mais nas últimas décadas [3], [5], [6] e [16].

Diferentemente da maioria dos algoritmos de otimização clássica e assim como nos algoritmos heurísticos, na solução de problemas por meio de técnicas metaheurísticas não se pode garantir a identificação da solução ótima global. Entretanto, com a utilização adequada dessas estratégias, soluções de excelente qualidade podem ser encontradas, a um custo computacional relativamente baixo (i.e., requisitos de memória e tempos de processamento factíveis), até mesmo para sistemas de grande porte. Ademais, as metaheurísticas apresentam relativa facilidade de implementação, necessitando apenas de ajustes em alguns parâmetros para trabalhar com diferentes tipos de problemas. Recentemente, em [31], é discutida a questão de ajuste de parâmetros para metaheurísticas evolutivas. Neste trabalho, é também proposta uma estratégia de busca baseada em algoritmos evolutivos adaptativos, contendo múltiplos operadores, inclusive operadores especialistas relacionados ao problema PET. A partir dos resultados apresentados, é possível verificar uma boa flexibilidade da estratégia proposta para se trabalhar com o planejamento de sistemas de diferentes tipos e tamanhos.

De forma geral, a classificação de técnicas metaheurísticas é uma difícil tarefa, tendo em mente que metaheurísticas com diferentes características podem compartilhar as mesmas ideias na identificação de soluções. Entretanto, de acordo com [45], baseando-se na forma como as soluções do problema são manipuladas durante o processo de otimização, algumas classes fundamentais de metaheurísticas podem ser distinguidas. São elas: metaheurísticas de busca local, que realizam pequenas alterações de forma iterativa em uma única solução; metaheurísticas 
baseadas em população, as quais realizam combinação de soluções para obtenção de novas; metaheurísticas construtivas, que, como o próprio nome sugere, constroem soluções de forma gradual em um processo iterativo a partir da solução vazia até atingir um determinado critério de interrupção; e metaheurísticas híbridas, que combinam ideias de diferentes classes.

\section{- Metaheurísticas de Busca Local}

Na solução de problemas de otimização via metaheurísticas de busca local, ou de busca por entornos, uma única solução é construída por meio de processo iterativo. Partindo de uma solução inicial definida, a cada iteração é realizado um movimento, ou seja, a substituição da solução corrente por uma solução vizinha no espaço de busca. Este movimento é normalmente chamado de "estratégia de movimento". A melhor solução dentre o conjunto de soluções em uma dada vizinhança é chamada de ótimo local. Quando a solução corrente é um ótimo local, ou seja, não existem soluções vizinhas melhores que a solução corrente, são utilizadas estratégias de "fuga", tais como aplicação de algum tipo de perturbação à solução corrente ou reinicialização da busca a partir da geração de uma nova solução aleatória [45]. As técnicas metaheurísticas de busca local mais comumente utilizadas para solução do problema PET são as de Recozimento Simulado (Simulated Annealing - SA) e de Busca Tabu (Tabu Search - TS).

No método de Recozimento Simulado, a busca é baseada na minimização da energia da estrutura cristalina de um material sólido, quando o mesmo é submetido ao processo de recozimento para remoção de defeitos em sua estrutura atômica. No SA, os estados possíveis de um material representam as soluções do espaço de busca, sendo as posições moleculares do sistema correspondentes às variáveis de decisão do problema de otimização. A energia de cada estado corresponde ao valor da função objetivo associada ao problema. A cada iteração, um novo estado vizinho ao corrente é gerado e passa a ser considerado como a nova solução corrente. Caso o novo estado apresente piora no valor da energia, é utilizada uma probabilidade de aceitação, o que permite ao SA escapar de uma solução de ótimo local. Maiores detalhes sobre esta técnica podem ser encontrados em [46].

Em [47], o método SA é utilizado para solução do problema PET de longo prazo. Uma versão paralelizada do SA [48] é utilizada para solução do mesmo 
problema. Em cada iteração deste caso, mais de uma nova solução vizinha é gerada. Com isso, é obtida uma melhora na qualidade das soluções e no tempo computacional em relação à versão original da ferramenta. O algoritmo SA é também utilizado em [29] para solução do problema PET com abordagem multiestágio. Para identificação do melhor plano de expansão, são minimizados os custos de investimento e de operação do sistema. A questão do pagamento pelo uso da rede de transmissão é também discutida neste trabalho. Em 2005, os mesmos autores fazem uso do SA para solução do problema PET multiestágio incluindo ainda a avaliação do critério de energia esperada não suprida (EENS) [49].

Da mesma forma que a metaheurística SA, a TS progride iterativamente de uma solução a outra e, para evitar o aprisionamento em um ótimo local, também permite uma degradação no valor da função objetivo na troca de soluções a cada iteração. De uma forma geral, partindo de uma solução inicial a busca move-se de uma solução para a melhor em sua vizinhança, não aceitando movimentos que levem a uma solução já visitada recentemente. Para que não haja uma busca em ciclos, os movimentos reversos aos recentemente realizados são armazenados em uma estrutura de memória dinâmica (lista tabu) durante um determinado espaço de tempo (iterações). Como exemplos de sucesso na utilização do algoritmo TS, dentre os vários trabalhos voltados para solução do problema PET e que utilizam essa mesma técnica, podem ser citados [11] e [50].

O problema PET multiestágio é solucionado em [11] para dois casos de estudo utilizando TS. Neste trabalho, as soluções iniciais de expansão são obtidas utilizando uma função gulosa semelhante à utilizada em [51]. Os custos de investimento, das perdas ôhmicas e de interrupção do fornecimento de energia são utilizados para guiar o processo de solução. A partir dos resultados obtidos, foi observado o relevante impacto proveniente da consideração dos custos de perdas e de confiabilidade na solução do PET.

Em [50] é proposta uma versão paralelizada do TS, contando com duas estratégias para melhorar a qualidade das soluções e reduzir o esforço computacional. A primeira estratégia corresponde a uma decomposição da vizinhança em subconjuntos, onde para cada subconjunto uma solução é avaliada e a melhor entre elas é selecionada como nova solução corrente. A segunda estratégia corresponde à consideração de listas tabu de diferentes tamanhos, o que permite uma exploração mais diversificada do espaço de busca. O desempenho da metodologia 
proposta aplicada à solução do problema PET é comparado ao desempenho das metaheurísticas SA, TS tradicional e Algoritmo Genético. Os resultados obtidos apontaram um melhor desempenho para as técnicas TS tradicional e TS paralelizada em relação às demais.

\section{- Metaheurísticas Baseadas em População}

De forma geral, metaheurísticas pertencentes a essa classe realizam evolução iterativa de um conjunto de soluções, normalmente chamado de população. A partir de um conjunto inicial dessas soluções, a cada iteração um novo conjunto é criado de acordo com a estratégia de geração relativa a cada técnica. As melhores soluções em cada iteração compõem o novo conjunto. Este processo é repetido até que o critério de parada seja atingido. Nesta classe, as técnicas Otimização por Enxame de Partículas (Particle Swarm Optimization - PSO), Sistemas Imunológicos Artificiais (Artificial Immune System - AIS), Estratégia Evolutiva (Evolutionary Strategy - ES) e Algoritmo Genético (Genetic Algorithm - GA) são exemplos de metaheurísticas utilizadas para solução do problema de planejamento de sistemas de potência.

A metaheurística PSO é uma técnica estocástica baseada em população de soluções e inspirada no comportamento social da revoada de pássaros e movimento de cardume de peixes. É observado que, apesar de cada organismo dentro do grupo possuir um comportamento de movimento independente, existe algum tipo de informação que é compartilhada com os demais. Sendo assim, a cada geração, as soluções potenciais chamadas de partículas avançam através do espaço do problema seguindo as atuais melhores partículas, que possuem os melhores valores de aptidão no momento. Em [52], a técnica PSO foi utilizada pela primeira vez para solução do problema PET. Neste trabalho, apenas sistemas de pequeno porte foram estudados. Posteriormente, diversas novas metodologias envolvendo PSO foram também propostas para o planejamento da expansão da transmissão, tais como [53], [54] e [55].

Já a técnica AIS se baseia na atividade do sistema imunológico biológico em um organismo. É considerada uma técnica robusta, adaptável e autoorganizada, que possui capacidade de aprendizado e de memória. Um exemplo do método AIS baseado em população é o inspirado na teoria de seleção clonal, utili- 
zado para reconhecimento de padrões e solução de problemas de otimização. De acordo com essa teoria, através da resposta imunológica ativada pelo reconhecimento entre antígeno e anticorpo, um organismo exposto a um antígeno invasor deve ser adaptado para combatê-lo. As células do anticorpo que reconhecem o antígeno são selecionadas para a clonagem e, assim, o antígeno pode ser eliminado do organismo. No algoritmo inspirado na seleção clonal, a população é formada por anticorpos (soluções do problema de otimização). Durante a evolução da população, são calculados parâmetros de afinidade (e.g., Distância Euclidiana) entre os anticorpos e padrões de antígenos. Os anticorpos de maior afinidade são selecionados para gerar descendentes, o que ocorre por meio dos processos de clonagem e de mutação. Já os anticorpos com baixa afinidade são removidos e substituídos por anticorpos gerados aleatoriamente [46].

Um exemplo de aplicação da técnica AIS para solução do problema PET com abordagem multiestágio pode ser encontrado em [56]. Para construção de populações iniciais é empregada a função gulosa utilizada na técnica construtiva Procedimento de Busca Adaptativa Aleatória Gulosa (Greedy Randomized Adaptive Search Procedures - GRASP), proposta em [51]. Na busca é considerada a minimização dos custos de investimento e de produção, sendo o último relacionado às perdas ôhmicas na transmissão. Neste trabalho, o desempenho das metaheurísticas é medido por meio de um índice que compara a qualidade das soluções (sequências) identificadas a cada execução com a qualidade da melhor solução conhecida.

O método ES é outro exemplo de metaheurística baseada em população. De forma geral, esta é uma técnica robusta e com poucos parâmetros a serem ajustados. O seu princípio básico está na evolução de uma população de indivíduos inspirada na evolução natural de espécies. Cada indivíduo representa uma possível solução para o problema de otimização a ser resolvido. Nesta técnica, a busca se dá a partir de uma população inicial e, a cada geração, uma população de filhos é gerada por meio de perturbações causadas em indivíduos copiados (clonados) da população atual. Por meio de um mecanismo de seleção os melhores indivíduos entre a população atual (progenitores) e os novos indivíduos gerados (clones modificados) são escolhidos para integrar a população da próxima geração. As novas populações tendem a apresentar melhores soluções para o problema em questão, o que resulta na convergência do processo. O principal mecanismo utilizado por 
esta técnica é o operador de mutação, responsável pela inserção de pequenas mudanças aleatórias nas informações (genes) dos indivíduos.

O problema PET multiestágio é solucionado em [57] por meio da metaheurística ES. A minimização dos custos de investimento é considerada como objetivo inicial do problema. A função heurística utilizada pela técnica construtiva GRASP, proposta em [51], é também utilizada para construção da população inicial neste trabalho. $\mathrm{O}$ conjunto dos melhores planos (população final) identificado pelo ES é analisado posteriormente em termos de confiabilidade, sendo calculado, para cada solução, o custo de interrupção de energia.

A metaheurística ES é também escolhida por [12] para solução do problema PET multiestágios. Neste último trabalho, é realizada uma discussão acerca da aplicação de critério probabilístico ou determinístico de segurança "N-1" na solução do problema PET.

Em [38] a técnica ES é utilizada no problema de planejamento da expansão da subtransmissão de energia elétrica. Neste trabalho, para definição das melhores alternativas é considerada a minimização do custo de investimento mais o custo das perdas ativas da rede de subtransmissão. A busca é realizada através de conjuntos reduzidos de ramos candidatos mais atrativos, os quais são identificados a partir de índices de desempenho propostos no próprio trabalho.

Outra metaheurística baseada em população e inspirada na teoria de seleção natural de espécies é o GA. Assim como na técnica ES, no GA, a cada geração, os indivíduos da população corrente são avaliados através da função objetivo, e os melhores são selecionados para serem os pais da próxima geração. Os indivíduos selecionados geram filhos por meio do cruzamento de informações. Os filhos gerados podem ainda sofrer modificações em suas características fundamentais, a partir do emprego do operador de mutação. O operador de cruzamento utilizado por esta técnica pode apresentar diversas formas, mas, de modo geral, tem a função de combinar segmentos de informações entre os pais para gerar os novos filhos. O operador de mutação é executado logo após o processo de cruzamento e tem por objetivo realizar modificações em determinadas propriedades genéticas de uma população, de forma aleatória. Este procedimento é repetido, geração após geração, até que o critério de parada seja atingido. Uma estratégia de seleção é também utilizada para definir os indivíduos que vão compor a população para a próxima geração. 
Em [15], o problema PET com abordagem multiestágio é tratado e solucionado por meio da técnica GA. Neste trabalho, a população inicial utilizada pela metaheurística é obtida por meio de solução de modelos aproximados de fluxo DC e do AHC proposto em trabalhos como [23], [25] e [26]. De forma análoga, em [17] é proposta uma metodologia para solução do problema PET multiestágio com restrições de segurança utilizando a técnica GA combinada com uma heurística construtiva. Neste trabalho, planos de expansão são construídos por meio da heurística com base em índices de sensibilidade. Estes planos são então considerados como soluções iniciais para emprego do GA, e o critério determinístico de segurança "N-1" passa a ser também considerado.

Já em [58], um GA especializado é utilizado para solução do PET. Estratégias de melhoramento local de soluções infactíveis, de geração da população inicial e de controle de diversidade da população para evitar a convergência prematura, são utilizadas na metodologia proposta neste trabalho. Estas estratégias apresentaram um bom efeito na metaheurística, resultando em um número menor de problemas de programação linear a serem resolvidos. Um GA especializado é também utilizado em [39] para solução do problema PET estático considerando o critério de segurança determinístico "N-1".

\section{- Metaheurísticas Construtivas}

As metaheurísticas classificadas como construtivas, assim como o próprio nome sugere, consistem de estratégias para a construção de soluções viáveis de forma gradativa, adicionando um elemento à solução parcial a cada passo iterativo. Dessa forma, partindo de uma solução inicialmente vazia, a solução parcial vai sendo incrementada paulatinamente até que o critério de parada seja atingido (e.g., até que a solução se torne viável) [45].

Entre as metaheurísticas desta classe, as mais comumente utilizadas para solução do problema de planejamento da expansão de sistemas de potência são o GRASP e a Otimização por Colônia de Formigas (Ant Colony Optimization ACO).

A técnica metaheurística GRASP, proposta inicialmente em [59], é uma técnica iterativa utilizada para solução de problemas de otimização combinatória. De uma forma geral, cada iteração desta técnica é composta de duas fases principais, 
uma fase de construção e uma fase de busca local. Na primeira fase, uma solução inicialmente vazia é iterativamente construída até se tornar viável por meio da adição gradual de novos elementos. A cada adição, um elemento é selecionado aleatoriamente dentre os elementos de uma lista de candidatos mais atrativos. A atratividade dos elementos é medida por meio de uma função heurística gulosa. Após cada adição dentro do processo construtivo, esta lista de candidatos é atualizada, refletindo a nova situação do problema. Na fase de busca local, a solução corrente, que inicialmente corresponde à solução construída na primeira fase, é substituída por uma nova solução vizinha de melhor qualidade. A melhor solução encontrada em todas as iterações da técnica GRASP é considerada como solução para o problema de otimização.

Em [51], a técnica metaheurística GRASP é utilizada para solução do problema PET de longo prazo com abordagem estática. Durante a fase de construção, dentro de cada iteração da metaheurística, são solucionados problemas de programação linear relativos à minimização do corte de carga. Os multiplicadores de Lagrange, subprodutos do método simplex empregado, são aproveitados como informações para a função gulosa responsável pela formação do conjunto de ramos candidatos ao reforço. Neste caso, uma solução é considerada viável quando não existem mais violações operacionais do problema. Após construção de uma solução viável pela primeira fase, reforços desnecessários presentes na solução corrente são ordenados de acordo com o seu respectivo custo e removidos a fim de identificar soluções viáveis de menor custo de investimento. Neste trabalho, a fase de busca local, utilizada para aprimorar as soluções obtidas na fase de construção, basicamente realiza a troca de circuitos, analisando planos vizinhos e utilizando técnicas de poda para evitar um número elevado de planos a serem analisados.

A técnica GRASP é ainda comumente combinada a outras técnicas com o intuito de melhorar a qualidade das soluções obtidas pelo seu algoritmo básico. É o caso, por exemplo, da utilização da técnica path-relinking. Esta técnica é utilizada como estratégia de intensificação, onde trajetórias que ligam pares de soluções de boa qualidade são exploradas na busca por melhores soluções. O objetivo é a incorporação de atributos existentes na estrutura de uma solução do par à estrutura da outra. Esta estratégia foi utilizada, por exemplo, em [60] para solução do problema PET estático. Neste trabalho, a técnica path-relinking é empregada a 
planos identificados após cada fase de busca local do algoritmo GRASP. No emprego da técnica, a solução a ser utilizada para construção da trajetória corrente é selecionada aleatoriamente dentro de um conjunto de soluções elite, o qual é construído durante processo iterativo. Os movimentos realizados entre as soluções na aplicação do path-relinking respeitam os custos de investimento dos reforços e os índices de sensibilidade obtidos com a utilização dos multiplicadores de Lagrange resultantes da solução de problemas de programação linear via método simplex.

Já a metaheurística ACO é uma técnica da inteligência coletiva, baseada no comportamento social de formigas na natureza. Devido ao seu alto nível de organização estruturada, uma colônia de formigas pode realizar tarefas complexas que podem exceder as capacidades individuais de um único elemento. Os algoritmos baseados em colônia de formigas tentam imitar este comportamento organizado na busca do caminho mais curto entre o ninho e a fonte de alimentos. No caso real, as formigas se comunicam através de rastros de feromônio depositados no solo. Da mesma forma, nos algoritmos artificiais, cada agente deposita uma quantidade de feromônio pelo caminho, o que altera a probabilidade deste ser escolhido pelo próximo agente. Sendo assim, um agente artificial pode ser considerado como um mecanismo estocástico de busca gulosa que constrói uma solução por meio de um procedimento probabilístico de adição de componentes a esta solução.

Para solução do problema PET estático, o algoritmo Sistema de Colônia de Formigas (Ant Colony Systems - ACS), compreendido entre as técnicas baseadas em ACO, é utilizado em [61]. Na função de busca é considerada a minimização do custo de investimento da expansão. Para guiar o processo e melhorar o desempenho do algoritmo proposto, são ainda considerados neste trabalho conceitos relacionados à função heurística gulosa proposta em [51].

Em [62], a técnica metaheurística ACO, considerando também os conceitos da função heurística gulosa de [51], é utilizada para solução do problema PET multiestágio. As melhores sequências identificadas pela metaheurística, com a minimização do valor presente de investimento, são também avaliadas em termos do custo de interrupção, utilizando o índice de confiabilidade LOLC (Loss of Load Cost). Na comparação com os métodos baseados em população ES e TS, o ACO apresentou melhor qualidade nas sequências cronológicas de investimento, entretanto, necessita de um número maior de parâmetros a serem ajustados. O mesmo pode ser verificado em [63]. 


\section{- Metaheurísticas Híbridas}

Algumas metaheurísticas apresentam abordagens que utilizam características de mais de uma das técnicas metaheurísticas descritas, sendo assim denominadas metaheurísticas hibridas [45]. É o caso, por exemplo, dos algoritmos "meméticos", que utilizam operadores provenientes de algoritmos evolucionários e de heurísticas e metaheurísticas de busca local. Em [64], por exemplo, é proposto um algoritmo memético multiobjetivo para solução do problema PET, considerando um índice de confiabilidade probabilístico. A metaheurística multiobjetivo Algoritmo Evolutivo da Força de Pareto II (Strength Pareto Evolutionary Algorithm SPEA-II), baseada em GA, é utilizada neste trabalho em conjunto com a metaheurística TS, de busca local. Após a finalização do processo de evolução utilizando o SPEA-II, as soluções são aperfeiçoadas utilizando TS.

Já em [65], o problema PET é solucionado por meio de uma metaheurística híbrida formada pelas técnicas GA e TS, considerando o critério de segurança determinístico "N-1". Diferentemente do caso anterior, a metaheurística de busca local TS é utilizada durante o processo de evolução das soluções pela metaheurística GA. A cada geração, as soluções geradas pelos mecanismos de seleção, recombinação e de mutação são aprimoradas utilizando TS.

Outro exemplo de metaheurística híbrida utilizada para solução do problema PET pode ser encontrado em [66], onde o TS paralelizado proposto em [50] é utilizado juntamente com a técnica de Otimização Ordinal (Ordinal Optimization OO), a fim de acelerar o processo de avaliação de soluções vizinhas durante o processo de busca. A metaheurística híbrida resultante é utilizada para solução do problema PET de longo prazo, sendo comparada às metaheurísticas SA, GA, TS tradicional, TS paralelizada e TS tradicional com OO. A metaheurística híbrida proposta apresentou uma redução no esforço computacional em comparação com as demais, o que justifica sua aplicação em estudos de sistemas de grande porte. Entretanto, o conjunto de soluções identificadas pela metaheurística híbrida apresentou qualidade inferior em relação às técnicas TS tradicional e TS paralelizado.

Como pode ser observado nesta seção, apesar do grande número de trabalhos que empregam técnicas metaheurísticas para solução do problema PET, há, ainda, uma necessidade de estudos mais criteriosos em termos de desempenho desses algoritmos e de suas soluções. Além de estudos comparativos entre as dife- 
rentes técnicas utilizadas para solução do problema de planejamento, assim como realizado em [16], é necessária também uma maior preocupação com a qualidade dos planos de expansão fornecidos por estas ferramentas. Partindo do fato de que é praticamente impossível considerar todos os aspectos de incertezas inerentes ao problema, principalmente para horizontes de médio e longo prazo, não só a solução ótima deve ser atingida, mas é necessário que um conjunto de soluções de boa qualidade, com opções diversificadas de reforços, seja apresentado ao planejador [63]. Este objetivo, razoavelmente atingido por grande parte das técnicas metaheurísticas apresentadas, é uma premissa adotada para o desenvolvimento da metodologia proposta nesta tese de doutorado.

Levando-se em consideração, ainda, que a maioria das técnicas de otimização utiliza parâmetros estocásticos em suas estruturas de busca, levantamentos estatísticos de performance precisam também ser considerados nos estudos de planejamento. A partir destes indicativos, é possível estabelecer uma maior confiança nos resultados e na utilização das ferramentas.

De acordo com estes aspectos, neste trabalho, tal como em [31], são conduzidos estudos estatísticos obtidos a partir de várias execuções do algoritmo proposto, considerando diferentes sementes para as funções geradoras de números aleatórios. Estes estudos permitem realizar uma análise mais criteriosa a respeito do desempenho da metodologia proposta e da qualidade apresentada pelas melhores soluções identificadas no processo de construção.

\section{4.}

\section{Critérios de Planejamento}

Qualquer equipamento pertencente ao sistema, assim como os novos equipamentos indicados nos planos de expansão, pode falhar em algum momento durante a sua operação. Dessa forma, a consideração de incertezas relativas à disponibilidade dos equipamentos é uma questão de extrema importância na solução do problema PET. Entretanto, a maioria dos trabalhos da literatura atual não considera qualquer tipo de critério relativo à segurança (adequação estática) do sistema no atendimento à demanda, restringindo a análise ao âmbito da rede intacta. Isto se deve, principalmente, ao grande esforço computacional necessário para a avaliação dos planos candidatos durante a solução do problema PET quando da consideração de restrições de segurança. 
Alguns trabalhos da literatura realizam a avaliação de critérios de segurança apenas para o conjunto final de soluções com os menores montantes de investimento, obtido a partir da ferramenta de otimização utilizada (e.g., [53], [57], [62] e [63]). Em alguns desses casos, são preservadas apenas as soluções finais que permitem a operação dos equipamentos dentro de seus limites técnicos e que garantem o atendimento total da carga. Em outros, o conjunto final de soluções é reordenado de acordo com índices de desempenho calculados para o sistema, obtidos a partir de um estudo estocástico de disponibilidade dos equipamentos. Entretanto, os custos de investimento correspondentes a estes estudos são mais elevados se comparados aos das soluções obtidas quando o critério de segurança é observado durante o processo de busca.

Em função de como é realizada a consideração de critérios de segurança na solução do problema PET, o estudo pode ser classificado como de abordagem determinística ou de abordagem probabilística.

\subsection{1. Planejamento via Abordagem Determinística}

Planos de expansão identificados com base na abordagem determinística de segurança devem ser capazes de garantir a continuidade do atendimento à demanda mesmo na condição de contingência de um ou mais equipamentos, a depender do critério adotado. Neste tipo de abordagem, aspectos relacionados às incertezas são negligenciados ou, muitas das vezes, simplificados [18]. Quando o critério determinístico "N-1" é adotado, por exemplo, o sistema deve garantir o total atendimento da carga, sem sobrecarregar seus componentes, tanto para o caso de operação com rede intacta quanto para o caso de contingência simples de qualquer um de seus equipamentos. Para o critério de segurança "N-2", o sistema deve ainda suportar quaisquer falhas simultâneas de dois equipamentos e, assim, sucessivamente. A inclusão de critérios determinísticos tais como o "N-1" e o "N-2" na solução do problema de planejamento da expansão de sistemas de potência, além de implicar em aumento de custo de investimento, representa também um aumento considerável do esforço computacional necessário para avaliação dos planos de expansão candidatos.

Em [39] é considerado o critério de segurança determinístico " $\mathrm{N}-1$ ", com a rede elétrica do sistema representada pelo modelo DC sem a consideração das 
perdas ôhmicas. Na avaliação operativa do sistema, tanto para a rede intacta quanto para o estudo de contingência, é permitida a variação do despacho de cada usina geradora entre os valores de mínimo e máximo de capacidade. O mesmo é considerado em [65].

Já em [31], onde o critério de segurança "N-1" também é considerado durante o processo de busca, uma política operativa diferente é adotada. Neste trabalho, as perdas ôhmicas da transmissão são consideradas e, para cada plano avaliado, o despacho base obtido para a condição de rede intacta deve ser respeitado na avaliação de contingência dos equipamentos. Um estudo relacionado ao relaxamento das restrições de capacidade nos equipamentos durante a operação do sistema em condição de contingência é também realizado. É possível verificar, a partir dos resultados obtidos, uma redução no custo dos planos de expansão para critérios "N-1" relaxados.

Uma metodologia para solução do problema PET multiestágio é proposta em [53] com a consideração do critério determinístico "N-1". Neste trabalho, é considerada a minimização do custo de investimento dos planos de expansão e de uma penalização referente às restrições de confiabilidade consideradas. Entretanto, visando amenizar o esforço computacional necessário, é adotada uma estratégia onde apenas o melhor plano identificado ao final de cada iteração do processo é avaliado em termos do critério "N-1". Neste trabalho, apenas um pequeno sistema foi utilizado para realização de testes da metodologia.

Outra estratégia relacionada à consideração de critérios determinísticos de confiabilidade na solução do problema PET está associada à inviabilidade de se considerar a contingência de todos os equipamentos da rede para o estudo de sistemas de maior porte [1]. Eventos raros e de pequena consequência para o atendimento à demanda, por exemplo, poderiam ser ignorados no PET de longo prazo, o que permitiria uma redução no custo de investimento dos planos de expansão. Neste sentido, uma prática comum no estudo do PET é a criação de uma lista de contingências contendo apenas os equipamentos mais críticos para a rede. Isto de acordo com o nível de importância do equipamento e/ou de seu histórico de funcionamento. Entretanto, a criação desta lista pode também se tornar uma tarefa difícil, levando-se em consideração que o conjunto de componentes críticos pode variar para diferentes configurações do sistema. Este problema se torna ainda maior quando a abordagem multiestágio é adotada, pois a criação de listas deve 
considerar as novas condições de carga e geração para cada estágio do planejamento [1].

Em [35], por exemplo, é utilizado o modelo disjuntivo para solução do problema PET com o objetivo de minimizar os custos de investimento e do corte esperado de carga. Devido ao grande número de variáveis de decisão decorrentes da consideração de cenários de despacho, relacionados a diferentes níveis de carga e de afluência hidrológica, um número reduzido de contingências é considerado nas restrições do problema. A partir de uma análise preliminar considerando todos os cenários, apenas as contingências que apresentam corte de carga são consideradas críticas e, por consequência, inseridas no modelo. Outro exemplo do emprego de listas reduzidas de contingências é encontrado em [17].

Pode-se dizer que a maioria das técnicas que consideram algum tipo de restrição de segurança na solução do problema PET é baseada em métodos determinísticos, sendo o critério de segurança "N-1" o mais utilizado [40] e [67]. Entretanto, existem ainda trabalhos mais recentes na literatura que examinam as saídas múltiplas de equipamentos durante a operação do sistema, como é o caso de [36], [41], [68] e [69]. Estes estudos são justificados pelo número crescente de blackouts envolvendo a saída simultânea de dois ou mais equipamentos da rede.

\subsection{2.}

\section{Planejamento via Abordagem Probabilística}

Um caminho alternativo para consideração de critérios de segurança na solução do problema PET, no que diz respeito à adequação estática, é a utilização da abordagem probabilística (confiabilidade). Essa abordagem se refere à consideração do caráter aleatório de cada componente da rede elétrica do sistema. Estes valores estão vinculados ao histórico estatístico de falhas destes componentes e são traduzidos em termos de taxas de falhas e tempos médios de reparo [19], [67]. A abordagem probabilística, além de considerar falhas múltiplas de equipamentos, possui a capacidade de capturar a severidade de eventos e a suas probabilidades de ocorrência [18], [70].

De uma forma geral, os algoritmos utilizados para avaliação da confiabilidade com abordagem probabilística são os de Enumeração de Estados e Simulação Monte Carlo (SMC) sequencial, não sequencial e pseudo-cronológica. Os índices de confiabilidade relativos ao atendimento à demanda referem-se à falha 
do sistema, caracterizada pela insuficiência de geração e/ou incapacidade de transmissão. Nos estudos de confiabilidade são então observadas a probabilidade de ocorrência das falhas, a frequência e a duração média dessas falhas, bem como o montante de energia não suprida e o custo associado. Os índices mais frequentemente utilizados no estudo do problema PET são:

- LOLE - Expectativa de Perda de Carga (Loss of Load Expectation);

- EENS - Energia Esperada não Suprida (Expected Energy Not-Supplied);

- LOLC - Custo de Corte de Carga (Loss of Load Cost).

Quando critérios probabilísticos são adotados, podem ser estipulados limiares para os valores dos índices de confiabilidade na formulação do problema (e.g., [40]) ou, em outros casos, o valor esperado do custo relativo à interrupção de energia é incorporado à função objetivo do PET (e.g., [71] e [22]), a qual deve ser minimizada durante o processo de solução.

Em [71] é proposta uma metodologia para solução do problema de planejamento da expansão de sistemas de geração e de transmissão de energia elétrica, considerando o critério probabilístico na avaliação de confiabilidade dos planos candidatos. O índice LOLC é considerado na função objetivo do problema juntamente com os custos de investimento e de produção. Neste trabalho é possível observar diferentes formas de abordagem do critério probabilístico na avaliação de planos candidatos à expansão. Isto se deve ao tratamento hierárquico utilizado na avaliação de planos candidatos para contornar o problema da explosão combinatória de alternativas de expansão. No início do processo são utilizados modelos mais simplificados e com menor custo de processamento. Em passos posteriores, após descarte das piores alternativas, são utilizados modelos mais sofisticados. Nos passos iniciais são então utilizados os modelos de Enumeração de Estados, considerando apenas o primeiro nível de contingências, e SMC não sequencial. Nestes passos são descartadas alternativas com base no índice EENS. Para avaliação mais rigorosa das soluções remanescentes é utilizado o modelo de SMC pseudo-cronológica. Os modelos de carga considerados neste trabalho variam durante o processo de solução desde a consideração apenas da carga pico até a consideração da curva anual de carga. 
O problema da expansão da rede de transmissão, incluindo a possibilidade de adições de reforços na geração e utilizando critérios probabilísticos, é também tratado em [40]. O método proposto neste trabalho busca a minimização do custo total da expansão, respeitando, além de restrições técnicas do problema, um limite máximo em horas por ano para o índice LOLE. Para o modelo de carga é considerada a curva de duração de carga.

A influência do custo da confiabilidade na solução do problema PET pode ser verificada em [63], quando as melhores sequências de investimento, identificadas para o problema multiestágio, por meio da metaheurística ACO, são avaliadas em termos do índice LOLC em um procedimento posterior à busca. Para obtenção do índice de confiabilidade é utilizada a SMC não sequencial, considerando o valor de carga pico e falha apenas da transmissão. Neste trabalho, devido à reordenação das melhores sequências obtidas com a metaheurística após inserção do custo de interrupção à função de aptidão, é possível verificar a importância da consideração do custo da confiabilidade no processo de planejamento da expansão.

Em [22], o custo do não suprimento de energia, expresso pelo índice LOLC, é incluído na função objetivo do problema PET e, portanto, considerado durante o processo de busca. O método de otimização utilizado neste trabalho é o ES. São propostos alguns mecanismos para contornar a complexidade decorrente da consideração da confiabilidade na função objetivo do problema. São eles: a consideração de memória para armazenamento de informações de soluções visitadas durante o processo de solução; o impedimento de avaliação da confiabilidade de uma solução caso seu custo de investimento seja maior que o custo total (investimento e LOLC) da pior solução do conjunto corrente de soluções; a interrupção prematura da avaliação da confiabilidade de uma solução cuja estimativa da LOLC esteja convergindo para um valor que a torne uma solução mais cara que a pior solução do conjunto corrente de soluções. O cálculo do índice LOLC é realizado por meio da SMC não sequencial considerando a curva anual de carga. Neste trabalho, os resultados obtidos com a metodologia proposta em comparação com um caso onde a confiabilidade é avaliada apenas para o conjunto final de soluções, mostram a importância de se considerar uma avaliação durante o processo de busca.

Apesar das vantagens pertinentes à observação do caráter aleatório da operação do sistema quando da utilização de abordagem probabilística, a aplicação de 
tais métodos tem sido limitada pelo grande esforço computacional envolvido na estimação dos índices e pela dificuldade de se pré-fixar níveis de confiabilidade adequados, já que os índices de confiabilidade são dependentes do modelo de carga utilizado. Discussões mais aprofundadas a respeito das abordagens determinística e probabilística no PET podem ser verificadas em [12], [18] e [72].

\section{5 .}

\section{Conclusões}

A partir da revisão realizada neste capítulo, verifica-se que diferentes formas de abordagem podem ser consideradas na solução do problema PET. Diversos aspectos, sejam eles técnicos, ambientais, sociais ou econômicos, influenciam na definição do problema. Dessa forma, faz-se necessária a utilização de ferramentas de otimização cada vez mais robustas, que permitam com mais simplicidade a consideração desses aspectos e que, ao mesmo tempo, acompanhem as constantes modificações sofridas pelos sistemas elétricos de transporte de energia. Nesse sentido, a ferramenta proposta nesta tese para solução do problema PET, a qual é apresentada no próximo capítulo, busca unir os procedimentos realizados pelo planejador na definição de reforços para a rede de transmissão com estratégias automáticas e estocásticas de otimização, a fim de identificar planos de expansão de boa qualidade a custos computacionais reduzidos. 


\section{3. Algoritmo Metaheurístico Construtivo}

\section{1. Introdução}

O algoritmo metaheurístico construtivo (AMC-PET) proposto nesta tese tem por objetivo identificar boas soluções (planos de expansão) para o problema PET estático. A ideia básica da metodologia proposta é a construção iterativa e paralela de planos de expansão viáveis de boa qualidade a partir da topologia base do sistema (solução vazia). $\mathrm{O}$ processo construtivo se dá por meio de adição gradual de reforços mais atrativos, pelo intercâmbio de informações entre as soluções em construção e pela perturbação e depuração dessas soluções. Ao final, as melhores soluções são submetidas a um mecanismo de refinamento. A dinâmica de construção é realizada utilizando-se mecanismos de busca local e de busca global, comumente empregados por técnicas heurísticas e metaheurísticas de otimização. Índices de atratividade/efetividade são utilizados para identificação de ramos que serão alterados durante as fases de adição de reforços e de depuração das soluções obtidas ao longo do processo construtivo.

A representação das soluções, os mecanismos construtivos utilizados pela metodologia, o algoritmo proposto para solução do PET e a formulação adotada para o problema estático são descritos no presente capítulo.

\section{2. Representação das Soluções}

Conforme comumente adotado por metaheurísticas evolucionárias, a representação de uma solução do problema de planejamento estático da transmissão no AMC-PET proposto é dada por meio de um indivíduo [46]. Cada indivíduo pode ser representado por um vetor composto por $n_{r c}$ posições (genes), as quais correspondem aos $n_{r c}$ ramos candidatos ao reforço do sistema. Dessa forma, cada gene do indivíduo (posição do vetor) corresponde a uma variável inteira e armazena a 
quantidade de reforços presente no respectivo ramo candidato, podendo variar de 0 (zero) até o número máximo de reforços que podem ser adicionados neste ramo.

Durante o processo construtivo, cada indivíduo é avaliado por meio de uma função objetivo relacionada ao problema de otimização. $O$ valor da função objetivo calculada para cada indivíduo representa sua própria aptidão.

\section{3.}

\section{Mecanismos Construtivos}

De forma geral, a estrutura básica do AMC-PET é semelhante à de um algoritmo heurístico construtivo, onde soluções (indivíduos) são construídas paralelamente a partir de uma solução vazia em direção à viabilidade (factibilidade) do problema. A cada nível construtivo (iteração) do AMC-PET, as soluções recebem novos reforços por meio de um mecanismo de adição (MA). Entretanto, além do MA, outros quatro mecanismos são também empregados às soluções em construção antes que o algoritmo avance para o próximo nível construtivo (próxima iteração).

Sendo assim, no nível construtivo corrente, após emprego do MA, as soluções em construção são submetidas aos mecanismos de cruzamento (MC) e de mutação (MM) de forma conjunta, a fim de se permitir, respectivamente, a troca de informações genéticas entre essas soluções e perturbações em suas estruturas. Este procedimento é realizado de forma idêntica ao modo como populações de indivíduos são evoluídas na técnica metaheurística Algoritmo Genético (Genetic Algorithm - GA).

Em seguida, ainda no nível construtivo corrente, com o propósito de se evitar uma explosão do número de soluções durante o processo construtivo, é empregado um mecanismo de seleção (MS). Este mecanismo é responsável por selecionar apenas um número reduzido de soluções, de boa qualidade, que seguem pelo processo.

Por fim, as soluções selecionadas no MS passam por um procedimento inverso ao realizado pelo MA, onde cada solução perde um reforço por meio de um mecanismo de depuração (MD). No MD é avaliada a efetividade dos reforços já adicionados, visando eliminar aquele que menos contribua para a construção de uma solução viável. 
O processo iterativo do AMC-PET, com emprego dos mecanismos MA, MC, MM, MS e MD a cada nível construtivo, converge após estagnação da melhor solução viável encontrada para o problema. Após convergência, as melhores soluções viáveis identificadas/construídas passam ainda por um mecanismo de refinamento (MR), onde são removidos eventuais reforços não necessários para garantir a viabilidade das soluções.

No emprego do AMC-PET, quatro conjuntos de indivíduos (soluções) são continuamente modificados/atualizados durante o processo construtivo a partir do emprego dos mecanismos:

- $\Omega_{\mathrm{V}}$ : Conjunto que recebe os indivíduos que já tenham atingido a viabilidade. Ou seja, este conjunto é formado pelos indivíduos que já não necessitam mais da adição de reforços e, portanto, correspondem a planos de expansão factíveis para o problema PET definido;

- $\Omega_{\mathrm{MA}}$ : Conjunto que recebe os indivíduos ainda inviáveis selecionados pelo MS e que foram gerados pelo MA;

- $\Omega_{\mathrm{MCM}}$ : Conjunto que recebe os indivíduos ainda inviáveis selecionados pelo MS e que foram gerados, de forma conjunta, pelos mecanismos MC e MM;

- $\Omega_{\mathrm{MD}}$ : Conjunto que recebe os indivíduos ainda inviáveis gerados a partir do emprego do MD.

Nas subseções que se seguem, são apresentados os detalhes de cada mecanismo empregado no AMC-PET para construção de soluções para o problema PET. Antes, porém, são apresentados os índices de sensibilidade utilizados por alguns destes mecanismos.

\subsection{1.}

\section{Índices de Sensibilidade}

Para a implementação do AMC-PET, proposto nesta tese de doutorado, foram utilizados três índices para classificação dos ramos candidatos.

O primeiro índice ( $\left.I n d_{c h-i j}\right)$ aborda o desempenho da rede intacta ("N-0"), sendo inicialmente utilizado para medir a atratividade dos ramos candidatos ao recebimento de um reforço, durante o emprego do MA. Este índice, expresso em 
p.u. (por unidade) da respectiva capacidade do circuito, é calculado para cada ramo candidato (ativo ou inativo) $i-j$, a partir da solução ótima do fluxo de potência DC. Neste trabalho, entende-se por ramo ativo aquele que possui pelo menos um circuito, seja ele pertencente à topologia base do sistema ou resultante de reforço durante o processo de expansão. O índice $I n d_{c h-i j}$, de acordo com a eq. (3.1), é diretamente relacionado ao módulo da abertura angular $\left(\left|\theta_{i j}\right|\right.$ em radianos) das tensões terminais do ramo e inversamente relacionado à reatância $\left(x_{i j}\right)$ e à máxima capacidade $\left(f_{i j}^{\max }\right)$ do circuito a ser adicionado.

$$
\operatorname{Ind}_{c h-i j}=\frac{\left|\theta_{i j}\right|}{x_{i j} f_{i j}^{\max }}
$$

Este índice visa identificar os circuitos com maior carregamento hipotético (sem considerar a consequente redução na abertura angular entre as barras terminais do ramo) após sua inserção. Tais circuitos terão, em princípio, maior potencial para contribuir para uma melhor distribuição do fluxo de potência ativa, o que traz benefícios para alguns aspectos operativos do sistema, como a redução das perdas ôhmicas e do nível de carregamento dos circuitos. Este último aspecto é fundamental para o bom desempenho do sistema, tanto para a condição de rede intacta quanto sob eventuais contingências.

$\mathrm{O}$ índice $I n d_{c h-i j}$ pode ser também utilizado para medir a efetividade de um ramo que recebeu ao menos um reforço. Neste caso, a eq. (3.1) fornecerá o real carregamento de um circuito já adicionado. Entende-se que ramos contendo circuito(s) com menor(es) valor(es) de carregamento podem ser considerados menos efetivos, ou seja, ramos para os quais a remoção de um reforço terá menor impacto negativo no desempenho do sistema. Durante a aplicação do MD será removido o (ou um dos) reforço(s) adicionado(s) ao ramo considerado menos efetivo (menor valor de $\left.\operatorname{Ind} d_{c h-i j}\right)$.

O segundo e terceiro índices, propostos nesta tese, abordam o critério de segurança "N-1" e são calculados para cada ramo ativo $i$-j, a partir de análises de contingências aplicadas à solução corrente (plano de expansão $n$ ). Pela própria composição destes dois índices infere-se que os ramos indicados por eles contribuem de forma significativa para o atendimento do critério de segurança considerado. Eles são utilizados apenas pelo mecanismo de adição (MA). 
No cálculo do segundo índice ( Ind $_{s c-i j}^{\text {próprio }}$ ), expresso em MW, são acumuladas as sobrecargas observadas no próprio ramo ativo e candidato $i-j$, durante a aplicação de $n c$ contingências ao plano de expansão (indivíduo) $n$. Para tal, é utilizada a eq. (3.2), onde $s c(n)_{c-i j}$ é a sobrecarga observada no ramo ativo $i-j$ por ocasião da contingência $c$.

$$
\operatorname{Ind}_{s c-i j}^{\text {próprio }}=\sum_{c=1}^{n c} s c(n)_{c-i j}
$$

Já para o terceiro índice ( $I n d_{s c-i j}^{\text {outros }}$ ), também expresso em MW, são observadas as sobrecargas ocorridas em qualquer ramo ativo $k-m$ do sistema $\left(s c(n)_{c-k m}\right)$, decorrente de uma contingência $c$, a qual corresponde à perda do (ou de um dos) reforço(s) do ramo candidato $i-j$. Caso a contingência $c$ resulte em corte de carga por ilhamento $\left(\operatorname{cci}(n)_{c}\right)$, este também deve ser considerado. Para o cálculo do terceiro índice é utilizada a eq. (3.3):

$$
\text { Ind }_{s c-i j}^{\text {outros }}=\sum_{(k, m) \in \Omega_{r}^{\text {ativo }}} s c(n)_{c-k m}+c c i(n)_{c}
$$

onde $\Omega_{r}^{\text {ativo }}$ representa o conjunto de ramos ativos do plano de expansão $n$.

O número de reforços pré-selecionados por meio de cada índice empregado no mecanismo MA é um parâmetro a ser definido pelo planejador.

\subsection{2. \\ Mecanismo de Adição}

Como resultado da aplicação do mecanismo de adição (MA) a um indivíduo corrente do processo construtivo é definido um novo indivíduo com somente um de seus genes incrementado, ou seja, é criado um novo plano de expansão com mais um reforço. O reforço adicionado é selecionado pela observação de índices de atratividade e do desempenho da respectiva configuração obtida frente ao problema de otimização.

A seguir são apresentados os passos básicos que compõem o MA:

i) A partir do indivíduo (plano de expansão) corrente, calcular índices de atratividade para os ramos candidatos ao reforço do sistema e selecionar $n_{r}$ ramos mais atrativos (e.g., 6 ramos) a partir destes índices; 
ii) Gerar $n_{r}$ novos indivíduos pela adição de um reforço em cada ramo selecionado no passo anterior, como ilustrado na Figura 3.1;

iii) Avaliar cada um dos indivíduos criados;

iv) Definir como resultado da aplicação do MA, o indivíduo (plano) que apresenta a melhor aptidão.

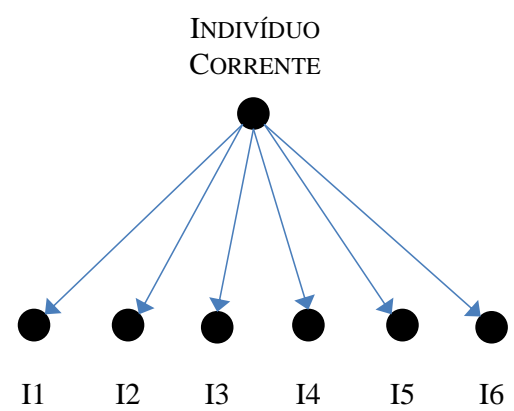

Figura 3.1 - Geração de novos indivíduos: passo (ii) do MA.

No problema PET, para o caso de ramos candidatos que não podem ser avaliados por quaisquer dos índices de atratividade (e.g., ramos para conexão de barras isoladas de geração e/ou carga), um procedimento adicional deve ser considerado simultaneamente ao passo (i) do MA, visando garantir que estes ramos possam também ser selecionados. Para tal, deve ser considerada uma taxa de adição (e.g., 50\%) que corresponde à probabilidade de cada um desses ramos seguir para o passo (ii) do MA, juntamente com os $n_{r}$ ramos selecionados pelos índices.

Cabe ainda salientar que alguns sistemas preveem a construção de barras (subestações) de passagem, i.e., sem a conexão direta de geração ou de carga. $\mathrm{Na}$ ocorrência desta situação deve ser realizado um tratamento especial para adição de reforços candidatos que promovem a interligação destas barras ao sistema. Sendo assim, no MA, a adição de reforços responsáveis pela interligação de barras de passagem isoladas é realizada em pares, de forma a garantir que a barra seja interligada ao sistema pelos dois lados e não se torne apenas uma barra terminal, o que não traz qualquer benefício ao sistema.

\subsection{3.}

Mecanismo de Cruzamento

Este mecanismo é comumente utilizado por metaheurísticas evolucionárias, como, por exemplo, o GA [73]. O mecanismo de cruzamento (MC) consiste, basi- 
camente, em combinar características de dois indivíduos (planos) diferentes a fim de criar dois novos indivíduos.

Neste trabalho, é utilizado o cruzamento uniforme, o qual é aplicado a pares de indivíduos para definição de dois novos. Dentro do conjunto de indivíduos progenitores, um par é selecionado por meio de sorteio, onde cada indivíduo possui uma probabilidade de ser escolhido proporcional à sua aptidão. Isso significa que indivíduos com maior aptidão têm maiores chances de procriação. Em seguida, uma "máscara" de bits é gerada pseudo-aleatoriamente, com a mesma dimensão (número de bits) dos indivíduos. De acordo com a máscara de bits gerada, os genes dos indivíduos progenitores são combinados para formar os indivíduos descendentes.

O par de indivíduos gerado pelo MC segue para posterior aplicação do mecanismo de mutação, apresentado no próximo subitem. O emprego do MC ao par de indivíduos progenitores selecionado está condicionado a uma taxa de probabilidade definida pelo planejador, conhecida como taxa de cruzamento. Dessa forma, quando por sorteio o MC não é empregado no par de indivíduos selecionado, os dois indivíduos descendentes que seguem são idênticos aos seus progenitores.

\subsection{4. Mecanismo de Mutação}

Assim como o MC, este mecanismo é frequentemente utilizado por metaheurísticas evolucionárias. O mecanismo de mutação (MM) é responsável por aplicar modificações aleatórias (perturbações) nos elementos de uma solução para criação de uma nova.

Cada solução resultante da aplicação do MC deve ser submetida ao MM. Durante a aplicação deste mecanismo, para cada elemento (gene) da solução em processo de mutação é realizado um primeiro sorteio que define, de acordo com certa probabilidade, chamada de taxa de mutação, se este elemento sofrerá ou não uma modificação. Em caso afirmativo, um segundo sorteio define, com igual probabilidade, se o elemento será incrementado ou decrementado, respeitando-se os limites superior e inferior para o elemento.

Após aplicação dos mecanismos MC e MM, os indivíduos resultantes são avaliados de acordo com a função objetivo definida para o problema. 


\subsection{5. \\ Mecanismo de Seleção}

O mecanismo de seleção (MS) é aplicado aos indivíduos produzidos pelos mecanismos MA, MC e MM. O objetivo é a definição de conjuntos reduzidos de indivíduos ainda inviáveis, que seguem para o próximo nível construtivo do AMC-PET, após passarem pelo MD, bem como a identificação de possíveis indivíduos que já atingiram a factibilidade para o problema.

Os melhores indivíduos inviáveis em termos de aptidão gerados pelo MA são selecionados pelo MS e armazenados no conjunto $\Omega_{\mathrm{MA}}$, com tamanho $n_{\mathrm{MA}}$, e os melhores indivíduos inviáveis gerados de forma conjunta pelos mecanismos MC e MM são selecionados pelo MS e armazenados no conjunto $\Omega_{\mathrm{MCM}}$, com tamanho $n_{\mathrm{MCM}}$. Os tamanhos desses conjuntos ( $n_{\mathrm{MA}}$ e $n_{\mathrm{MCM}}$ ) são parâmetros a serem ajustados pelo planejador para o emprego do AMC-PET.

Já os planos viáveis identificados pelo MS são armazenados no conjunto de indivíduos viáveis $\left(\Omega_{\mathrm{V}}\right)$. Este conjunto é atualizado durante o processo construtivo sempre que uma nova solução viável para o problema é identificada.

Um cuidado especial deve ser tomado durante o armazenamento de indivíduos viáveis no conjunto $\Omega_{\mathrm{V}}$. Por um lado, é possível que um indivíduo viável recém-identificado seja formado por reforços que equivalem a um subconjunto dos reforços de uma solução viável que já pertence ao $\Omega_{\mathrm{V}}$, identificada, por exemplo, em níveis construtivos anteriores. De forma contrária, é possível ainda, que uma solução já presente no $\Omega_{\mathrm{V}}$ possua reforços equivalentes a um subconjunto dos reforços da solução viável identificada no nível construtivo corrente. Em ambos os casos, apenas uma das soluções deve permanecer no $\Omega_{\mathrm{V}}$, a que possuir o menor número de reforços e, consequentemente, o menor investimento.

Os indivíduos que compõem o conjunto $\Omega_{\mathrm{V}}$, apesar de já terem atingido a viabilidade, participam ainda do processo construtivo, sendo utilizados no emprego dos mecanismos MC e MM conforme apresentado na Seção 3.4. Portanto, este conjunto deve ter tamanho $n_{\mathrm{V}}$ definido, sendo também um parâmetro a ser estabelecido pelo planejador. 


\subsection{6. \\ Mecanismo de Depuração}

No processo iterativo do AMC-PET, o mecanismo de depuração (MD) é empregado aos indivíduos dos conjuntos $\Omega_{\mathrm{MA}}$ e $\Omega_{\mathrm{MCM}}$ e, ainda, aos eventuais indivíduos viáveis identificados no nível construtivo (iteração) corrente.

A aplicação do MD a um dado indivíduo consiste em decrementar um de seus genes, de modo a se obter um novo indivíduo com um reforço a menos. A escolha do reforço a ser removido é realizada por meio de um índice de efetividade. Este índice é calculado para todos os ramos reforçados do indivíduo e deve ser capaz de relacioná-los ao desempenho do plano. Dessa forma, espera-se que a remoção do reforço pertencente ao ramo indicado pelo índice de efetividade corresponda ao menor impacto negativo no desempenho do indivíduo. Por princípio, o novo indivíduo foi depurado em relação ao indivíduo que lhe deu origem. Espera-se, então, que este novo indivíduo tenha um potencial mais elevado para contribuir positivamente no processo construtivo.

Caso o reforço removido pelo MD seja de interligação de uma barra de passagem e sua remoção a torne uma barra terminal, os reforços remanescentes de interligação desta barra são também eliminados. Este procedimento reduz o investimento do plano e não causa efeito negativo à operação do sistema.

Todos os indivíduos resultantes da aplicação do MD devem ser avaliados de acordo com a função objetivo definida para o problema. Após avaliação, os indivíduos inviáveis são armazenados no conjunto $\Omega_{\mathrm{MD}}$. Este conjunto tem seu tamanho limitado a $n_{\mathrm{MA}}+n_{\mathrm{MCM}}$ indivíduos, permanecendo apenas os indivíduos com melhores aptidões. Esta limitação se faz necessária uma vez que o tamanho do conjunto $\Omega_{\mathrm{MD}}$ poderia atingir valores elevados para níveis mais avançados do processo construtivo, quando aumenta a identificação (via MS) de indivíduos viáveis no nível construtivo (iteração) corrente. Os eventuais planos viáveis obtidos após o emprego do MD são inseridos no conjunto $\Omega_{\mathrm{V}}$, seguindo o mesmo procedimento de atualização deste conjunto conforme definido na Subseção 3.3.5. 


\subsection{7. \\ Mecanismo de Refinamento}

Este mecanismo é empregado aos indivíduos do conjunto $\Omega_{\mathrm{V}}$ após convergência do procedimento iterativo do AMC-PET proposto. Nesta fase, os indivíduos (planos de expansão) podem apresentar reforços desnecessários, ou seja, reforços que podem ser removidos sem tornar inviável o respectivo plano. Exemplos de adoção desta estratégia podem ser verificados em [25] e [28].

Sendo assim, quando aplicado a um indivíduo, o mecanismo de refinamento (MR) realiza a remoção de seus reforços um a um, verificando a viabilidade de cada indivíduo resultante. O processo é aplicado a cada indivíduo do $\Omega_{\mathrm{V}}$ até que não existam mais planos de expansão viáveis resultantes da remoção gradual de reforços. Caso seja identificado um indivíduo viável, este é inserido ao final da lista de indivíduos do $\Omega_{\mathrm{V}}$, para que seja também submetido ao MR.

Finalmente, o indivíduo que tenha gerado um ou mais indivíduos viáveis após aplicação do MR é excluído do conjunto $\Omega_{\mathrm{V}}$. Isto é feito para garantir que nenhuma solução do $\Omega_{\mathrm{V}}$ seja formada por reforços que sejam equivalentes a um subconjunto de reforços pertencentes a outra solução viável do conjunto, assim como observado na aplicação do MS.

Cabe salientar que, quando o MR é aplicado, nem sempre o indivíduo precisa passar por uma avaliação completa. Se na avaliação operativa de rede intacta da configuração resultante dada pela adição dos reforços indicados, um corte de carga é apresentado, ou se algum corte ou sobrecarga em equipamento surge na avaliação do sistema sob alguma contingência, o indivíduo é não viável, e, portanto, pode ser descartado. Este processo reduz consideravelmente o esforço computacional envolvido na fase de refinamento de soluções do AMC-PET. Terminado o processo, o $\Omega_{\mathrm{V}}$ conterá as soluções finais identificadas para o problema PET.

\section{4.}

\section{Fluxograma do AMC-PET}

A partir da topologia base do sistema, os mecanismos apresentados na Seção 3.3 trabalham intercala e iterativamente em um processo de construção gradual, a fim de identificar bons planos de expansão. O fluxograma representativo do AMC-PET é exibido na Figura 3.2 e discutido a seguir. 


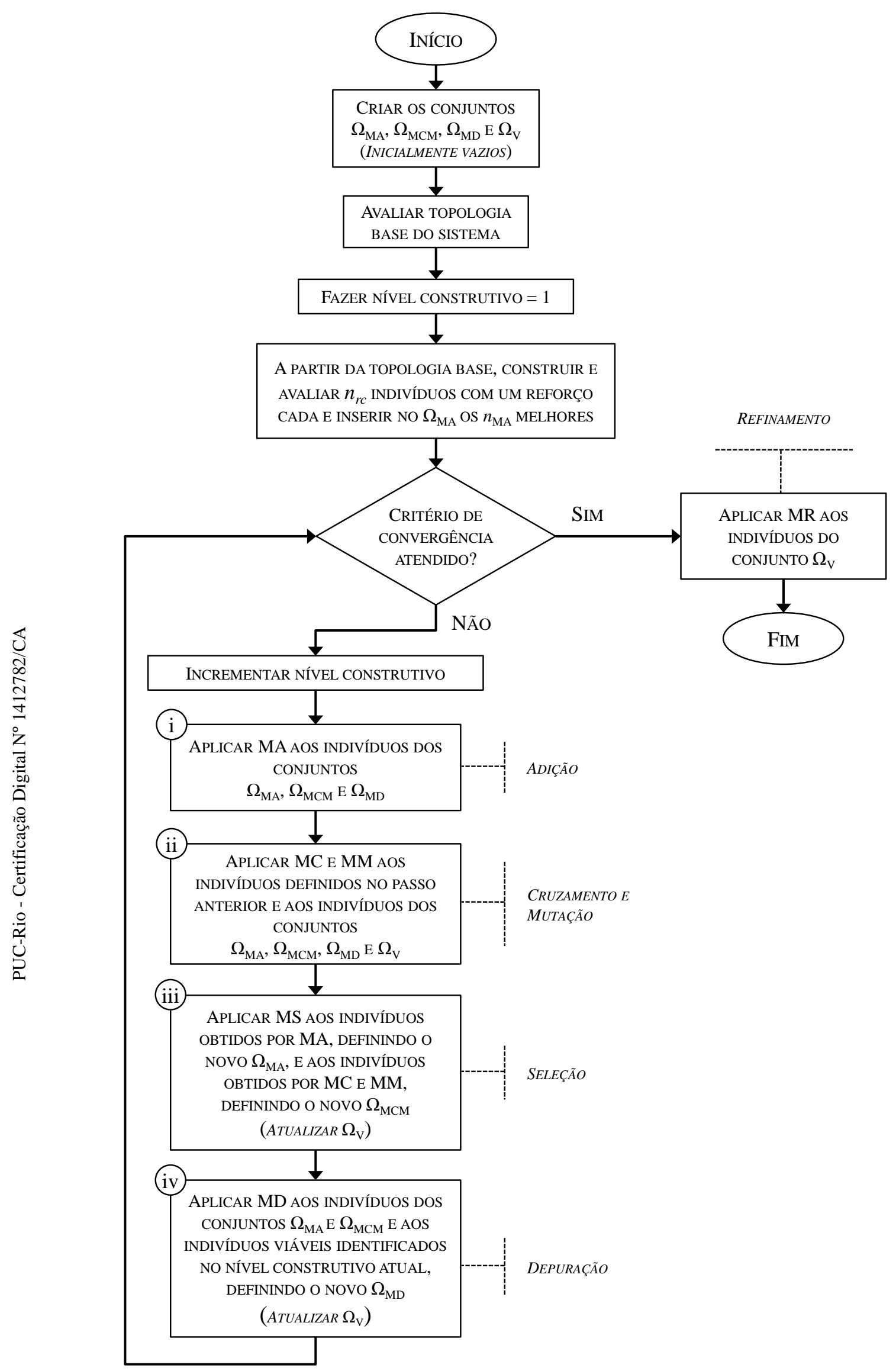

Figura 3.2 - Fluxograma representativo do AMC-PET. 
Inicialmente, são criados os conjuntos de planos de expansão (indivíduos) a serem utilizados e atualizados durante todo o processo construtivo. Os conjuntos apresentados na Seção $3.3\left(\Omega_{\mathrm{MA}}\right.$ e $\Omega_{\mathrm{MCM}}, \Omega_{\mathrm{MD}}$ e $\left.\Omega_{\mathrm{V}}\right)$ são inicialmente vazios e têm seus tamanhos definidos pelo planejador do sistema.

Em seguida, a topologia base do sistema é avaliada de acordo com a função objetivo definida para o problema. Ao longo de todo o processo construtivo, a avaliação dos indivíduos está relacionada à análise de fluxo de potência da rede, sendo as informações provenientes desta avaliação utilizadas também para cálculo dos índices de atratividade e de efetividade dos ramos candidatos ao reforço do sistema.

Após a avaliação da topologia base do sistema, o processo construtivo é iniciado, com a definição do primeiro nível construtivo do AMC-PET. Neste nível, são inicialmente obtidos $n_{r c}$ indivíduos, cada um contendo apenas um reforço em sua configuração. Ou seja, cada um dos $n_{r c}$ ramos candidatos do sistema recebe um reforço e define um novo indivíduo. Em seguida, os indivíduos obtidos são avaliados e os $n_{\mathrm{MA}}$ melhores em termos de aptidão são inseridos no conjunto $\Omega_{\mathrm{MA}}$. Estritamente no primeiro nível construtivo, o conjunto $\Omega_{\mathrm{MA}}$ recebe indivíduos selecionados por meio de um procedimento simples e diferente do MS.

A partir de então, é iniciada a porção iterativa do AMC-PET, a qual é interrompida assim que o critério de convergência for atingido. Como critério de convergência, adota-se a estagnação (permanência) do melhor indivíduo viável, pertencente ao conjunto $\Omega_{\mathrm{V}}$, por $n_{p}$ níveis construtivos (iterações) consecutivos, sendo $n_{p}$ um parâmetro definido pelo planejador. A cada nível construtivo, até que o critério de convergência seja atingido, os mecanismos de construção são aplicados aos conjuntos de indivíduos, de acordo com os 4 passos da parcela iterativa do fluxograma da Figura 3.2, detalhados a seguir:

i) ADIÇÃO - Aplicar o MA aos indivíduos dos conjuntos $\Omega_{\mathrm{MA}}, \Omega_{\mathrm{MCM}}$ e $\Omega_{\mathrm{MD}}$ (deve-se notar que o $\Omega_{\mathrm{MCM}}$ e $\Omega_{\mathrm{MD}}$ ainda serão conjuntos vazios na primeira vez que este passo for executado);

ii) CRuzamento e MutaÇão - Unir todos os indivíduos obtidos no passo anterior e os indivíduos dos conjuntos $\Omega_{\mathrm{MA}}, \Omega_{\mathrm{MCM}}, \Omega_{\mathrm{MD}}$ e $\Omega_{\mathrm{V}}$ (sendo este último também vazio ao menos na primeira execução deste passo), formando o conjunto de indivíduos progenitores, aos quais os mecanis- 
mos MC e MM serão empregados. Estes mecanismos são aplicados de forma a gerar novos indivíduos (excluídas as repetições) com um número máximo de reforços igual ao número no nível construtivo mais um. A geração de novos indivíduos é interrompida quando o total de indivíduos obtidos é igual ao número de indivíduos progenitores;

iii) SELEÇÃO - Aplicar o MS aos indivíduos definidos no passo (i), para determinar o novo $\Omega_{\mathrm{MA}}$, e aos indivíduos definidos no passo (ii), para determinar o novo $\Omega_{\mathrm{MCM}}$. Eventuais indivíduos viáveis serão inseridos no $\Omega_{\mathrm{V}}$

iv) DEPURAÇÃO - Aplicar o MD aos indivíduos dos conjuntos $\Omega_{\mathrm{MA}}$ e $\Omega_{\mathrm{MCM}}$ e, ainda, aos eventuais indivíduos viáveis identificados no nível construtivo corrente. Os indivíduos inviáveis decorrentes da aplicação do MD formam o novo $\Omega_{\mathrm{MD}}$. Eventuais indivíduos viáveis são inseridos no $\Omega_{\mathrm{V}}$.

Atingido o critério de convergência, a parte iterativa do algoritmo é terminada. Finalmente, o sexto mecanismo (MR) é aplicado ao $\Omega_{\mathrm{V}}$, visando refinar, se possível, este conjunto de indivíduos, o qual contém as melhores soluções para o problema PET.

Salienta-se que as soluções finais do primeiro nível do processo construtivo têm apenas um reforço, isto é, a topologia base mais um reforço. A partir do segundo nível, quando os mecanismos MC, MM e MD são também empregados no processo, os indivíduos podem apresentar um conjunto de reforços limitado ao nível construtivo mais um reforço (em sistemas com barras de passagem este limite deve ser ampliado pelo número de barras deste tipo interligadas no presente indivíduo). Essa delimitação garante ao processo construtivo um comportamento parcimonioso, melhorando seu desempenho.

\section{5.}

\section{Parâmetros do AMC-PET}

Para o emprego do AMC-PET o planejador deve atribuir valores para os seguintes parâmetros:

1. Tamanhos $n_{\mathrm{MA}}, n_{\mathrm{MCM}}$ e $n_{\mathrm{V}}$ dos conjuntos $\Omega_{\mathrm{MA}}, \Omega_{\mathrm{MCM}}$ e $\Omega_{\mathrm{V}}$, respectivamente (o tamanho do $\Omega_{\mathrm{MD}}$ não poderá exceder a $n_{\mathrm{MA}}+n_{\mathrm{MCM}}$ ); 
2. Tamanho do $n_{r}$ e sua distribuição entre os índices de atratividade estabelecidos para o emprego do MA;

3. Taxa de adição para seleção de ramos candidatos que não podem ser avaliados pelos índices de atratividade no MA;

4. Taxas de cruzamento e de mutação dos mecanismos MC e MM;

5. Critério de convergência do algoritmo, dado pela estagnação $n_{p}$.

Dos parâmetros listados, os que mais influenciam no desempenho global do AMC-PET são aqueles que delimitam: os tamanhos dos conjuntos utilizados ( $n_{\mathrm{MA}}$, $n_{\mathrm{MCM}}$ e $\left.n_{\mathrm{V}}\right)$, a quantidade de indivíduos avaliados no MA $\left(n_{r}\right)$ e o critério de convergência $\left(n_{p}\right)$.

Os tamanhos $n_{\mathrm{MA}}$ e $n_{\mathrm{MCM}}$ dos conjuntos $\Omega_{\mathrm{MA}}$ e $\Omega_{\mathrm{MCM}}$, respectivamente, estão diretamente relacionados ao número de indivíduos gerados e avaliados pelos mecanismos MA, MC, MM e MD. Já o tamanho $n_{\mathrm{V}}$, do conjunto $\Omega_{\mathrm{V}}$, tem impacto no número de indivíduos gerados pelos mecanismos MC e MM e, ainda, na quantidade de avaliações realizadas pelo MR, que acontece ao fim do processo iterativo do AMC-PET.

Por sua vez, o tamanho $n_{r}$ afeta o número de indivíduos que são avaliados no emprego do MA. Cabe salientar que a distribuição de $n_{r}$ entre os índices de atratividade estabelecidos não interfere no número de indivíduos avaliados. Porém, ela tem impacto na qualidade dos ramos candidatos indicados para adição de reforços.

O valor da estagnação $n_{p}$ interfere diretamente no número total de níveis construtivos utilizados durante todo o processo. Este parâmetro tem impacto significativo no tempo de processamento e na qualidade das soluções encontradas.

A taxa de adição empregada no MA altera minimamente a quantidade de indivíduos avaliados. Esta taxa é aplicada somente a ramos especiais (e.g., ramos para conexão de barras isoladas de geração e/ou carga), os quais, quando presentes, representam uma parcela muito pequena dos ramos candidatos.

Finalmente, as taxas de cruzamento e de mutação, implementadas para os mecanismos MC e MM, não interferem na quantidade de indivíduos avaliados, podendo apenas contribuir para a qualidade dos indivíduos obtidos após o emprego destes mecanismos. Eles são aqui aplicados com a finalidade de permitir a troca de informações entre as soluções em construção, assim como a perturbação de 
suas estruturas. A partir de testes preliminares realizados com o AMC-PET, verificou-se que as taxas de cruzamento e de mutação não alteram significativamente o desempenho do algoritmo desde que ajustadas, respectivamente, dentro das faixas de $5 \%$ a $15 \%$ e de $60 \%$ a $80 \%$.

Assim como todas as técnicas metaheurísticas e construtivas, o AMC-PET deve ter seus parâmetros devidamente ajustados, visando aprimorar seu desempenho. No entanto, pode-se antecipar, com base nos resultados que serão analisados ao longo desta tese, que o AMC-PET apresenta uma elevada robustez para o seu conjunto de parâmetros. Planos de expansão de boa qualidade são identificados para os três diferentes sistemas estudados, mesmo quando um só ajuste de parâmetros (com exceção do $n_{p}$ ) é considerado, conforme evidenciado ao final do Capítulo 5 .

\section{6.}

\section{Análise da Dinâmica do Processo Construtivo}

Dos parâmetros listados na seção anterior, os que influenciam diretamente na quantidade de indivíduos (soluções) avaliados a cada nível construtivo do AMC-PET são os tamanhos dos conjuntos ( $n_{\mathrm{MA}}, n_{\mathrm{MCM}}$ e $\left.n_{\mathrm{V}}\right)$ e o valor de $n_{r}$. A fim de verificar o número de indivíduos avaliados durante a evolução do AMC-PET em função desses parâmetros, por exemplo, os seguintes valores serão considerados: $n_{\mathrm{MA}}=n_{\mathrm{MCM}}=10, n_{\mathrm{V}}=20$ e $n_{r}=5$.

No primeiro nível construtivo do AMC-PET, são avaliados $n_{r c}$ indivíduos, cada um contendo apenas um reforço. Ou seja, cada ramo candidato do problema recebe um reforço e define um indivíduo. Destes, são selecionados os $10\left(n_{\mathrm{MA}}\right)$ melhores para compor o $\Omega_{\mathrm{MA}}$. Os demais conjuntos $\left(\Omega_{\mathrm{V}}, \Omega_{\mathrm{MCM}}\right.$ e $\left.\Omega_{\mathrm{MD}}\right)$ permanecem vazios.

Para um determinado nível construtivo $\mathrm{k}$ (com $\mathrm{k}>1$ ), a dinâmica de evolução do processo iterativo do AMC-PET pode ser observada na Figura 3.3, onde estão representados os passos de (i) a (iv) do algoritmo. Nesta figura, as linhas contínuas representam o fluxo de indivíduos inviáveis pelo processo construtivo, já as linhas tracejadas representam o fluxo dos indivíduos viáveis. Os conjuntos "INDIVÍDUOS OBTIDOS PELO MA" e "INDIVÍDUOS OBTIDOS PELOS MECANISMOS MC E MM" são conjuntos intermediários, os quais não são submetidos ao MS. 


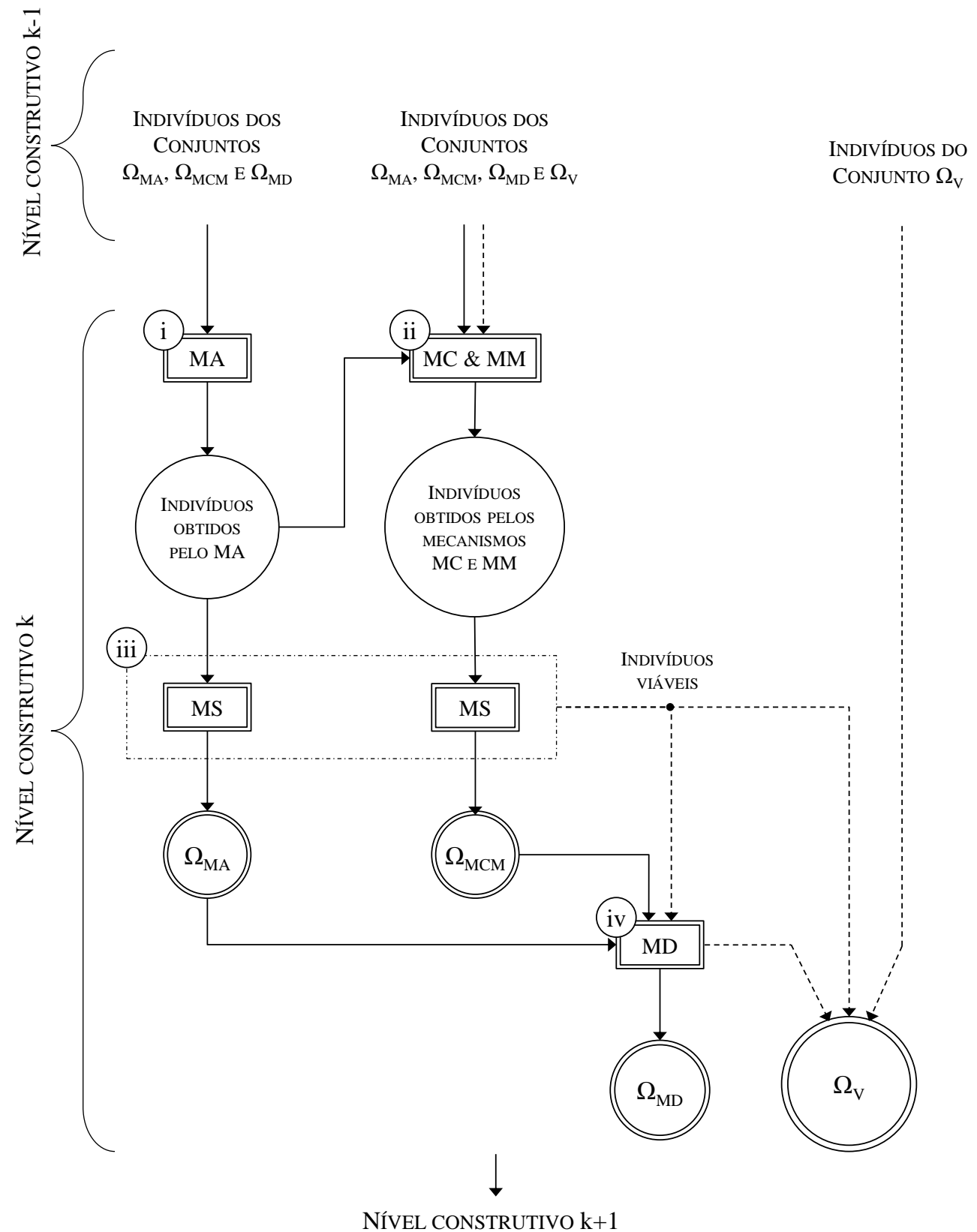

Figura 3.3 - Dinâmica de evolução do AMC-PET.

De acordo com o passo (i) do algoritmo, no segundo nível construtivo ( $\mathrm{k}=$ 2) o MA é empregado a apenas 10 indivíduos, aqueles pertencentes ao conjunto $\Omega_{\mathrm{MA}}$ criado no primeiro nível. Para cada indivíduo, são então selecionados os 5 ramos mais atrativos $\left(n_{r}\right)$, originando 5 novos indivíduos com um reforço a mais em cada um desses ramos. Estes indivíduos são avaliados e apenas um permanece, conforme MA apresentado na Subseção 3.3.2. Sendo assim, um total de 50 indivíduos é avaliado neste momento. Destes, 10 formam o conjunto "INDIVÍDUOS OBTIDOS PELO MA". 
No passo (ii) do algoritmo, ainda no segundo nível construtivo, os mecanismos MC e MM são aplicados a 20 indivíduos (10 obtidos no passo anterior, do conjunto "INDivíDUOS obTidos PELO MA", e 10 do $\Omega_{\mathrm{MA}}$ atual). Com um conjunto de 20 progenitores, são gerados e avaliados 20 novos indivíduos, que compõem o conjunto "INDivíduos obTidos PELOS MECANISMOS MC E MM”. Esses indivíduos possuem, no máximo, 3 reforços, uma vez que são limitados ao valor k+1.

Com emprego do MS no passo (iii), um novo conjunto $\Omega_{\mathrm{MA}}$ é criado, recebendo os $10\left(n_{\mathrm{MA}}\right)$ indivíduos gerados pelo MA no passo (i), e o conjunto $\Omega_{\mathrm{MCM}}$ deixa de ser vazio, recebendo $10\left(n_{\mathrm{MCM}}\right)$ indivíduos dos 20 gerados no passo (ii). Excepcionalmente no segundo nível construtivo, o conjunto $\Omega_{\mathrm{MA}}$ recebe todos os indivíduos gerados no passo (i), uma vez que possuem a mesma dimensão. A partir do terceiro nível construtivo, o número de indivíduos gerados pelo MA no passo (i) fica maior que $n_{\mathrm{MA}}$.

Considerando que nenhum indivíduo tenha atingido a viabilidade no segundo nível construtivo, o MD é empregado a 20 indivíduos (indivíduos do $\Omega_{\mathrm{MA}}$ e do $\Omega_{\mathrm{MCM}}$ ), definindo novos 20 indivíduos com um reforço a menos em suas configurações. Estes indivíduos são avaliados e formam o conjunto $\Omega_{\mathrm{MD}}$.

Deste modo, de acordo com o exemplo exposto, foram avaliados 90 (50 no MA; 20 nos mecanismos MC e MM; 20 no MD) indivíduos no segundo nível construtivo do AMC-PET. A partir de então, para $\mathrm{k}>2$, e até que soluções viáveis sejam identificadas, o processo interativo é estabilizado com avaliação de:

- 200 indivíduos no passo (i), ou seja, 5 para cada um dos 40 indivíduos dos conjuntos $\Omega_{\mathrm{MA}}, \Omega_{\mathrm{MCM}}$ e $\Omega_{\mathrm{MD}}$;

- 80 indivíduos no passo (ii), uma vez que o conjunto de progenitores é formado pelos 40 indivíduos obtidos no passo (i) mais os 40 dos conjuntos $\Omega_{\mathrm{MA}}, \Omega_{\mathrm{MCM}}$ e $\Omega_{\mathrm{MD}} ;$ e

- 20 indivíduos no passo (iv), com emprego do MD aos 20 indivíduos dos conjuntos $\Omega_{\mathrm{MA}}$ e $\Omega_{\mathrm{MCM}}$.

Portanto, exceto para duas primeiras iterações, são avaliados ao menos 300 indivíduos por nível construtivo. Vale destacar que para problemas de pequeno porte, este número de avaliações não implica em custo computacional acentuado. 
Contudo, para sistemas reais, como o que será visto no Capítulo 5, maior atenção deve ser dedicada aos parâmetros do AMC-PET.

Quando indivíduos começam a atingir a viabilidade, o conjunto $\Omega_{\mathrm{V}}$ deixa de ser vazio. Nessa situação, o número de indivíduos avaliados no passo (i) não é alterado. Já no passo (ii), sendo o conjunto $\Omega_{\mathrm{V}}$ limitado a 20 indivíduos, passam a serem gerados e avaliados, no máximo, 100 indivíduos (40 dos conjuntos $\Omega_{\mathrm{MA}}$, $\Omega_{\mathrm{MCM}}$ e $\Omega_{\mathrm{MD}}, 40$ gerados pelo passo (i) e 20 do conjunto $\Omega_{\mathrm{V}}$ ). No passo (iv), o número de indivíduos avaliados será igual a 20 mais o número de indivíduos viáveis encontrados no nível corrente.

Cabe salientar que os indivíduos dos conjuntos $\Omega_{\mathrm{MA}}, \Omega_{\mathrm{MCM}}$ e $\Omega_{\mathrm{MD}}$ são substituídos por novos a cada nível do processo construtivo, diferentemente do conjunto $\Omega_{\mathrm{V}}$, o qual é apenas atualizado.

Terminada a porção iterativa do AMC-PET, com a estagnação da melhor solução viável identificada, o sexto mecanismo (MR) deve ser aplicado aos indivíduos presentes no $\Omega_{\mathrm{V}}$, visando, se possível, refinar os indivíduos deste conjunto. $\mathrm{O} \Omega_{\mathrm{V}}$ resultante contém as melhores soluções para o PET identificadas pelo algoritmo proposto.

\section{7. \\ AMC-PET Aplicado ao Problema Estático}

Como já mencionado, na formulação do problema PET estático para um horizonte de planejamento de longo prazo, modelos matemáticos simplificados são comumente utilizados para representar a rede elétrica do sistema. Dentre eles, o modelo linear DC da rede é o mais empregado. Nesta seção é apresentada a formulação do problema PET adotada para aplicação da metodologia proposta, a qual considera o critério de segurança "N-1" e utiliza o modelo de fluxo DC, com inclusão das perdas ôhmicas, para avaliar as configurações obtidas ao longo do processo construtivo.

O problema PET, até mesmo quando a modelagem DC é adotada, consiste em um problema de otimização não linear inteira mista, com um número de alternativas de expansão do sistema combinatoriamente explosivo. A consideração de restrições de segurança aumenta ainda mais a complexidade do problema e a dificuldade de se encontrar o plano ótimo de expansão. Uma estratégia comum para tratar o problema da não linearidade das equações presentes no PET, e que é ado- 
tada por vários trabalhos da área [3], é o desacoplamento do problema original em dois subproblemas: investimento e operação, os quais são resolvidos, alternada e interativamente.

\subsection{1.}

\section{Subproblema de Investimento}

Este subproblema tem por objetivo a identificação de planos de expansão com custos de investimento reduzidos, e que sejam capazes de atender a demanda futura respeitando certos critérios de segurança. Sendo assim, o subproblema de investimento pode ser definido por:

$$
\begin{array}{ll}
\text { Min.: } & f(n)=\sum_{(i j) \in \Omega_{r c}} c_{i j} n_{i j}+\alpha_{i n v}\left(c c(n)+\sum_{c=1}^{n c}\left[c c i(n)_{c}+s c(n)_{c}\right]\right) \\
\text { s.a.: } & 0 \leq n_{i j} \leq n_{i j}^{\max }, \quad \forall(i j) \in \Omega_{r c}
\end{array}
$$

onde:

$f(n)$ é a função objetivo do problema;

$n$ é o vetor decisão (indivíduo);

$n_{i j}$ é o componente do vetor $n$ que armazena o número de reforços adicionados ao ramo candidato $i-j$;

$c_{i j}$ é o custo de adição de um reforço no ramo candidato $i$-j, dado em $10^{6} \$$;

$\Omega_{r c}$ é o conjunto de todos os ramos candidatos;

$\alpha_{i n v}$ corresponde a uma penalização aplicada (dada em $10^{6} \$ / \mathrm{MW}$, para toda e qualquer decisão de investimento $n$ ): ao corte de carga da rede intacta $(c c(n))$, ao corte de carga por ilhamento decorrente da contingência $c\left(\operatorname{cci}(n)_{c}\right)$ e às sobrecargas decorrentes da contingência $c\left(s c(n)_{c}\right)$;

$n c$ é o número de contingências observadas na aplicação do critério de segurança; $n_{i j}^{\max }$ é o número máximo de reforços que podem ser adicionados ao ramo candidato $i-j$.

Os cortes e sobrecargas são expressos em MW. Portanto, a penalidade $\alpha_{i n v}$ é dada em unidades monetárias por MW.

Nesta tese de doutorado, é adotado o critério de segurança "N-1" [12], [18]. Dessa forma, para que um plano de expansão possa ser considerado viável, o sistema de transmissão deve garantir o total atendimento da carga, sem sobrecarregar 
seus equipamentos, mesmo para o caso da contingência simples de qualquer um de seus circuitos (linha de transmissão ou transformador). A penalização $\alpha_{i n v}$, aplicada a eventuais cortes de carga e/ou sobrecargas nos equipamentos, visa permitir a consideração de soluções (i.e., planos) inviáveis em termos do critério de segurança adotado, principalmente em etapas iniciais do algoritmo de otimização proposto. Entretanto, o processo construtivo converge para soluções viáveis do problema PET.

\subsection{2.}

\section{Subproblema de Operação}

O subproblema de operação é responsável por avaliar, tanto sob a condição de rede intacta quanto sob contingências simples, cada plano de expansão $n$ obtido ao longo do processo construtivo. Para a consideração da rede intacta, o despacho ótimo de geração, que minimiza o custo de produção e o corte de carga do sistema, é obtido pelo problema de otimização linear definido por:

$$
\text { Min.: } \quad \sum_{i \in \Omega_{b g}} c_{g i} g_{i}+\alpha_{o p} \sum_{k \in \Omega_{b c}} r_{k}
$$

s.a.:

$$
\begin{array}{ll}
g+B \theta+r=d+d_{f i c} & \\
\left|b_{i j} \theta_{i j}\right| \leq n_{i j}^{0} f_{i j}^{\max } ; & \forall(i j) \in \Omega_{r e} \\
\left|b_{i j} \theta_{i j}\right| \leq n_{i j} f_{i j}^{\max } ; & \forall(i j) \in \Omega_{r c} \\
g^{\min } \leq g \leq g^{\max } & \\
0 \leq r \leq d & \forall(i) \in \Omega_{b}, i \neq b s w \\
-\pi \leq \theta_{i} \leq \pi ; & \\
\theta_{b s w}=0 &
\end{array}
$$

onde:

$\Omega_{b g}$ é o conjunto das barras de geração;

$c_{g i}$ é o custo de produção dos geradores da barra $i$;

$g$ é o vetor de geração com componente $g_{i}$;

$\alpha_{o p}$ é a penalização, de valor elevado em relação ao custo de produção (e.g., 10 vezes superior ao maior custo de produção), aplicada ao corte de carga; 
$\Omega_{b c}$ e o conjunto de barras de carga;

$r$ é o vetor de geração fictícia para cada decisão de investimento $n$. O somatório das componentes $r_{k}$ do vetor $r$ fornece o valor de $c c(n)$ utilizado em (3.4a);

$B$ é a matriz de susceptâncias do sistema;

$\theta$ é o vetor de ângulos das tensões nodais com componente $\theta_{i}$;

$d$ é o vetor de demanda;

$d_{f i c}$ é o vetor de cargas (demandas) fictícias para representação das perdas na transmissão;

$\theta_{i j}$ é a abertura angular apresentada pelas tensões das barras terminais $i$ e $j$;

$b_{i j}$ é a susceptância equivalente do ramo $i-j$;

$n_{i j}^{0}$ é o número de circuitos existentes no ramo $i-j$, na topologia base do sistema;

$f_{i j}^{\max }$ é o valor máximo de fluxo de potência ativa para cada circuito do ramo $i$-j;

$\Omega_{r e}$ é o conjunto dos ramos que já possuem circuitos na topologia base da rede (ramos existentes);

$g_{\min }$ e $g_{\max }$ são, respectivamente, vetores com os limites mínimos e máximos de potência das unidades geradoras;

$b s w$ é o índice que representa a barra de referência angular para o sistema (barra swing).

Para a aplicação do critério "N-1", em cada ramo ativo do sistema deve ser retirado um circuito. Em seguida, um problema de otimização semelhante ao problema (3.5) é resolvido. $\mathrm{Na}$ análise sob contingência, pretende-se avaliar a capacidade de atendimento da demanda sem a possibilidade de redespacho da geração, exceto para a barra de referência, para a qual são mantidos os seus limites mínimo e máximo de capacidade. Essa política operativa é adotada em [31]. Neste novo problema, os limites de capacidade dos circuitos são ignorados, de modo a tornar possível o atendimento total da demanda, exceto em situações de ilhamento, quando, para uma dada contingência $c$, os possíveis cortes de carga (gerações fictícias) devem ser identificados e acumulados em $\operatorname{cci}(n)_{c}$. As eventuais sobrecargas são contabilizadas por meio de $s c(n)_{c}$.

Identificado os possíveis cortes de carga para a rede intacta $(c c(n))$ e sob cada contingência $\left(\operatorname{cci}(n)_{c}\right)$, assim como as eventuais sobrecargas $\left(s c(n)_{c}\right)$, o plano $n$ pode ser completamente avaliado pelo subproblema de investimento. 


\subsection{3. \\ Perdas Ôhmicas na Transmissão}

A fim de se obter uma melhor representação dos fluxos de potência ativa e, consequentemente, da operação futura do sistema, as perdas ôhmicas da transmissão devem ser levadas em consideração na avaliação do subproblema de operação. Para o cálculo das perdas, um processo iterativo simples é realizado durante a avaliação de cada plano sob a condição de rede intacta, conforme [12], [29] e [31].

Após a solução do problema de otimização modelado em (3.5), as perdas para cada ramo ativo $i-j$ do sistema são calculadas como:

$$
P_{i j}^{\text {Perdas }}=g_{i j} \theta_{i j}^{2}
$$

onde $g_{i j}$ é a condutância equivalente do ramo $i-j$.

Em seguida, para cada ramo, as barras terminais $i$ e $j$ recebem metade das perdas estimadas na forma de cargas fictícias, sendo o problema de otimização (3.5) resolvido novamente. Todo o processo é repetido uma segunda vez, visando uma maior precisão para os valores calculados. Os vetores finais de carga (incluindo as cargas fictícias que representam as perdas ativas) e de geração obtidos para a rede intacta (i.e., com a consideração dos cortes de carga) fornecem os valores utilizados nas avaliações sob contingências.

\section{8. \\ Conclusões}

No presente capítulo é apresentada a metodologia proposta para solução do problema PET, denominada algoritmo metaheurístico construtivo (AMC-PET). Os mecanismos empregados pela técnica, bem como a dinâmica do processo construtivo, são detalhadamente descritos e ilustrados. A formulação do problema estático de planejamento da transmissão adotado nesta tese de doutorado é também apresentada neste capítulo.

A combinação de características de diferentes ferramentas de otimização, já bem difundidas para solução do PET, e a capacidade de trabalhar com a construção gradual e paralela de um conjunto de soluções, apontam para uma boa expectativa em relação ao emprego do algoritmo, o que é confirmado pelos resultados expostos nos próximos capítulos. Ajustes do algoritmo, tendo em vista, a manu- 
tenção da diversidade de soluções e as características de dimensão dos sistemas, são também apresentados nos próximos capítulos.

Um caso tutorial, com emprego do AMC-PET na solução do problema de planejamento da expansão para o Sistema Garver [23], é apresentado no Apêndice $\mathrm{C}$ ao final desta tese. 


\section{4. Aplicações em Sistemas de Pequeno Porte}

\section{1. Introdução}

Com o intuito de analisar o desempenho do algoritmo metaheurístico construtivo (AMC-PET) proposto nesta tese de doutorado, são utilizados no presente capítulo dois sistemas comumente empregados em estudos de planejamento da rede de transmissão. São eles o sistema IEEE-RTS [74], com as modificações consideradas por [75] e [30], e a configuração do Sistema Sul Brasileiro (SSB) considerada em [25] e [31]. Os estudos relatados neste capítulo foram fundamentais para o desenvolvimento da metodologia, propiciando o campo de testes necessário para a proposição, investigação e aprimoramento dos principais mecanismos, índices de sensibilidade e procedimentos utilizados.

Praticamente todas as rotinas computacionais do AMC-PET foram implementadas na linguagem C\#.NET. As exceções ficam por conta da utilização do método simplex da biblioteca GLPK para solução dos problemas de otimização linear e da utilização de uma biblioteca em FORTRAN para solução do fluxo de potência DC a cada contingência simples da rede de transmissão. O computador utilizado possui processador Intel Xeon de $3.5 \mathrm{GHz}$.

Nas seções a seguir são apresentados os índices utilizados para avaliação de desempenho da metodologia e os resultados obtidos para cada sistema a partir de várias combinações de parâmetros.

\section{2.}

\section{Índices de Desempenho}

A fim de avaliar o desempenho da metodologia proposta são utilizados quatro índices de desempenho, os quais são calculados a partir de várias execuções do AMC-PET. A descrição destes quatro índices é feita a seguir: 
- $\mathrm{T}_{\mathrm{S}}(\mathrm{em} \%)$ : É a razão percentual entre o número de execuções de sucesso e o número total de execuções realizadas [31]. Uma execução é considerada de sucesso quando encontra pelo menos uma solução (plano de expansão) das 10 melhores conhecidas para o problema;

- $\mathrm{T}_{\mathrm{M}}$ (unidade de tempo): É a média dos tempos de todas as execuções realizadas;

- $\mathrm{D}_{\text {Best }}(\mathrm{em} \%)$ : É o desvio percentual médio entre o menor investimento encontrado em cada execução e o investimento do melhor plano de expansão conhecido;

- $\mathrm{D}_{10 \mathrm{Best}}(\mathrm{em} \%)$ : É o desvio percentual médio entre os 10 melhores investimentos encontrados em cada execução e o investimento do melhor plano conhecido.

O cálculo de índices estatísticos de desempenho é uma estratégia de grande importância na avaliação de metodologias estocásticas para solução de problemas de otimização. A partir de diversas execuções do algoritmo, utilizando-se sementes diferentes para o gerador de números pseudoaleatórios em cada uma delas, é possível estabelecer uma análise quantitativa consistente a respeito de seu desempenho $^{3}$.

Além disso, é muito importante a avalição da qualidade das melhores soluções encontradas pela metodologia e não apenas da melhor delas. Em geral, as incertezas inerentes ao PET são negligenciadas na formulação do problema, no todo ou em grande parte. Portanto, é necessário que o planejador disponha de mais de uma opção (plano de expansão) para reforço da rede. Dos índices de desempenho propostos, o $\mathrm{D}_{10 \mathrm{Best}}$, por exemplo, permite ao planejador avaliar a qualidade média das 10 melhores soluções encontradas nas execuções do algoritmo, servindo como indicador quantitativo do desempenho da metodologia neste quesito.

\section{3.}

\section{Resultados - IEEE-RTS}

O sistema IEEE-RTS de 24 barras [74], comumente empregado em estudos de planejamento da expansão, é o primeiro utilizado para avaliação do desempe-

\footnotetext{
${ }^{3}$ De acordo com o algoritmo do AMC-PET exposto no Capítulo 3, a utilização de diferentes sementes para geração de números pseudoaleatórios influencia na construção de soluções apenas a partir do segundo nível construtivo, quando sorteios passam a ser realizados.
} 
nho do algoritmo AMC-PET proposto. Este sistema possui em sua topologia original 38 circuitos, entre LTs e transformadores, distribuídos em 34 ramos. Os valores de demanda em cada barra e a capacidade de geração de cada unidade foram triplicados em relação à sua versão original, conforme [75], resultando em montantes de 8850 MW de carga e 10215 MW de capacidade de geração instalada. Os valores de investimento dos ramos candidatos à expansão foram ainda multiplicados por 100, do mesmo modo que em [39]. Para a penalidade $\alpha_{i n v}$, do subproblema de investimento, foi considerado o valor de $10^{6} \$ / \mathrm{MW}$. Os dados do sistema IEEE-RTS para estudo do PET são apresentados no Apêndice A, Seção A.1.

$\mathrm{Na}$ avaliação da rede intacta para o sistema IEEE-RTS, foi adotada uma ordem de despacho. Para tal, os custos de geração $c_{g i}$ presentes na função objetivo do problema de otimização (3.5) são considerados iguais à ordem de prioridade. São adotados como ramos candidatos os 34 ramos existentes na topologia base da rede e mais 7 ramos novos, perfazendo um total de 41 ramos candidatos a expansão, os quais podem receber no máximo 3 reforços.

A fim de verificar a sensibilidade da metodologia proposta aos tamanhos dos conjuntos $\Omega_{\mathrm{MA}}$ e $\Omega_{\mathrm{MCM}}\left(n_{\mathrm{MA}}\right.$ e $n_{\mathrm{MCM}}$, respectivamente), assim como ao número de ramos selecionados por meio de cada índice de atratividade no emprego do MA, foram efetuados diversos testes com a variação destes parâmetros. Em cada teste foram realizadas 100 execuções do algoritmo AMC-PET, sendo que para cada execução foi adotada uma semente distinta para o gerador de números pseudoaleatórios. O menor investimento encontrado em todos os testes foi de 681,00 milhões de unidades monetárias (\$), sendo identificadas 10 diferentes soluções com este mesmo valor. Dentre essas soluções, a que apresenta menor valor de perdas ativas $(138,90 \mathrm{MW})$ possui os seguintes 17 reforços:

$$
\begin{aligned}
& n_{01-05}=1, n_{02-04}=1, n_{03-09}=2, n_{06-10}=2, n_{07-08}=3, n_{09-12}=1, n_{10-12}=2, \\
& n_{12-13}=2, n_{20-23}=1 \text { e } n_{14-23}=2 .
\end{aligned}
$$

Na Tabela 4.1 estão presentes os resultados de 16 testes (A.1 até A.16) com variação de tamanho dos conjuntos $\Omega_{\mathrm{MA}}$ e $\Omega_{\mathrm{MCM}}$, para os quais se adotou $n_{r}$ igual a 5 ramos, sendo 1 selecionado pelo $\operatorname{Ind}_{c h-i j}, 2$ pelo $\operatorname{Ind}_{s c-i j}^{\text {próprio }}$ e 2 pelo $\operatorname{Ind}_{s c-i j}^{\text {outros }}$. Todos os ramos candidatos ao reforço da rede para o sistema IEEE-RTS podem 
ser avaliados pelos índices de atratividade propostos. Portanto, não há necessidade de definir uma taxa de adição para emprego do MA.

Ainda em relação aos testes apresentados, informa-se que os valores considerados para as taxas de cruzamento e de mutação dos mecanismos MC e MM foram $65 \%$ e $8 \%$, respectivamente. Finalmente, o tamanho do $\Omega_{\mathrm{V}}$ foi limitado em 100 indivíduos $\left(n_{\mathrm{V}}=100\right)$, sendo o critério de parada definido como a permanência da melhor solução (menor valor de $f(n)$ ) deste conjunto por 5 níveis consecuti$\operatorname{vos}\left(\right.$ i.e., $n_{p}=5$ ).

Tabela 4.1 - Resultados com variação de $\boldsymbol{n}_{\mathrm{MA}}$ e $\boldsymbol{n}_{\mathrm{MCM}}$ - IEEE-RTS.

\begin{tabular}{|c|c|c|c|c|c|c|}
\hline \multirow{2}{*}{ Teste } & \multirow[b]{2}{*}{$n_{\mathrm{MA}}$} & \multirow[b]{2}{*}{$n_{\mathrm{MCM}}$} & \multicolumn{4}{|c|}{ Índices de Desempenho } \\
\hline & & & $\begin{array}{c}T_{S} \\
(\%)\end{array}$ & $\underset{(\mathbf{m i n})}{\mathbf{T}_{\mathbf{M}}}$ & $\begin{array}{l}D_{\text {Best }} \\
(\%)\end{array}$ & $\begin{array}{c}D_{10 \text { Best }} \\
(\%)\end{array}$ \\
\hline A. 1 & 5 & 5 & 97 & 0,15 & 0,21 & 4,84 \\
\hline A. 2 & 5 & 10 & 98 & 0,17 & 0,06 & 3,90 \\
\hline A. 3 & 10 & 5 & 100 & 0,17 & 0,00 & 3,34 \\
\hline A. 4 & 10 & 10 & 100 & 0,22 & 0,00 & 2,29 \\
\hline A.5 & 10 & 20 & 100 & 0,25 & 0,00 & 1,57 \\
\hline A.6 & 20 & 10 & 100 & 0,25 & 0,00 & 1,34 \\
\hline A. 7 & 20 & 20 & 100 & 0,31 & 0,00 & 0,90 \\
\hline A. 8 & 20 & 30 & 100 & 0,35 & 0,00 & 0,85 \\
\hline A.9 & 30 & 20 & 100 & 0,35 & 0,00 & 0,73 \\
\hline A.10 & 30 & 30 & 100 & 0,41 & 0,00 & 0,63 \\
\hline A.11 & 30 & 40 & 100 & 0,44 & 0,00 & 0,53 \\
\hline A.12 & 40 & 30 & 100 & 0,45 & 0,00 & 0,48 \\
\hline A.13 & 40 & 40 & 100 & 0,50 & 0,00 & 0,43 \\
\hline A.14 & 40 & 50 & 100 & 0,53 & 0,00 & 0,40 \\
\hline A. 15 & 50 & 40 & 100 & 0,54 & 0,00 & 0,35 \\
\hline A. 16 & 50 & 50 & 100 & 0,61 & 0,00 & 0,27 \\
\hline
\end{tabular}

Verifica-se que todos os testes exibidos na Tabela 4.1 apresentam um elevado percentual de acerto $\left(\mathrm{T}_{\mathrm{S}}\right)$, mesmo para tamanhos muito reduzidos dos conjuntos $\Omega_{\mathrm{MA}}$ e $\Omega_{\mathrm{MCM}}$, como é o caso do Teste A.1. Observa-se ainda, que o aumento dos parâmetros $n_{\mathrm{MA}}$ e $n_{\mathrm{MCM}}$ causa um pequeno impacto no esforço computacional $\mathrm{T}_{\mathrm{M}}$, dado em minutos na Tabela 4.1.

Considerando o Teste A.1, que apresenta o menor valor para o índice $\mathrm{T}_{\mathrm{S}}$ (97\%), o índice $\mathrm{D}_{\text {Best }}$ atingiu 0,21\% em 100 execuções do algoritmo. Dessa forma, espera-se que em uma execução, considerando os parâmetros adotados neste teste, a melhor solução apresente um investimento apenas $0,21 \%$ maior que o melhor valor conhecido (681,00 milhões de \$). Interpretação análoga é feita para o índice 
$\mathrm{D}_{10 \text { Best. }}$ Portanto, espera-se que as 10 melhores soluções de uma execução do algoritmo apresentem investimento médio 4,84\% acima do melhor valor conhecido. Com o aumento dos tamanhos dos conjuntos $\Omega_{\mathrm{MA}}$ e $\Omega_{\mathrm{MCM}}$, verifica-se uma redução significativa do índice $\mathrm{D}_{10 \text { Best. }}$ Ou seja, verifica-se uma melhora na qualidade das 10 melhores soluções encontradas em cada execução com aumento dos parâmetros $n_{\mathrm{MA}}$ e $n_{\mathrm{MCM}}$.

Em relação à convergência, foram necessários, em média, 22,9 níveis construtivos para as execuções do algoritmo no Teste A.1. Com o aumento gradual dos parâmetros, foi possível identificar uma pequena redução no número médio de níveis necessários para atingir o mesmo critério (21,3 para o Teste A.7; 21 para o Teste A.10; 20,9 para o Teste A.13 e 20,8 para o Teste A.16). Dadas as características do processo de construção, as quais permitem que apenas soluções com um total de reforços limitado pelo número do nível mais um possam prosseguir para o próximo nível, e considerando que são necessários, conforme verificado nos testes, um mínimo de 17 reforços para compor um plano de expansão viável (factível) para o sistema IEEE-RTS, pode-se afirmar que apenas a partir do décimo sexto nível construtivo torna-se possível identificar uma solução viável para o problema. Dessa forma, considerando o critério de convergência adotado $\left(n_{p}=5\right)$, o vigésimo nível corresponde ao menor nível de convergência possível para o processo.

A fim de ilustrar a evolução do processo construtivo proposto, na Figura 4.1 é apresentado um gráfico contendo a avaliação da melhor solução de cada nível do AMC-PET para a primeira execução realizada no Teste A.1. Neste gráfico, a curva em azul representa o custo de investimento (milhões de \$), o qual aumenta com a evolução do processo construtivo, conforme o esperado. A curva em vermelho corresponde à soma entre os montantes de corte de carga e de eventuais sobrecargas (em MW) referentes ao melhor plano de cada nível. Este valor se torna nulo a partir do $17^{\circ}$ nível construtivo, quando os primeiros planos viáveis são identificados ( $\Omega_{\mathrm{V}}$ não vazio). Para este nível, a melhor solução viável apresenta investimento de 757,00 milhões de \$. No nível seguinte, um novo plano passa a representar a melhor solução para o problema, com investimento de 697,00 milhões de $\$$. O investimento de 681,00 milhões de $\$$, que corresponde à melhor solução conhecida, é identificado no $19^{\circ}$ nível, antes mesmo do emprego do MR. Dessa forma, de acordo com o critério de convergência adotado $\left(n_{p}=5\right)$, o proces- 
so construtivo é interrompido no $23^{\circ}$ nível. Finalmente, a curva em verde da Figura 4.1 apresenta o progresso do valor de aptidão, $f(n)$, calculado conforme expressão (3.4a). Como pode ser verificado, $f(n)$ decresce com a evolução do processo, até se igualar ao investimento da melhor solução viável, o que ocorre a partir do $17^{\circ}$ nível.

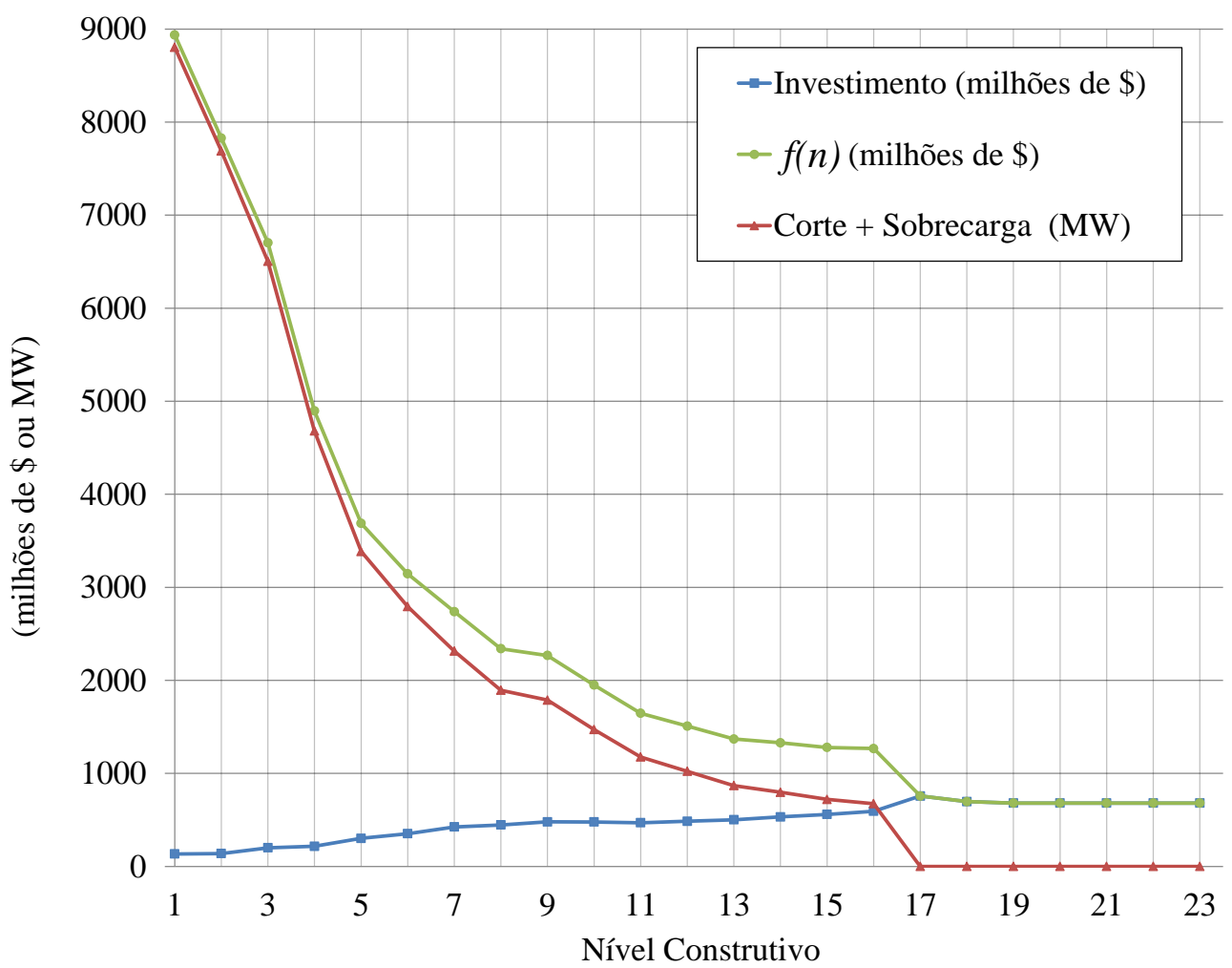

Figura 4.1 - Evolução do processo construtivo - Execução 1 do Teste A.1.

Para verificação de desempenho do AMC-PET de acordo com a variação do parâmetro $n_{r}$ e de sua distribuição entre os índices de atratividade no emprego do MA, foram realizados mais 15 testes (A.17 até A.31), os quais apresentaram os resultados dispostos na Tabela 4.2 a seguir. Com os tamanhos dos conjuntos $\Omega_{\mathrm{MA}}$ e $\Omega_{\mathrm{MCM}}$ fixos em $10\left(n_{\mathrm{MA}}=n_{\mathrm{MCM}}=10\right)$, foram realizados testes variando a quantidade de reforços selecionados a partir de cada um dos três índices de atratividade. Na Tabela 4.2, o Teste A.23 é equivalente ao Teste A.4 apresentado na Tabela 4.1 , já que correspondem aos mesmos valores para os parâmetros.

Como pode ser observado, o algoritmo AMC-PET se mostrou pouco sensível ao aumento de $n_{r}$, sendo mais preponderante a proporção do número de ramos selecionados a partir de cada índice de atratividade. Este fato pode ser comprovado por uma análise dos resultados fornecidos pelo Teste A.31, o qual corresponde 
ao maior valor do parâmetro $n_{r}$ (9 reforços). Neste teste, foram obtidos os piores valores para todos os índices de desempenho apresentados. Em contrapartida, o Teste A.1 foi capaz de propiciar um $\mathrm{T}_{\mathrm{S}}$ de $100 \%$, mesmo com um $n_{r}$ bem reduzido (3 reforços).

Tabela 4.2 - Resultados em função do valor e composição de $\boldsymbol{n}_{\boldsymbol{r}}$ - IEEE-RTS.

\begin{tabular}{||c|c|c|c|c|c|c|c||}
\hline \multirow{2}{*}{ Teste } & \multicolumn{3}{|c|}{ Distribuição de $\boldsymbol{n}_{\boldsymbol{r}}$} & \multicolumn{4}{c||}{ Índices de Desempenho } \\
\cline { 2 - 8 } & Ind $_{c h-i j}$ & Ind $_{s c-i j}^{\text {própio }}$ & Ind $_{s c-i j}^{\text {outros }}$ & $\begin{array}{c}\mathbf{T}_{\mathbf{S}} \\
(\boldsymbol{\%})\end{array}$ & $\begin{array}{c}\mathbf{T}_{\mathbf{M}} \\
(\mathbf{m i n})\end{array}$ & $\begin{array}{c}\mathbf{D}_{\text {Best }} \\
(\boldsymbol{\%})\end{array}$ & $\begin{array}{c}\mathbf{D}_{\mathbf{1 0 B e s t}} \\
(\mathbf{\%})\end{array}$ \\
\hline A.17 & 1 & 1 & 1 & 100 & 0,17 & 0,00 & 3,00 \\
\hline A.18 & 2 & 1 & 1 & 100 & 0,22 & 0,00 & 2,42 \\
\hline A.19 & 1 & 2 & 1 & 100 & 0,21 & 0,00 & 2,23 \\
\hline A.20 & 1 & 1 & 2 & 100 & 0,21 & 0,00 & 2,97 \\
\hline A.21 & 2 & 2 & 1 & 98 & 0,22 & 0,16 & 2,43 \\
\hline A.22 & 2 & 1 & 2 & 99 & 0,23 & 0,06 & 2,64 \\
\hline A.23 & 1 & 2 & 2 & 100 & 0,22 & 0,00 & 2,29 \\
\hline A.24 & 2 & 2 & 2 & 94 & 0,25 & 0,42 & 2,87 \\
\hline A.20 & 3 & 1 & 1 & 100 & 0,24 & 0,00 & 2,87 \\
\hline A.26 & 1 & 3 & 1 & 100 & 0,23 & 0,00 & 2,18 \\
\hline A.27 & 1 & 1 & 3 & 100 & 0,22 & 0,00 & 2,77 \\
\hline A.28 & 3 & 3 & 1 & 97 & 0,24 & 0,23 & 2,66 \\
\hline A.29 & 3 & 1 & 3 & 97 & 0,25 & 0,26 & 2,83 \\
\hline A.30 & 1 & 3 & 3 & 100 & 0,26 & 0,00 & 2,37 \\
\hline A.31 & 3 & 3 & 3 & 91 & 0,28 & 0,55 & 3,11 \\
\hline
\end{tabular}

\section{4.}

\section{Resultados - SSB}

Uma configuração do Sistema Sul Brasileiro (SSB) [43] foi também utilizada neste capítulo. Esta configuração possui 46 barras em sua topologia base, sendo 11 inicialmente isoladas da rede. Dentre essas 11 barras, 2 possuem geração e 9 correspondem a barras de passagem. Esta configuração do SSB possui ainda 47 ramos ativos, nos quais estão instalados 62 circuitos (linhas de transmissão e transformadores). Os 47 ramos existentes e mais 32 ramos novos totalizam 79 ramos candidatos, os quais podem receber até 3 reforços cada um. Este sistema possui uma carga total de 6880 MW e uma capacidade máxima de geração de 10545 MW no horizonte de planejamento. Para o cálculo das perdas, assim como adotado em [31], o valor de resistência de cada circuito é considerado igual a 10\% do valor de sua reatância. A ordem de despacho adotada para os testes realizados com esta configuração e as demais informações do sistema são apresentadas no Apêndice A, Seção A.2 desta tese. 
Assim como para o sistema IEEE-RTS, diversos testes foram realizados utilizando-se o SSB. A melhor solução encontrada para este último sistema possui investimento de 239,021 milhões de \$. As perdas ôhmicas obtidas para a configuração resultante correspondem a 184,78 MW. Os seguintes 22 reforços estão presentes nesta solução:

$$
\begin{aligned}
& n_{02-05}=1, n_{12-14}=1, n_{19-21}=1, n_{20-23}=2, n_{24-33}=1, n_{33-34}=1, n_{32-43}=1, \\
& n_{42-44}=1, n_{44-45}=1, n_{20-21}=3, n_{42-43}=3, n_{46-06}=2, n_{31-32}=1 \text { e } n_{05-06}=3 .
\end{aligned}
$$

\subsection{1.}

\section{Testes Iniciais}

Quanto aos testes realizados para avaliar a sensibilidade do AMC-PET em relação aos seus parâmetros, inicialmente tem-se a Tabela 4.3 que apresenta os resultados para 16 combinações dos tamanhos $n_{\mathrm{MA}}$ e $n_{\mathrm{MCM}}$ dos conjuntos $\Omega_{\mathrm{MA}} \mathrm{e}$ $\Omega_{\mathrm{MCM}}$, respectivamente (Testes de B.1 até B.16). Quase todos os demais parâmetros utilizados são mantidos iguais aos adotados para o sistema IEEE-RTS. Apenas o critério de parada é minimamente alterado, sendo $n_{p}$ ampliado para 6 iterações (níveis construtivos).

Tabela 4.3 - Resultados com variação de $n_{M A}$ e $n_{M C M}-$ SSB.

\begin{tabular}{|c|c|c|c|c|c|c||}
\hline \multirow{2}{*}{ Teste } & \multirow{2}{*}{$\boldsymbol{n}_{\mathbf{M A}}$} & \multirow{2}{*}{$\boldsymbol{n}_{\mathbf{M C M}}$} & \multicolumn{4}{|c||}{ Índices de Desempenho } \\
\cline { 5 - 7 } & & & $\begin{array}{c}\mathbf{T}_{\mathbf{S}} \\
\mathbf{( \% )}\end{array}$ & $\begin{array}{c}\mathbf{T}_{\mathbf{M}} \\
(\mathbf{m i n})\end{array}$ & $\begin{array}{c}\mathbf{D}_{\text {Best }} \\
\mathbf{( \% )}\end{array}$ & $\begin{array}{c}\mathbf{D}_{\mathbf{1 0 B e s}} \\
(\mathbf{\%})\end{array}$ \\
\hline B.1 & 30 & 30 & 81 & 1,68 & 1,40 & 7,89 \\
\hline B.2 & 30 & 40 & 91 & 1,85 & 0,74 & 6,89 \\
\hline B.3 & 40 & 30 & 87 & 1,83 & 1,11 & 7,48 \\
\hline B.4 & 40 & 40 & 89 & 2,02 & 0,93 & 6,72 \\
\hline B.5 & 40 & 50 & 96 & 2,28 & 0,39 & 5,71 \\
\hline B.6 & 50 & 40 & 92 & 2,23 & 0,64 & 6,24 \\
\hline B.7 & 50 & 50 & 96 & 2,46 & 0,35 & 5,52 \\
\hline B.8 & 50 & 60 & 97 & 2,72 & 0,26 & 4,76 \\
\hline B.9 & 60 & 50 & 94 & 2,64 & 0,54 & 5,89 \\
\hline B.10 & 60 & 60 & 98 & 2,88 & 0,19 & 4,50 \\
\hline B.11 & 60 & 70 & 96 & 3,13 & 0,42 & 4,86 \\
\hline B.12 & 70 & 60 & 99 & 3,05 & 0,12 & 4,76 \\
\hline B.13 & 70 & 70 & 95 & 3,29 & 0,36 & 5,05 \\
\hline B.14 & 70 & 80 & 97 & 3,52 & 0,24 & 4,62 \\
\hline B.15 & 80 & 70 & 94 & 3,38 & 0,40 & 5,19 \\
\hline B.16 & 80 & 80 & 98 & 3,64 & 0,22 & 4,81 \\
\hline
\end{tabular}


Para o SSB, três ramos candidatos não podem inicialmente ser avaliados pelos índices de atratividade. São ramos responsáveis pela possível interligação à rede das duas barras de geração isoladas. Para a inserção de reforços nestes ramos durante o emprego do MA, foi utilizada uma taxa de adição de 50\%. Salienta-se que durante o processo construtivo, após interligação de uma barra de geração isolada, o ramo de interligação reforçado passa também a ser naturalmente avaliado pelos índices de atratividade. Os ramos de interligação não reforçados continuam a ser selecionados de acordo com a taxa de adição. Alguns testes adicionais, realizados considerando a taxa de adição de $100 \%$ (i.e., seleção de todos os reforços para interligação das barras de geração isoladas), apresentaram aumento no $\mathrm{T}_{\mathrm{M}}$, o qual não resultou em melhora significativa para os demais índices de desempenho.

O aumento gradual dos tamanhos dos conjuntos $\Omega_{\mathrm{MA}}$ e $\Omega_{\mathrm{MCM}}$ implica em uma pequena redução do número de níveis necessários para convergência do processo construtivo. Se para o Teste B.1 a convergência acontece, em média, com 31 níveis, no Teste B.16 as execuções convergem, em média, com 29,2 níveis construtivos. De acordo com a Tabela 4.3, e conforme exposto para alguns testes no gráfico da Figura 4.2, com o aumento dos tamanhos $n_{\mathrm{MA}}$ e $n_{\mathrm{MCM}}$ verifica-se um pequeno e quase linear acréscimo no $\mathrm{T}_{\mathrm{M}}$. Este acréscimo pode ser facilmente explicado pelo maior número de indivíduos avaliados durante o processo de construção. O aumento destes dois parâmetros acarreta, ainda, uma melhora na qualidade dos índices $\mathrm{T}_{\mathrm{S}}, \mathrm{D}_{\mathrm{Best}}$ e $\mathrm{D}_{10 \mathrm{Best}}$, ocorrendo uma saturação para tamanhos de conjuntos variando entre 50 e 80 .

Os resultados exibidos na Tabela 4.3 confirmam a eficiência e robustez da metodologia proposta em se tratando da melhor solução encontrada (i.e., $\mathrm{T}_{\mathrm{S}} \mathrm{e}$ $\left.\mathrm{D}_{\text {Best }}\right)$. Adotando-se, por exemplo, os parâmetros conforme o Teste B.12, que apresenta $T_{S}$ de $99 \%$, espera-se que a melhor solução de uma execução do AMCPET apresente um investimento apenas $0,12 \%\left(\mathrm{D}_{\text {Best }}\right)$ maior que o melhor valor conhecido $(239,021$ milhões de \$). O mesmo não pode ser dito em relação à qualidade média das 10 melhores soluções identificadas em cada um dos testes $\left(\mathrm{D}_{10 \mathrm{Best}}\right)$. Para o Teste B.12, a título de exemplo, espera-se que as 10 melhores soluções de uma execução do algoritmo apresentem investimento médio 4,76\% maior que o investimento da melhor solução conhecida, valor que precisa ainda ser melhorado, conforme discussão realizada a seguir. 


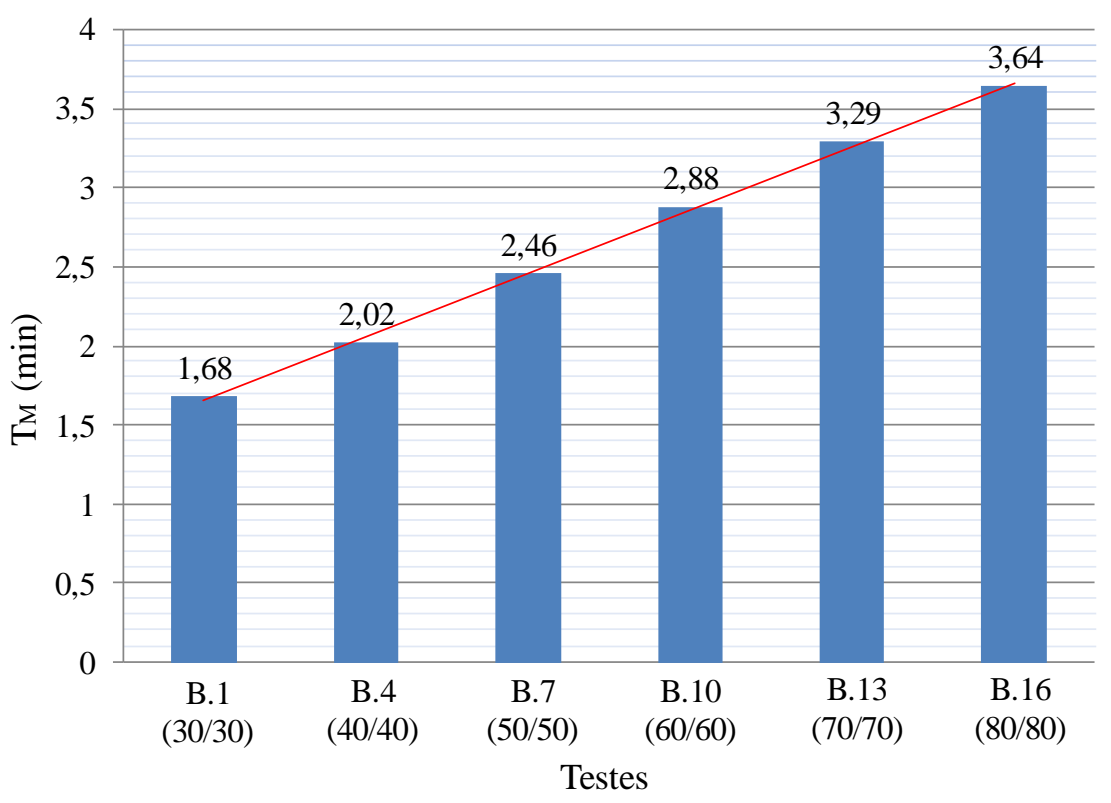

Figura 4.2 - Comportamento do índice $T_{M}$ com variação de $n_{M A}$ e $n_{M C M}$.

A Tabela 4.4 apresenta informações relativas às 10 melhores soluções (planos de expansão) identificadas em todos os testes realizados. Pode ser destacado que, conforme esperado, os planos com maior número de reforços tendem a apresentar menores níveis de perdas. Neste sentido, cabe destacar que a minimização das perdas ôhmicas poderia também ser incluída na função de avaliação das soluções, de acordo com o problema (3.4), principalmente para solução do problema PET com tensões em níveis de subtransmissão, onde as perdas são mais acentuadas [20], [76]. Diversos benefícios para a rede podem ser destacados com a minimização das perdas. Como exemplo, podem ser citadas a obtenção de sistemas mais confiáveis e a otimização de investimentos futuros, ambas resultantes do melhor balanceamento na distribuição dos fluxos de potência entre os circuitos, o que produz uma maior "reserva de capacidade".

Outro ponto importante está relacionado ao desempenho ideal tendo em mente o índice $\mathrm{D}_{10 \text { Best }} \mathrm{O}$ limite inferior para o $\mathrm{D}_{10 \text { Best }}$, igual a $1,72 \%$, pode ser obtido ao se aplicar o cálculo deste índice aos planos da Tabela 4.4. Pelos resultados apresentados na Tabela 4.3 fica evidente que o desempenho do AMC-PET pode ser aprimorado em relação ao conjunto das 10 melhores soluções obtidas em cada teste para o SSB. 
Tabela 4.4 - Os 10 melhores planos de expansão identificados - SSB.

\begin{tabular}{||c|c|c|c||}
\hline Plano & $\begin{array}{c}\text { Investimento } \\
\text { (milhões de \$) }\end{array}$ & $\begin{array}{c}\text { Perdas Ativas } \\
\text { (MW) }\end{array}$ & $\begin{array}{c}\text { Número de } \\
\text { Reforços }\end{array}$ \\
\hline 1 & 239,021 & 184,78 & 22 \\
\hline 2 & 239,425 & 185,02 & 22 \\
\hline 3 & 240,233 & 181,11 & 22 \\
\hline 4 & 240,637 & 181,36 & 22 \\
\hline 5 & 242,556 & 181,90 & 22 \\
\hline 6 & 242,960 & 182,15 & 22 \\
\hline 7 & 245,087 & 176,04 & 23 \\
\hline 8 & 246,456 & 179,11 & 23 \\
\hline 9 & 247,410 & 176,84 & 24 \\
\hline 10 & 247,466 & 179,25 & 24 \\
\hline
\end{tabular}

Considerando-se todos os parâmetros do AMC-PET, é possível concluir que o $n_{p}$ (estagnação) tem impacto direto na qualidade do conjunto das melhores soluções encontradas (melhores indivíduos do $\Omega_{\mathrm{V}}$ final). Logicamente, com o aumento de $n_{p}$ haverá um maior número de iterações do processo construtivo, sendo que as iterações adicionais darão prioridade à troca de material genético entre indivíduos completos (i.e., soluções cheias e viáveis) ou quase completos. Nestas novas iterações o tamanho médio dos indivíduos não deve ser alterado significativamente. Este fato já foi percebido nos últimos níveis construtivos das execuções realizadas nos testes da Tabela 4.3.

Com o objetivo de melhorar o desempenho do AMC-PET em relação à qualidade das melhores soluções (índice $\mathrm{D}_{10 \mathrm{Best}}$ ), foram repetidos os Testes B.10, B.13 e B.16 adotando-se o aumento do critério de convergência para $n_{p}=12$. Os resultados obtidos para os novos testes (B.17 até B.19) estão presentes na Tabela 4.5. Verifica-se uma redução significativa, em média $38 \%$, do índice $\mathrm{D}_{10 \mathrm{Best}}$, com aumento médio de $26 \%$ no $\mathrm{T}_{\mathrm{M}}$. Ganhos significativos em termos de $\mathrm{T}_{\mathrm{S}}$ e do índice $\mathrm{D}_{\text {Best }}$ também podem ser observados para estes testes.

Tabela 4.5 - Resultados impondo maior estagnação $\left(n_{p}=12\right)$ - SSB.

\begin{tabular}{|c|c|c|c|c|c|c||}
\hline \multirow{2}{*}{ Teste } & \multirow{2}{*}{$\boldsymbol{n}_{\text {MA }}$} & \multirow{2}{*}{$\boldsymbol{n}_{\mathbf{M C M}}$} & \multicolumn{4}{|c||}{ Índices de Desempenho } \\
\cline { 4 - 7 } & & & $\begin{array}{c}\mathbf{T}_{\mathbf{S}} \\
(\mathbf{\%})\end{array}$ & $\begin{array}{c}\mathbf{T}_{\mathbf{M}} \\
(\mathbf{m i n})\end{array}$ & $\begin{array}{c}\mathbf{D}_{\text {Best }} \\
(\mathbf{\%})\end{array}$ & $\begin{array}{c}\mathbf{D}_{\mathbf{1 0 B e s t}} \\
(\mathbf{\%})\end{array}$ \\
\hline B.17 & 60 & 60 & 100 & 3,64 & 0,04 & 2,88 \\
\hline B.18 & 70 & 70 & 99 & 4,18 & 0,13 & 3,15 \\
\hline B.19 & 80 & 80 & 100 & 4,65 & 0,04 & 2,91 \\
\hline
\end{tabular}


Com a finalidade de avaliar de forma isolada a qualidade das execuções do AMC-PET, algumas dentre as 100 execuções realizadas para o Teste B.17, com diferentes características de desempenho, são descritas a seguir.

Em termos de qualidade do conjunto final de soluções identificadas, a segunda execução do Teste B.17, a qual atingiu a convergência com 34 níveis construtivos, foi capaz de identificar 9 dos 10 melhores planos exibidos na Tabela 4.4 (Planos 1 até 9). O décimo melhor plano apontado nesta execução é formado por 24 reforços e possui investimento de 252,163 milhões de $\$$, com perdas ativas de 177,03 MW. Dessa forma, o desvio médio entre os investimentos das 10 melhores soluções identificadas nesta execução em relação ao investimento da melhor solução conhecida (239,021 milhões de \$) é de apenas $1,96 \%$, valor muito próximo ao limite inferior para o índice $\mathrm{D}_{10 \mathrm{Best}}(1,72 \%$, obtido para as soluções da Tabela 4.4). Das 100 execuções realizadas no Teste B.17, 19 apresentaram igual desempenho para este índice, ou seja, uma em cada 5 execuções encontrou as nove melhores soluções conhecidas.

Ainda em relação à qualidade do conjunto final de soluções, pode-se dizer que a pior execução do Teste B.17 apresentou um desvio médio de 8,11\% entre os investimentos das suas 10 melhores soluções em relação ao melhor investimento conhecido (equivalente ao $\left.\mathrm{D}_{10 \mathrm{Best}}\right)$. Contudo, esta execução, que demandou 36 níveis construtivos, foi capaz de identificar 3 dos 10 melhores planos conhecidos (Planos 1, 3 e 5 da Tabela 4.4), inclusive o melhor dentre todos. Cabe salientar que apenas esta execução apresentou tal desempenho. As execuções com o segundo e terceiro piores desempenhos apresentaram desvios médios para as 10 melhores soluções de 7,26\% e 5,06\%, respectivamente. Essas duas execuções também identificaram o melhor plano de expansão conhecido.

Por fim, destaca-se que apenas 8 execuções do Teste B.17 não foram capazes de identificar a melhor solução conhecida para este problema (Plano 1 da Tabela 4.4). Dentre elas, a que apresentou como melhor solução o maior valor de investimento, encontrou os Planos 5 (sua melhor solução), 7, 8 e 9, atingindo a convergência com 51 níveis construtivos. Mesmo apresentando um desvio de $1,48 \%$ entre a melhor solução encontrada e a melhor conhecida, esta execução apresentou um desvio médio para o conjunto das 10 melhores soluções, em relação ao melhor investimento conhecido, de $4,86 \%$, sendo este valor inferior aos citados no parágrafo anterior. Entre as demais execuções não classificadas como 
de sucesso, cinco apresentaram o Plano 2 da Tabela 4.4 como o melhor encontrado, uma o Plano 3 e outra o Plano 4.

\subsection{2.}

\section{Testes com Ampliação de $\boldsymbol{n}_{\boldsymbol{p}}$ e Variação de $\boldsymbol{n}_{\boldsymbol{r}}$}

Com o propósito de verificar o desempenho do AMC-PET segundo a variação do número de ramos $\left(n_{r}\right)$ empregado pelo MA, assim como em relação à distribuição de $n_{r}$ entre os índices de atratividade, 15 novos testes (B.20 até B.34) foram realizados com o SSB. Os resultados são apresentados na Tabela 4.6. Para realização destes testes, os tamanhos $n_{\mathrm{MA}}$ e $n_{\mathrm{MCM}}$ dos conjuntos $\Omega_{\mathrm{MA}}$ e $\Omega_{\mathrm{MCM}}$ foram, respectivamente, fixados em 70 e 60 . O critério de convergência adotado foi de $n_{p}=12$. Na Tabela 4.6, o Teste B.26 possui os mesmos parâmetros adotados no Teste B.12 da Tabela 4.3, exceto o critério de convergência $n_{p}$, o qual foi ampliado de 6 para 12.

Tabela 4.6 - Resultados em função do valor e composição de $\boldsymbol{n}_{r}$ - SSB.

\begin{tabular}{||c|c|c|c|c|c|c|c||}
\hline \multirow{2}{*}{ Teste } & \multicolumn{3}{|c|}{ Distribuição de $\boldsymbol{n}_{\boldsymbol{r}}$} & \multicolumn{4}{c||}{ Índices de Desempenho } \\
\cline { 2 - 8 } & Ind $_{\text {ch-ij }}$ & Ind $_{s c-i j}^{\text {própio }}$ & Ind $_{s c-i j}^{\text {outros }}$ & $\begin{array}{c}\mathbf{T}_{\mathbf{S}} \\
(\mathbf{\%})\end{array}$ & $\begin{array}{c}\mathbf{T}_{\mathbf{M}} \\
(\mathbf{m i n})\end{array}$ & $\begin{array}{c}\mathbf{D}_{\text {Best }} \\
(\mathbf{\%})\end{array}$ & $\begin{array}{c}\mathbf{D}_{\mathbf{1 0 B e s t}} \\
(\mathbf{\%})\end{array}$ \\
\hline B.20 & 1 & 1 & 1 & 93 & 3,69 & 0,54 & 3,78 \\
\hline B.21 & 2 & 1 & 1 & 70 & 4,08 & 1,87 & 5,78 \\
\hline B.22 & 1 & 2 & 1 & 100 & 3,57 & 0,08 & 3,30 \\
\hline B.23 & 1 & 1 & 2 & 98 & 3,78 & 0,17 & 3,08 \\
\hline B.24 & 2 & 2 & 1 & 78 & 4,36 & 1,43 & 5,12 \\
\hline B.25 & 2 & 1 & 2 & 74 & 4,32 & 1,62 & 5,74 \\
\hline B.26 & 1 & 2 & 2 & 100 & 3,84 & 0,06 & 2,80 \\
\hline B.27 & 2 & 2 & 2 & 79 & 4,45 & 1,35 & 6,54 \\
\hline B.28 & 3 & 1 & 1 & 49 & 4,88 & 3,10 & 6,65 \\
\hline B.29 & 1 & 3 & 1 & 99 & 3,83 & 0,10 & 3,42 \\
\hline B.30 & 1 & 1 & 3 & 100 & 3,63 & 0,02 & 4,25 \\
\hline B.31 & 3 & 3 & 1 & 79 & 5,50 & 1,47 & 4,89 \\
\hline B.32 & 3 & 1 & 3 & 59 & 5,14 & 2,54 & 6,08 \\
\hline B.33 & 1 & 3 & 3 & 98 & 4,37 & 0,15 & 3,58 \\
\hline B.34 & 3 & 3 & 3 & 63 & 6,06 & 2,24 & 5,62 \\
\hline
\end{tabular}

Assim como verificado a partir dos resultados obtidos para o sistema IEEERTS, para o SSB a variação da proporção de $n_{r}$ entre os índices de atratividade produziu um impacto mais significativo no desempenho do algoritmo que o próprio aumento deste parâmetro. Uma análise da Tabela 4.6 permite constatar que as 
combinações que privilegiam os índices de sobrecarga ( $\operatorname{Ind} d_{s c-i j}^{\text {próprio }}$ e $\left.I n d_{s c-i j}^{\text {outros }}\right)$ propiciaram os melhores valores para os índices de desempenho da metodologia, o que pode ser comprovado pelos testes B.22, B.23, B.26, B.29, B.30 e B.33. Contudo, apesar de representar o menor impacto positivo na seleção de reforços, o Ind $d_{c h-i j}$, que estima a necessidade de reforço em relação à rede intacta do sistema, se faz indispensável. Testes realizados sem a utilização deste índice não foram capazes de identificar nenhuma das 10 melhores soluções apresentadas na Tabela 4.4 .

Para todos os testes apresentados (B.1 até B.34), é possível identificar a combinação de parâmetros adotada no Teste B.26 (Tabela 4.6) como sendo a melhor em termos do conjunto final de soluções. Na média, as 10 melhores soluções identificadas em cada execução deste teste apresentam investimento apenas 2,80\% maior que o investimento da melhor solução conhecida, valor muito próximo ao limite inferior de $1,72 \%$ para o $\mathrm{D}_{10 \text { Best }}$. Além disso, esta combinação proporciona $\mathrm{T}_{\mathrm{S}}$ máximo (100\%), sendo que a melhor solução conhecida é identificada em 86 das 100 execuções realizadas. Mesmo sem demandar um valor elevado para o $\mathrm{T}_{M}$ (3,84 minutos) o Teste B.26 apresenta, ainda, um valor muito reduzido para o índice $\mathrm{D}_{\text {Best }}\left(4^{\circ}\right.$ menor valor, igual a $\left.0,06 \%\right)$. Entretanto, se o interesse reside na qualidade da melhor solução identificada em cada execução, pode-se afirmar que a combinação adotada no teste B.30 (Tabela 4.6) se apresenta como a melhor dentre os testes realizados. Neste teste, a melhor solução conhecida foi encontrada em 91 das 100 execuções realizadas. A taxa de sucesso $\left(\mathrm{T}_{\mathrm{S}}\right)$ também é de $100 \%$. Esta combinação de parâmetros identifica para a melhor solução de cada execução, em média, um investimento apenas $0,02 \%$ ( $\left.\mathrm{D}_{\text {Best }}\right)$ maior que o investimento da melhor solução conhecida, com um $\mathrm{T}_{\mathrm{M}}$ relativamente baixo (3,63 minutos).

A análise realizada no parágrafo anterior é subjetiva. Um critério objetivo para identificar a melhor combinação de parâmetros seria, por exemplo, considerar uma composição dos quatro índices de desempenho. Desse modo, pode ser definido um novo índice de decisão $\mathrm{I}_{\text {decisão }}^{t}$, calculado para cada teste $t$ realizado e dado pela soma ponderada dos índices de desempenho normalizados, conforme a seguinte relação: 


$$
\mathrm{I}_{\text {decisão }}^{t}=\left(\frac{\mathrm{T}_{\mathrm{M}}^{t}}{\mathrm{~T}_{\mathrm{M}}^{\max }}\right)+\left(\frac{\mathrm{D}_{\text {Best }}^{t}}{\mathrm{D}_{\text {Best }}^{\max }}\right)+\left(\frac{\mathrm{D}_{10 \mathrm{Best}}^{t}}{\mathrm{D}_{10 \mathrm{Best}}^{\max }}\right)-\left(\frac{\mathrm{T}_{\mathrm{S}}^{t}}{\mathrm{~T}_{\mathrm{S}}^{\max }}\right)
$$

onde os valores do denominador $\left(T_{M}^{\max }, D_{\text {Best }}^{\max }, D_{10 \text { Best }}^{\max }\right.$ e $\left.T_{S}^{\max }\right)$ são os maiores apresentados a partir de cada índice em todos os testes.

De acordo com a relação (4.1), o teste que apresentar o menor valor para o índice de decisão é considerado como o de melhor combinação de parâmetros. É importante observar que na soma ponderada para o cálculo do índice de decisão todos os índices de desempenho possuem o mesmo peso em módulo, contudo, apenas o $\mathrm{T}_{\mathrm{S}}$ normalizado possui valor negativo para este peso. Isto se deve ao fato de que, dentre todos os índices de desempenho este é o único cujo interesse reside em obter valores mais elevados.

Os valores do índice $\mathrm{I}_{\text {decisão }}^{t}$ calculados para os 34 testes realizados estão apresentados em ordem crescente na Tabela 4.8. Adotando-se, então, o índice de decisão, verifica-se que a combinação de parâmetros do Teste B.17 (Tabela 4.5) é apontada como a melhor dentre todas as 34 combinações apresentadas, ou seja, o Teste B.17 apresenta o menor valor para o índice de decisão ( $\left.\mathrm{I}_{\text {decisão }}^{\mathrm{B} .17}=-0,02\right)$. Verifica-se ainda que, de forma geral, os menores valores para o índice de decisão são apresentados pelos testes cujas combinações priorizam a seleção de reforços a partir dos índices de sobrecarga ( Ind ${ }_{s c-i j}^{\text {próprio }}$ e $\left.I n d_{s c-i j}^{o u t r o s}\right)$.

Tabela 4.7 - Índices de decisão - SSB.

\begin{tabular}{|c|c||c|c||c|c||c|c||}
\hline Teste & $\mathrm{I}_{\text {decisão }}^{t}$ & Teste & $\mathrm{I}_{\text {decisão }}^{t}$ & Teste & $\mathrm{I}_{\text {decisão }}^{t}$ & Teste & $\mathrm{I}_{\text {decisão }}^{t}$ \\
\hline B.17 & $-0,02$ & B.12 & 0,16 & B.13 & 0,35 & B.27 & 1,21 \\
\hline B.26 & 0,01 & B.8 & 0,17 & B.15 & 0,40 & B.31 & 1,21 \\
\hline B.22 & 0,03 & B.33 & 0,24 & B.9 & 0,42 & B.25 & 1,22 \\
\hline B.23 & 0,09 & B. 7 & 0,26 & B.6 & 0,45 & B.21 & 1,31 \\
\hline B.29 & 0,11 & B.5 & 0,27 & B.2 & 0,51 & B. 34 & 1,80 \\
\hline B.10 & 0,13 & B.14 & 0,27 & B.4 & 0,60 & B.32 & 1,85 \\
\hline B.18 & 0,14 & B.16 & 0,30 & B. 3 & 0,74 & B.28 & 2,16 \\
\hline B.30 & 0,14 & B.11 & 0,31 & B.1 & 0,92 & - & - \\
\hline B.19 & 0,15 & B.20 & 0,33 & B. 24 & 1,05 & - & - \\
\hline
\end{tabular}

De acordo com esse mesmo critério, o pior valor para o índice de decisão foi apresentado pelo Teste B.28 ( $\left.\mathrm{I}_{\text {decisão }}^{\text {B.22 }}=2,16\right)$, seguido pelos testes cujas combina- 
ções de parâmetros permitem selecionar um número maior de reforços a partir do índice $I_{\text {Ind }}$-ij.

Finalmente, em relação aos resultados apresentados para o SSB, vale destacar que para o melhor plano identificado (Plano 1 da Tabela 4.4, com investimento de 239,021 milhões de \$), apenas a barra 6 , dentre as 9 barras de passagem isoladas, foi conectada à rede $\left(n_{46-06}=2\right.$ e $\left.n_{05-06}=3\right)$. Além disso, das 2 barras de geração inicialmente desconectadas (28 e 31), apenas a barra 31 foi interligada ao sistema $\left(n_{31-32}=1\right)$. Isto significa que a construção do reforço de geração na barra 28 (desconectada), definido no estudo de planejamento da expansão da geração, poderia ser postergada. Entretanto, a interligação dessas duas barras de geração ao sistema poderia ser imposta como uma restrição ao problema PET. Considerando este último caso, um novo estudo foi realizado. A nova melhor solução identificada corresponde a um investimento de 246,840 milhões de $\$$, com perdas ôhmicas de 184,78 MW. Nesta solução, estão presentes os reforços da melhor solução geral (i.e., após todas as execuções realizadas) encontrada (Plano 1) e mais um reforço entre as barras 28 e $31\left(n_{28-31}=1\right)$. A operação do sistema na condição de rede intacta não foi alterada após conexão da barra 28 , o que pode ser facilmente compreendido devido à prioridade de despacho dessa barra, conforme ordem estabelecida pela Tabela A.3 do Apêndice A, Seção A.2. Contudo, o sistema passa a ter uma maior reserva de geração, o que o torna mais robusto.

\section{5. Análise Geral dos Parâmetros Utilizados}

A variação dos principais parâmetros do AMC-PET, cujos ajustes são de responsabilidade do planejador, foi examinada ao longo dos testes realizados com os sistemas IEEE-RTS e SSB. Algumas considerações podem ser tecidas a respeito dos resultados obtidos.

Primeiramente, foi possível verificar que o aumento dos tamanhos dos conjuntos $\Omega_{\mathrm{MA}}$ e $\Omega_{\mathrm{MCM}}\left(n_{\mathrm{MA}}\right.$ e $n_{\mathrm{MCM}}$, respectivamente) se mostrou efetivo até atingir determinadas dimensões. A partir de então, identifica-se uma saturação em termos da qualidade dos índices de desempenho do algoritmo.

Em relação ao aumento do número de ramos $\left(n_{r}\right)$ selecionados para adição de reforço na aplicação do mecanismo de adição (MA), pode-se concluir que o desempenho do algoritmo foi pouco influenciado. Maior impacto foi observado 
pela distribuição deste parâmetro $\left(n_{r}\right)$ entre os três índices de atratividade utilizados. Os melhores resultados para o desempenho do algoritmo foram percebidos quando os índices calculados com base na operação do sistema para a condição de contingência (índices Ind próprio $_{\text {e }} I n d_{s c-i j}^{\text {outros }}$ ) foram privilegiados na seleção de novos reforços. Contudo, a presença do índice calculado com base na operação de rede intacta (índice $I n d_{c h-i j}$ ) se fez indispensável para a identificação das melhores soluções conhecidas.

Ainda em relação ao MA, com a utilização de dois diferentes valores para a taxa de adição (50\% e 100\%), a qual é responsável por permitir a seleção de reforços em ramos que não podem ser avaliados pelos índices de atratividade, foi possível observar apenas um impacto no esforço computacional, o qual é menor para a menor taxa de adição. Para realização de um estudo mais conclusivo a respeito deste parâmetro, deve ser utilizado um sistema com um número maior de barras de geração e/ou de carga isoladas, o que intensificaria a importância deste parâmetro.

Não foram realizados estudos com a variação do tamanho $n_{\mathrm{V}}$ do conjunto de indivíduos viáveis $\Omega_{\mathrm{V}}$, o qual foi limitado em 100 indivíduos (planos) para todos os testes apresentados. Verificou-se, contudo, que para o IEEE-RTS este limite não foi atingido em nenhum destes testes. Já para o SSB, apenas nos últimos testes realizados, com o aumento do critério de convergência $\left(n_{p}\right)$, o valor limite para o tamanho $n_{\mathrm{V}}$ foi atingido. Isto leva a crer que o limite adotado para o tamanho do $\Omega_{\mathrm{V}}$ possa ser reduzido, sem prejuízo para o desempenho do AMC-PET. Este fato não foi investigado para estes dois sistemas. No entanto, conforme já salientado, o ajuste deste e de outros parâmetros receberá maior atenção no Capítulo 5, dedicado ao estudo de um sistema real.

As taxas de cruzamento e de mutação, empregadas pelos mecanismos $\mathrm{MC}$ e MM, foram fixadas em $65 \%$ e $8 \%$, respectivamente, para os testes apresentados neste documento. Variações em torno dos valores adotados para estes parâmetros não foram capazes de provocar impactos significativos no desempenho do AMCPET.

Finalmente, para o SSB foram considerados dois diferentes valores para o critério de convergência $\left(n_{p}\right)$ do AMC-PET, permanência (estagnação) do melhor indivíduo do $\Omega_{\mathrm{V}}$ por 6 e por 12 níveis consecutivos. Observou-se que o aumento 
de $n_{p}$ impacta direta e positivamente no desempenho do algoritmo, tanto em termos da incidência da melhor solução conhecida $\left(\mathrm{D}_{\text {Best }}\right)$, embora menos intensamente, quanto em relação à qualidade do conjunto final de soluções ( $\mathrm{T}_{\mathrm{S}}$ e $\left.\mathrm{D}_{10 \mathrm{Best}}\right)$. O decorrente acréscimo no esforço computacional pode ser considerado como relativamente baixo (e.g., $\mathrm{T}_{\mathrm{M}}$ passando de 3,05 minutos, no Teste B.12, para 3,84 minutos, no Teste B.26).

\section{6.}

\section{Mecanismo de Seleção com Estratégia de Diversidade}

Com o intuito de melhorar o desempenho do AMC-PET, foi incluída ao processo construtivo uma estratégia de diversidade para a seleção de indivíduos realizada pelo MS. A estratégia de diversidade previne a presença de indivíduos similares nos conjuntos $\Omega_{\mathrm{MA}}$ e $\Omega_{\mathrm{MCM}}$ e, portanto, aumenta a probabilidade de se encontrar a solução ótima global para o problema PET, além de permitir a identificação de ótimos locais de melhor qualidade.

Dentre as estratégias possíveis para introduzir diversidade ao mecanismo MS optou-se pela inclusão de um algoritmo de classificação ("clusterização"). Nesta tese é utilizado o algoritmo K-Means [77], onde a similaridade entre os indivíduos no processo de classificação é medida pela distância Euclidiana. Com o emprego desta técnica, os indivíduos do conjunto "INDIVÍDUOS OBTIDOS PELO MA”, da Figura 3.3, são distribuídos em $n_{\mathrm{MA}}$ classes. Para compor o novo conjunto $\Omega_{\mathrm{MA}}$ é selecionado o melhor indivíduo, em termos de aptidão, dentro de cada uma dessas classes. De modo análogo, os indivíduos do conjunto "INDIVíDUOS OBTIDOS PELOS MECANISMOS MC E MM" são distribuídos em $n_{\mathrm{MCM}}$ classes e o novo conjunto $\Omega_{\mathrm{MCM}}$ é construído a partir do melhor indivíduo de cada classe.

Com base na análise dos parâmetros do AMC-PET apresentada anteriormente, novos testes foram realizados com os sistemas IEEE-RTS e SSB considerando o emprego da estratégia de diversidade. Em todos os testes, o parâmetro $n_{r}$ foi ajustado para seleção de 4 ramos no emprego do MA, sendo 1 selecionado

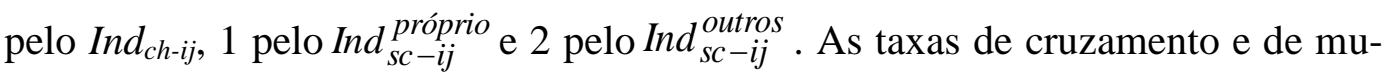
tação foram mantidas, respectivamente, em $65 \%$ e $8 \%$. A taxa de adição do MA foi mantida em $50 \%$ e o tamanho do conjunto $\Omega_{\mathrm{V}}\left(n_{\mathrm{V}}\right)$ foi limitado em 100 indivíduos. Para o IEEE-RTS, o critério de convergência foi ampliado para $6\left(n_{p}=6\right) \mathrm{e}$ 
para o SSB $n_{p}$ foi mantido em 12. Os tamanhos dos conjuntos $\Omega_{\mathrm{MA}}$ e $\Omega_{\mathrm{MCM}}$ foram variados na realização dos testes.

Os resultados apresentados pelos testes realizados tanto com o IEEE-RTS quanto com o SSB, ambos publicados em [78] e presentes, respectivamente, na Tabela 4.8 e na Tabela 4.9, não apontam melhora substancial no desempenho do AMC-PET com a inclusão da estratégia de diversidade adotada. Pode-se, então, concluir que para estes sistemas a qualidade nos resultados é apenas mantida.

Tabela 4.8 - Resultados com estratégia de diversidade no MS - IEEE-RTS.

\begin{tabular}{|c|c|c|c|c|c|c|}
\hline \multirow{2}{*}{ Teste } & \multirow{2}{*}{$\boldsymbol{n}_{\mathbf{M A}}$} & $\boldsymbol{n}_{\mathbf{M C M}}$ & \multicolumn{4}{|c|}{ Índices de Desempenho } \\
\cline { 4 - 7 } & & & $\begin{array}{c}\mathbf{T}_{\mathbf{S}} \\
\mathbf{( \% )}\end{array}$ & $\begin{array}{c}\mathbf{T}_{\mathbf{M}} \\
(\mathbf{m i n})\end{array}$ & $\begin{array}{c}\mathbf{D}_{\text {Best }} \\
(\mathbf{\%})\end{array}$ & $\begin{array}{c}\mathbf{D}_{\mathbf{1 0 B e s t}} \\
\mathbf{( \% )}\end{array}$ \\
\hline A.32 & 5 & 5 & 92 & 0,16 & 0,52 & 4,21 \\
\hline A.33 & 5 & 10 & 94 & 0,23 & 0,23 & 3,31 \\
\hline A.34 & 10 & 5 & 98 & 0,19 & 0,10 & 2,81 \\
\hline A.35 & 10 & 10 & 100 & 0,25 & 0,00 & 2,60 \\
\hline A.36 & 10 & 20 & 100 & 0,33 & 0,00 & 1,79 \\
\hline A.37 & 20 & 10 & 100 & 0,29 & 0,00 & 1,29 \\
\hline A.38 & 20 & 20 & 100 & 0,37 & 0,00 & 1,42 \\
\hline A.39 & 20 & 30 & 100 & 0,46 & 0,00 & 1,47 \\
\hline A.40 & 30 & 20 & 100 & 0,43 & 0,00 & 0,85 \\
\hline A.41 & 30 & 30 & 100 & 0,50 & 0,00 & 1,05 \\
\hline
\end{tabular}

Dessa forma, verifica-se que a nova versão do mecanismo de seleção (MS), considerando a estratégia de diversidade, não tem impacto significativo em sistemas de pequeno/médio porte. Porém, como será visto no próximo capítulo, é fundamental para o bom desempenho da metodologia quando aplicada em sistemas reais.

Tabela 4.9 - Resultados com estratégia de diversidade no MS - SSB.

\begin{tabular}{|c|c|c|c|c|c|c||}
\hline \multirow{2}{*}{ Teste } & \multirow{2}{*}{$\boldsymbol{n}_{\mathbf{M A}}$} & $\boldsymbol{n}_{\mathbf{M C M}}$ & \multicolumn{4}{|c||}{ Índices de Desempenho } \\
\cline { 4 - 7 } & & & $\begin{array}{c}\mathbf{T}_{\mathbf{S}} \\
(\mathbf{\%})\end{array}$ & $\begin{array}{c}\mathbf{T}_{\mathbf{M}} \\
(\mathbf{m i n})\end{array}$ & $\begin{array}{c}\mathbf{D}_{\text {Best }} \\
(\mathbf{\%})\end{array}$ & $\begin{array}{c}\mathbf{D}_{\mathbf{1 0 B e s t}} \\
(\mathbf{\%})\end{array}$ \\
\hline B.35 & 30 & 30 & 100 & 4,42 & 0,02 & 4,30 \\
\hline B.36 & 30 & 40 & 99 & 4,91 & 0,11 & 3,96 \\
\hline B.37 & 40 & 30 & 100 & 4,25 & 0,03 & 4,33 \\
\hline B.38 & 40 & 40 & 99 & 4,56 & 0,11 & 4,40 \\
\hline B.39 & 40 & 50 & 100 & 5,48 & 0,02 & 4,02 \\
\hline B.40 & 50 & 40 & 100 & 4,85 & 0,01 & 4,09 \\
\hline B.41 & 50 & 50 & 100 & 5,37 & 0,02 & 3,85 \\
\hline B.42 & 50 & 60 & 100 & 5,48 & 0,03 & 3,92 \\
\hline B.43 & 60 & 50 & 100 & 5,97 & 0,03 & 4,06 \\
\hline B.44 & 60 & 60 & 100 & 6,15 & 0,00 & 3,41 \\
\hline
\end{tabular}




\section{7.}

\section{Conclusões}

Estão presentes neste capítulo os resultados obtidos a partir da aplicação do AMC-PET para solução do problema de planejamento estático da transmissão de sistemas de pequeno porte. Os estudos realizados têm o intuito de permitir a investigação do desempenho da ferramenta, o qual é medido quantitativamente por meio de índices de avalição propostos, calculados estatisticamente com base em diversas execuções da rotina implementada.

A partir dos resultados apresentados, é possível estabelecer uma base de conhecimento acerca do comportamento do AMC-PET em relação à variação dos parâmetros inerentes, cujos ajustes são de responsabilidade do planejador, e às estratégias de construção adotadas pelos principais mecanismos. As experiências obtidas são utilizadas para realização de ajustes dos parâmetros e de aprimoramentos dos principais mecanismos da ferramenta, de forma a prepará-la para aplicação na solução do problema PET em um sistema de grande porte, conforme é apresentado no próximo capítulo. 


\section{5. Aplicação em um Sistema de Grande Porte}

\section{1. Introdução}

A fim de verificar o desempenho do algoritmo metaheurístico construtivo (AMC-PET) frente a um problema PET real de grande porte, é proposto neste capítulo um sistema obtido para considerar a região geoelétrica sul do Brasil, denominado Sistema Geoelétrico Sul do Brasil (SGSB). Este sistema contempla os estados do Rio Grande do Sul, Santa Catarina, Paraná e Mato Grosso do Sul [79]. Para composição do SGSB, são consideradas as linhas de transmissão (LTs) e subestações que compõem a rede básica desta região, com tensões de $230 \mathrm{kV}$ e $525 \mathrm{kV}$. A topologia base do sistema corresponde ao ano de 2017 e o ano de 2025 é considerado como o último ano do horizonte de planejamento. Dois diferentes cenários de despacho de geração e de montantes de carga são considerados no problema: Norte Seco (região norte do Brasil importadora de energia) e Norte Úmido (região norte do Brasil exportadora de energia).

Primeiramente, este capítulo apresenta as premissas adotadas para composição do SGSB criado e para definição do problema PET. Em seguida, são apresentados e analisados os resultados obtidos com o emprego do AMC-PET para solução do problema.

Finalmente, os resultados apresentados pelo AMC-PET para este sistema são comparados aos resultados produzidos pela metaheurística Algoritmo Genético (Genetic Algorithm - GA), a qual é também implementada, em sua versão clássica, nesta tese de doutorado. 


\section{2.}

\section{Definição do SGSB}

\subsection{1.}

\section{Considerações Iniciais}

No Brasil, o órgão responsável por realizar estudos de planejamento do setor energético é a Empresa de Pesquisa Energética (EPE). Dentre estes estudos, cabe à EPE desenvolver o planejamento da expansão do sistema de transmissão de energia elétrica.

As obras de expansão para a transmissão definidas pela EPE são apresentadas em relatórios gerenciais denominados "Programa de Expansão da Transmissão" e "Plano de Expansão de Longo Prazo". Estes relatórios contêm todas as obras de expansão definidas em estudos de planejamento do Sistema Interligado Nacional (SIN), que corresponde ao sistema elétrico brasileiro. As obras presentes nesses relatórios correspondem tanto a instalações de novos equipamentos na rede quanto a ampliações e reforços de ativos já em operação. As obras de novas instalações correspondem à construção de novas LTs e transformadores e de novas subestações, já as ampliações e reforços correspondem, por exemplo, a recapacitações e seccionamentos de LTs e suporte de reativos em subestações.

Para definição do problema PET proposto neste trabalho, os anos de 2017 e 2025 são considerados, respectivamente, como ano base e último ano do horizonte de planejamento, ou seja, o período de estudo corresponde ao intervalo 20172025. Para este período, as obras indicadas pela EPE podem ser verificadas nos dois relatórios citados no parágrafo anterior, os quais estão disponíveis em [79].

No estudo proposto nesta tese de doutorado, não é de interesse a previsão de construção de novas subestações ou a realização de obras para ampliações de ativos já em operação. Portanto, apenas a indicação de reforços referentes à construção de novas LTs e novos transformadores será investigada. Dessa forma, a topologia base do sistema obtido corresponde a uma rede hipotética para o ano de 2017. Essa rede já possui todas as obras de novas subestações e ampliações presentes em [79], previstas para construção entre os anos de 2017 e 2025. Ou seja, para definição da topologia base (2017), foi construído um sistema equivalente para a rede geoelétrica sul (ano horizonte de planejamento - 2025) e, em seguida, foram eliminados apenas os reforços referentes à construção de novos circuitos 
(LTs e transformadores) no intervalo 2017-2025. As definições consideradas para equivalência da rede são apresentadas a seguir.

\subsection{2.}

\section{Topologia Base da Rede}

Para definição do sistema equivalente proposto, foram utilizados dados completos da rede elétrica brasileira, a qual compõe o SIN. Estes dados são disponibilizados pela EPE em arquivos históricos do ANAREDE, programa computacional desenvolvido pelo Centro de Pesquisas de Energia Elétrica (Cepel) e amplamente utilizado para realização de análise de redes no Brasil. Nestes arquivos estão presentes as representações elétricas dos equipamentos utilizados no transporte de energia elétrica (LTs, transformadores, capacitores, etc.).

$\mathrm{Na}$ representação equivalente da rede, foram definidas as áreas de interesse dentro do sistema elétrico completo, as quais correspondem às barras e LTs da região geoelétrica sul do Brasil, com níveis de tensão de $230 \mathrm{kV}$ e $525 \mathrm{kV}$. O sistema equivalente foi então obtido a partir de um "recorte" da rede, onde as barras de interligação com outras áreas do sistema, bem como as de interligação com barras de outros níveis de tensão dentro da mesma área, são consideradas como barras de fronteira. Nessa representação, as injeções de potência nas barras de fronteira, provenientes de barras não pertencentes ao sistema equivalente, são simuladas por cargas ou gerações fictícias conectadas a essas barras, com valores constantes para um determinado ponto de operação da rede.

$\mathrm{Na}$ caracterização do problema para estudo PET de longo prazo, algumas simplificações foram ainda necessárias para definição do sistema final. Barras fictícias utilizadas para representação de capacitores conectados em série com as LTs, bem como de transformadores de três enrolamentos, foram eliminadas da rede equivalente obtida. Para tanto, as devidas considerações foram adotadas. Para eliminação das barras fictícias utilizadas para representação de capacitores série, foram somadas as reatâncias das duas LTs conectadas a essa barra, resultando em apenas uma LT equivalente. De forma similar, a barra fictícia utilizada para representação do transformador de três enrolamentos também foi eliminada, sendo somadas as impedâncias dos enrolamentos primário e secundário, resultando em um transformador equivalente representado apenas por um valor de impedância série. 
Ao final dos processos de equivalência e simplificações da rede para o ano de 2025 e, ainda, após eliminação das obras correspondentes aos novos circuitos previstos para construção dentro do intervalo considerado para o planejamento (2017-2025), foi definida a topologia base para o sistema da região geoelétrica sul do Brasil (SGSB). Essa topologia possui um total de 242 barras (subestações), interligadas por uma rede formada por 345 ramos, onde estão instalados 467 circuitos, entre LTs e transformadores. Os dados de barra e os dados dos circuitos existentes na topologia base obtida para o SGSB estão disponíveis, respectivamente, nas Tabelas B.1 e B.2, presentes no Apêndice B.

\subsection{3.}

\section{Lista de Ramos Candidatos ao Reforço}

A fim de realizar o planejamento da transmissão para a rede do sistema real criado, é proposta a lista de ramos candidatos ao reforço apresentada na Tabela B.3, presente no Apêndice B. Esta lista é composta de 108 ramos candidatos, sendo que 83 ramos já possuem circuitos na configuração base da rede (ramos existentes) e 25 são ramos novos, sem qualquer circuito em operação. Para formar a lista de ramos candidatos, foram adotadas as premissas apresentadas a seguir.

Inicialmente, todos os ramos com obras previstas pela EPE em [79] para o período de 2017 a 2025 foram adicionados à lista de candidatos. Estas obras correspondem aos circuitos (LTs e transformadores) excluídos no sistema equivalente criado para 2025 a fim de formar a rede para a topologia base do ano de 2017 . No total, estas obras correspondem à construção de 44 circuitos em 34 ramos do sistema, sendo 12 ramos já existentes e 22 ramos novos. Na Tabela B.3, com a lista completa de ramos candidatos, estes correspondem aos ramos de 1 a 34 .

Na Tabela B.3, cada ramo possui dois custos de investimento diferentes, $c_{i j}^{1}$ e $c_{i j}^{2}$. O primeiro equivale ao custo de se construir um reforço (circuito) simples no ramo $i-j$, já o segundo corresponde ao custo de se construir dois circuitos simples ou um circuito duplo, no caso de LTs. Nos ramos destinados à instalação de transformadores ou de LTs em circuitos simples, $c_{i j}^{1}$ corresponde a $50 \%$ de $c_{i j}^{2}$. Já nos ramos destinados a LTs com opção para circuito duplo, $c_{i j}^{1}$ corresponde a 
$62,5 \%$ de $c_{i j}^{2}$. Na definição do SGSB, apenas os ramos com obras de circuito duplo previstas em [79] podem receber este tipo de circuito. Para os demais ramos candidatos adotou-se apenas a opção para dois circuitos simples.

Por meio de uma inspeção do sistema, outros 3 ramos novos foram propostos para possível reforço da topologia base do sistema, 1 para interligação de barras com nível de tensão de $230 \mathrm{kV}$ (ramo 35 na Tabela B.3) e outros 2 para interligação de barras de $525 \mathrm{kV}$ (ramos 36 e 37 na Tabela B.3). Essas possíveis obras são capazes de permitir a ligação elétrica de subestações geograficamente próximas e têm o intuito de reforçar a malha da rede, aumentando a confiabilidade das respectivas regiões. Vale destacar que foi observada a inexistência de áreas de preservação ambiental, tais como reservas indígenas e unidades de conservação, no trajeto de eventuais circuitos construídos nestes ramos.

Os custos de investimento associados a cada um desses ramos foram calculados com base nos custos apresentados pelas obras presentes em [79] e, dado que não foram adotados circuitos duplos, correspondem à construção de apenas 1 circuito simples $\left(c_{i j}^{1}\right)$ ou de 2 circuitos simples $\left(c_{i j}^{2}\right)$. Especificamente para as LTs, o custo para construção de 1 circuito simples é formado por uma parcela fixa, associada à ligação da LT em cada subestação, e uma parcela que depende do comprimento deste circuito. Estes valores variam de acordo com o tipo de cabo utilizado, que por sua vez, depende do nível de tensão da LT a ser construída. Os cabos do tipo "Drake" e "Rail" foram adotados, respectivamente, para LTs com tensões de $230 \mathrm{kV}$ e $525 \mathrm{kV}$, sendo estes os cabos mais recorrentes para estes níveis de tensão em [79]. Os custos utilizados para calcular os investimentos dos 3 ramos novos propostos, estão apresentado na Tabela 5.1. Para definição da capacidade máxima de potência ativa nesses ramos, foram também consideradas as capacidades típicas para cada cabo, conforme apresentado em [79].

Tabela 5.1 - Custos dos cabos para construção de LTs.

\begin{tabular}{|c|c|c|}
\hline \hline Tipo de Cabo & $\begin{array}{c}\text { Custo Fixo } \\
(\mathbf{R} \$ \mathbf{1 0 0 0})\end{array}$ & $\begin{array}{c}\text { Custo Variável } \\
(\mathbf{R} \mathbf{\$} 1000 / \mathbf{k m})\end{array}$ \\
\hline Drake $1 \times 795 \mathrm{MCM}$ & $2 \times 4792,580$ & 409,198 \\
\hline Rail $4 \times 954 \mathrm{MCM}$ & $2 \times 11120,620$ & 1028,692 \\
\hline
\end{tabular}

Para o comprimento das LTs foi considerada a distância entre as barras (subestações) terminais dos ramos, acrescidas de $20 \%$ a fim de considerar o trajeto de 
cada LT após sua construção. Os comprimentos de 119 km, 132 km e 161 km foram considerados, respectivamente, para os ramos 35, 36 e 37 da Tabela B.3 (ramos novos propostos).

As impedâncias equivalentes $Z_{i j}$ dos circuitos para os ramos novos, ou seja, parâmetros de resistência $R_{i j}$ e reatância $X_{i j}$ para cada ramo $i-j$, foram calculadas a partir dos parâmetros típicos de LTs por comprimento, apresentados para cada tipo de cabo na Tabela 5.2. Nesta tabela, $r$ e $x$ são, respectivamente, a resistência e a reatância série, dadas em ohms/km, e y é a susceptância shunt da LT, dada em mhos $/ \mathrm{km}$.

Tabela 5.2 - Parâmetros típicos de LTs por comprimento.

\begin{tabular}{|c|c|c|c||}
\hline Tipo de Cabo & $\begin{array}{c}\text { Resistência }(\boldsymbol{r}) \\
(\mathbf{o h m s} / \mathbf{k m})\end{array}$ & $\begin{array}{c}\text { Reatância }(\boldsymbol{x}) \\
(\mathbf{o h m s} / \mathbf{k m})\end{array}$ & $\begin{array}{c}\text { Susceptância shunt }(\boldsymbol{y}) \\
(\mathbf{m h o s} / \mathbf{k m})\end{array}$ \\
\hline Drake $1 \times 795 \mathrm{MCM}$ & 0,0845591 & 0,494708 & $3,35538 \times 10^{-6}$ \\
\hline Rail $4 \times 954 \mathrm{MCM}$ & 0,0181957 & 0,317551 & $5,22459 \times 10^{-6}$ \\
\hline
\end{tabular}

A partir dos valores da Tabela 5.2, é possível obter a impedância característica $Z_{c}$ e a constante de propagação $\gamma$ das LTs, conforme equações (5.1) e (5.2), respectivamente:

$$
\begin{gathered}
Z_{c}=\sqrt{(r+j x) / y} \\
\gamma=\sqrt{(r+j x) y}
\end{gathered}
$$

Finalmente, a impedância equivalente de cada ramo $i$-j pode ser calculada:

$$
Z_{i j}=\left(R_{i j}+j X_{i j}\right)=\frac{Z_{c} \operatorname{senh}\left(\gamma L_{i j}\right)}{Z_{i j}^{b a s e}}
$$

onde: $L_{i j}$ é o comprimento total da LT do ramo $i-j$, dado em km, e $Z_{i j}^{b a s e}$ é a impedância base do trecho ao qual pertence o ramo. Vale mencionar que não é calculada a susceptância shunt equivalente, uma vez que o modelo utilizado é o DC com perdas.

Os demais ramos presentes na lista de candidatos, ou seja, os ramos de 38 a 108 da Tabela B.3, foram selecionados a partir de análises de fluxo de potência da rede com a topologia base, considerando a rede tanto na condição intacta quanto na ocorrência de contingências simples dos circuitos. Nestas análises, são consideradas a carga e a geração para o ano horizonte de planejamento (2025) em dois 
diferentes cenários: Norte Seco (importador) e Norte Úmido (exportador), ambos com condição de carga pesada.

Observando o comportamento da rede intacta em cada cenário, foram selecionados para composição da lista de candidatos os ramos que apresentam carregamento igual ou superior a $50 \%$ de suas respectivas capacidades. Foram selecionados 45 ramos observando o carregamento da rede para o cenário Norte Seco e 26 ramos para o cenário Norte Úmido.

Já a partir de estudo de contingências, foram selecionados os ramos que apresentam montantes de sobrecarga iguais ou superiores a 10MW quando ocorre a perda de um circuito pertencente a qualquer um dos ramos da lista de contingências considerada, a qual é definida na Subseção 5.2.5. Os montantes de sobrecarga

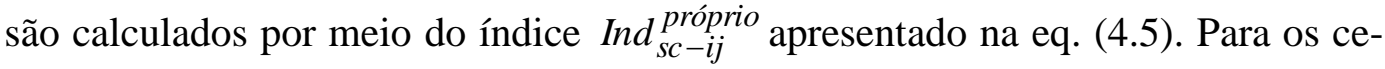
nários Norte Seco e Norte Úmido, 14 e 3 ramos, respectivamente, apresentam montantes de sobrecarga superiores à $10 \mathrm{MW}$ de acordo com esta análise. Foram ainda selecionados os ramos em que a remoção de um circuito causa montantes de sobrecargas e/ou cortes de carga por ilhamento iguais ou superiores a $10 \mathrm{MW}$ em toda a rede, conforme Ind $d_{s c-i j}^{\text {outros }}$, apresentado na eq. (4.6). Por meio deste último critério, nos cenários Norte Seco e Norte Úmido, 20 e 18 ramos, respectivamente, foram selecionados.

A partir dessas análises, é possível perceber que o cenário Norte Seco apresenta maior "estresse" para a rede da região geoelétrica sul do Brasil se comparado ao cenário Norte Úmido.

Finalmente, após eliminação de interseções, 71 ramos foram adicionados à lista de candidatos ao reforço da rede (ramos de 38 a 108 da Tabela B.3). Nestes ramos, os eventuais circuitos a serem construídos possuem as mesmas características elétricas (resistência, reatância e capacidade) e, no caso de LTs, também o mesmo comprimento que os respectivos circuitos já em operação na rede. Os custos para construção de circuitos nestes ramos (1 circuito simples ou 2 circuitos simples) foram calculados considerando o nível de tensão adequado e os tipos de cabos conforme dados da Tabela 5.1.

É importante destacar que a viabilidade técnica de construção de circuitos nos 71 últimos ramos candidatos propostos não foi analisada. Ou seja, algumas subestações terminais destes ramos podem necessitar de expansão para receber 
novas LTs ou novos transformadores, sendo que os respectivos custos não estão sendo computados.

\subsection{4.}

\section{Cenários de Carga e de Geração}

O Sistema Interligado Nacional (SIN) é responsável por garantir a interligação elétrica entre a geração e a carga para as diferentes regiões do Brasil. Essas regiões apresentam diferentes condições climáticas e de disponibilidade de fontes energéticas, as quais variam durante os períodos do ano. Na Figura 5.1 é possível visualizar, de forma geral, o SIN do ano de 2017, conforme disponibilizado pelo Operador Nacional do Sistema (ONS) [80].

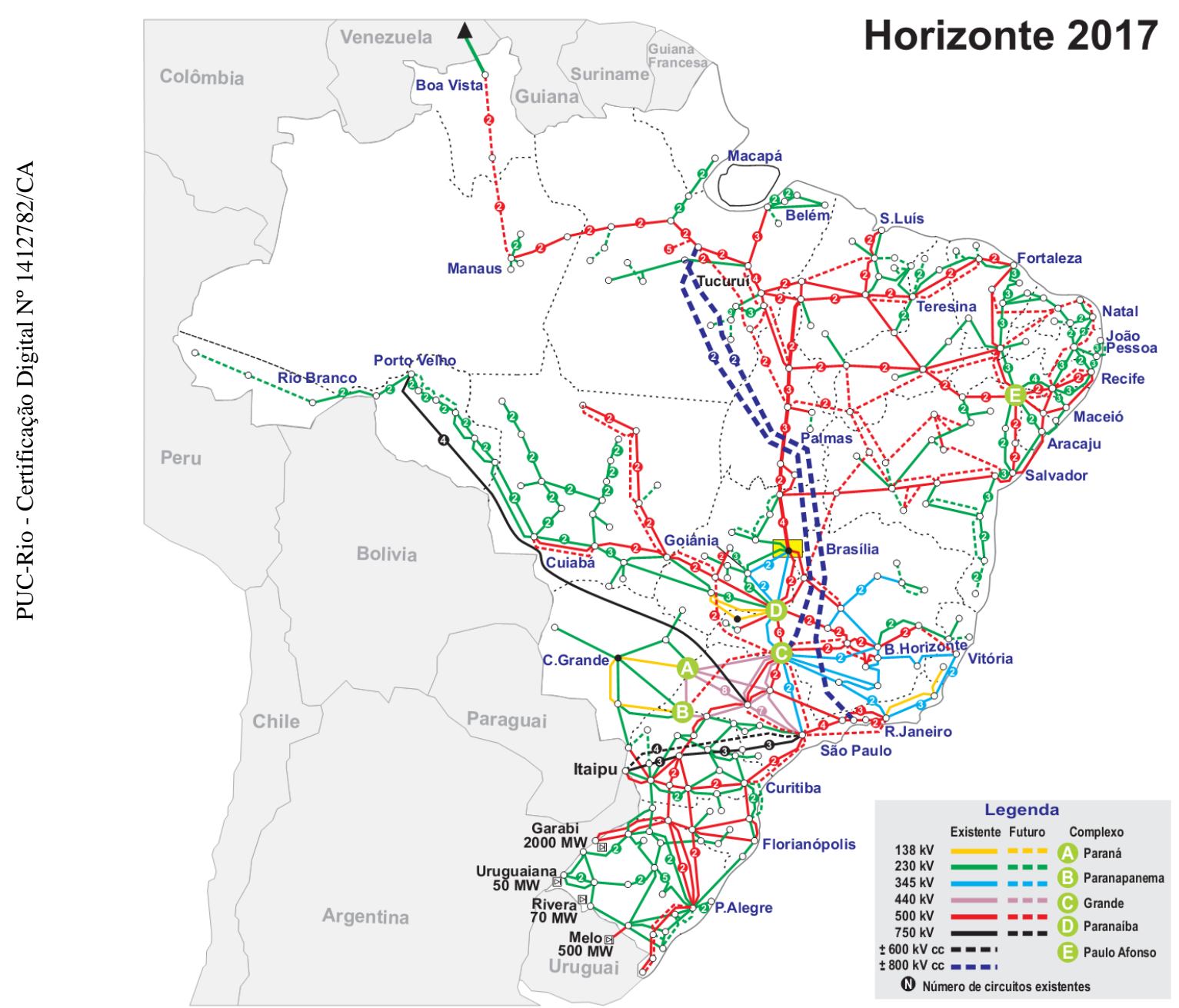

Figura 5.1 - Sistema Interligado Nacional (SIN) - Sistema de Transmissão Horizonte de 2017 [80]. 
Para garantir uma adequada operação do sistema, com um melhor aproveitamento dos recursos energéticos de cada região, é necessária uma rede de transmissão flexível do ponto de vista operacional. Portanto, é de extrema importância que já na fase de planejamento da expansão dessas redes, sejam consideradas diferentes condições da carga e de geração disponível.

Nesta tese, são considerados dois diferentes cenários para o estudo do problema PET com o SGSB, a fim de considerar diferentes condições de operação da rede de transmissão. O primeiro cenário, que corresponde à condição de maior "estresse" para a região geoelétrica sul do Brasil, é denominado Norte Seco. Este cenário configura a região geoelétrica norte do país como importadora de energia elétrica. No segundo cenário, denominado Norte Úmido, essa região se comporta como exportadora de energia elétrica. Mais informações sobre o comportamento do sistema elétrico brasileiro podem ser encontradas em [81].

As condições de carga e de despacho de geração para cada um desses cenários são disponibilizadas pela EPE por meio de arquivos históricos do ANAREDE para três diferentes patamares de carga: leve, média e pesada. Neste trabalho, os dois cenários são analisados para o patamar de carga pesada.

\subsection{5. \\ Despacho de Geração e Lista de Contingências}

Para avaliação das configurações da rede, obtidas a partir de cada plano de expansão durante o processo de solução do PET, deve ser considerado o redespacho de geração para operação com rede intacta, conforme subproblema de operação (4.2a) apresentado na Subseção 4.2.2. Dessa forma, são considerados limites mínimo e máximo de geração para cada barra de geração do sistema, sejam elas barras internas ao sistema equivalente, sejam elas barras de fronteira com geração fictícia. Para esses limites, são considerados, respectivamente, $90 \%$ e $110 \%$ do despacho apresentado nos pontos de operação presentes nos arquivos históricos do ANAREDE disponibilizados pela EPE para cada cenário. Ou seja, cada barra de geração pode variar seu despacho $10 \%$ abaixo e $10 \%$ acima do ponto original de operação dentro de cada cenário. Os despachos originais para cada cenário podem ser verificados na Tabela B.1, presente no Apêndice B.

Ainda conforme função objetivo do subproblema de operação (4.2a), é necessária a definição dos custos de geração para as barras de geração do sistema 
equivalente obtido. Dessa forma, assim como adotado para os sistemas IEEE-RTS e SSB analisados no Capítulo 4, estes custos foram considerados iguais à prioridade de cada uma dessas barras no despacho de geração. As ordens de prioridade para cada cenário, apresentadas na Tabela B.1, foram definidas considerando as capacidades de geração de cada barra para o cenário Norte Seco, onde as barras com maiores capacidades possuem prioridade no despacho.

É necessário ainda definir a lista de ramos para análise de contingências da rede. Para o SGSB obtido, apenas 38 dos 345 ramos da topologia base do sistema, não sofrem contingência na análise "N-1", conforme pode ser verificado na Tabela B.2. Estes ramos são responsáveis pela interligação à rede de barras terminais de carga e/ou geração. Entende-se que a viabilidade de reforçar qualquer um destes ramos pode ser facilmente avaliada, até mesmo sem o emprego de ferramentas de otimização.

Para o estudo de contingências, são ainda considerados os 25 ramos novos da lista de candidatos que eventualmente recebam reforços durante o processo construtivo de soluções. Dessa forma, a lista de contingência para análise do critério de segurança "N-1" é formada por, no máximo, 332 ramos. Na avaliação de um determinado plano de expansão durante o processo de solução do problema PET, pelo menos 307 contingências simples são analisadas, isso considerando que nenhum dos 25 ramos de novas ligações esteja sendo reforçado. Por fim, cabe destacar que os ramos da lista de contingências que possuem mais de um circuito, perdem apenas um desses circuitos na análise. Como existem ramos compostos por circuitos com características elétricas diferentes, o circuito a ser removido corresponde ao que possui maior capacidade de fluxo de potência e, no caso de empate da capacidade, é removido o circuito com menor valor de reatância. Dessa forma, garante-se sempre a pior situação de perda de um circuito.

\section{3.}

\section{Ajuste do AMC-PET para Sistema de Grande Porte}

Após a realização de alguns testes preliminares com o sistema SGSB, o qual se trata de um problema de grande porte com maior número de opções de reforços, foi verificada a grande importância de se adotar uma estratégia de diversidade durante o processo construtivo do AMC-PET. Com a utilização da estratégia de diversidade apresentada na Seção 4.6 foi possível obter, com maior recorrência, 
soluções de melhor qualidade, isto é, que demandam menores montantes de investimento. Entretanto, foi verificada ainda a necessidade de ajustes no processo construtivo da metodologia, a fim de reduzir o esforço computacional necessários para solução do problema.

Basicamente, além do emprego da estratégia de diversidade, duas modificações foram realizadas em relação à metodologia apresentada na Seção 3.4:

- os indivíduos dos conjuntos $\Omega_{\mathrm{MA}}, \Omega_{\mathrm{MCM}}$ e $\Omega_{\mathrm{MD}}$ deixaram de ser utilizados como progenitores no passo (ii) do algoritmo, onde são empregados os mecanismos MC e MM;

- o MR, em uma versão relaxada, foi introduzido na porção iterativa do AMC-PET, sendo aplicado a cada solução viável identificada.

A primeira modificação tem por objetivo reduzir o número de indivíduos gerados e avaliados no cruzamento e na mutação e, por consequência, reduzir o esforço computacional na solução do problema de grande porte. Em termos de informação genética, o processo não é prejudicado, uma vez que os indivíduos gerados no passo (i), que continuam como progenitores no passo (ii), são criados exatamente a partir dos conjuntos $\Omega_{\mathrm{MA}}, \Omega_{\mathrm{MCM}}$ e $\Omega_{\mathrm{MD}}$, apresentando apenas um reforço a mais em suas configurações. Esse ajuste no AMC-PET reduziu o esforço computacional necessário sem causar, entretanto, impacto negativo no desempenho do algoritmo.

A segunda modificação objetiva reduzir o esforço computacional no emprego do MR, o qual é aplicado ao final do processo construtivo do AMC-PET. Nos estudos com o sistema de maior porte, foi verificado que algumas soluções do conjunto $\Omega_{\mathrm{V}}$ apresentam diversos reforços desnecessários para garantir a viabilidade, implicando em um número elevado de avaliações no emprego deste mecanismo. Portanto, uma versão relaxada do MR passou também a ser empregada a cada solução viável identificada durante o processo construtivo. Sendo assim, o conjunto $\Omega_{\mathrm{V}}$ passa a ser composto por soluções viáveis prévia e parcialmente refinadas.

Nesta versão relaxada do MR, diferentemente de sua versão original, se um determinado reforço ao ser removido causar corte e/ou sobrecarga na rede durante a avaliação do indivíduo, a sua remoção não é mais testada em qualquer outro 
indivíduo viável decorrente desse indivíduo sob emprego do MR relaxado. Ou seja, é considerado que se um reforço é necessário para que não ocorra corte e/ou sobrecarga na rede para um dado subconjunto de circuitos da solução viável, ele será também necessário em qualquer outro subconjunto dessa solução. Com isso, o conjunto final $\Omega_{\mathrm{V}}$, após convergência do AMC-PET, apresenta indivíduos viáveis com um número muito menor de reforços, entretanto, precisam ainda passar pelo MR em sua versão original. O esforço computacional necessário para emprego do MR após convergência do AMC-PET foi significativamente reduzido com emprego do MR relaxado durante o processo iterativo e o desempenho do algoritmo não sofreu alteração.

\section{4. \\ Resultados - SGSB}

O AMC-PET, considerando os ajustes apresentados nas Seções 4.6 e 5.3, é empregado na solução do problema PET com o SGSB, separadamente para os cenários Norte Seco e Norte Úmido. Em seguida, a partir das soluções encontradas para cada caso, são definidas soluções finais, capazes de atender ambos os cenários.

O ajuste dos parâmetros do AMC-PET para todos os testes realizados com o SGSB foi efetuado com base nos estudos apresentados no capítulo anterior. As taxas de cruzamento e de mutação para os mecanismos MC e MM foram mantidas em $65 \%$ e $8 \%$, respectivamente. O tamanho máximo do conjunto $\Omega_{\mathrm{V}}$ nos testes com o SGSB foi reduzido para $50\left(n_{\mathrm{V}}=50\right)$ em relação aos testes realizados no Capítulo 4. Este sistema implica em avaliações mais demoradas em termos de custo computacional, isso devido à sua dimensão, portanto, a redução de $n_{\mathrm{V}}$ se torna necessária uma vez que os indivíduos desse conjunto são utilizados como progenitores durante o processo construtivo. O critério de convergência do AMCPET foi ampliado para $20\left(n_{p}=20\right)$ em todos os testes. A taxa de adição para permitir o reforço em ramos que interligam barras de carga e/ou geração no emprego do MA foi mantida em 50\%. Para os demais parâmetros $\left(n_{\mathrm{MA}}, n_{\mathrm{MCM}}\right.$ e $\left.n_{r}\right)$ foram consideradas diferentes combinações, as quais compõem os testes apresentados a seguir para cada cenário. 


\subsection{1.}

\section{Cenário Norte Seco}

Para o cenário Norte Seco, o SGSB apresenta um montante de 18527,6 MW de carga. Considerando os limites de geração adotados, uma capacidade total de geração de 20838,8 MW está disponível.

Em todos os testes realizados com o SGSB para o cenário Norte Seco utilizando o AMC-PET, o melhor plano de expansão (solução) identificado possui 22 reforços (circuitos), distribuídos em 19 ramos candidatos da rede, conforme apresentado na Tabela 5.3 a seguir. Um investimento de 833,442 milhões de R $\$$ é necessário para construção dos reforços para essa solução. Um montante de 602,82 MW de perdas é apresentado pela configuração da rede resultante.

Tabela 5.3 - Melhor solução - SGSB - Cenário Norte Seco.

\begin{tabular}{|c|c|c|c|}
\hline \multicolumn{3}{|c|}{ Ramo Candidato } & \multirow{2}{*}{$\begin{array}{c}\text { Número de } \\
\text { Reforços }\end{array}$} \\
\hline $\mathbf{N}^{\circ}$ & DE & PARA & \\
\hline 2 & 6754 & 6602 & 2 \\
\hline 12 & 7749 & 7024 & 1 \\
\hline 17 & 7903 & 7731 & 2 \\
\hline 19 & 7980 & 7794 & 2 \\
\hline 25 & 38857 & 4290 & 1 \\
\hline 26 & 7024 & 6763 & 1 \\
\hline 39 & 47120 & 9261 & 1 \\
\hline 41 & 7922 & 9265 & 1 \\
\hline 46 & 7763 & 6651 & 1 \\
\hline 50 & 7762 & 7763 & 1 \\
\hline 53 & 6754 & 6601 & 1 \\
\hline 58 & 6651 & 6688 & 1 \\
\hline 67 & 9208 & 9209 & 1 \\
\hline 69 & 7734 & 7731 & 1 \\
\hline 77 & 6715 & 7042 & 1 \\
\hline 80 & 6619 & 7739 & 1 \\
\hline 82 & 7824 & 7823 & 1 \\
\hline 85 & 6649 & 6626 & 1 \\
\hline 86 & 7755 & 38857 & 1 \\
\hline TOTAL & - & - & 22 \\
\hline
\end{tabular}

Informações das 10 melhores soluções (planos de expansão) encontradas em 12 testes realizados com o cenário Norte Seco estão presentes na Tabela 5.4. Observe que todas essas soluções apresentam 22 reforços distribuídos em 19 ramos candidatos. 
Tabela 5.4 - Melhores soluções - SGSB - Cenário Norte Seco.

\begin{tabular}{|c|c|c|c|c||}
\hline Plano & $\begin{array}{c}\text { Investimento } \\
\text { (milhões de R\$) }\end{array}$ & $\begin{array}{c}\text { Perdas Ativas } \\
\text { (MW) }\end{array}$ & $\begin{array}{c}\text { Total de } \\
\text { Ramos }\end{array}$ & $\begin{array}{c}\text { Total de } \\
\text { Reforços }\end{array}$ \\
\hline AMC-NS.1 & 833,442 & 602,82 & 19 & 22 \\
\hline AMC-NS.2 & 836,511 & 602,01 & 19 & 22 \\
\hline AMC-NS.3 & 837,534 & 603,13 & 19 & 22 \\
\hline AMC-NS.4 & 840,603 & 602,33 & 19 & 22 \\
\hline AMC-NS.5 & 842,526 & 602,05 & 19 & 22 \\
\hline AMC-NS.6 & 845,595 & 601,24 & 19 & 22 \\
\hline AMC-NS.7 & 846,618 & 602,37 & 19 & 22 \\
\hline AMC-NS.8 & 847,559 & 602,38 & 19 & 22 \\
\hline AMC-NS.9 & 849,687 & 601,56 & 19 & 19 \\
\hline AMC-NS.10 & 850,628 & 601,58 & & \\
\hline
\end{tabular}

Na Tabela 5.5 estão apresentadas informações relativas à variação dos parâmetros e ao desempenho do AMC-PET para os 12 testes realizados. Cada teste apresentado na Tabela 5.5 corresponde à realização de 30 execuções do AMCPET com diferentes sementes para geração dos números pseudoaleatórios. Vale destacar que nesta tabela o índice $\mathrm{T}_{\mathrm{M}}$ é apresentado em horas, diferentemente dos testes do Capítulo 4, onde o índice é apresentado em minutos.

Tabela 5.5 - Resultados do AMC-PET - SGSB - Cenário Norte Seco.

\begin{tabular}{|c|c|c|c|c|c|c|c|c|c|}
\hline \multirow{3}{*}{ Teste } & \multicolumn{5}{|c|}{ Parâmetros do AMC-PET } & \multirow{2}{*}{\multicolumn{4}{|c|}{ Índices de Desempenho }} \\
\hline & \multicolumn{2}{|c|}{$\begin{array}{c}\text { Tamanho dos } \\
\text { Conjuntos }\end{array}$} & \multicolumn{3}{|c|}{ Distribuição de $n_{r}$} & & & & \\
\hline & $n_{\mathrm{MA}}$ & $n_{\mathrm{MCM}}$ & $\operatorname{Ind}_{c h-i j}$ & $\operatorname{Ind} d_{s c-i j}^{\text {próprio }}$ & Ind $d_{s c-i j}^{\text {outros }}$ & $\begin{array}{c}\mathbf{T}_{\mathbf{S}} \\
(\%)\end{array}$ & $\begin{array}{l}\mathbf{T}_{\mathbf{M}} \\
(\mathbf{h})\end{array}$ & $\begin{array}{l}D_{\text {Best }} \\
(\%)\end{array}$ & $\begin{array}{c}D_{10 B e s t} \\
(\%)\end{array}$ \\
\hline C.1 & 30 & 30 & 1 & 1 & 2 & 50,00 & 4,90 & 7,45 & 12,25 \\
\hline C. 2 & 30 & 30 & 1 & 2 & 1 & 63,33 & 4,08 & 4,38 & 8,74 \\
\hline C. 3 & 30 & 30 & 1 & 2 & 2 & 53,33 & 4,76 & 5,36 & 11,00 \\
\hline C. 4 & 30 & 30 & 1 & 1 & 3 & 50,00 & 4,14 & 7,19 & 11,78 \\
\hline C. 5 & 40 & 40 & 1 & 1 & 2 & 60,00 & 4,72 & 5,65 & 11,78 \\
\hline C.6 & 40 & 40 & 1 & 2 & 1 & 83,33 & 4,77 & 2,53 & 5,31 \\
\hline C.7 & 40 & 40 & 1 & 2 & 2 & 63,33 & 4,60 & 5,64 & 9,01 \\
\hline C.8 & 40 & 40 & 1 & 1 & 3 & 56,67 & 6,69 & 5,42 & 11,46 \\
\hline C.9 & 50 & 50 & 1 & 1 & 2 & 40,00 & 6,29 & 8,44 & 13,43 \\
\hline C. 10 & 50 & 50 & 1 & 2 & 1 & 36,67 & 6,05 & 7,41 & 11,47 \\
\hline C.11 & 50 & 50 & 1 & 2 & 2 & 43,33 & 5,70 & 7,58 & 13,18 \\
\hline C.12 & 50 & 50 & 1 & 1 & 3 & 36,67 & 6,78 & 7,52 & 13,68 \\
\hline
\end{tabular}

A partir dos resultados apresentados na Tabela 5.5 é possível perceber que, embora também apresente bons resultados, a utilização dos valores 50 e 50 para os parâmetros $n_{\mathrm{MA}}$ e $n_{\mathrm{MCM}}$ (tamanhos dos conjuntos $\Omega_{\mathrm{MA}}$ e $\Omega_{\mathrm{MCM}}$ ), não produziu, 
na média, um desempenho tão bom quanto os desempenhos apresentados pela utilização dos valores 3030 e 40 40. A razão para este comportamento pode estar ligada ao fato de que o aumento no tamanho dos conjuntos, aliado ao emprego da estratégia de diversidade, amplia a participação de indivíduos que não contribuem com o processo construtivo. Esses indivíduos acabam originando planos de expansão localizados em regiões do espaço de solução, as quais não envolvem os melhores planos conhecidos.

Dentre os testes em análise, destaca-se o desempenho superior apresentado pelo Teste C.6, o qual apresenta o maior $\mathrm{T}_{\mathrm{S}}(83,33 \%)$ e os menores valores dos índices $\mathrm{D}_{\text {Best }}(2,53 \%)$ e $\mathrm{D}_{10 \text { Best }}(5,31 \%)$. Contudo, verifica-se uma boa qualidade do conjunto das melhores soluções identificadas em todos os testes. Considerando-se os valores apresentados pelo índice $\mathrm{D}_{10 \mathrm{Best}}$ nos Testes C.1 a C.12, espera-se que o investimento das 10 melhores soluções encontradas em uma execução do AMC-PET seja, em média, 10,89\% maior que o investimento da melhor solução conhecida para o cenário (833,442 milhões de $\mathrm{R} \$)$.

Salienta-se, ainda, que em cada teste apresentado na Tabela 5.5, as 30 execuções do AMC-PET foram suficientes para encontrar todas as 10 melhores soluções conhecidas (Tabela 5.4). Ou seja, pode-se esperar que planos de expansão de boa qualidade farão parte do conjunto final de soluções desde que um número adequado de execuções do algoritmo seja realizado. Tal afirmação pode ser confirmada pelo cálculo do número mínimo de execuções $\left(N_{\mathrm{exc}}^{\min }\right)$ do AMC-PET para identificar as 10 melhores soluções conhecidas para o cenário Norte Seco. O $N_{\text {exc }}^{\min }$ obtido para cada teste (partindo sempre da $1^{\mathrm{a}}$ execução) é apresentado na segunda coluna da Tabela 5.6. Verifica-se que em 8 dos 12 testes um número de execuções menor ou igual a 8 foi suficiente para identificar as 10 melhores soluções conhecidas. Com base na média de todos os testes, espera-se que a realização de 10 execuções seja suficiente. Caso somente as 10 primeiras execuções fossem realizadas, apenas os Testes C.2, C.5, C.9 e C.12 (aqueles com maiores $N_{\mathrm{exc}}^{\min }$ ) não teriam $100 \%$ de acerto. Ainda assim, eles teriam identificado, respectivamente, 7 , 8, 8 e 7 das 10 melhores soluções conhecidas. Porém, as 4 melhores (AMC-NS.1 a AMC-NS.4) seriam identificadas por todos eles. 
Tabela 5.6 - Testes C.1 a C.12: informações adicionais - SGSB - Cenário Norte Seco.

\begin{tabular}{|c|r|r|}
\hline Teste & $N_{\text {exc }}^{\min }$ & $N C_{\text {conv }}^{\text {médio }}$ \\
\hline C.1 & 7 & 90,23 \\
\hline C. 2 & 21 & 101,43 \\
\hline C. 3 & 4 & 107,93 \\
\hline C. 4 & 4 & 98,17 \\
\hline C.5 & 19 & 90,43 \\
\hline C.6 & 4 & 131,40 \\
\hline C.7 & 4 & 108,53 \\
\hline C. 8 & 13 & 102,00 \\
\hline C.9 & 7 & 78,93 \\
\hline C.10 & 8 & 86,20 \\
\hline C.11 & 18 & 87,77 \\
\hline C. 12 & 9,58 & 74,53 \\
\hline MÉDIA & & 96,46 \\
\hline
\end{tabular}

Ainda na Tabela 5.6, na terceira coluna, é apresentado o número médio de níveis construtivos $\left(N C_{\text {conv }}^{\text {médio }}\right)$ necessários em cada teste para convergência do

AMC-PET. Com base no $N C_{\text {conv }}^{\text {médio }}$ dos 12 testes $(96,46)$, e sabendo que $n_{p}$ é igual a 20, espera-se que a identificação da melhor solução viável ocorra entre o $76^{\circ}$ e $77^{\circ}$ nível construtivo.

\subsection{2.}

\section{Cenário Norte Úmido}

No cenário Norte Úmido, a carga total corresponde a 15001,6 MW. Já a capacidade máxima de geração equivale a 16902,4 MW. A melhor solução identificada para este cenário em todos os testes realizados corresponde a um investimento de 385,819 milhões de $\mathrm{R} \$$ e é composta por 9 reforços, distribuídos em 7 ramos candidatos conforme indicado na Tabela 5.7. Para este cenário, as 10 melhores soluções identificadas em todos os testes realizados estão presentes na Tabela 5.8.

Verifica-se que um número bem menor de reforços é necessário para atendimento do cenário Norte Úmido se comparado ao cenário Norte Seco, aproximadamente $60 \%$ menor. Devido a este fato, incrementos maiores nos valores de investimento podem ser verificados entre as soluções apresentadas na Tabela 5.8, ou seja, esses planos não apresentam valores de investimentos tão próximos quanto os do cenário Norte Seco. Ao se realizar, por exemplo, o cálculo do índice de desempenho $\mathrm{D}_{10 \text { Best }}$ para essas soluções, tem-se como resultado o valor de $6,28 \%$. Já 
para as 10 melhores soluções do cenário Norte Seco (Tabela 5.4), o mesmo cálculo resulta em um $\mathrm{D}_{10 \text { Best }}$ de $1,16 \%$. Portanto, são esperados valores bem mais elevados para o índice $\mathrm{D}_{10 \mathrm{Best}}$ nos testes realizados com o cenário Norte Úmido se comparados aos apresentados pelos testes com o cenário Norte Seco.

Tabela 5.7 - Melhor solução - SGSB - Cenário Norte Úmido.

\begin{tabular}{|c|c|c|c||}
\hline \multicolumn{3}{|c|}{ Ramo Candidato } & \multirow{2}{*}{$\begin{array}{c}\text { Número de } \\
\text { Reforços }\end{array}$} \\
\cline { 1 - 2 } $\mathbf{N}^{\circ}$ & DE & PARA & 2 \\
\hline 19 & 7980 & 7794 & 1 \\
\hline 24 & 38857 & 7771 & 2 \\
\hline 41 & 7922 & 9265 & 1 \\
\hline 77 & 6715 & 7042 & 1 \\
\hline 85 & 6649 & 6626 & 1 \\
\hline 86 & 7755 & 38857 & 1 \\
\hline 94 & 7304 & 9180 & 9 \\
\hline TOTAL & - & - & \\
\hline
\end{tabular}

Tabela 5.8 - Melhores soluções - SGSB - Cenário Norte Úmido.

\begin{tabular}{||c|c|c|c|c|}
\hline Plano & $\begin{array}{c}\text { Investimento } \\
\text { (milhões de R\$) }\end{array}$ & $\begin{array}{c}\text { Perdas Ativas } \\
\text { (MW) }\end{array}$ & $\begin{array}{c}\text { Total de } \\
\text { Ramos }\end{array}$ & $\begin{array}{c}\text { Total de } \\
\text { Reforços }\end{array}$ \\
\hline AMC-NU.1 & 385,819 & 423,846 & 7 & 9 \\
\hline AMC-NU.2 & 389,911 & 423,844 & 7 & 9 \\
\hline AMC-NU.3 & 405,373 & 421,373 & 7 & 9 \\
\hline AMC-NU.4 & 409,465 & 421,371 & 7 & 9 \\
\hline AMC-NU.5 & 409,798 & 424,705 & 7 & 9 \\
\hline AMC-NU.6 & 413,890 & 424,703 & 7 & 9 \\
\hline AMC-NU.7 & 414,504 & 423,924 & 7 & 9 \\
\hline AMC-NU.8 & 418,596 & 423,922 & 7 & 9 \\
\hline AMC-NU.9 & 424,576 & 423,875 & 8 & 9 \\
\hline AMC-NU.10 & 428,668 & 423,874 & 8 & 9 \\
\hline
\end{tabular}

As 10 melhores soluções apresentadas na Tabela 5.8 foram identificadas em 12 testes realizados com o cenário Norte Úmido, considerando as mesmas combinações de parâmetros utilizadas nos Testes C.1 a C.12, realizados para o cenário Norte Seco. Cada teste corresponde a 30 execuções da rotina implementada para o AMC-PET. Os desempenhos apresentados por estes testes são exibidos na Tabela 5.9 .

Os tempos médios por execução $\left(\mathrm{T}_{\mathrm{M}}\right)$ verificados em todos os testes com o cenário Norte Úmido são bem reduzidos se comparados aos tempos médios gastos pelas execuções do AMC-PET com o cenário Norte Seco. Na média, houve uma 
redução de $83,03 \%$ nos valores do índice $\mathrm{T}_{\mathrm{M}}$. Isso se deve ao menor número de reforços necessário para que um indivíduo do processo construtivo atinja a viabilidade neste cenário e, consequentemente, resulta em um número menor de níveis construtivos necessários para convergência do AMC-PET.

Tabela 5.9 - Resultados do AMC-PET - SGSB - Cenário Norte Úmido.

\begin{tabular}{|c|c|c|c|c|c|c|c|c|c|}
\hline \multirow{3}{*}{ Teste } & \multicolumn{5}{|c|}{ Parâmetros do AMC-PET } & \multirow{2}{*}{\multicolumn{4}{|c|}{ Índices de Desempenho }} \\
\hline & \multicolumn{2}{|c|}{$\begin{array}{c}\text { Tamanho dos } \\
\text { Conjuntos }\end{array}$} & \multicolumn{3}{|c|}{ Distribuição de $n_{r}$} & & & & \\
\hline & $n_{\mathrm{MA}}$ & $n_{\mathrm{MCM}}$ & Ind $d_{c h-i j}$ & Ind $d_{s c-i j}^{\text {proprio }}$ & $\operatorname{Ind}_{s c-i j}^{\text {outros }}$ & $\begin{array}{c}\mathrm{T}_{\mathrm{S}} \\
(\%)\end{array}$ & $\begin{array}{l}\mathbf{T}_{M} \\
(\mathbf{h})\end{array}$ & $\begin{array}{l}\text { D }_{\text {Best }} \\
(\%)\end{array}$ & $\begin{array}{c}D_{10 B e s t} \\
(\%)\end{array}$ \\
\hline D.1 & 30 & 30 & 1 & 1 & 2 & 100 & 0,68 & 2,06 & 11,02 \\
\hline D.2 & 30 & 30 & 1 & 2 & 1 & 100 & 0,69 & 2,23 & 11,06 \\
\hline D. 3 & 30 & 30 & 1 & 2 & 2 & 100 & 0,67 & 1,93 & 10,40 \\
\hline D. 4 & 30 & 30 & 1 & 1 & 3 & 100 & 0,77 & 1,86 & 9,83 \\
\hline D.5 & 40 & 40 & 1 & 1 & 2 & 100 & 0,91 & 1,72 & 10,06 \\
\hline D.6 & 40 & 40 & 1 & 2 & 1 & 100 & 0,81 & 1,56 & 9,95 \\
\hline D.7 & 40 & 40 & 1 & 2 & 2 & 100 & 0,88 & 1,42 & 10,05 \\
\hline D. 8 & 40 & 40 & 1 & 1 & 3 & 100 & 0,90 & 1,96 & 10,60 \\
\hline D. 9 & 50 & 50 & 1 & 1 & 2 & 100 & 1,00 & 1,18 & 9,58 \\
\hline D.10 & 50 & 50 & 1 & 2 & 1 & 100 & 1,06 & 1,86 & 10,40 \\
\hline D.11 & 50 & 50 & 1 & 2 & 2 & 100 & 1,15 & 1,69 & 9,95 \\
\hline D.12 & 50 & 50 & 1 & 1 & 3 & 100 & 1,28 & 0,68 & 8,81 \\
\hline
\end{tabular}

A partir dos valores apresentados pelo índice $\mathrm{D}_{\text {Best }}$ em todos os testes da Tabela 5.9, espera-se que, em média, o investimento da melhor solução identificada em cada execução do AMC-PET seja apenas 1,68\% maior que o investimento da melhor solução conhecida $(385,819$ milhões de $\mathrm{R} \$)$. De acordo com o índice $\mathrm{D}_{10 \text { Best }}$, espera-se que o investimento médio das 10 melhores soluções encontradas em uma execução da rotina seja, em média, $10,14 \%$ maior que o investimento da melhor solução.

Em todos os testes da Tabela 5.9, as 30 execuções realizadas foram suficientes para encontrar as 10 melhores soluções conhecidas para esse problema (Tabela 5.8). Ou seja, o ajuste dos parâmetros não influenciou na identificação, em cada teste, das melhores soluções conhecidas. Na média de todos os testes, espera-se também para o cenário Norte Seco que a realização de, aproximadamente, 10 execuções seja suficiente para identificação das 10 melhores soluções conhecidas, conforme pode ser verificado na segunda coluna da Tabela 5.10. Nesta tabela, verifica-se que os Testes D.1, D.3, D.7 e D.8 são os que necessitam de mais exe- 
cuções para identificação das melhores soluções $\left(N_{\text {exc }}^{\min }\right.$ igual a $21,18,13$ e 18 , respectivamente). Contudo, caso fossem realizadas apenas as 10 primeiras execuções, seriam ainda assim identificadas 9 entre as 10 melhores soluções conhecidas pelos Testes D.1, D.3 e D.7 e 8 soluções pelo Teste D.8.

Tabela 5.10 - Testes D.1 a D.12: informações adicionais - SGSB - Cenário Norte Úmido.

\begin{tabular}{|c|r|c|}
\hline Teste & $N_{\text {exc }}^{\min }$ & $N C_{\text {conv }}^{\text {médio }}$ \\
\hline D.1 & 21 & 44,13 \\
\hline D.2 & 8 & 46,73 \\
\hline D.3 & 18 & 41,57 \\
\hline D.4 & 1 & 48,63 \\
\hline D.5 & 9 & 45,50 \\
\hline D.6 & 3 & 41,60 \\
\hline D.7 & 13 & 41,87 \\
\hline D.8 & 8 & 43,43 \\
\hline D.9 & 5 & 40,27 \\
\hline D.10 & 5 & 44,60 \\
\hline D.11 & 3 & 44,43 \\
\hline D.12 & 9,33 & 50,83 \\
\hline MÉDIA & & 44,47 \\
\hline
\end{tabular}

No processo construtivo do AMC-PET para o cenário Norte Úmido, a identificação da melhor solução ocorre, aproximadamente, com 24,47 níveis construtivos. Isto pode ser verificado a partir da média dos valores de $N C_{\text {conv }}^{\text {médio }}$ apresentados na terceira coluna da Tabela 5.10 para cada teste e do critério de convergência adotado $\left(n_{p}=20\right)$.

Retornando aos resultados da Tabela 5.9, é possível afirmar que os testes realizados apresentaram índices de desempenho com baixíssima variabilidade, o que indica que os conjuntos de parâmetros adotados não foram capazes de influenciar na qualidade dos resultados apresentada pelos testes, a qual se mostra muito elevada. Dessa forma, para o cenário Norte Úmido, poderia, por exemplo, ser considerada a utilização de tamanhos menores para os conjuntos $\Omega_{\mathrm{MA}}$ e $\Omega_{\mathrm{MCM}}$ e do critério de convergência.

Portanto, 12 novos testes foram então realizados, considerando como critério de convergência $n_{p}=10$, metade do valor considerando anteriormente, e os valores de $n_{\mathrm{AM}}$ e $n_{\mathrm{MCM}}$ variando conforme testes apresentados na Tabela 5.11. Os valores dos demais parâmetros foram mantidos. 
Tabela 5.11 - Resultados do AMC-PET com parâmetros reduzidos - SGSB - Cenário Norte Úmido.

\begin{tabular}{|c|c|c|c|c|c|c|c|c|c|}
\hline \multirow{3}{*}{ Teste } & \multicolumn{5}{|c|}{ Parâmetros do AMC-PET } & \multirow{2}{*}{\multicolumn{4}{|c|}{ Índices de Desempenho }} \\
\hline & \multicolumn{2}{|c|}{$\begin{array}{c}\text { Tamanho dos } \\
\text { Conjuntos }\end{array}$} & \multicolumn{3}{|c|}{ Distribuição de $n_{r}$} & & & & \\
\hline & $n_{\mathrm{MA}}$ & $n_{\mathrm{MCM}}$ & $I n d_{c h-i j}$ & Ind $d_{s c-i j}^{\text {proprio }}$ & Ind $d_{s c-i j}^{\text {outros }}$ & $\begin{array}{c}\mathbf{T}_{\mathbf{S}} \\
(\%)\end{array}$ & $\begin{array}{l}\mathbf{T}_{\mathbf{M}} \\
(\mathbf{h})\end{array}$ & $\begin{array}{l}\text { D }_{\text {Best }} \\
(\%)\end{array}$ & $\begin{array}{c}D_{\text {10Best }} \\
(\%)\end{array}$ \\
\hline D.17 & 20 & 20 & 1 & 1 & 2 & 100 & 0,32 & 3,11 & 12,95 \\
\hline D.18 & 20 & 20 & 1 & 2 & 1 & 100 & 0,30 & 2,87 & 12,57 \\
\hline D.19 & 20 & 20 & 1 & 2 & 2 & 100 & 0,32 & 2,91 & 12,25 \\
\hline D. 20 & 20 & 20 & 1 & 1 & 3 & 100 & 0,33 & 3,25 & 12,93 \\
\hline D.21 & 30 & 30 & 1 & 1 & 2 & 100 & 0,41 & 3,08 & 13,09 \\
\hline D.22 & 30 & 30 & 1 & 2 & 1 & 100 & 0,37 & 3,38 & 13,41 \\
\hline D. 23 & 30 & 30 & 1 & 2 & 2 & 100 & 0,43 & 3,72 & 13,38 \\
\hline D.24 & 30 & 30 & 1 & 1 & 3 & 100 & 0,42 & 2,87 & 12,40 \\
\hline D. 25 & 40 & 40 & 1 & 1 & 2 & 100 & 0,48 & 1,96 & 11,70 \\
\hline D.26 & 40 & 40 & 1 & 2 & 1 & 100 & 0,47 & 3,41 & 13,64 \\
\hline D. 27 & 40 & 40 & 1 & 2 & 2 & 100 & 0,49 & 3,21 & 13,02 \\
\hline D.28 & 40 & 40 & 1 & 1 & 3 & 100 & 0,52 & 3,38 & 13,36 \\
\hline
\end{tabular}

Verifica-se que, mesmo com a diminuição dos parâmetros, a taxa de sucesso $\left(\mathrm{T}_{\mathrm{S}}\right)$ permanece em $100 \%$ para todos os testes da Tabela 5.11. Pode ser verificado ainda que, embora haja um aumento (inteiramente aceitável) nos valores apresentados pelos índices $\mathrm{D}_{\text {Best }}$ e $\mathrm{D}_{10 \mathrm{Best}}$, um ganho elevado é observado no tempo médio de execução $\left(\mathrm{T}_{\mathrm{M}}\right)$. Comparando-se, por exemplo, os testes D.1 a D.8 da Tabela 5.9 com os testes D.21 a D.28 da Tabela 5.11, que utilizam os mesmos valores dos parâmetros $n_{\mathrm{MA}}$ e $n_{\mathrm{MCM}}(3030$ ou 4040 ), é verificada uma redução média de $43,11 \%$ para o índice $\mathrm{T}_{\mathrm{M}}$.

Dos 12 novos testes realizados considerando a redução dos parâmetros, apenas o Teste D.28 foi capaz de identificar, na totalidade, as melhores soluções conhecidas para o problema (Tabela 5.8). Contudo, os Testes D.17 a D.27, identificaram ainda assim, na média, $85,45 \%$ dessas soluções.

Finalmente, na média para estes testes, são necessários 23,36 níveis construtivos para convergência do AMC-PET. Dessa forma, considerando o emprego de $n_{p}=10$, espera-se que a identificação da melhor solução aconteça com, aproximadamente, 13,36 níveis construtivos. 


\subsection{3.}

\section{Cenários Norte Seco e Norte Úmido - Soluções Globais}

Apesar do número de reforços para atendimento do cenário Norte Úmido ser menor (Tabela 5.8) em comparação com o número de reforços apresentados pelas soluções identificadas para o cenário Norte Seco (Tabela 5.4), verifica-se que alguns reforços são exclusivos deste cenário. Conforme apresentado na Tabela 5.7 em comparação com a Tabela 5.3, por exemplo, um reforço a mais é necessário no ramo candidato 41 (7922-9265) para o cenário Norte Úmido e são ainda indicados para este cenário reforços nos ramos candidatos 24 (38857-7771) e 94 (73049180), os quais não apresentam reforços para o cenário Norte Seco. A partir dessas diferenças, e após análise da rede, é possível verificar que a melhor solução identificada para o cenário Norte Seco, apesar de conter um número maior de reforços, não atende ao cenário Norte Úmido. Sendo assim, é necessária a realização de um estudo para definição de soluções globais que sejam capazes de atender aos dois cenários simultaneamente.

Para definição dessas soluções, pode ser realizado, por exemplo, um estudo de sobreposição de reforços entre as melhores soluções identificadas para cada cenário. Selecionando-se, por exemplo, os 6 melhores planos de expansão do cenário Norte Seco (Tabela 5.4) e os 3 melhores para o cenário Norte Úmido (Tabela 5.8), são obtidos 18 novos planos por sobreposição simples dos reforços. Para o último cenário, que apresenta maior variação dos investimentos entre as 10 melhores soluções identificadas (Tabela 5.8), é selecionado um número menor de planos. A partir destas sobreposições, e considerando a existência de interseções entre os reforços, a solução com menor custo de investimento é obtida a partir da combinação entre a melhor solução identificada para o cenário Norte Seco (AMCNS.1) e a terceira melhor identificada para o cenário Norte Úmido (AMC-NU.3). Essa solução apresenta 24 reforços, distribuídos em 20 ramos candidatos, e um investimento de 869,062 milhões de R \$.

Entretanto, uma solução global construída pela sobreposição de soluções obtidas para os dois cenários pode apresentar reforços desnecessários para atendimento dos critérios "N-0" e "N-1", tanto em um quanto no outro cenário. Isso é possível, uma vez que reforços presentes na melhor solução de um cenário podem contribuir para distribuição do fluxo na rede para o outro, tornando desnecessária 
a construção de algum eventual reforço. Dessa forma, a fim de identificar um possível subconjunto de reforços que corresponda a uma solução de menor investimento para cada uma das 18 soluções obtidas por sobreposição dos reforços, pode ser empregado, por exemplo, o MR utilizado pelo AMC-PET. Neste mecanismo, conforme apresentado na Subseção 3.3.7, são avaliadas todas as possibilidades de eliminação de reforços e manutenção da viabilidade (factibilidade) dos planos resultantes. Neste caso, para identificação das soluções globais para o problema, cada solução avaliada durante o emprego do MR deve atender aos dois cenários.

Após realização de tal procedimento, as 10 melhores soluções identificadas, capazes de atender simultaneamente aos dois cenários considerados, são apresentadas na Tabela 5.12 a seguir.

Tabela 5.12 - Melhores soluções globais - SGSB.

\begin{tabular}{|c|c|c|c|}
\hline Plano & $\begin{array}{c}\text { Investimento } \\
\text { (milhões de R\$) }\end{array}$ & $\begin{array}{c}\text { Total de } \\
\text { Ramos }\end{array}$ & $\begin{array}{c}\text { Total de } \\
\text { Reforços }\end{array}$ \\
\hline AMC-SG.1 & 849,508 & 20 & 24 \\
\hline AMC-SG.2 & 852,577 & 20 & 24 \\
\hline AMC-SG.3 & 853,600 & 20 & 24 \\
\hline AMC-SG.4 & 856,669 & 20 & 24 \\
\hline AMC-SG.5 & 858,593 & 20 & 24 \\
\hline AMC-SG.6 & 861,662 & 20 & 24 \\
\hline AMC-SG.7 & 869,062 & 20 & 24 \\
\hline AMC-SG.8 & 872,131 & 20 & 24 \\
\hline AMC-SG.9 & 873,154 & 20 & 24 \\
\hline AMC-SG.10 & 875,461 & 21 & 25 \\
\hline
\end{tabular}

A melhor solução global identificada (AMC-SG.1) é derivada da sobreposição de reforços pertencentes às melhores soluções identificadas para cada cenário (AMC-NS.1 e AMC.NU.1), diferentemente do que ocorreu com a sobreposição simples das soluções. Os reforços que compõem este plano podem ser verificados na Tabela 5.13. Destes reforços, aqueles que pertencem aos ramos candidatos destacados em verde (9 reforços em 6 ramos candidatos) são comuns às obras indicadas pela EPE (44 circuitos nos ramos candidatos de 1 a 34 da Tabela B.3 no Apêndice B). Os demais reforços estão presentes em ramos definidos para a lista de candidatos a partir de análises de fluxo de potência na rede, conforme apresentado na Subseção 5.2.3 deste capítulo. 
Tabela 5.13 - Solução AMC-SG.1 - SGSB.

\begin{tabular}{|c|c|c|c|}
\hline \multicolumn{3}{|c|}{ Ramo Candidato } & \multirow{2}{*}{$\begin{array}{l}\text { Número de } \\
\text { Reforços }\end{array}$} \\
\hline $\mathbf{N}^{\circ}$ & DE & PARA & \\
\hline 2 & 6754 & 6602 & 2 \\
\hline 12 & 7749 & 7024 & 1 \\
\hline 17 & 7903 & 7731 & 2 \\
\hline 19 & 7980 & 7794 & 2 \\
\hline 24 & 38857 & 7771 & 1 \\
\hline 26 & 7024 & 6763 & 1 \\
\hline 39 & 47120 & 9261 & 1 \\
\hline 41 & 7922 & 9265 & 2 \\
\hline 46 & 7763 & 6651 & 1 \\
\hline 50 & 7762 & 7763 & 1 \\
\hline 53 & 6754 & 6601 & 1 \\
\hline 58 & 6651 & 6688 & 1 \\
\hline 67 & 9208 & 9209 & 1 \\
\hline 69 & 7734 & 7731 & 1 \\
\hline 77 & 6715 & 7042 & 1 \\
\hline 80 & 6619 & 7739 & 1 \\
\hline 82 & 7824 & 7823 & 1 \\
\hline 85 & 6649 & 6626 & 1 \\
\hline 86 & 7755 & 38857 & 1 \\
\hline 94 & 7304 & 9180 & 1 \\
\hline TOTAL & - & - & 24 \\
\hline
\end{tabular}

Portanto, aproximadamente $20,45 \%$ dos reforços presentes na melhor solução global definida são comuns aos reforços indicados pela EPE em [79]. Entretanto, cabe salientar que na definição das obras previstas para a região geoelétrica sul do Brasil e apresentadas em [79], são consideradas informações relativas ao problema que não são analisadas nesta tese. Como exemplo, pode ser citada a incapacidade, em termos de espaço físico, de alguma subestação (barra) considerada no problema PET receber a entrada de novas LTs. Este fato resultaria na impossibilidade de alguns ramos considerados como candidatos nesta tese de receberem reforços. Além disso, informações relacionadas à entrada futura de alguma usina ou grandes blocos de carga, ainda não representadas no sistema utilizado, podem definir a necessidade de reforços específicos. Podem também resultar no impedimento da construção de eventuais reforços, restrições ambientais não consideradas neste estudo. Sendo assim, a definição dos planos globais de expansão para o SGSB aqui realizada é baseada apenas na análise de comportamento da rede em termos de fluxo de potência e é altamente dependente da lista de ramos candidatos ao reforço considerada. 
De qualquer forma, o problema de planejamento da transmissão definido pode ser caracterizado como de grande porte e de difícil solução, sendo suficiente para demonstrar a capacidade da ferramenta AMC-PET proposta na identificação de bons planos de expansão.

\section{5 .}

\section{Análise de Desempenho: AMC-PET versus GA}

A fim de verificar o desempenho do AMC-PET na solução de problemas de grande porte, os resultados apresentados na seção anterior são comparados aos obtidos pelo emprego da metaheurística Algoritmo Genético (GA), uma técnica comumente empregada para solução do planejamento da transmissão.

O GA implementado nesta tese corresponde à sua versão clássica, a qual é baseada no emprego dos operadores de cruzamento e de mutação, com certa probabilidade (taxa de cruzamento e taxa de mutação), a indivíduos (planos de expansão) selecionados na geração corrente do algoritmo, com o intuito de formar novos indivíduos. Os indivíduos são gerados a cada iteração (geração) até que um critério de convergência seja atingido, por exemplo, a estagnação do melhor indivíduo identificado por um determinado número $n_{p-G A}$ de gerações. Os operadores de cruzamento e de mutação são idênticos aos mecanismos MC e MM apresentados nas Subseções 3.3.3 e 3.3.4. A seleção dos indivíduos para o emprego dos operadores, ou seja, a seleção dos indivíduos progenitores, é realizada com base em uma roleta criada a partir de suas respectivas aptidões. Nesta roleta, os indivíduos com melhores aptidões possuem maiores chances de serem selecionados. O tamanho da população de indivíduos, $N_{\text {Pop }}$, é um parâmetro a ser definido pelo planejador. A representação dos indivíduos no GA implementado é idêntica à representação utilizada no AMC-PET, conforme apresentado na Seção 3.2.

Na utilização da metaheurística GA, é necessária ainda a definição de uma população inicial de indivíduos, a qual pode ser gerada aleatoriamente ou utilizando alguma heurística baseada em informações do problema de otimização a ser solucionado, sendo esta última estratégia conhecida como inicialização "inteligente" [1]. Em relação à geração da população inicial, nesta tese foram consideradas três diferentes versões do GA para solução do problema PET: população inicial com todos os indivíduos gerados aleatoriamente (GA-01), população inicial com metade dos indivíduos gerados aleatoriamente e metade utilizando uma heurística 
construtiva (GA-02) e, por fim, população inicial com todos os indivíduos gerados por meio da heurística construtiva (GA-03). Excluindo a fase de geração da população inicial, as três versões implementadas da metaheurística GA são idênticas.

Nas subseções a seguir são apresentadas as metodologias utilizadas para geração das populações iniciais de cada versão implementada do GA. Os resultados obtidos em cada uma dessas versões, quando empregadas para solução do problema PET com o SGSB, são também apresentados e comparados aos resultados do AMC-PET.

\subsection{1. Populações Iniciais}

Para geração dos indivíduos da população inicial da versão GA-01, cada gene (posição do vetor plano de expansão) do indivíduo recebe reforços a partir do sorteio de um número pseudoaleatório. Com $5 \%$ de probabilidade, o gene recebe o valor 2 ( 2 reforços), com $10 \%$ de probabilidade, o gene recebe o valor 1 ( 1 reforço) e, com $85 \%$ de probabilidade, o gene recebe valor 0 (nenhum reforço). As probabilidades para adição de 0,1 ou 2 reforços foram ajustadas a fim de que os indivíduos resultantes possuam um total de reforços próximo daqueles apresentados pelos melhores indivíduos identificados pela ferramenta AMC-PET. Adotando esta estratégia, cada indivíduo gerado apresenta um número médio de reforços igual a, aproximadamente, 22. Cabe salientar que, caso não houvesse esta informação, seriam necessárias diversas simulações com o GA visando definir este número médio de reforços para os indivíduos da população inicial.

Já na versão GA-02, inicialmente é gerada a metade "inteligente" da população inicial, utilizando uma heurística construtiva. Nesta heurística, $N_{\text {Pop }} / 2$ indivíduos (planos de expansão) são construídos por meio da adição de reforços até que um critério de viabilidade relaxado seja atingido. Para viabilidade, é adotado o total atendimento do critério "N-0" e o atendimento do critério de segurança " $\mathrm{N}$ 1" relaxado, onde os equipamentos de transmissão podem apresentar até $30 \%$ de sobrecarga durante a avaliação de contingências. A adoção de um critério relaxado nesta fase do GA visa identificar indivíduos formados por um bom material genético sem, entretanto, apresentar um número elevado de reforços. Vale destacar que este critério de viabilidade, com "N-1" relaxado, só é adotado para construção da população inicial. Durante o processo de evolução do GA, os indivíduos 
são classificados como viáveis apenas quando são capazes de garantir o total atendimento da carga sem apresentar qualquer corte ou sobrecarga, tanto no " $\mathrm{N}-0$ " quanto no "N-1".

No emprego da heurística construtiva adotada na versão GA-02, é utilizado o conjunto $\Omega_{\text {PI }}$ (conjunto de indivíduos para população inicial inteligente). Neste conjunto são armazenados os indivíduos que já tenham atingido a viabilidade, ou seja, que atendam aos critérios "N-0" e "N-1" relaxado, Este conjunto é inicialmente vazio e recebe indivíduos até que possua $N_{\text {Pop }} / 2$ indivíduos, quando o processo construtivo termina. Com a convergência do processo construtivo, os indivíduos do conjunto $\Omega_{\text {PI }}$ passam a integrar a população inicial do GA.

Os seguintes passos compõem a heurística construtiva utilizada:

i) A partir da topologia base da rede (indivíduo vazio), criar e avaliar $n_{r c}$ indivíduos, cada um contendo apenas um reforço em cada um dos $n_{r c}$ ramos candidatos, e definir nível construtivo como primeiro;

ii) Verificar se algum indivíduo gerado no nível construtivo corrente é viável. Caso algum indivíduo seja viável, retirá-lo do processo construtivo e armazená-lo no conjunto $\Omega_{\mathrm{PI}}$;

iii) Se o número de indivíduos do $\Omega_{\mathrm{PI}}$ é igual a $N_{\text {Pop }} / 2$, fim do algoritmo. Caso contrário, seguir para o passo (iv);

iv) Se o número de indivíduos inviáveis gerados no nível construtivo atual é maior que $N_{\max }$, selecionar apenas os $N_{\max }$ melhores indivíduos em termos de aptidão para seguir no processo construtivo;

v) Incrementar nível construtivo;

vi) A partir de cada indivíduo no nível construtivo atual, criar e avaliar três novos indivíduos formados pela adição de um reforço em cada um dos ramos indicados pelos índices de atratividade definidos na Subseção 3.3.1 ( Ind $_{c h-i j}$, Ind $_{s c-i j}^{\text {próprio }}$ e Ind Ic-ij $\left._{\text {outros }}\right)$ e retornar ao passo (ii).

$\mathrm{Na}$ heurística construtiva, o passo (iv) garante a estabilização do número de indivíduos gerados a cada nível construtivo, de forma que não aconteça uma ex- 
plosão do número de indivíduos gerados e avaliados. O parâmetro $N_{\max }$ pode, por exemplo, ser considerado igual a $N_{\text {Pop }} / 2$.

No passo (vi), um eventual ramo que não possa ser avaliado pelos índices de atratividade pode também ser selecionado e definir um novo indivíduo a partir da taxa de adição, de forma idêntica à que é realizada no emprego do MA durante o processo construtivo do AMC-PET, conforme apresentado na Subseção 3.3.2.

Definidos $N_{\text {Pop }} / 2$ indivíduos utilizando a heurística construtiva, devem ser gerados os $N_{\text {Pop }} / 2$ indivíduos restantes para formação da população inicial. Para definição destes indivíduos, são sorteados aleatoriamente e adicionados reforços até que o investimento de cada indivíduo atinja o investimento médio apresentado pela primeira metade de indivíduos, gerada pela heurística construtiva.

Por fim, para geração da população inicial da versão GA-03, todos os $N_{\text {Pop }}$ indivíduos são gerados de forma "inteligente", utilizando a mesma heurística construtiva empregada pela versão GA-02. Portanto, na versão GA-03, o algoritmo converge quando o conjunto $\Omega_{\text {PI }}$ possui $N_{\text {Pop }}$ indivíduos.

\subsection{2. Resultados - GA}

Foram realizados dois testes utilizando cada versão implementada do GA, considerando dois diferentes tamanhos de população $\left(N_{\text {Pop }}=600\right.$ e 800$)$ e dois critérios de convergência $\left(n_{p-G A}=60\right.$ e 80). Cada teste consiste na realização de 30 execuções das rotinas implementadas (GA-01, GA-02 e GA-03) utilizando diferentes sementes para geração dos números pseudoaleatórios. Os resultados apresentados por estes testes, considerando inicialmente o cenário Norte Seco, estão apresentados na Tabela 5.14. Vale destacar que os índices de desempenho $\mathrm{T}_{\mathrm{S}}$, $D_{\text {Best }}$ e $D_{10 \text { Best }}$ apresentados pelo emprego da metaheurística GA foram calculados com base nas melhores soluções conhecidas para o problema, as quais correspondem às soluções presentes na Tabela 5.4.

Os valores $N_{\text {Pop }}=600$ e $n_{p-G A}=60$, adotados para realização dos testes com emprego da metaheurística GA e solução do problema PET para o cenário Norte Seco, foram definidos a fim de que, na média, o índice $T_{M}$ apresentasse valores próximos daqueles encontrados nos testes com o emprego do AMC-PET. Dessa forma, os demais índices de desempenho $\left(\mathrm{T}_{\mathrm{S}}, \mathrm{D}_{\text {Best }}\right.$ e $\left.\mathrm{D}_{10 \mathrm{Best}}\right)$ podem ser comparados de forma direta entre os resultados do GA e os resultados do AMC-PET. Já os 
valores $N_{\text {Pop }}=800$ e $n_{p-G A}=80$ foram adotados com o intuito de aprimorar o desempenho no emprego do GA.

Tabela 5.14 - Resultados do GA - SGSB - Cenário Norte Seco.

\begin{tabular}{|c|c|c|c|c|c|c|c||}
\hline \multirow{2}{*}{ Teste } & \multirow{2}{*}{ Versão do GA } & \multicolumn{3}{|c|}{ Parâmetros do GA } & \multicolumn{4}{|c|}{ Índices de Desempenho } \\
\cline { 3 - 8 } & & $\boldsymbol{N}_{\text {Pop }}$ & $\boldsymbol{n}_{p-\text { GA }}$ & $\begin{array}{c}\mathbf{T}_{\mathbf{S}} \\
(\boldsymbol{\%})\end{array}$ & $\begin{array}{c}\mathbf{T}_{\mathbf{M}} \\
(\mathbf{h})\end{array}$ & $\begin{array}{c}\mathbf{D}_{\text {Best }} \\
(\boldsymbol{\%})\end{array}$ & $\begin{array}{c}\mathbf{D}_{\mathbf{1 0 B e s t}} \\
(\%)\end{array}$ \\
\hline E.1 & GA-01 & 600 & 60 & 0 & 6,48 & 22,75 & 25,85 \\
\hline E.2 & GA-01 & 800 & 80 & 0 & 11,28 & 17,03 & 19,74 \\
\hline E.3 & GA-02 & 600 & 60 & 0 & 5,66 & 22,61 & 25,66 \\
\hline E.4 & GA-02 & 800 & 80 & 0 & 10,84 & 15,28 & 18,01 \\
\hline E.5 & GA-03 & 600 & 60 & 0 & 6,87 & 21,40 & 24,34 \\
\hline E.6 & GA-03 & 800 & 80 & 0 & 10,83 & 17,00 & 19,11 \\
\hline
\end{tabular}

É possível verificar a partir dos resultados apresentados na Tabela 5.14 valores mais elevados para os índices $\mathrm{D}_{\text {Best }}$ e $\mathrm{D}_{10 \mathrm{Best}}$ quando comparados aos apresentados pelo AMC-PET. Na média, para os testes com emprego da metaheurística GA, mesmo considerando aqueles com parâmetros mais elevados, os valores do índice $\mathrm{D}_{\text {Best }}$ são $211,30 \%$ maiores que para os valores apresentados por este índice nos Testes de C.1 a C.12 (Tabela 5.5) com o emprego do AMC-PET. Já para o índice $\mathrm{D}_{10 \mathrm{Best}}$, o aumento médio é de $99,43 \%$. Mesmo se forem comparados os menores valores dos índices $D_{\text {Best }}$ e $D_{10 \text { Best }}$ obtidos pelo $G A\left(D_{\text {Best }}=17,00 \%\right.$ e $\left.\mathrm{D}_{10 \mathrm{Best}}=18,01 \%\right)$ com os maiores valores encontrados nos testes com o AMCPET $\left(\mathrm{D}_{\text {Best }}=8,44 \%\right.$ e $\left.\mathrm{D}_{10 \mathrm{Best}}=13,68 \%\right)$, ainda assim é possível constatar o melhor desempenho apresentado pelo AMC-PET.

Por fim, é ainda mais impactante verificar que todos os testes da Tabela 5.14 apresentaram taxas de sucesso nulas, ou seja, $\mathrm{T}_{\mathrm{S}}$ é igual a $0 \%$ para todos os conjuntos de parâmetros. Isso significa que nenhuma das execuções dos testes realizados foi capaz de encontrar qualquer solução entre as 10 melhores identificadas pelo AMC-PET para o cenário Norte Seco. As informações sobre as 10 melhores soluções encontradas pelo GA para este cenário, considerando todas as três versões implementadas, estão apresentadas na Tabela 5.15.

Uma observação importante a ser destacada é que as melhores soluções da Tabela 5.15 foram encontradas apenas em uma execução do Teste E.4. Nenhum dos demais testes, em nenhuma de suas execuções, foi capaz de identificar qualquer uma dessas soluções. Quando o Teste E.4 não é considerado, a melhor solu- 
ção identificada com o GA apresenta investimento de 932,583 milhões de R\$ e é formada por 20 reforços, distribuídos em 17 ramos candidatos.

Tabela 5.15 - Melhores soluções do GA - SGSB - Cenário Norte Seco.

\begin{tabular}{|c|c|c|c|c|}
\hline Plano & $\begin{array}{c}\text { Investimento } \\
\text { (milhões de R\$) }\end{array}$ & $\begin{array}{c}\text { Perdas Ativas } \\
\text { (MW) }\end{array}$ & $\begin{array}{c}\text { Total de } \\
\text { Ramos }\end{array}$ & $\begin{array}{c}\text { Total de } \\
\text { Reforços }\end{array}$ \\
\hline GA-NS.1 & 881,707 & 592,304 & 19 & 22 \\
\hline GA-NS.2 & 916,750 & 593,708 & 20 & 23 \\
\hline GA-NS.3 & 918,309 & 591,506 & 20 & 24 \\
\hline GA-NS.4 & 919,527 & 591,714 & 20 & 23 \\
\hline GA-NS.5 & 919,731 & 590,315 & 20 & 23 \\
\hline GA-NS.6 & 921,573 & 593,172 & 19 & 23 \\
\hline GA-NS.7 & 921,818 & 593,160 & 19 & 24 \\
\hline GA-NS.8 & 922,892 & 591,840 & 21 & 23 \\
\hline GA-NS.9 & 923,946 & 591,307 & 20 & 23 \\
\hline GA-NS.10 & 925,460 & 590,221 & 20 & 23 \\
\hline
\end{tabular}

Quando o mecanismo de refinamento (MR), mecanismo que compõe o AMC-PET, é empregado ao conjunto das 10 melhores soluções identificadas pelo GA e apresentadas na Tabela 5.15, alguns eventuais reforços são ainda eliminados. As 10 melhores soluções resultantes do emprego do MR estão presentes na Tabela 5.16. É possível perceber que ainda assim, nenhum dos 10 melhores indivíduos conhecidos (Tabela 5.4) foi identificado.

Tabela 5.16 - Melhores soluções do GA com MR - SGSB - Cenário Norte Seco.

\begin{tabular}{||c|c|c|c|c||}
\hline Plano & $\begin{array}{c}\text { Investimento } \\
\text { (milhões de R\$) }\end{array}$ & $\begin{array}{c}\text { Perdas Ativas } \\
\text { (MW) }\end{array}$ & $\begin{array}{c}\text { Total de } \\
\text { Ramos }\end{array}$ & $\begin{array}{c}\text { Total de } \\
\text { Reforços }\end{array}$ \\
\hline GA-NS-MR.1 & 881,707 & 592,304 & 19 & 22 \\
\hline GA-NS-MR.2 & 887,722 & 592,344 & 19 & 22 \\
\hline GA-NS-MR.3 & 890,224 & 593,741 & 19 & 22 \\
\hline GA-NS-MR.4 & 890,791 & 591,537 & 19 & 22 \\
\hline GA-NS-MR.5 & 891,814 & 592,656 & 19 & 22 \\
\hline GA-NS-MR.6 & 894,883 & 591,849 & 19 & 22 \\
\hline GA-NS-MR.7 & 898,607 & 591,153 & 19 & 22 \\
\hline GA-NS-MR.8 & 901,308 & 591,900 & 19 & 22 \\
\hline GA-NS-MR.9 & 905,400 & 592,212 & 19 & 19 \\
\hline GA-NS-MR.10 & 907,691 & 590,385 & & 22 \\
\hline
\end{tabular}

Os mesmos testes realizados com o GA considerando o cenário Norte Seco, com as mesmas combinações de parâmetros, foram também realizados para solução do PET com o cenário Norte Úmido. Os resultados obtidos para estes testes estão presentes na Tabela 5.17 . 
Tabela 5.17 - Resultados do GA - SGSB - Cenário Norte Úmido.

\begin{tabular}{||c|c|c|c|c|c|c|c||}
\hline \multirow{2}{*}{ Teste } & \multirow{2}{*}{ Versão do GA } & \multicolumn{3}{|c|}{ Parâmetros do GA } & \multicolumn{3}{c|}{ Índices de Desempenho } \\
\cline { 3 - 8 } & & $N_{\text {Pop }}$ & $n_{p-G A}$ & $\begin{array}{c}\mathbf{T}_{\mathbf{S}} \\
(\%)\end{array}$ & $\begin{array}{c}\mathbf{T}_{\mathbf{M}} \\
(\mathbf{h})\end{array}$ & $\begin{array}{c}\mathbf{D}_{\text {Best }} \\
(\%)\end{array}$ & $\begin{array}{c}\mathbf{D}_{\mathbf{1 0 B e s t}} \\
(\%)\end{array}$ \\
\hline F.1 & GA-01 & 600 & 60 & 93,33 & 4,01 & 2,83 & 11,60 \\
\hline F.2 & GA-01 & 800 & 80 & 93,33 & 5,94 & 1,60 & 11,40 \\
\hline F.3 & GA-02 & 600 & 60 & 96,67 & 3,87 & 3,86 & 12,48 \\
\hline F.4 & GA-02 & 800 & 80 & 96,67 & 6,13 & 3,41 & 10,64 \\
\hline F.5 & GA-03 & 600 & 60 & 93,33 & 3,68 & 4,95 & 13,19 \\
\hline F.6 & GA-03 & 800 & 80 & 100,00 & 6,59 & 2,37 & 10,37 \\
\hline
\end{tabular}

Os índices de desempenho presentes na Tabela 5.17 foram calculados conforme melhores soluções conhecidas para o cenário Norte Úmido, as quais estão presentes na Tabela 5.8 .

Por se tratar de um problema menos complexo, que exige um número menor de reforços, é possível perceber taxas de sucesso $\left(\mathrm{T}_{\mathrm{S}}\right)$ bem elevadas apresentadas pelos testes utilizando o GA para o cenário Norte Úmido, diferentemente do ocorrido com o cenário Norte Seco. Além disso, todas as 10 melhores soluções conhecidas para o cenário Norte Úmido (Tabela 5.8) foram identificadas utilizando as três versões implementadas do GA.

Contudo, apesar da metaheurística GA apresentar melhores resultados para o cenário Norte Úmido em relação ao cenário Norte Seco, os índices de desempenho são ainda inferiores aos apresentados pelos testes realizados com emprego do AMC-PET, tanto na Tabela 5.9, com parâmetros mais elevados, quanto na Tabela 5.11, com parâmetros reduzidos. No primeiro caso, por exemplo, o AMC-PET apresenta um valor médio de $1,68 \%$ para o índice $\mathrm{D}_{\text {Best }}$, enquanto o valor médio deste índice para os testes realizados com emprego da metaheurística GA é de $3,17 \%$. Ou seja, em média, o $\mathrm{D}_{\text {Best }}$ é $88,78 \%$ maior para os testes com GA, sendo obtidos com tempo médio ( $\mathrm{T}_{\mathrm{M}}$ ) de processamento 459,63\% maior (i.e., 5,60 vezes o tempo médio do AMC-PET). Já o valor médio deste índice para os testes do AMC-PET com parâmetros reduzidos é de 3,10\%. Em relação a este último valor, o $\mathrm{D}_{\text {Best }}$ é 2,40\% maior para os testes realizados com GA, porém, são obtidos com tempo médio 1143,62\% maior (neste caso, o GA gastou, em média, 12,44 vezes o tempo do AMC-PET). 
Como já mencionado anteriormente, devido ao menor número de reforços necessários para atendimento do cenário Norte Úmido, maiores incrementos nos valores de investimentos são observados entre as melhores soluções identificadas (Tabela 5.8). Consequentemente, valores mais elevados são esperados para o índice $\mathrm{D}_{10 \text { Best }}$. Sendo assim, não cabe comparar o desempenho do AMC-PET e da metaheurística GA para este cenário a partir deste índice. Portanto, a fim de comparar o desempenho apontado pelo conjunto das melhores soluções obtidas a partir das ferramentas AMC-PET e GA para o cenário Norte Úmido, são então calculados os desvios percentuais médios apresentados pelos investimentos das três melhores soluções de cada teste realizado em relação ao investimento da melhor solução conhecida.

Com a metaheurística GA, o desvio médio apresentado pelas três melhores soluções de cada teste em relação à melhor solução é de 6,04\%, sendo, aproximadamente, 45,33\% maior que o desvio percentual médio calculado para os testes realizados com o AMC-PET da Tabela 5.9, que corresponde a 4,15\%. O desvio apresentado pelo GA é, ainda, 3,31\% maior que o desvio médio calculado para os testes da Tabela 5.11, que é de 5,84\%. Cabe ressaltar que, para este último caso, os resultados obtidos pelo AMC-PET foram obtidos 12,44 vezes mais rápido que os resultados obtidos pelo GA, e, ainda assim, apresentam menor desvio percentual médio entre aos investimentos das três melhores soluções e o investimento da melhor solução conhecida.

Por fim, análise importante pode ser ainda realizada em relação ao custo computacional $\left(\mathrm{T}_{\mathrm{M}}\right)$ necessário para solução do cenário Norte Úmido em relação ao cenário Norte Seco. Conforme já mencionado na Subseção 5.4.2, nos resultados apresentados pelo AMC-PET, verifica-se que os mesmos conjuntos de parâmetros foram utilizados para solução dos dois cenários (Tabela 5.5 e Tabela 5.9). Contudo, devido ao menor número de reforços necessários para o atendimento ao cenário Norte Úmido, houve uma redução média de 82,99\% do índice $\mathrm{T}_{\mathrm{M}}$, indicando uma adaptação expressiva e automática da ferramenta às dimensões do problema. Já a partir da metaheurística GA, para a qual os mesmos conjuntos de parâmetros também foram utilizados para solução dos dois cenários, foi verificada, na média, uma redução bem menos significativa para os valores do índice $\mathrm{T}_{M}$ no cenário Norte Úmido, de 41,84\%. Os números apresentados indicam que, sem qualquer alteração nos parâmetros adotados, o AMC-PET gastou no cenário Norte 
Úmido, em média, apenas $17,01 \%$ do tempo necessário para resolver o cenário Norte Seco, ou seja, foi 5,88 vezes mais rápido. Já para o GA, a adaptação foi bem menor, sendo necessário, em média, um tempo 58,16\% daquele gasto para o cenário Norte Seco. Portanto, com o emprego da metaheurística GA, e mantido o ajuste de parâmetros, o tempo médio de processamento para o Norte Úmido não cai nem pela metade em relação ao cenário Norte Seco.

\section{6.}

\section{Análise Complementar de Desempenho do AMC-PET}

Com o propósito de verificar o desempenho do AMC-PET quando é utilizado o mesmo conjunto de parâmetros para solução dos três diferentes sistemas abordados nesta tese, foram realizados novos testes com os sistemas IEEE-RTS e SSB. São eles os Testes A.42 e B.45, respectivamente. Os resultados para estes dois testes foram obtidos após 30 execuções do algoritmo e estão apresentados na Tabela 5.18 a seguir. Nestes novos testes, o AMC-PET é empregado considerando a utilização da estratégia de diversidade proposta na Seção 4.6 e também os ajustes da ferramenta propostos na Seção 5.3. Nesta mesma tabela, estão presentes, ainda, os resultados dos Testes C.2 e D.2 apresentados na Seção 5.4, realizados para o sistema SGSB (cenários Norte Seco e Norte Úmido, respectivamente) utilizando as mesmas condições para a ferramenta.

Tabela 5.18 - Análise de desempenho - Sistemas IEEE-RTS, SSB e SGSB.

\begin{tabular}{|c|c|c|c|c|c|c|c|}
\hline \multirow[b]{2}{*}{ Teste } & \multirow[b]{2}{*}{ Sistema } & \multirow[b]{2}{*}{$n_{p}$} & \multicolumn{4}{|c|}{ Índices de Desempenho } & \multirow[b]{2}{*}{$N C_{\text {conv }}^{\text {médio }}$} \\
\hline & & & $\begin{array}{c}\mathrm{T}_{\mathrm{S}} \\
(\%)\end{array}$ & $\begin{array}{c}\mathbf{T}_{M} \\
(\mathbf{m i n})\end{array}$ & $\begin{array}{l}D_{\text {Best }} \\
(\%)\end{array}$ & $\begin{array}{c}D_{10 B e s t} \\
(\%)\end{array}$ & \\
\hline A. 42 & IEEE-RTS & 6 & 100,00 & 0,40 & 0,00 & 1,33 & 23,40 \\
\hline B. 45 & SSB & 12 & 86,67 & 2,44 & 1,59 & 5,33 & 52,97 \\
\hline C. 2 & SGSB - NS & 20 & 63,33 & 244,80 & 4,38 & 8,74 & 101,43 \\
\hline D. 2 & SGSB - NU & 20 & 100,00 & 41,40 & 2,23 & 11,06 & 46,73 \\
\hline
\end{tabular}

Para os parâmetros do AMC-PET, os quais são discutidos na Seção 3.5, os seguintes valores foram considerados na realização de todos os testes da Tabela 5.18: o parâmetro $n_{r}$ é ajustado para seleção de 4 ramos, sendo selecionado 1 ramo pelo Ind $_{c h-i j}, 2$ pelo Ind Ic-ij $_{\text {prório }}$ e 1 pelo Ind ${ }_{s c-i j}^{\text {outros }}$; os tamanhos $n_{\mathrm{MA}}$ e $n_{\mathrm{MCM}}$ dos conjuntos $\Omega_{\mathrm{MA}}$ e $\Omega_{\mathrm{MCM}}$, respectivamente, são iguais a 30 ; o tamanho $n_{\mathrm{V}}$, do conjunto 
$\Omega_{\mathrm{V}}$, é igual para 50; as taxas de cruzamento e de mutação são, respectivamente, iguais a $65 \%$ e $8 \%$; e a taxa de adição, empregada no MA, é igual a 50\%. A única exceção em relação à definição dos parâmetros para os testes desta última tabela, corresponde ao critério de convergência $n_{p}$, o qual foi ajustado conforme valores apresentados na própria tabela.

Mediante todos os resultados apresentados e analisados nesta tese, verificase que o desempenho do AMC-PET pode ser refinado com ajuste de alguns parâmetros, principalmente dos tamanhos dos conjuntos $\Omega_{\mathrm{MA}}$ e $\Omega_{\mathrm{MCM}}$ e da distribuição do $n_{r}$ entre os índices de atratividade. Contudo, é possível constatar, a partir dos resultados presentes na Tabela 5.18, a grande robustez apresentada pelo AMCPET em relação a este ajuste. Verifica-se que, mesmo frente às diferentes dimensões dos problemas estudados, um só ajuste de parâmetros (exceção feita ao $n_{p}$ ) foi capaz de garantir boas soluções para o planejamento da transmissão para cada um dos sistemas utilizados. Este é um aspecto altamente positivo da metodologia proposta.

\section{7. Conclusões}

Neste capítulo são apresentadas todas as premissas adotadas para a proposição de um problema PET de grande porte, relativo à solução do planejamento da expansão com sistema real, o qual corresponde à região geoelétrica sul do Brasil. É definido um sistema cuja topologia base, referente ao ano de 2017, é composta por 242 barras e 345 ramos, com 467 circuitos. A rede é então planejada para atendimento da demanda para o ano de 2025. Dois cenários de carga e geração são considerados no estudo, os cenários Norte Seco e Norte Úmido.

Planos de expansão de excelente qualidade são obtidos para ambos os cenários com o emprego do AMC-PET para solução do problema real de grande porte. A partir dos índices de desempenho apresentados, é possível verificar uma preservação na qualidade das soluções identificadas para o problema mesmo com a variação dos parâmetros relativos à metodologia. Soluções globais para o problema, capazes de atender de forma simultânea aos dois cenários estudados, são definidas a partir de um estudo considerando as combinações entre as melhores soluções identificadas separadamente para cada um deles. 
A fim de verificar o desempenho do AMC-PET em relação a ferramentas já bastante empregadas para solução do problema PET, são expostos também neste capítulo resultados apresentados por três diferentes versões da metaheurística Algoritmo Genético (GA). A partir da comparação quantitativa dos resultados obtidos, via índices de desempenho, é possível comprovar a maior robustez e eficácia do AMC-PET na solução do problema de planejamento da expansão da transmissão de sistemas de grande porte. 


\section{6. \\ Conclusões e Trabalhos Futuros}

\section{1. Conclusões}

Esta tese apresenta uma nova metodologia para solução do problema de planejamento estático da expansão da transmissão, denominada algoritmo metaheurístico construtivo (AMC-PET). Um processo de construção de indivíduos (planos de expansão), paralelo, gradual, com intercâmbio de características genéticas, perturbação e depuração, constitui a nova metaheurística construtiva, a qual é empregada ao PET de longo prazo. Informações de operação do sistema para condição de rede intacta e sob contingência são utilizadas durante o processo construtivo para indicação de reforços a serem adicionados ou removidos da rede. Estas informações são traduzidas por meio de índices de sensibilidade. De forma geral, o método proposto se assemelha à forma como os planejadores do sistema procuram as melhores configurações de expansão de transmissão.

$\mathrm{O}$ critério determinístico de segurança " $\mathrm{N}-1$ " é adotado ao longo de todo o processo construtivo para produzir soluções de mais baixo custo, quando comparadas àquelas obtidas por metodologias que consideram as restrições de segurança apenas para as melhores soluções obtidas ao término do processo de otimização. O modelo DC, incluindo as perdas na transmissão, é utilizado para avaliação de desempenho das configurações obtidas pela metodologia proposta.

Dois sistemas de pequeno porte, comumente empregados por trabalhos relacionados à área, são utilizados para análise e ajuste dos parâmetros do AMC-PET. Em seguida, a fim de verificar o desempenho da ferramenta na identificação de reforços para uma rede real de grande porte, é definido um novo problema PET, o qual corresponde ao planejamento da rede básica para a região geoelétrica sul do Brasil. Para essa região é definido um sistema, denominado Sistema Geoelétrico Sul do Brasil (SGSB). Este sistema é composto por 242 barras e 345 ramos em sua topologia base, a qual corresponde ao ano de 2017. O ano de 2025 é considerado como horizonte de planejamento. Dois cenários de carga e geração são anali- 
sados na solução do problema, o cenário Norte Seco, com a região norte do país importadora de energia elétrica, e o cenário Norte Úmido, que corresponde à região norte do país exportadora.

A avaliação de desempenho do AMC-PET é realizada a partir de estudos estatísticos dos resultados obtidos em várias execuções do algoritmo, e é traduzida por meio de índices de desempenho adotados/propostos. Nestes estudos, não só a incidência e a qualidade da melhor solução identificada para cada sistema são avaliadas (índices $\mathrm{T}_{\mathrm{S}}$ e $\mathrm{D}_{\text {Best }}$, respectivamente), mas a qualidade do conjunto final das melhores soluções obtidas (índice $\mathrm{D}_{10 \mathrm{Best}}$ ) é também objeto de interesse. Este último aspecto é igualmente importante aos demais, pois oferece aos planejadores diferentes alternativas de expansão de boa qualidade. Ademais, é verificado, ainda, o desempenho relacionado ao tempo médio de processamento necessário para execução do algoritmo (índice $\mathrm{T}_{\mathrm{M}}$ ).

De acordo com os resultados obtidos em todas as aplicações, verifica-se que o AMC-PET proposto apresenta um excelente desempenho para solução do problema, não apenas em termos da melhor solução, mas também em relação à qualidade das melhores soluções construídas, o que é comprovado pelo conjunto de índices de desempenho.

Já os índices de sensibilidade (atratividade/efetividade) utilizados durante o processo construtivo apresentam grande eficiência na indicação de reforços, permitindo uma leitura atualizada do comportamento da rede a cada configuração analisada. Destaque pode ser dado aos índices de sobrecarga propostos neste trabalho, os quais utilizam as informações do estudo de contingências da rede.

Deve-se ressaltar que a metodologia implementada considera perdas ôhmicas e o critério "N-1", o que implica em um número muito elevado de soluções de problemas de otimização, principalmente para o sistema real de grande porte. Considerados os tempos médios necessários para solução do problema, pode-se assegurar que o método proposto apresenta alta eficiência computacional.

Por fim, cabe destacar o excelente desempenho apresentado pela ferramenta AMC-PET proposta em relação ao emprego da metaheurística Algoritmo Genético (GA), implementada em sua versão clássica. Além da acentuada melhor qualidade das soluções apresentadas, quando comparado ao GA, é possível verificar uma maior adaptação do AMC-PET em termos de custo computacional às dimensões do problema em solução. 


\section{2.}

\section{Propostas de Trabalhos Futuros}

Partindo da metodologia proposta nesta tese de doutorado e dos resultados verificados com o seu emprego a problemas diversificados de planejamento da expansão da transmissão, são apresentadas a seguir as principais ações vislumbradas para continuidade do estudo:

- Aprimoramento do algoritmo metaheurístico construtivo (AMC-PET) proposto nesta tese. Para este fim, podem ser realizados:

- Estudos de estratégias para ajuste adaptativo dos parâmetros presentes na metodologia, a fim de reduzir a necessidade de interferência do planejador;

- Adaptações no critério de convergência do processo iterativo presente no AMC-PET, de forma que não apenas a estagnação da melhor solução seja verificada, mas também a qualidade das melhores soluções em construção;

- Aperfeiçoamento dos índices de sensibilidade utilizados pelos mecanismos de adição (MA) e de depuração (MD) empregados pelo AMC-PET, bem como a proposição de novos;

- Ajustes da estratégia de diversidade empregada pelo mecanismo de seleção (MS) do AMC-PET a fim de evitar o direcionamento do processo construtivo para regiões do espaço de solução que não contenham planos de boa qualidade, porém mantendo a sua capacidade de diversificação. Novas técnicas de diversidade podem também ser verificadas;

- Adaptações para solução simultânea do PET considerando dois ou mais cenários. Ou seja, durante o processo construtivo, realizar, simultaneamente, a avaliação de cada indivíduo com base em todos os cenários a serem atendidos; 
- Implementação de novos procedimentos visando aplicar o AMC-PET em problemas com elevada participação de fontes renováveis intermitentes.

- Realização de um estudo de mapeamento em relação à qualidade dos índices de confiabilidade e ao custo de investimento necessário para expansão do sistema a partir de análises relaxadas do subproblema de operação (versões relaxadas do critério "N-1"). Ou seja, verificar, em termos de confiabilidade, a resposta da rede reforçada pelas soluções identificadas para o PET considerando pequenos valores de sobrecarga nos equipamentos de transmissão, conforme proposto por [31]. Espera-se que a tolerância de pequenas violações na capacidade térmica dos circuitos não cause um relevante impacto na qualidade de funcionamento do sistema. Por outro lado, espera-se uma significativa redução nos montantes de investimento necessários;

- Realização de implementações à metodologia atual para considerar o planejamento a multiestágio (ou dinâmico) da transmissão;

- Incorporação do problema de compensação reativa da rede durante a solução do PET, ao menos considerando o conjunto final de soluções viáveis do AMC-PET. 


\section{7. \\ Referências bibliográficas}

1. REZENDE, L. S. Planejamento da Expansão de Sistemas de Transmissão: Avaliação de Metaheurísticas e Critérios de Segurança. Tese de Doutorado - UNIFEI. Itajubá. 2011.

2. FISCHL, R. Optimal System Expansion: A Critical Review. System Engineering for Power: Status \& Prospects, ERDA \& EPRI Conf. Henniker: [s.n.]. 1975.

3. LATORRE, G. et al. Classification of Publications and Models on Transmission Planning. IEEE Transactions on Power Systems, 18, May 2003. 938-946.

4. LEE, C. W. et al. Transmission Expansion Planning From Past to Future. Proceeding of Power Systems Conference and Exposition - PSCE. Atlanta: [s.n.]. 2006. p. 257-265.

5. HEMMATI, R.; HOOSHMAND, R. A.; KHODABAKHSHIAN, A. State-ofthe-Art of Transmission Expansion Planning: Comprehensive Review. Renewable and Sustainable Energy Reviews 23, p. 312-319, 2013.

6. LUMBRERAS, S.; RAMOS, A. The new Challenges to Transmission Expansion Planning. Survey of Recent Practice and Literature Review. Electric Power Systems Research - EPSR, May 2016. 19-29.

7. RODRIGUEZ, J. I. R.; FALCÃO, D. M.; TARANTO, G. N. Planejamento da Expansão da Transmissão de Curto Prazo Utilizando Modelo CA com Restrições Dinâmicas de Segurança. Anais do XI SEPOPE. Belém: [s.n.]. 2009.

8. ROMERO, R. et al. Test Systems and Mathematical Models for Transmission Network Expansion Planning. IEE Proceedings - Gener. Transm. Distrib., 149, Jan. 2002. 27-36.

9. RIDER, M. J.; GARCIA, A. V.; ROMERO, R. Power System Transmission Network Expansion Planning Using AC Model. IET Gener. Transm. Distrib., 1, 2007. 731-742.

10. AlGUACIL, N.; MOTTO, A. L.; CONEJO, A. J. Transmission Expansion Planning: A Mixed-Integer LP Approach. IEEE Transactions on Power Systems, 18, Aug. 2003. 1070-1077. 
11. LEITE DA SILVA, A. M. et al. Tabu Search Applied to transmission Expansion Planning Considering Losses and Interruption Costs. Proceedings of 10th PMAPS. Rincón: [s.n.]. 2008. p. 25-29.

12. LEITE DA SILVA, A. M. et al. Transmission Expansion Planning: A Discussion on Reliability and "N-1" Security Criteria. Proceedings of the 11th PMAPS. Singapore: [s.n.]. 2010. p. 244-251.

13. DELGADO, M. A. J.; RIDER, M. J. Algoritmo Branch and Bound Não Linear para Resolver o Problema de Planejamento da Expansão de Sistemas de Transmissão. Anais do V SBSE. Foz do Iguaçu: [s.n.]. 2014. p. $1-6$.

14. POUBEL, R. P. B. et al. A Coupled Model to Multistage Transmission Expansion Planning. Journal of Control, Automation and Electrical Systems - SBA, v. 26, p. 272-282, 2015.

15. ESCOBAR, A. H.; GALlEGO, R. A.; ROMERO, R. Multistage and Coordinated Planning of the Expansion of Transmission Systems. IEEE Transactions on Power Systems, 19, May 2004. 735-744.

16. LEITE DA SILVA, A. M. et al. Performance Comparison of Metaheuristics to Solve the Multi-stage Transmission Expansion Planning Problem. IET Gener. Transm. Distrib., 5, 2011. 360-367.

17. POUBEL, R. P. B. et al. Tree Searching Heuristic Algorithm for Multi-stage Transmission Planning Considering Security Constraints via Genetic Algorithm. Electric Power Systems Research - EPSR, 142, 2017. 290-297.

18. LI, W.; CHOUDHURY, P. Probabilistic Transmission Planning. IEEE Power and Energy Magazine, v. 5, p. 46-53, Sep.-Oct. 2007.

19. LEITE DA SILVA, A. M. et al. Pseudo-Chronological Simulation for Composite Reliability Analysis with Time Varying Loads. IEEE Transactions on Power Systems, 15, Feb. 2000. 73-80.

20. MANSO, L. A. F. et al. Constructive Heuristic Algorithm for Subtransmission System Planning. Proceedings of 18th PSCC. Wroclaw: [s.n.]. 2014.

21. ABREU, P. E. et al. Planejamento da Expansão de Redes de Transmissão Considerando o Custo da Confiabilidade. Anais do XXI SNPTEE. Florianópolis: [s.n.]. 2011. p. 1-9.

22. MANSO, L. A. F. et al. Transmission Expansion Planning Including Unreliability Costs. Proceedings of 12th PMAPS. Instanbul: [s.n.]. 2012. p. $1-6$. 
23. GARVER, L. L. Transmission Network Estimation Using Liner Programming. IEEE Transaction on Power Apparatus and Systems, PAS89, Sep. 1970. 1688-1697.

24. DUSONCHET, Y. P.; EL-ABIAD, A. H. Discrete Optimization and the Planning of Electric Power Networks. IEEE Transactions on Circuit Theory, CT-20, May 1973. 230-238.

25. MONTICELLI, A. et al. Interactive Transmission Network Planning Using a Least-Effort Criterion. IEEE Transactions on Power Apparatus and Systems, PAS-101, Oct. 1982. 3919-3925.

26. VILLASANA, R.; GARVER, L. L.; SALON, S. J. Transmission Network Planning Using Linear Programming. IEEE Transactions on Power Apparatus and Systems, PAS-104, Feb. 1985. 349-356.

27. ROMERO, R.; MONTICELLI, A. A Hierarchical Decomposition Approach for Transmission Network Expansion Planning. IEEE Transactions on Power Systems, 9, Feb. 1994. 373-380.

28. ROMERO, R. et al. Analysis of Heuristic Algorithms for the Transportation Model in Static and Multistage Planning in Network Expasion Systems. IEE Proceedings - Gener. Transm. Distrib., 150, Set. 2003. 521-526.

29. BRAGA, A. S. D.; SARAIVA, J. T. Transmission Expansion Planning and Long Term Marginal Prices Calculation Using Simulated Annealing. IEEE Bologna PowerTech Conference. Bolonga, Italy: [s.n.]. 2003.

30. ROMERO, R. et al. Constructive Heuristic Algorithm for the DC Model in Network Transmission Expansion Planning. IEE Proceedings - Gener. Transm., 152, 2005. 277-282.

31. LEITE DA SILVA, A. M.; FREIRE, M. R.; HONÓRIO, L. M. Transmission Expansion Planning Optimization by Adaptative Multi-operator Evolutionary Algorithms. Electric Power Systems Research - EPSR, v. 133, p. 173-181, 2016.

32. KHORASANI, H.; POURAKBARI-KASMAEI, M.; ROMERO, R. A Heuristic Method for Transmission Network Expansion Planning under Security Constraints. Proceedings of IEPEM. Istanbul: [s.n.]. 2013. p. 1-7.

33. BINATO, S.; PEREIRA, M. V. F.; GRANVILLE, S. A New Benders Decomposition Approach to Solve Power Transmission Network Design Problems. IEEE Transactions on Power Systems, 16, May 2001. 235-240.

34. BAHIENSE, L. et al. A Mixed Integer Disjunctive Model for Transmission Network Expansion. IEEE Transactions on Power Systems, 19, Aug. 2001. 560-565. 
35. OLIVEIRA, G. C.; BINATO, S.; PEREIRA, M. V. F. Value-Based Transmission Expansion Planning of Hydrothermal Systems Under Uncertainty. IEEE Transactions on Power Systems, 22, Nov. 2007. 1429-1435.

36. MOREIRA, A.; STREET, A.; ARROYO, J. M. An Adjustable Robust Optimization Approach for Contingency-Constrained Transmission Expansion Planning. IEEE Transactions on Power Systems, 30, Jul. 2015. 2013-2022.

37. YOUSSEF, H. K.; HACKAM, R. New Transmission Planning Model. IEEE Transactions on Power Systems, 4, Feb. 1989. 9-18.

38. MANSO, L. A. F. et al. Metodologia para o Planejamento de Reforços em Reforços em Sistemas de Subtransmissão. Anais do XIII SEPOPE. Foz do Iguaçu: [s.n.]. 2014.

39. SILVA, I. J. et al. Transmission Network Expansion Planning with Security Constraints. IEE Proces. - Gener. Transm. Distrib., 152, Nov. 2005. 828-836.

40. CHOI, J. et al. A Method for Composite Power System Expansion Planning Considering Probabilistic Reliability Criteria. IEEE Power Engineering Society General Meeting, 2, 2005. 1270-1276.

41. CHOI, J.; MOUNT, T. D.; THOMAS, R. J. Transmission Expansion Planning Using Contingency Criteria. IEEE Transactions on Power Systems, 22, Nov. 2007. 2249-2261.

42. ROMERO, R.; MONTICELLI, A. A Zero-One Enumeration Method for Optmizing Investments in Transmission Expansion Planning. IEEE Transactions on Power Systems, 9, Aug. 1994. 1385-1391.

43. HAFFNER, S. et al. Branch and Bound Algorithm for Transmission System Expansion Planning Using a Transportation Model. IEE Gener. Transm. Distrib., 147, May 2000. 149-156.

44. PEREIRA, M. V. F. et al. A Decomposition Approach to Automated Generation/Transmission Expansion Planning. IEEE Transactions on Power Apparatus and Systems, PAS-104, Nov. 1985. 3074-3083.

45. SÖRENSEN, K.; GLOVER, F. Metaheuristics. In: GASS, S. I.; FU, M. C. Encyclopedia of Operations Research and Management Science. New York: Springer US, 2013. p. 960-970.

46. TALBI, E.-G. Metaheuristics: From Design to Implementation. New Jersey: John Wiley \& Son, 2009.

47. ROMERO, R.; GALlEGO, R. A.; MONTICELLI, A. Transmission System Expansion Planning by Simulated Annealing. IEEE Transactions on Power Systems, 11, Feb. 1996. 364-369. 
48. GALLEGO, R. A. et al. Parallel Simulated Annealing Applied to Long Term Transmission Network Expansion Planning. IEEE Transactions on Power Systems, 12, Feb. 1997. 181-188.

49. BRAGA, A. S. D.; SARAIVA, J. T. A Multiyear Dynamic Approach for Transmission Expansion Planning and Long-Term Marginal Costs Computation. IEEE Transactions on Power Systems, 20, Aug. 2005. 16311639.

50. MORI, H.; SONE, Y. A Parallel Tabu Search Based Approach to Transmission Network Expansion Planning. IEEE Porto Power Tech Conference. Porto: [s.n.]. 2001.

51. BINATO, S.; OLIVEIRA, G. C.; ARAÚJO, J. L. A Greedy Randomized Adaptive Search Procedure for Transmission Exapansion Plannig. IEEE Trasactions on Power Systems, 16, May 2001. 247-253.

52. SENSARMA, P. S.; RAHMANI, M.; CARVALHO, A. A Comprehensive Method for Optimal Expansion Planning Using Particle Swarm Optimization. IEEE Power Engineering Society Winter Meeting, 2, 2002. 1317-1322.

53. YUEHUI, C. et al. An Improved Particle Swarm Optimization Algorithm for Multistage and Coordinated Planning of Transmission Systems. Proceeding of Transmission and Distribuition Conference and Exhibition. Dalian: [s.n.]. 2005. p. 1-6.

54. YU, Q.; GUO, J.; DUAN, X. Dynamic Multi-stage Transmission Network Expansion Planning. Proceeding of DRPT. Nanjuing: [s.n.]. 2008. p. 635640.

55. MENDONÇA, I. M.; SILVA JUNIOR, I. C.; MARCATO, A. L. M. Static Planning of the Expansion of Electrical Energy Transmission Systems Using Particle Swarm Optimization. Electrical Power and Energy Systems EPES, 60, 2014. 234-244.

56. REZENDE, L. S.; LEITE DA SILVA, A. M.; HONÓRIO, L. M. Artificial Immune Systems and Differential Evolution Based Approaches Applied to Multi-Stage Transmission Expansion Planning. Proceedings of the 15th ISAP. Curitiba: [s.n.]. 2009. p. 1-6.

57. LEITE DA SILVA, M. et al. Evolution Strategies to Transmission Expansion Planning Considering Unreliability Costs. Proceedings of 9th PMAPS. Stockholm: [s.n.]. 2006. p. 1-7.

58. ROMERO, R.; RIDER, M. J.; SILVA, I. J. A Metaheuristic to Solve the Transmission Expansion Planning. IEEE Transactions on Power Systems, 22, Nov. 2007. 2289-2291. 
59. FEO, T. A.; RESENDE, M. G. C. Greedy Randomized Adaptive Search Procedures. Journal of Global Optimization, 6, 1995. 109-133.

60. FARIA JR, H. et al. Power Transmission Network Design by Greedy Randomized Adaptive Path Relinking. IEEE Transactions on Power Systems, 20, Feb. 2005. 43-49.

61. REZENDE, L. S. et al. Planejamento da Expansão da Transmissão Utilizando Colônia de Formigas. Anais do XVI CBA. Salvador: [s.n.]. 2006.

62. LEITE DA SILVA, A. M. et al. Metaheuristic-Based Optimization Methods for Transmission Expansion Planning Considering Unreliability Costs. In: Optimization Advances in Electric Power Systems. [S.1.]: Nova Publishers, 2008. Cap. Chapter 4, p. 59-86.

63. LEITE DA SILVA, A. M. et al. Reliability Worth Applied to Transmission Expansion Planning based on Ant Colony System. Electrical Power and Energy Systems - EPES, 32, 2010. 1077-1084.

64. KAKUTA, K.; MORI, K. A Multi-objective Memetic Algorithm for Probabilistic Transmission Network Expansion Planning. Systems Man and Cybernetics - SMC. Istanbul: [s.n.]. 2010. p. 1414-1419.

65. KHORASANI, H. Algoritmo Tabu Search Especializado para o Problema de Planejamento da Expansão de Sistemas de Transmissão. Ilha Solteira. Fev. 2015.

66. MORI, H.; IIMURA, Y. Transmission Network Expansion Planning with a Hybrid Meta-Heuristic Method of Parrallel Tabu Search and Ordinal Optimization. Intelligent Systems Applications to Power Systems. Toki Messe: [s.n.]. 2007. p. 1-6.

67. BARROS, J. R. P. Planejamento da Expansão da Transmissão Baseado em Custos Marginais de Confiabilidade. Itajubá. Ago. 2004.

68. ARROYO, J. M.; ALGUACIL, N.; CARRIÓN, M. A Risk-Based Approach for Transmission Network Expansion Planning Under Deliberate Outages. IEEE Transactions on Power Systems, 25, Aug. 2010. 1759-1766.

69. JIA, Y. et al. Risk-Based Power System Security Analysis Considering Cascading Outages. IEEE Transactions on Industrial Informatics, 2, April 2016. 872-882.

70. PEREIRA, M. V. F.; BALU, N. J. Composite Generation/Transmission Reliability Evaluation. Proceedings of the IEEE, 80, Ago. 1992. 470-491.

71. MANSO, L. A. F.; LEITE DA SILVA, A. M. Probabilistic Criteria for Power System Expansion Planning. Electric Power Syst. Research, 69, 2004. 51-58. 
72. LI, W.; CHOUDHURY, P. Probabilistic Planning of Transmission Systems: Why, How and an Actual Example. IEEE Power Engineering Society General Meeting, 2008. 1-8.

73. GOLDBERG, D. E. Genetic Algorithms in Search, Optimization and Machine Learning. [S.1.]: Addison-Wesley Publishing Company, 1989.

74. RELIABILITY TEST SYSTEM TASK FORCE OF THE IEEE SUBCOMMITTEE ON THE APPLICATION OF PROBABILITY METHODS. IEEE Reliability Test System. IEEE Transactions on Power Apparatus and Systems, PAS-98, Nov./Dez. 1979. 2047-2054.

75. FANG, R.; HILL, D. J. A New Strategy for Transmission Expansion in Competitive Electricity Markets. IEEE Transactions on Power Systems, 18, Fev. 2003. 374-380.

76. ASSIS, F. A. Metodologias de Suporte ao Planejamento de Reforços em Sistemas de Subtransmissão. Dissertação de Mestrado - UFSJ. São João delRei. 2014.

77. MACQUEEN, J. B. Some Methods for classification and Analysis of Multivariate Observations. Proc. 5th Berkeley Symp. on Mathematical Statistics and Probability. EUA, Berkeley: [s.n.]. 1967. p. 281-297.

78. LEITE DA SILVA, A. M. et al. Constructive MetaheuristicsApplied to Transmission Expansion Planning with Security Constraints. 19th ISAP. San Antonio, TX, USA: [s.n.]. 2017. p. 1-7.

79. EMPRESA DE PESQUISA ENERGÉTICA - EPE. Estudos para Expansão da Transmissão - Consolidação das Análises e Pareceres Técnicos - Ciclo 2016 - $2^{\circ}$ Semestre. Rio de Janeiro. 2016.

80. ONS. Operador Nacional do Sistema Elétrico - Mapas do SIN. Disponivel em: <http://ons.org.br/pt/paginas/sobre-o-sin/mapas>. Acesso em: 14 Novembro 2017.

81. AGÊNCIA NACIONAL DE ENERGIA ELÉTRICA - ANEEL. Atlas de Energia Elétrica do Brasil. 2. ed. Brasília: [s.n.], 2005. 


\section{Apêndice A. \\ Dados dos sistemas de pequeno porte}

\section{A.1. IEEE-RTS}

O diagrama do Sistema IEEE-RTS pode ser visualizado na Figura A.1 a seguir. Os dados de barra para este sistema estão presentes na Tabela A.1. Os dados de ramos candidatos ao reforço para o estudo PET são apresentados na Tabela A.2. Nesta última tabela, os ramos de 1 a 34 possuem circuitos em operação na topologia base da rede, já os ramos de 35 a 41 correspondem a ramos novos.

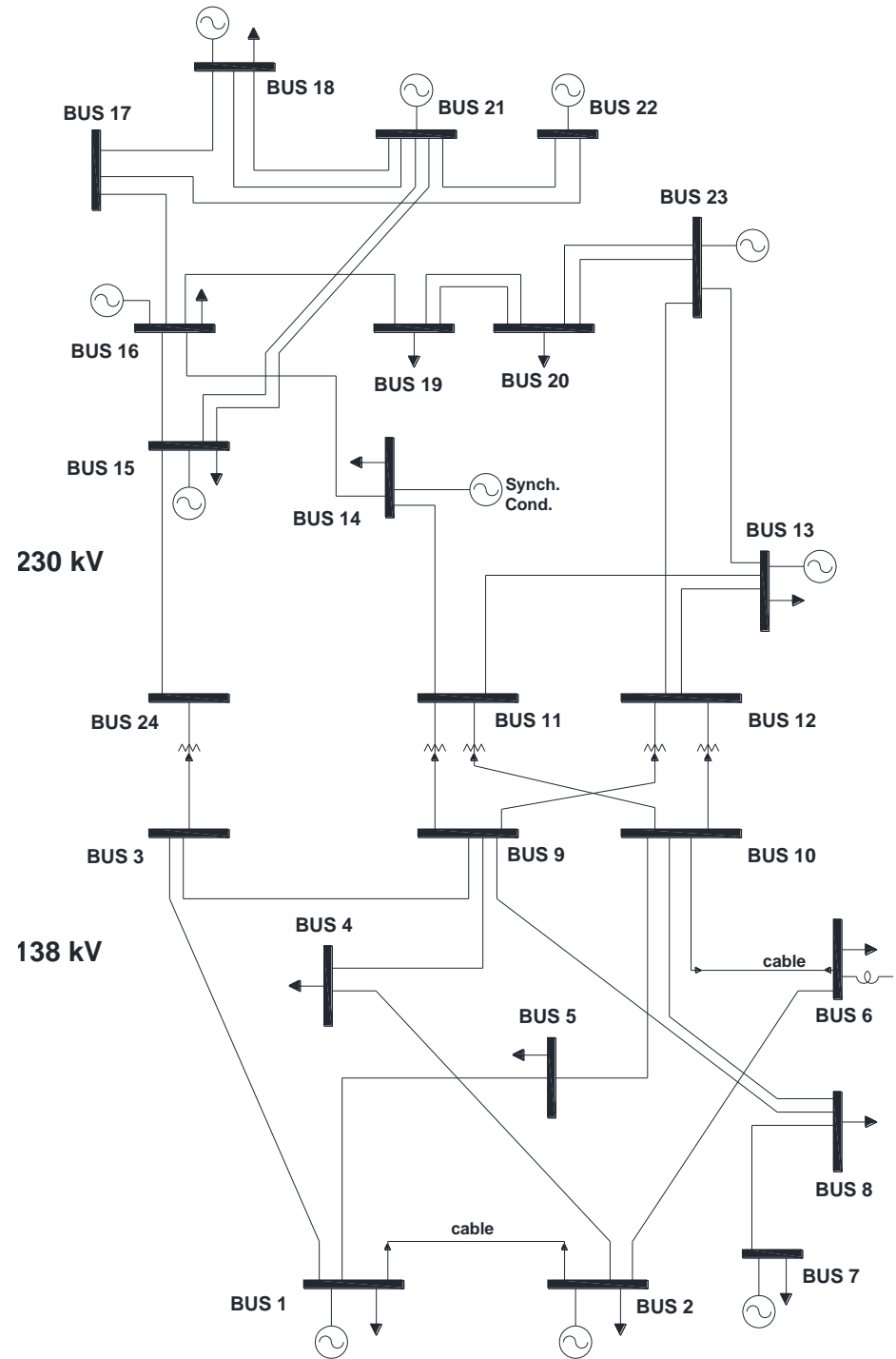

Figura A.1 - Diagrama do IEEE-RTS [74]. 
Tabela A.1 - Dados de barra - IEEE-RTS.

\begin{tabular}{|c|c|c|c|c|}
\hline Barra & $\begin{array}{l}\text { Carga } \\
\text { (MW) }\end{array}$ & $\begin{array}{c}\text { Geração } \\
\text { Máxima } \\
\text { (MW) }\end{array}$ & $\begin{array}{c}\text { Prioridade } \\
\text { no Despacho } \\
\text { da Geração }\end{array}$ & $\begin{array}{c}\text { Nível de } \\
\text { Tensão } \\
(\mathbf{k V )}\end{array}$ \\
\hline 01 & 324 & 576 & 3 & 138 \\
\hline 02 & 291 & 576 & 1 & 138 \\
\hline 03 & 540 & 0 & - & 138 \\
\hline 04 & 222 & 0 & - & 138 \\
\hline 05 & 213 & 0 & - & 138 \\
\hline 06 & 408 & 0 & - & 138 \\
\hline 07 & 375 & 900 & 2 & 138 \\
\hline 08 & 513 & 0 & - & 138 \\
\hline 09 & 525 & 0 & - & 138 \\
\hline 10 & 585 & 0 & - & 138 \\
\hline 11 & 0 & 0 & - & 230 \\
\hline 12 & 0 & 0 & - & 230 \\
\hline 13 & 795 & 1773 & 4 & 230 \\
\hline 14 & 582 & 0 & - & 230 \\
\hline 15 & 951 & 645 & 5 & 230 \\
\hline 16 & 300 & 465 & 7 & 230 \\
\hline 17 & 0 & 0 & - & 230 \\
\hline 18 & 999 & 1200 & 9 & 230 \\
\hline 19 & 543 & 0 & - & 230 \\
\hline 20 & 384 & 0 & - & 230 \\
\hline 21 & 0 & 1200 & 8 & 230 \\
\hline 22 & 0 & 900 & 10 & 230 \\
\hline 23 & 0 & 1980 & 6 & 230 \\
\hline 24 & 0 & 0 & - & 230 \\
\hline TOTAL: & 8850 & 10215 & & \\
\hline
\end{tabular}


Tabela A.2 - Dados de ramos candidatos - IEEE-RTS.

\begin{tabular}{|c|c|c|c|c|c|c|c|}
\hline $\mathbf{N}^{\circ}$ & DE & PARA & $\begin{array}{l}\text { Circuitos } \\
\text { existentes }\end{array}$ & $\begin{array}{c}\boldsymbol{R}_{i j} \\
\text { (p.u.) }\end{array}$ & $\begin{array}{c}X_{i j} \\
\text { (p.u.) }\end{array}$ & $\begin{array}{l}f_{i j}^{\max } \\
\text { (MW) }\end{array}$ & $\begin{array}{c}c_{i j} \\
\text { (milhões de \$) }\end{array}$ \\
\hline 01 & 01 & 02 & 1 & 0,0026 & 0,0139 & 175 & 3 \\
\hline 02 & 01 & 03 & 1 & 0,0546 & 0,2112 & 175 & 55 \\
\hline 03 & 01 & 05 & 1 & 0,0218 & 0,0845 & 175 & 22 \\
\hline 04 & 02 & 04 & 1 & 0,0328 & 0,1267 & 175 & 33 \\
\hline 05 & 02 & 06 & 1 & 0,0497 & 0,1920 & 175 & 50 \\
\hline 06 & 03 & 09 & 1 & 0,0308 & 0,1190 & 175 & 31 \\
\hline 07 & 03 & 24 & 1 & 0,0023 & 0,0839 & 400 & 50 \\
\hline 08 & 04 & 09 & 1 & 0,0268 & 0,1037 & 175 & 27 \\
\hline 09 & 05 & 10 & 1 & 0,0228 & 0,0883 & 175 & 23 \\
\hline 10 & 06 & 10 & 1 & 0,0139 & 0,0605 & 175 & 16 \\
\hline 11 & 07 & 08 & 1 & 0,0159 & 0,0614 & 175 & 16 \\
\hline 12 & 08 & 09 & 1 & 0,0427 & 0,1651 & 175 & 43 \\
\hline 13 & 08 & 10 & 1 & 0,0427 & 0,1651 & 175 & 43 \\
\hline 14 & 09 & 11 & 1 & 0,0023 & 0,0839 & 400 & 50 \\
\hline 15 & 09 & 12 & 1 & 0,0023 & 0,0839 & 400 & 50 \\
\hline 16 & 10 & 11 & 1 & 0,0023 & 0,0839 & 400 & 50 \\
\hline 17 & 10 & 12 & 1 & 0,0023 & 0,0839 & 400 & 50 \\
\hline 18 & 11 & 13 & 1 & 0,0061 & 0,0476 & 500 & 66 \\
\hline 19 & 11 & 14 & 1 & 0,0054 & 0,0418 & 500 & 58 \\
\hline 20 & 12 & 13 & 1 & 0,0061 & 0,0476 & 500 & 66 \\
\hline 21 & 12 & 23 & 1 & 0,0124 & 0,0966 & 500 & 134 \\
\hline 22 & 13 & 23 & 1 & 0,0111 & 0,0865 & 500 & 120 \\
\hline 23 & 14 & 16 & 1 & 0,0050 & 0,0389 & 500 & 54 \\
\hline 24 & 15 & 16 & 1 & 0,0022 & 0,0173 & 500 & 24 \\
\hline 25 & 15 & 21 & 2 & 0,0063 & 0,0490 & 500 & 68 \\
\hline 26 & 15 & 24 & 1 & 0,0067 & 0,0519 & 500 & 72 \\
\hline 27 & 16 & 17 & 1 & 0,0033 & 0,0259 & 500 & 36 \\
\hline 28 & 16 & 19 & 1 & 0,0030 & 0,0231 & 500 & 32 \\
\hline 29 & 17 & 18 & 1 & 0,0018 & 0,0144 & 500 & 20 \\
\hline 30 & 17 & 22 & 1 & 0,0135 & 0,1053 & 500 & 146 \\
\hline 31 & 18 & 21 & 2 & 0,0033 & 0,0259 & 500 & 36 \\
\hline 32 & 19 & 20 & 2 & 0,0051 & 0,0396 & 500 & 55 \\
\hline 33 & 20 & 23 & 2 & 0,0028 & 0,0216 & 500 & 30 \\
\hline 34 & 21 & 22 & 1 & 0,0087 & 0,0678 & 500 & 94 \\
\hline 35 & 01 & 08 & 0 & 0,0174 & 0,1344 & 500 & 35 \\
\hline 36 & 02 & 08 & 0 & 0,0164 & 0,1267 & 500 & 33 \\
\hline 37 & 06 & 07 & 0 & 0,0249 & 0,1920 & 500 & 50 \\
\hline 38 & 13 & 14 & 0 & 0,0058 & 0,0447 & 500 & 62 \\
\hline 39 & 14 & 23 & 0 & 0,0080 & 0,0620 & 500 & 86 \\
\hline 40 & 16 & 23 & 0 & 0,0106 & 0,0822 & 500 & 114 \\
\hline 41 & 19 & 23 & 0 & 0,0078 & 0,0606 & 500 & 84 \\
\hline
\end{tabular}


A.2.

SSB

O diagrama simplificado do Sistema Sul Brasileiro (SSB) é apresentado na Figura A.2. Os dados relativos às barras da rede são apresentados na Tabela A.3. Por fim, os dados dos ramos candidatos ao reforço estão presentes na Tabela A.4. Dentre estes ramos, os 47 primeiros (ramos de 1 a 47) possuem circuitos na topologia base do sistema, já os 32 ramos restantes (ramos de 48 a 79) configuram novos caminhos para o reforço da rede no estudo PET.

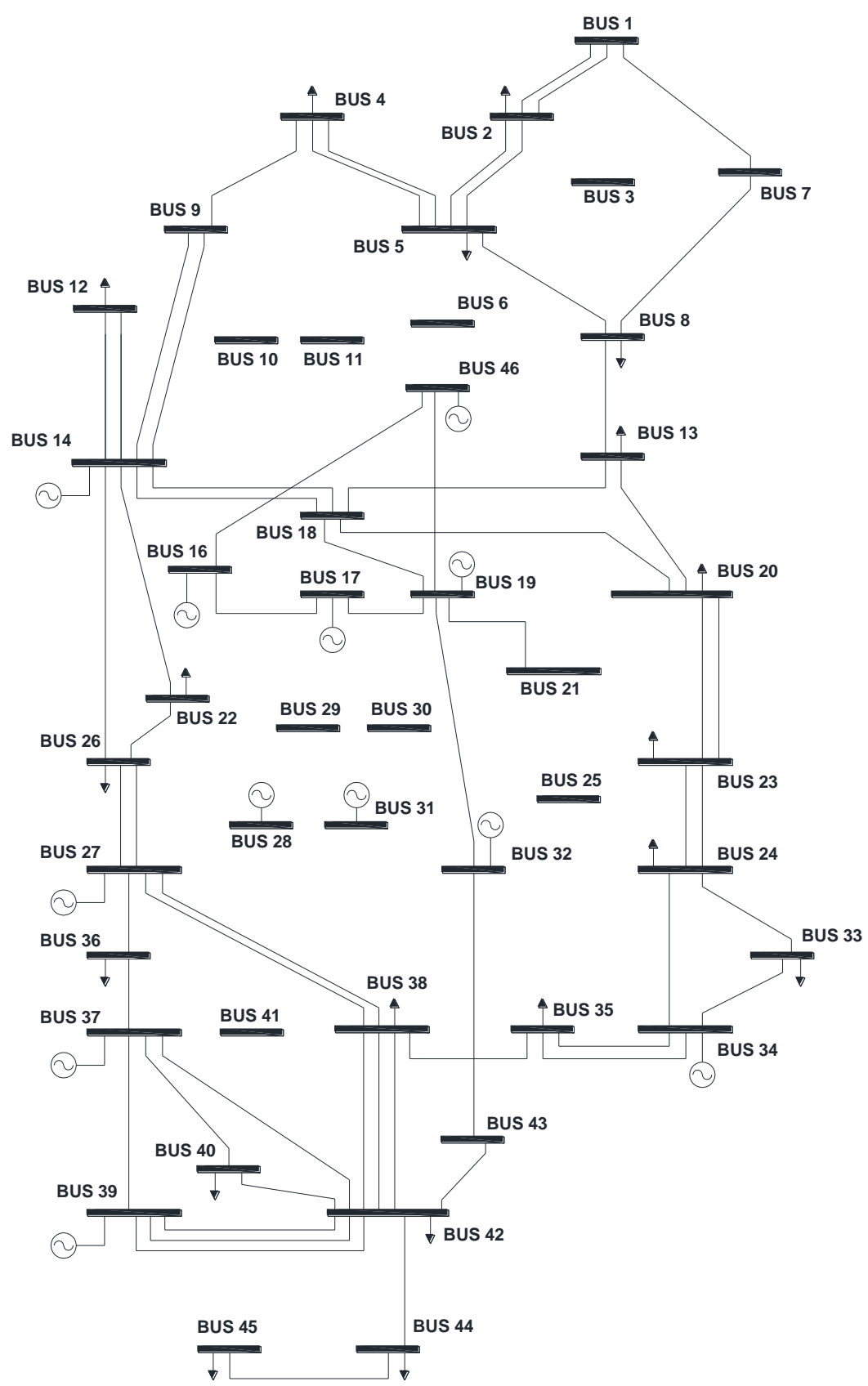

Figura A.2 - Diagrama do SSB [43]. 
Tabela A.3 - Dados de barra - SSB.

\begin{tabular}{|c|c|c|c|c|}
\hline Barra & $\begin{array}{l}\text { Carga } \\
(\mathbf{M W})\end{array}$ & $\begin{array}{c}\text { Geração } \\
\text { Máxima } \\
\text { (MW) }\end{array}$ & $\begin{array}{c}\text { Prioridade } \\
\text { no Despacho } \\
\text { da Geração }\end{array}$ & $\begin{array}{c}\text { Nível de } \\
\text { Tensão } \\
(\mathbf{k V )}\end{array}$ \\
\hline 01 & 0 & 0 & - & 230 \\
\hline 02 & 443,1 & 0 & - & 230 \\
\hline 03 & 0 & 0 & - & 500 \\
\hline 04 & 300,7 & 0 & - & 230 \\
\hline 05 & 238 & 0 & - & 230 \\
\hline 06 & 0 & 0 & - & 500 \\
\hline 07 & 0 & 0 & - & 230 \\
\hline 08 & 72,2 & 0 & - & 230 \\
\hline 09 & 0 & 0 & - & 230 \\
\hline 10 & 0 & 0 & - & 500 \\
\hline 11 & 0 & 0 & - & 230 \\
\hline 12 & 511,9 & 0 & - & 230 \\
\hline 13 & 185,8 & 0 & - & 230 \\
\hline 14 & 0 & 1257 & 10 & 230 \\
\hline 15 & 0 & 0 & - & 230 \\
\hline 16 & 0 & 2000 & 11 & 500 \\
\hline 17 & 0 & 1050 & 2 & 500 \\
\hline 18 & 0 & 0 & - & 230 \\
\hline 19 & 0 & 1670 & 1 & 500 \\
\hline 20 & 1091,2 & 0 & - & 230 \\
\hline 21 & 0 & 0 & - & 500 \\
\hline 22 & 81,9 & 0 & - & 230 \\
\hline 23 & 458,1 & 0 & - & 230 \\
\hline 24 & 478,2 & 0 & - & 230 \\
\hline 25 & 0 & 0 & - & 500 \\
\hline 26 & 231,9 & 0 & - & 230 \\
\hline 27 & 0 & 220 & 6 & 230 \\
\hline 28 & 0 & 800 & 12 & 500 \\
\hline 29 & 0 & 0 & - & 230 \\
\hline 30 & 0 & 0 & - & 500 \\
\hline 31 & 0 & 700 & 8 & 500 \\
\hline 32 & 0 & 500 & 7 & 500 \\
\hline 33 & 229,1 & 0 & - & 230 \\
\hline 34 & 0 & 748 & 5 & 230 \\
\hline 35 & 216 & 0 & - & 230 \\
\hline 36 & 90,1 & 0 & - & 230 \\
\hline 37 & 0 & 300 & 9 & 230 \\
\hline 38 & 216 & 0 & - & 230 \\
\hline 39 & 0 & 600 & 3 & 230 \\
\hline 40 & 262,1 & 0 & - & 230 \\
\hline 41 & 0 & 0 & - & 500 \\
\hline 42 & 1607,9 & 0 & - & 230 \\
\hline 43 & 0 & 0 & - & 500 \\
\hline 44 & 79,1 & 0 & - & 230 \\
\hline 45 & 86,7 & 0 & - & 230 \\
\hline 46 & 0 & 700 & 4 & 500 \\
\hline TOTAL: & 6880 & 10545 & & \\
\hline
\end{tabular}


Tabela A.4 - Dados de ramos candidatos - SSB.

\begin{tabular}{|c|c|c|c|c|c|c|c|}
\hline $\mathbf{N}^{\circ}$ & DE & PARA & $\begin{array}{l}\text { Circuitos } \\
\text { existentes }\end{array}$ & $\begin{array}{c}\boldsymbol{R}_{i j} \\
\text { (p.u.) }\end{array}$ & $\begin{array}{c}X_{i i} \\
\text { (p.u.) }\end{array}$ & $\begin{array}{l}f_{i j}^{\max } \\
\text { (MW) }\end{array}$ & $\begin{array}{c}c_{i j} \\
(\text { milhões de \$) }\end{array}$ \\
\hline 01 & 01 & 07 & 1 & 0,00616 & 0,0616 & 270 & 4,349 \\
\hline 02 & 01 & 02 & 2 & 0,01065 & 0,1065 & 270 & 7,076 \\
\hline 03 & 04 & 09 & 1 & 0,00924 & 0,0924 & 270 & 6,217 \\
\hline 04 & 05 & 09 & 1 & 0,01173 & 0,1173 & 270 & 7,732 \\
\hline 05 & 05 & 08 & 1 & 0,01132 & 0,1132 & 270 & 7,480 \\
\hline 06 & 07 & 08 & 1 & 0,01023 & 0,1023 & 270 & 6,823 \\
\hline 07 & 04 & 05 & 2 & 0,00566 & 0,0566 & 270 & 4,046 \\
\hline 08 & 02 & 05 & 2 & 0,00324 & 0,0324 & 270 & 2,581 \\
\hline 09 & 08 & 13 & 1 & 0,01348 & 0,1348 & 240 & 8,793 \\
\hline 10 & 09 & 14 & 2 & 0,01756 & 0,1756 & 220 & 11,267 \\
\hline 11 & 12 & 14 & 2 & 0,00740 & 0,0740 & 270 & 5,106 \\
\hline 12 & 14 & 18 & 2 & 0,01514 & 0,1514 & 240 & 9,803 \\
\hline 13 & 13 & 18 & 1 & 0,01805 & 0,1805 & 220 & 11,570 \\
\hline 14 & 13 & 20 & 1 & 0,01073 & 0,1073 & 270 & 7,126 \\
\hline 15 & 18 & 20 & 1 & 0,01997 & 0,1997 & 200 & 12,732 \\
\hline 16 & 19 & 21 & 1 & 0,00278 & 0,0278 & 1500 & 32,632 \\
\hline 17 & 16 & 17 & 1 & 0,00078 & 0,0078 & 2000 & 10,505 \\
\hline 18 & 17 & 19 & 1 & 0,00061 & 0,0061 & 2000 & 8,715 \\
\hline 19 & 14 & 26 & 1 & 0,01614 & 0,1614 & 220 & 10,409 \\
\hline 20 & 14 & 22 & 1 & 0,00840 & 0,0840 & 270 & 5,712 \\
\hline 21 & 22 & 26 & 1 & 0,00790 & 0,0790 & 270 & 5,409 \\
\hline 22 & 20 & 23 & 2 & 0,00932 & 0,0932 & 270 & 6,268 \\
\hline 23 & 23 & 24 & 2 & 0,00774 & 0,0774 & 270 & 5,308 \\
\hline 24 & 26 & 27 & 2 & 0,00832 & 0,0832 & 270 & 5,662 \\
\hline 25 & 24 & 34 & 1 & 0,01647 & 0,1647 & 220 & 10,611 \\
\hline 26 & 24 & 33 & 1 & 0,01448 & 0,1448 & 240 & 9,399 \\
\hline 27 & 33 & 34 & 1 & 0,01265 & 0,1265 & 270 & 8,288 \\
\hline 28 & 27 & 36 & 1 & 0,00915 & 0,0915 & 270 & 6,167 \\
\hline 29 & 27 & 38 & 2 & 0,02080 & 0,2080 & 200 & 13,237 \\
\hline 30 & 36 & 37 & 1 & 0,01057 & 0,1057 & 270 & 7,025 \\
\hline 31 & 34 & 35 & 2 & 0,00491 & 0,0491 & 270 & 3,591 \\
\hline 32 & 35 & 38 & 1 & 0,01980 & 0,198 & 200 & 12,631 \\
\hline 33 & 37 & 39 & 1 & 0,00283 & 0,0283 & 270 & 2,329 \\
\hline 34 & 37 & 40 & 1 & 0,01281 & 0,1281 & 270 & 8,389 \\
\hline 35 & 37 & 42 & 1 & 0,02105 & 0,2105 & 200 & 13,388 \\
\hline 36 & 39 & 42 & 3 & 0,02030 & 0,2030 & 200 & 12,934 \\
\hline 37 & 40 & 42 & 1 & 0,00932 & 0,0932 & 270 & 6,268 \\
\hline 38 & 38 & 42 & 3 & 0,00907 & 0,0907 & 270 & 6,116 \\
\hline 39 & 32 & 43 & 1 & 0,00309 & 0,0309 & 1400 & 35,957 \\
\hline 40 & 42 & 44 & 1 & 0,01206 & 0,1206 & 270 & 7,934 \\
\hline 41 & 44 & 45 & 1 & 0,01864 & 0,1864 & 200 & 11,924 \\
\hline 42 & 19 & 32 & 1 & 0,00195 & 0,0195 & 1800 & 23,423 \\
\hline 43 & 46 & 19 & 1 & 0,00222 & 0,0222 & 1800 & 26,365 \\
\hline 44 & 46 & 16 & 1 & 0,00203 & 0,0203 & 1800 & 24,319 \\
\hline 45 & 18 & 19 & 1 & 0,00125 & 0,0125 & 600 & 8,178 \\
\hline 46 & 20 & 21 & 1 & 0,00125 & 0,0125 & 600 & 8,178 \\
\hline 47 & 42 & 43 & 1 & 0,00125 & 0,0125 & 600 & 8,178 \\
\hline 48 & 02 & 04 & 0 & 0,00882 & 0,0882 & 270 & 5,965 \\
\hline 49 & 14 & 15 & 0 & 0,00374 & 0,0374 & 270 & 2,884 \\
\hline 50 & 46 & 10 & 0 & 0,00081 & 0,0081 & 2000 & 10,889 \\
\hline
\end{tabular}


(continuação Tabela A.4)

\begin{tabular}{|c|c|c|c|c|c|c|c|}
\hline $\mathbf{N}^{\circ}$ & DE & PARA & $\begin{array}{c}\text { Circuitos } \\
\text { existentes }\end{array}$ & $\begin{array}{c}\boldsymbol{R}_{i j} \\
\text { (p.u.) }\end{array}$ & $\begin{array}{c}X_{i j} \\
\text { (p.u.) }\end{array}$ & $\begin{array}{l}f_{i j}^{\max } \\
(\mathbf{M W})\end{array}$ & $\begin{array}{c}c_{i j} \\
\text { (milhões de \$) }\end{array}$ \\
\hline 51 & 04 & 11 & 0 & 0,02246 & 0,2246 & 240 & 14,247 \\
\hline 52 & 05 & 11 & 0 & 0,00915 & 0,0915 & 270 & 6,167 \\
\hline 53 & 46 & 06 & 0 & 0,00128 & 0,0128 & 2000 & 16,005 \\
\hline 54 & 46 & 03 & 0 & 0,00203 & 0,0203 & 1800 & 24,319 \\
\hline 55 & 16 & 28 & 0 & 0,00222 & 0,0222 & 1800 & 26,365 \\
\hline 56 & 16 & 32 & 0 & 0,00311 & 0,0311 & 1400 & 36,213 \\
\hline 57 & 17 & 32 & 0 & 0,00232 & 0,0232 & 1700 & 27,516 \\
\hline 58 & 19 & 25 & 0 & 0,00325 & 0,0325 & 1400 & 37,748 \\
\hline 59 & 21 & 25 & 0 & 0,00174 & 0,0174 & 2000 & 21,121 \\
\hline 60 & 25 & 32 & 0 & 0,00319 & 0,0319 & 1400 & 37,109 \\
\hline 61 & 31 & 32 & 0 & 0,00046 & 0,0046 & 2000 & 7,052 \\
\hline 62 & 28 & 31 & 0 & 0,00053 & 0,0053 & 2000 & 7,819 \\
\hline 63 & 28 & 30 & 0 & 0,00058 & 0,0058 & 2000 & 8,331 \\
\hline 64 & 27 & 29 & 0 & 0,00998 & 0,0998 & 270 & 6,672 \\
\hline 65 & 26 & 29 & 0 & 0,00541 & 0,0541 & 270 & 3,894 \\
\hline 66 & 28 & 41 & 0 & 0,00339 & 0,0339 & 1300 & 39,283 \\
\hline 67 & 28 & 43 & 0 & 0,00406 & 0,0406 & 1200 & 46,701 \\
\hline 68 & 31 & 41 & 0 & 0,00278 & 0,0278 & 1500 & 32,632 \\
\hline 69 & 32 & 41 & 0 & 0,00309 & 0,0309 & 1400 & 35,957 \\
\hline 70 & 41 & 43 & 0 & 0,00139 & 0,0139 & 2000 & 17,284 \\
\hline 71 & 40 & 45 & 0 & 0,02205 & 0,2205 & 180 & 13,994 \\
\hline 72 & 15 & 16 & 0 & 0,00125 & 0,0125 & 600 & 8,178 \\
\hline 73 & 46 & 11 & 0 & 0,00125 & 0,0125 & 600 & 8,178 \\
\hline 74 & 24 & 25 & 0 & 0,00125 & 0,0125 & 600 & 8,178 \\
\hline 75 & 29 & 30 & 0 & 0,00125 & 0,0125 & 600 & 8,178 \\
\hline 76 & 40 & 41 & 0 & 0,00125 & 0,0125 & 600 & 8,178 \\
\hline 77 & 02 & 03 & 0 & 0,00125 & 0,0125 & 600 & 8,178 \\
\hline 78 & 05 & 06 & 0 & 0,00125 & 0,0125 & 600 & 8,178 \\
\hline 79 & 09 & 10 & 0 & 0,00125 & 0,0125 & 600 & 8,178 \\
\hline
\end{tabular}




\section{Apêndice B. \\ Dados do sistema de grande porte (SGSB)}

Os dados de carga e geração para cada cenário do Sistema Geoelétrico Sul do Brasil (SGSB) considerado nesta tese para o estudo PET, bem como as demais informações das barras do sistema, estão presentes na Tabela B.1 a seguir. As informações dos ramos com circuitos existentes na topologia base deste sistema são apresentadas na Tabela B.2. Finalmente, os dados relativos aos ramos candidatos ao reforço são apresentados na Tabela B.3. Nesta tabela, a cada ramo candidato estão associados dois custos, $c_{i j}^{1}$ e $c_{i j}^{2}$, que correspondem, respectivamente, aos custos de se adicionar um reforço ou dois reforços no ramo $i-j$. Nos ramos destinados à construção de transformadores e de LTs em circuitos simples, $c_{i j}^{1}$ corresponde a $50 \%$ de $c_{i j}^{2}$. Já nos ramos destinados à construção de LTs com opção para circuito duplo, $c_{i j}^{1}$ corresponde a $62,5 \%$ de $c_{i j}^{2}$.

Tabela B.1 - Dados de barra - SGSB.

\begin{tabular}{|c|r|r|r|r|c|c|c||}
\hline \multirow{3}{*}{ Barra } & \multicolumn{2}{|c|}{$\begin{array}{c}\text { Carga } \\
\text { (MW) }\end{array}$} & \multicolumn{2}{c|}{$\begin{array}{c}\text { Despacho Geração } \\
\text { (MW) }\end{array}$} & \multicolumn{2}{c|}{$\begin{array}{c}\text { Prioridade no Des- } \\
\text { pacho da Geração }\end{array}$} & $\begin{array}{c}\text { Nível de } \\
\text { Tensão } \\
\text { (kV) }\end{array}$ \\
\cline { 2 - 9 } & $\begin{array}{c}\text { C. Norte } \\
\text { Seco }\end{array}$ & $\begin{array}{c}\text { C. Norte } \\
\text { Úmido }\end{array}$ & $\begin{array}{c}\text { C. Norte } \\
\text { Seco }\end{array}$ & $\begin{array}{c}\text { C. Norte } \\
\text { Úmido }\end{array}$ & $\begin{array}{c}\text { C. Norte } \\
\text { Seco }\end{array}$ & $\begin{array}{c}\text { C. Norte } \\
\text { Úmido }\end{array}$ & \\
\hline 4290 & 0 & 0 & 215 & 603 & 21 & 10 & 230 \\
\hline 6190 & 44 & 44 & 0 & 0 & - & - & 230 \\
\hline 6601 & 160 & 152 & 0 & 0 & - & - & 230 \\
\hline 6602 & 46 & 0 & 0 & 0 & - & - & 230 \\
\hline 6603 & 78 & 0 & 0 & 0 & - & - & 230 \\
\hline 6608 & 0 & 0 & 298 & 0 & 16 & - & 230 \\
\hline 6615 & 207 & 173 & 0 & 0 & - & - & 230 \\
\hline 6616 & 211 & 190 & 0 & 0 & - & - & 230 \\
\hline 6617 & 204 & 173 & 0 & 0 & - & - & 230 \\
\hline 6618 & 181 & 159 & 0 & 0 & - & - & 230 \\
\hline 6619 & 150 & 117 & 0 & 0 & - & - & 230 \\
\hline 6623 & 26 & 26 & 0 & 0 & - & - & 230 \\
\hline 6624 & 266 & 266 & 0 & 0 & - & - & 230 \\
\hline 6625 & 0 & 0 & 0 & 0 & - & - & 230 \\
\hline 6626 & 0 & 0 & 0 & 0 & - & - & 525 \\
\hline 6627 & 145 & 130 & 0 & 0 & - & - & 230 \\
\hline 6628 & 196 & 0 & 0 & 2020 & - & 35 & 525 \\
\hline 6629 & 14 & 14 & 0 & 0 & - & - & 230 \\
\hline 6630 & 0 & 0 & 0 & 0 & - & - & 525 \\
\hline 6649 & 0 & 0 & 1472 & 1587 & 53 & 2 & 525 \\
\hline
\end{tabular}

(continua) 
(continuação Tabela B.1)

\begin{tabular}{|c|c|c|c|c|c|c|c|}
\hline \multirow{2}{*}{ Barra } & \multicolumn{2}{|c|}{$\begin{array}{l}\text { Carga } \\
\text { (MW) }\end{array}$} & \multicolumn{2}{|c|}{$\begin{array}{c}\text { Despacho Geração } \\
\text { (MW) }\end{array}$} & \multicolumn{2}{|c|}{$\begin{array}{l}\text { Prioridade no Des- } \\
\text { pacho da Geração }\end{array}$} & \multirow{2}{*}{$\begin{array}{c}\text { Nível de } \\
\text { Tensão } \\
\text { (kV) }\end{array}$} \\
\hline & $\begin{array}{l}\text { C. Norte } \\
\text { Seco }\end{array}$ & $\begin{array}{l}\text { C. Norte } \\
\text { Úmido }\end{array}$ & $\begin{array}{l}\text { C. Norte } \\
\text { Seco }\end{array}$ & $\begin{array}{l}\text { C. Norte } \\
\text { Úmido }\end{array}$ & $\begin{array}{l}\text { C. Norte } \\
\text { Seco }\end{array}$ & $\begin{array}{l}\text { C. Norte } \\
\text { Úmido }\end{array}$ & \\
\hline 6651 & 32 & 0 & 0 & 18 & - & 32 & 230 \\
\hline 6652 & 117 & 128 & 0 & 0 & - & - & 230 \\
\hline 6653 & 126 & 126 & 0 & 0 & - & - & 230 \\
\hline 6662 & 0 & 0 & 1410 & 837 & 1 & 4 & 525 \\
\hline 6663 & 0 & 0 & 134 & 100 & 29 & 21 & 230 \\
\hline 6664 & 0 & 0 & 176 & 176 & 24 & 19 & 230 \\
\hline 6665 & 181 & 157 & 0 & 0 & - & - & 230 \\
\hline 6673 & 0 & 0 & 0 & 0 & - & - & 230 \\
\hline 6680 & 228 & 249 & 0 & 0 & - & - & 230 \\
\hline 6688 & 255 & 248 & 0 & 0 & - & - & 230 \\
\hline 6708 & 174 & 214 & 0 & 0 & - & - & 230 \\
\hline 6710 & 0 & 0 & 0 & 0 & - & - & 525 \\
\hline 6715 & 0 & 0 & 295 & 176 & 17 & 20 & 230 \\
\hline 6730 & 73 & 35 & 0 & 0 & - & - & 230 \\
\hline 6731 & 102 & 12 & 0 & 0 & - & - & 230 \\
\hline 6732 & 124 & 147 & 0 & 0 & - & - & 230 \\
\hline 6733 & 139 & 96 & 0 & 0 & - & - & 230 \\
\hline 6747 & 13 & 13 & 0 & 0 & - & - & 230 \\
\hline 6754 & 267 & 86 & 0 & 0 & - & - & 230 \\
\hline 6755 & 0 & 0 & 1052 & 620 & 6 & 9 & 525 \\
\hline 6757 & 0 & 0 & 1061 & 630 & 5 & 8 & 525 \\
\hline 6758 & 0 & 0 & 0 & 0 & - & - & 525 \\
\hline 6759 & 3 & 3 & 0 & 0 & - & - & 230 \\
\hline 6761 & 171 & 140 & 0 & 0 & - & - & 230 \\
\hline 6762 & 121 & 99 & 0 & 0 & - & - & 230 \\
\hline 6763 & 32 & 23 & 0 & 0 & - & - & 230 \\
\hline 6764 & 170 & 143 & 0 & 0 & - & - & 230 \\
\hline 6854 & 173 & 0 & 0 & 0 & - & - & 230 \\
\hline 7000 & 220 & 122 & 0 & 0 & - & - & 230 \\
\hline 7001 & 23 & 23 & 12 & 4 & 52 & 34 & 230 \\
\hline 7015 & 0 & 0 & 0 & 0 & - & - & 525 \\
\hline 7020 & 0 & 0 & 0 & 0 & - & - & 230 \\
\hline 7021 & 20 & 0 & 0 & 0 & - & - & 230 \\
\hline 7022 & 43 & 0 & 0 & 0 & - & - & 230 \\
\hline 7023 & 50 & 0 & 0 & 0 & - & - & 230 \\
\hline 7024 & 39 & 0 & 0 & 0 & - & - & 230 \\
\hline 7041 & 110 & 110 & 0 & 0 & - & - & 230 \\
\hline 7042 & 0 & 0 & 0 & 0 & - & - & 230 \\
\hline 7265 & 13 & 13 & 0 & 0 & - & - & 230 \\
\hline 7299 & 0 & 0 & 0 & 0 & - & - & 230 \\
\hline 7300 & 0 & 0 & 0 & 0 & - & - & 525 \\
\hline 7302 & 0 & 0 & 746 & 443 & 9 & 14 & 230 \\
\hline 7304 & 0 & 0 & 598 & 348 & 13 & 16 & 230 \\
\hline 7306 & 0 & 0 & 604 & 364 & 12 & 15 & 230 \\
\hline 7307 & 208,2 & 0 & 0 & 0 & - & - & 230 \\
\hline 7308 & 0 & 0 & 111 & 65 & 33 & 25 & 230 \\
\hline 7310 & 0 & 0 & 111 & 65 & 34 & 26 & 230 \\
\hline 7312 & 0 & 0 & 87 & 52 & 38 & 30 & 230 \\
\hline 7584 & 10 & 10 & 0 & 0 & - & - & 230 \\
\hline 7624 & 22 & 22 & 0 & 0 & - & - & 230 \\
\hline
\end{tabular}


(continuação Tabela B.1)

\begin{tabular}{|c|c|c|c|c|c|c|c|}
\hline \multirow{2}{*}{ Barra } & \multicolumn{2}{|c|}{$\begin{array}{l}\text { Carga } \\
\text { (MW) }\end{array}$} & \multicolumn{2}{|c|}{$\begin{array}{c}\text { Despacho Geração } \\
\text { (MW) }\end{array}$} & \multicolumn{2}{|c|}{$\begin{array}{l}\text { Prioridade no Des- } \\
\text { pacho da Geração }\end{array}$} & \multirow{2}{*}{$\begin{array}{c}\text { Nível de } \\
\text { Tensão } \\
\text { (kV) }\end{array}$} \\
\hline & $\begin{array}{l}\text { C. Norte } \\
\text { Seco }\end{array}$ & $\begin{array}{l}\text { C. Norte } \\
\text { Úmido }\end{array}$ & $\begin{array}{l}\text { C. Norte } \\
\text { Seco }\end{array}$ & $\begin{array}{l}\text { C. Norte } \\
\text { Úmido }\end{array}$ & $\begin{array}{l}\text { C. Norte } \\
\text { Seco }\end{array}$ & $\begin{array}{l}\text { C. Norte } \\
\text { Úmido }\end{array}$ & \\
\hline 7711 & 0 & 0 & 0 & 0 & - & - & 525 \\
\hline 7712 & 0 & 0 & 0 & 0 & - & - & 525 \\
\hline 7713 & 0 & 0 & 0 & 0 & - & - & 525 \\
\hline 7719 & 0 & 0 & 974 & 570 & 7 & 11 & 525 \\
\hline 7722 & 0 & 0 & 0 & 0 & - & - & 525 \\
\hline 7723 & 148 & 150 & 0 & 0 & - & - & 230 \\
\hline 7724 & 0 & 0 & 22 & 0 & 47 & - & 230 \\
\hline 7725 & 147 & 132 & 0 & 0 & - & - & 230 \\
\hline 7731 & 374 & 340 & 0 & 0 & - & - & 230 \\
\hline 7732 & 0 & 0 & 0 & 0 & - & - & 525 \\
\hline 7733 & 0 & 0 & 0 & 0 & - & - & 525 \\
\hline 7734 & 295 & 378 & 0 & 0 & - & - & 230 \\
\hline 7736 & 0 & 0 & 0 & 0 & - & - & 525 \\
\hline 7739 & 0 & 0 & 0 & 0 & - & - & 230 \\
\hline 7740 & 369 & 327 & 0 & 0 & - & - & 230 \\
\hline 7741 & 0 & 0 & 0 & 0 & - & - & 525 \\
\hline 7743 & 314 & 184 & 0 & 0 & - & - & 230 \\
\hline 7744 & 0 & 0 & 0 & 0 & - & - & 525 \\
\hline 7745 & 135 & 110 & 0 & 0 & - & - & 230 \\
\hline 7747 & 0 & 0 & 0 & 0 & - & - & 230 \\
\hline 7748 & 0 & 0 & 0 & 0 & - & - & 525 \\
\hline 7749 & 0 & 190 & 17 & 0 & 51 & - & 230 \\
\hline 7750 & 0 & 0 & 0 & 0 & - & - & 525 \\
\hline 7751 & 0 & 0 & 0 & 0 & - & - & 525 \\
\hline 7752 & 0 & 0 & 0 & 0 & - & - & 525 \\
\hline 7753 & 0 & 0 & 170 & 0 & 26 & - & 525 \\
\hline 7755 & 301 & 309 & 0 & 0 & - & - & 230 \\
\hline 7757 & 0 & 152 & 86 & 0 & 39 & - & 230 \\
\hline 7758 & 63 & 22 & 0 & 0 & - & - & 230 \\
\hline 7759 & 0 & 0 & 0 & 0 & - & - & 525 \\
\hline 7760 & 38 & 0 & 0 & 940 & - & 3 & 525 \\
\hline 7762 & 0 & 0 & 1314 & 1662 & 2 & 1 & 525 \\
\hline 7763 & 82,5 & 103,6 & 0 & 0 & - & - & 230 \\
\hline 7765 & 0 & 0 & 0 & 0 & - & - & 525 \\
\hline 7766 & 0 & 0 & 1196 & 707 & 4 & 6 & 525 \\
\hline 7770 & 257 & 290 & 0 & 0 & - & - & 230 \\
\hline 7771 & 49 & 0 & 0 & 0 & - & - & 230 \\
\hline 7776 & 110 & 126 & 0 & 0 & - & - & 230 \\
\hline 7778 & 251 & 198 & 0 & 0 & - & - & 230 \\
\hline 7779 & 188 & 183 & 0 & 0 & - & - & 230 \\
\hline 7780 & 93 & 66 & 0 & 0 & - & - & 230 \\
\hline 7781 & 0 & 11 & 30 & 0 & 44 & - & 230 \\
\hline 7782 & 79 & 106 & 0 & 0 & - & - & 230 \\
\hline 7785 & 0 & 0 & 0 & 0 & - & - & 230 \\
\hline 7790 & 149 & 119 & 0 & 0 & - & - & 230 \\
\hline 7794 & 383 & 368 & 0 & 0 & - & - & 230 \\
\hline 7800 & 15 & 126 & 0 & 0 & - & - & 230 \\
\hline 7802 & 0 & 0 & 235 & 537 & 18 & 12 & 230 \\
\hline 7808 & 330 & 229 & 0 & 0 & - & - & 230 \\
\hline 7812 & 0 & 0 & 172 & 81 & 25 & 23 & 230 \\
\hline
\end{tabular}


(continuação Tabela B.1)

\begin{tabular}{|c|c|c|c|c|c|c|c|}
\hline \multirow{2}{*}{ Barra } & \multicolumn{2}{|c|}{$\begin{array}{l}\text { Carga } \\
\text { (MW) }\end{array}$} & \multicolumn{2}{|c|}{$\begin{array}{c}\text { Despacho Geração } \\
\text { (MW) }\end{array}$} & \multicolumn{2}{|c|}{$\begin{array}{l}\text { Prioridade no Des- } \\
\text { pacho da Geração }\end{array}$} & \multirow{2}{*}{$\begin{array}{c}\text { Nível de } \\
\text { Tensão } \\
\text { (kV) }\end{array}$} \\
\hline & $\begin{array}{l}\text { C. Norte } \\
\text { Seco }\end{array}$ & $\begin{array}{l}\text { C. Norte } \\
\text { Úmido }\end{array}$ & $\begin{array}{l}\text { C. Norte } \\
\text { Seco }\end{array}$ & $\begin{array}{l}\text { C. Norte } \\
\text { Úmido }\end{array}$ & $\begin{array}{l}\text { C. Norte } \\
\text { Seco }\end{array}$ & $\begin{array}{l}\text { C. Norte } \\
\text { Úmido }\end{array}$ & \\
\hline 7820 & 0 & 0 & 920 & 537 & 8 & 13 & 230 \\
\hline 7823 & 0 & 0 & 0 & 0 & - & - & 230 \\
\hline 7824 & 230 & 208 & 0 & 0 & - & - & 230 \\
\hline 7826 & 288 & 308 & 0 & 0 & - & - & 230 \\
\hline 7830 & 164 & 0 & 0 & 0 & - & - & 230 \\
\hline 7850 & 0 & 0 & 130 & 0 & 30 & - & 230 \\
\hline 7900 & 193 & 0 & 0 & 0 & - & - & 230 \\
\hline 7903 & 188 & 0 & 0 & 0 & - & - & 230 \\
\hline 7904 & 46 & 0 & 0 & 0 & - & - & 230 \\
\hline 7921 & 0 & 0 & 0 & 0 & - & - & 230 \\
\hline 7922 & 0 & 0 & 0 & 0 & - & - & 230 \\
\hline 7923 & 147 & 139 & 0 & 0 & - & - & 230 \\
\hline 7924 & 84 & 66 & 0 & 0 & - & - & 230 \\
\hline 7926 & 0 & 0 & 0 & 0 & - & - & 230 \\
\hline 7927 & 0 & 0 & 0 & 0 & - & - & 230 \\
\hline 7928 & 0 & 0 & 0 & 0 & - & - & 230 \\
\hline 7929 & 0 & 0 & 0 & 0 & - & - & 230 \\
\hline 7980 & 177 & 0 & 0 & 0 & - & - & 230 \\
\hline 7982 & 121 & 0 & 0 & 0 & - & - & 230 \\
\hline 7990 & 130 & 0 & 0 & 0 & - & - & 230 \\
\hline 8135 & 52 & 46 & 0 & 0 & - & - & 230 \\
\hline 8321 & 38 & 0 & 0 & 0 & - & - & 230 \\
\hline 8333 & 21 & 21 & 0 & 0 & - & - & 230 \\
\hline 8720 & 0 & 0 & 20 & 0 & 49 & - & 525 \\
\hline 8721 & 0 & 0 & 0 & 0 & - & - & 525 \\
\hline 8731 & 0 & 0 & 149 & 88 & 27 & 22 & 230 \\
\hline 8736 & 0 & 0 & 121 & 71 & 31 & 24 & 230 \\
\hline 8741 & 0 & 0 & 614 & 0 & 11 & - & 525 \\
\hline 8771 & 0 & 0 & 91 & 0 & 37 & - & 525 \\
\hline 8772 & 0 & 19 & 616 & 0 & 10 & - & 525 \\
\hline 8780 & 0 & 0 & 93 & 44 & 36 & 27 & 230 \\
\hline 8952 & 0 & 0 & 1220 & 725 & 3 & 5 & 525 \\
\hline 9002 & 100 & 82 & 0 & 0 & - & - & 230 \\
\hline 9010 & 90 & 68 & 0 & 0 & - & - & 230 \\
\hline 9015 & 140 & 114 & 0 & 0 & - & - & 230 \\
\hline 9020 & 241 & 236 & 0 & 0 & - & - & 230 \\
\hline 9030 & 63 & 62 & 0 & 0 & - & - & 230 \\
\hline 9040 & 0 & 0 & 0 & 0 & - & - & 230 \\
\hline 9045 & 53 & 42 & 0 & 0 & - & - & 230 \\
\hline 9050 & 0 & 0 & 0 & 0 & - & - & 230 \\
\hline 9051 & 142 & 0 & 0 & 0 & - & - & 230 \\
\hline 9060 & 0 & 0 & 0 & 0 & - & - & 230 \\
\hline 9062 & 46 & 37 & 0 & 0 & - & - & 230 \\
\hline 9065 & 164 & 135 & 0 & 0 & - & - & 230 \\
\hline 9066 & 118 & 99 & 0 & 0 & - & - & 230 \\
\hline 9090 & 0 & 0 & 107 & 63 & 35 & 28 & 230 \\
\hline 9095 & 21 & 21 & 0 & 0 & - & - & 230 \\
\hline 9097 & 39 & 30 & 0 & 0 & - & - & 230 \\
\hline 9098 & 0 & 0 & 197 & 0 & 22 & - & 230 \\
\hline 9100 & 0 & 108 & 25,4 & 0 & 46 & - & 230 \\
\hline
\end{tabular}


(continuação Tabela B.1)

\begin{tabular}{|c|c|c|c|c|c|c|c|}
\hline \multirow{2}{*}{ Barra } & \multicolumn{2}{|c|}{$\begin{array}{l}\text { Carga } \\
\text { (MW) }\end{array}$} & \multicolumn{2}{|c|}{$\begin{array}{c}\text { Despacho Geração } \\
\text { (MW) }\end{array}$} & \multicolumn{2}{|c|}{$\begin{array}{l}\text { Prioridade no Des- } \\
\text { pacho da Geração }\end{array}$} & \multirow{2}{*}{$\begin{array}{c}\text { Nível de } \\
\text { Tensão } \\
\text { (kV) }\end{array}$} \\
\hline & $\begin{array}{l}\text { C. Norte } \\
\text { Seco }\end{array}$ & $\begin{array}{l}\text { C. Norte } \\
\text { Úmido }\end{array}$ & $\begin{array}{l}\text { C. Norte } \\
\text { Seco }\end{array}$ & $\begin{array}{l}\text { C. Norte } \\
\text { Úmido }\end{array}$ & $\begin{array}{l}\text { C. Norte } \\
\text { Seco }\end{array}$ & $\begin{array}{l}\text { C. Norte } \\
\text { Úmido }\end{array}$ & \\
\hline 9110 & 207 & 171 & 0 & 0 & - & - & 230 \\
\hline 9120 & 83 & 59 & 0 & 0 & - & - & 230 \\
\hline 9130 & 132 & 127 & 0 & 0 & - & - & 230 \\
\hline 9140 & 0 & 0 & 422 & 250 & 15 & 17 & 230 \\
\hline 9165 & 125 & 181 & 0 & 0 & - & - & 230 \\
\hline 9170 & 30 & 26 & 0 & 0 & - & - & 230 \\
\hline 9180 & 101 & 116 & 0 & 0 & - & - & 230 \\
\hline 9184 & 140 & 113 & 0 & 0 & - & - & 230 \\
\hline 9188 & 0 & 0 & 27 & 8 & 45 & 33 & 230 \\
\hline 9192 & 0 & 120 & 21 & 0 & 48 & - & 230 \\
\hline 9195 & 0 & 36 & 19 & 0 & 50 & - & 230 \\
\hline 9204 & 124 & 114 & 0 & 0 & - & - & 230 \\
\hline 9206 & 131 & 131 & 0 & 0 & - & - & 230 \\
\hline 9208 & 351,2 & 143 & 0 & 0 & - & - & 230 \\
\hline 9209 & 149 & 139 & 0 & 0 & - & - & 230 \\
\hline 9210 & 143 & 122 & 0 & 0 & - & - & 230 \\
\hline 9213 & 75 & 67 & 0 & 0 & - & - & 230 \\
\hline 9230 & 165 & 133 & 0 & 0 & - & - & 230 \\
\hline 9233 & 0 & 0 & 70 & 325 & 40 & 7 & 230 \\
\hline 9245 & 294 & 258 & 0 & 0 & - & - & 230 \\
\hline 9250 & 0 & 0 & 142 & 39 & 28 & 31 & 230 \\
\hline 9261 & 133 & 154 & 0 & 0 & - & - & 230 \\
\hline 9264 & 103 & 81 & 0 & 0 & - & - & 230 \\
\hline 9265 & 59 & 44 & 0 & 0 & - & - & 230 \\
\hline 9272 & 98 & 79 & 0 & 0 & - & - & 230 \\
\hline 9276 & 310 & 296 & 0 & 0 & - & - & 230 \\
\hline 9280 & 141 & 119 & 0 & 0 & - & - & 230 \\
\hline 9283 & 82 & 63 & 0 & 0 & - & - & 230 \\
\hline 9286 & 236 & 176 & 0 & 0 & - & - & 230 \\
\hline 9290 & 116 & 149 & 0 & 0 & - & - & 230 \\
\hline 9304 & 107 & 91 & 0 & 0 & - & - & 230 \\
\hline 9306 & 82 & 71 & 0 & 0 & - & - & 230 \\
\hline 9310 & 117 & 93 & 0 & 0 & - & - & 230 \\
\hline 9314 & 121 & 106 & 0 & 0 & - & - & 230 \\
\hline 9330 & 168 & 129 & 0 & 0 & - & - & 230 \\
\hline 9340 & 0 & 0 & 0 & 0 & - & - & 230 \\
\hline 9345 & 43 & 35 & 0 & 0 & - & - & 230 \\
\hline 9350 & 60 & 127 & 0 & 0 & - & - & 230 \\
\hline 38853 & 0 & 0 & 56 & 231 & 41 & 18 & 230 \\
\hline 38857 & 0 & 0 & 224 & 0 & 20 & - & 230 \\
\hline 38858 & 0 & 135 & 46 & 0 & 42 & - & 230 \\
\hline 39841 & 0 & 0 & 227 & 63 & 19 & 29 & 230 \\
\hline 39850 & 252 & 170 & 0 & 0 & - & - & 230 \\
\hline 44651 & 0 & 0 & 0 & 0 & - & - & 230 \\
\hline 44652 & 30 & 30 & 0 & 0 & - & - & 230 \\
\hline 44653 & 22 & 22 & 0 & 0 & - & - & 230 \\
\hline 44655 & 35 & 31 & 0 & 0 & - & - & 230 \\
\hline 44841 & 237 & 180 & 0 & 0 & - & - & 230 \\
\hline 44900 & 158 & 169 & 0 & 0 & - & - & 230 \\
\hline 44914 & 0 & 0 & 118 & 0 & 32 & - & 230 \\
\hline
\end{tabular}


(continuação Tabela B.1)

\begin{tabular}{|c|c|c|c|c|c|c|c|}
\hline \multirow{2}{*}{ Barra } & \multicolumn{2}{|c|}{$\begin{array}{l}\text { Carga } \\
\text { (MW) }\end{array}$} & \multicolumn{2}{|c|}{$\begin{array}{c}\text { Despacho Geração } \\
\text { (MW) }\end{array}$} & \multicolumn{2}{|c|}{$\begin{array}{l}\text { Prioridade no Des- } \\
\text { pacho da Geração }\end{array}$} & \multirow{2}{*}{$\begin{array}{l}\text { Nível de } \\
\text { Tensão } \\
\text { (kV) }\end{array}$} \\
\hline & $\begin{array}{l}\text { C. Norte } \\
\text { Seco }\end{array}$ & $\begin{array}{l}\text { C. Norte } \\
\text { Úmido }\end{array}$ & $\begin{array}{l}\text { C. Norte } \\
\text { Seco }\end{array}$ & $\begin{array}{l}\text { C. Norte } \\
\text { Úmido }\end{array}$ & $\begin{array}{l}\text { C. Norte } \\
\text { Seco }\end{array}$ & $\begin{array}{l}\text { C. Norte } \\
\text { Úmido }\end{array}$ & \\
\hline 44920 & 155 & 70 & 0 & 0 & - & - & 230 \\
\hline 44925 & 88 & 0 & 0 & 0 & - & - & 230 \\
\hline 46851 & 205 & 110 & 0 & 0 & - & - & 230 \\
\hline 46942 & 224 & 210 & 0 & 0 & - & - & 230 \\
\hline 47120 & 0 & 0 & 33 & 0 & 43 & - & 230 \\
\hline 47121 & 0 & 0 & 0 & 0 & - & - & 525 \\
\hline 50211 & 0 & 0 & 186 & 0 & 23 & - & 230 \\
\hline 50212 & 0 & 0 & 0 & 0 & - & - & 525 \\
\hline 50213 & 0 & 0 & 0 & 0 & - & - & 525 \\
\hline 50214 & 0 & 0 & 0 & 0 & - & - & 230 \\
\hline 50215 & 0 & 0 & 452 & 0 & 14 & - & 230 \\
\hline 50216 & 0 & 0 & 0 & 0 & - & - & 230 \\
\hline 50220 & 0 & 0 & 0 & 0 & - & - & 230 \\
\hline 51001 & 115 & 85 & 0 & 0 & - & - & 230 \\
\hline 51002 & 0 & 0 & 0 & 0 & - & - & 230 \\
\hline 51003 & 0 & 0 & 0 & 0 & - & - & 230 \\
\hline 51004 & 71,7 & 133 & 0 & 0 & - & - & 230 \\
\hline 51020 & 102 & 0 & 0 & 0 & - & - & 230 \\
\hline 51457 & 79 & 45 & 0 & 0 & - & - & 230 \\
\hline 51693 & 55 & 0 & 0 & 0 & - & - & 230 \\
\hline 51703 & 19 & 19 & 0 & 0 & - & - & 230 \\
\hline 51704 & 0 & 0 & 0 & 0 & - & - & 230 \\
\hline TOTAL: & $18.527,6$ & $15.001,6$ & $18.944,4$ & $15.049,0$ & & & \\
\hline
\end{tabular}


Tabela B.2 - Dados de ramos existentes - SGSB.

\begin{tabular}{|c|c|c|c|c|c|c|c|}
\hline $\mathbf{N}^{\circ}$ & DE & PARA & $\begin{array}{c}\text { ID do } \\
\text { circuito } \\
\text { no ramo }\end{array}$ & $\begin{array}{c}\boldsymbol{R}_{i j} \\
\text { (p.u.) }\end{array}$ & $\begin{array}{c}X_{i j} \\
\text { (p.u.) }\end{array}$ & $\begin{array}{c}f_{i j}^{\max } \\
(\mathbf{M W})\end{array}$ & $\begin{array}{c}\text { Contingência } \\
\text { no "N-1" }\end{array}$ \\
\hline 1 & 6601 & 6603 & 1 & 0,00434 & 0,02530 & 390 & $\checkmark$ \\
\hline 2 & 6601 & 7763 & 1 & 0,00853 & 0,04441 & 288 & $\checkmark$ \\
\hline 3 & 6601 & 7776 & 1 & 0,02170 & 0,11229 & 237 & $\checkmark$ \\
\hline 4 & 6603 & 7763 & 1 & 0,00141 & 0,00834 & 390 & $\checkmark$ \\
\hline 5 & 6608 & 6625 & 1 & 0,01070 & 0,06390 & 392 & $\checkmark$ \\
\hline 6 & 6608 & 44920 & 1 & 0,00458 & 0,03240 & 350 & $\checkmark$ \\
\hline 7 & 6615 & 6617 & 1 & 0,00260 & 0,01260 & 382 & $\checkmark$ \\
\hline 8 & 6615 & 6618 & 1 & 0,00340 & 0,01640 & 396 & $\checkmark$ \\
\hline 9 & 6615 & 6664 & 1 & 0,00360 & 0,02180 & 385 & $\checkmark$ \\
\hline 10 & 6615 & 44841 & 1 & 0,00200 & 0,00980 & 276 & $\checkmark$ \\
\hline 11 & 6616 & 6619 & 1 & 0,00700 & 0,03380 & 298 & $\checkmark$ \\
\hline 12 & 6616 & 6619 & 2 & 0,00550 & 0,03350 & 165 & \\
\hline 13 & 6617 & 6619 & 1 & 0,00120 & 0,00740 & 385 & $\checkmark$ \\
\hline 14 & 6617 & 7001 & 1 & 0,00091 & 0,00354 & 420 & \\
\hline 15 & 6619 & 6664 & 1 & 0,00070 & 0,00390 & 386 & $\checkmark$ \\
\hline 16 & 6619 & 6673 & 1 & 0,00020 & 0,00090 & 220 & \\
\hline 17 & 6619 & 6762 & 1 & 0,00380 & 0,01880 & 298 & $\checkmark$ \\
\hline 18 & 6619 & 7739 & 1 & 0,00011 & 0,00010 & 684 & $\checkmark$ \\
\hline 19 & 6619 & 7739 & 2 & 0,00011 & 0,00010 & 684 & \\
\hline 20 & 6624 & 6625 & 1 & 0,00201 & 0,01031 & 350 & \\
\hline 21 & 6624 & 6625 & 2 & 0,00170 & 0,01030 & 357 & $\checkmark$ \\
\hline 22 & 6624 & 6625 & 3 & 0,00220 & 0,01090 & 357 & \\
\hline 23 & 6624 & 7820 & 1 & 0,01220 & 0,07690 & 323 & $\checkmark$ \\
\hline 24 & 6624 & 44925 & 1 & 0,01000 & 0,06000 & 284 & $\checkmark$ \\
\hline 25 & 6625 & 44925 & 1 & 0,00920 & 0,05750 & 383 & $\checkmark$ \\
\hline 26 & 6626 & 6755 & 1 & 0,00050 & 0,00730 & 1636 & $\checkmark$ \\
\hline 27 & 6626 & 7760 & 1 & 0,00204 & 0,02459 & 2401 & $\checkmark$ \\
\hline 28 & 6627 & 6615 & 1 & 0,00270 & 0,01610 & 328 & $\checkmark$ \\
\hline 29 & 6627 & 6615 & 2 & 0,00270 & 0,01610 & 328 & \\
\hline 30 & 6627 & 6615 & 3 & 0,00340 & 0,01700 & 325 & \\
\hline 31 & 6627 & 6618 & 1 & 0,00610 & 0,03250 & 243 & $\checkmark$ \\
\hline 32 & 6627 & 6688 & 1 & 0,02080 & 0,12580 & 335 & $\checkmark$ \\
\hline 33 & 6627 & 6733 & 1 & 0,01600 & 0,08070 & 175 & $\checkmark$ \\
\hline 34 & 6627 & 44655 & 1 & 0,00672 & 0,03413 & 300 & $\checkmark$ \\
\hline 35 & 6630 & 6626 & 1 & 0,00081 & 0,01361 & 3096 & $\checkmark$ \\
\hline 36 & 6630 & 6665 & 1 & 0,00000 & 0,01500 & 672 & $\checkmark$ \\
\hline 37 & 6630 & 6665 & 2 & 0,00000 & 0,01500 & 672 & \\
\hline 38 & 6649 & 6626 & 1 & 0,00069 & 0,01294 & 3455 & $\checkmark$ \\
\hline 39 & 6651 & 6688 & 1 & 0,01590 & 0,08090 & 350 & $\checkmark$ \\
\hline 40 & 6651 & 7042 & 1 & 0,01442 & 0,08049 & 160 & $\checkmark$ \\
\hline 41 & 6653 & 6624 & 1 & 0,01130 & 0,06990 & 323 & $\checkmark$ \\
\hline 42 & 6653 & 7820 & 1 & 0,00150 & 0,00890 & 323 & $\checkmark$ \\
\hline 43 & 6653 & 7820 & 2 & 0,00150 & 0,00890 & 323 & \\
\hline 44 & 6653 & 44920 & 1 & 0,00765 & 0,04795 & 323 & $\checkmark$ \\
\hline 45 & 6662 & 7748 & 1 & 0,00010 & 0,00124 & 2182 & \\
\hline 46 & 6662 & 7748 & 2 & 0,00010 & 0,00127 & 2182 & \\
\hline 47 & 6663 & 6731 & 1 & 0,01340 & 0,06690 & 164 & $\checkmark$ \\
\hline 48 & 6664 & 6629 & 1 & 0,00080 & 0,00470 & 386 & \\
\hline 49 & 6664 & 6747 & 1 & 0,00020 & 0,00130 & 315 & $\checkmark$ \\
\hline 50 & 6665 & 7757 & 1 & 0,02629 & 0,19266 & 338 & $\checkmark$ \\
\hline
\end{tabular}


(continuação Tabela B.2)

\begin{tabular}{|c|c|c|c|c|c|c|c|}
\hline $\mathbf{N}^{\circ}$ & DE & PARA & $\begin{array}{c}\text { ID do } \\
\text { circuito } \\
\text { no ramo }\end{array}$ & $\begin{array}{c}\boldsymbol{R}_{i j} \\
\text { (p.u.) }\end{array}$ & $\begin{array}{c}X_{i j} \\
\text { (p.u.) }\end{array}$ & $\begin{array}{l}f_{i j}^{\max } \\
(\mathbf{M W})\end{array}$ & $\begin{array}{l}\text { Contingência } \\
\text { no "N-1" }\end{array}$ \\
\hline 51 & 6673 & 6759 & 1 & 0,00220 & 0,01330 & 119 & \\
\hline 52 & 6673 & 44651 & 1 & 0,00080 & 0,00470 & 220 & \\
\hline 53 & 6680 & 7763 & 1 & 0,00310 & 0,01820 & 350 & \\
\hline 54 & 6680 & 7763 & 2 & 0,00310 & 0,01820 & 350 & \\
\hline 55 & 6708 & 6754 & 1 & 0,00360 & 0,01840 & 182 & \\
\hline 56 & 6708 & 6754 & 2 & 0,00360 & 0,01820 & 237 & $\checkmark$ \\
\hline 57 & 6708 & 7776 & 1 & 0,01514 & 0,07836 & 237 & $\checkmark$ \\
\hline 58 & 6715 & 6651 & 1 & 0,00440 & 0,03560 & 261 & $\checkmark$ \\
\hline 59 & 6715 & 6688 & 1 & 0,01100 & 0,08890 & 280 & $\checkmark$ \\
\hline 60 & 6715 & 7042 & 1 & 0,00363 & 0,02654 & 350 & $\checkmark$ \\
\hline 61 & 6730 & 7826 & 1 & 0,01244 & 0,07710 & 417 & $\checkmark$ \\
\hline 62 & 6732 & 6733 & 1 & 0,00420 & 0,02120 & 175 & $\checkmark$ \\
\hline 63 & 6747 & 6761 & 1 & 0,00460 & 0,02700 & 315 & $\checkmark$ \\
\hline 64 & 6754 & 6601 & 1 & 0,00780 & 0,03980 & 182 & $\checkmark$ \\
\hline 65 & 6754 & 7763 & 1 & 0,01440 & 0,07270 & 237 & $\checkmark$ \\
\hline 66 & 6757 & 6758 & 1 & 0,00000 & 0,00020 & 363 & \\
\hline 67 & 6757 & 6758 & 2 & 0,00000 & 0,00020 & 363 & \\
\hline 68 & 6757 & 6758 & 3 & 0,00000 & 0,00020 & 363 & \\
\hline 69 & 6757 & 6758 & 4 & 0,00000 & 0,00020 & 363 & \\
\hline 70 & 6761 & 6616 & 1 & 0,00230 & 0,01100 & 298 & $\checkmark$ \\
\hline 71 & 6762 & 6761 & 1 & 0,00350 & 0,01680 & 299 & $\checkmark$ \\
\hline 72 & 6763 & 7265 & 1 & 0,00010 & 0,00040 & 103 & \\
\hline 73 & 6763 & 7739 & 1 & 0,02210 & 0,11475 & 259 & $\checkmark$ \\
\hline 74 & 6763 & 7749 & 1 & 0,02474 & 0,12624 & 359 & $\checkmark$ \\
\hline 75 & 6763 & 7778 & 1 & 0,00977 & 0,04708 & 259 & \\
\hline 76 & 6763 & 7778 & 2 & 0,00977 & 0,04708 & 240 & \\
\hline 77 & 6764 & 6618 & 1 & 0,00530 & 0,02670 & 182 & $\checkmark$ \\
\hline 78 & 6764 & 6663 & 1 & 0,01050 & 0,05360 & 182 & $\checkmark$ \\
\hline 79 & 6854 & 6616 & 1 & 0,00037 & 0,00285 & 335 & \\
\hline 80 & 6854 & 6616 & 2 & 0,00037 & 0,00285 & 335 & \\
\hline 81 & 7000 & 6665 & 1 & 0,00760 & 0,06480 & 699 & $\checkmark$ \\
\hline 82 & 7000 & 44914 & 1 & 0,00813 & 0,04877 & 318 & $\checkmark$ \\
\hline 83 & 7020 & 6732 & 1 & 0,00440 & 0,02280 & 259 & \\
\hline 84 & 7020 & 6732 & 2 & 0,00520 & 0,02820 & 333 & $\checkmark$ \\
\hline 85 & 7020 & 7022 & 1 & 0,00930 & 0,05570 & 408 & $\checkmark$ \\
\hline 86 & 7020 & 7023 & 1 & 0,01700 & 0,09170 & 333 & $\checkmark$ \\
\hline 87 & 7021 & 7022 & 1 & 0,01720 & 0,08910 & 259 & $\checkmark$ \\
\hline 88 & 7042 & 7023 & 1 & 0,02120 & 0,11430 & 333 & $\checkmark$ \\
\hline 89 & 7042 & 7041 & 1 & 0,00306 & 0,02238 & 350 & \\
\hline 90 & 7299 & 6616 & 1 & 0,00350 & 0,01710 & 164 & $\checkmark$ \\
\hline 91 & 7299 & 6731 & 1 & 0,00990 & 0,04910 & 164 & $\checkmark$ \\
\hline 92 & 7299 & 6761 & 1 & 0,00080 & 0,00460 & 342 & $\checkmark$ \\
\hline 93 & 7299 & 6764 & 1 & 0,00460 & 0,02740 & 342 & $\checkmark$ \\
\hline 94 & 7300 & 7711 & 1 & 0,00137 & 0,01724 & 2214 & $\checkmark$ \\
\hline 95 & 7302 & 7723 & 1 & 0,00060 & 0,00637 & 590 & \\
\hline 96 & 7302 & 7723 & 2 & 0,00060 & 0,00637 & 590 & \\
\hline 97 & 7304 & 7723 & 1 & 0,00378 & 0,02408 & 715 & $\checkmark$ \\
\hline 98 & 7304 & 7747 & 1 & 0,00543 & 0,03731 & 350 & $\checkmark$ \\
\hline 99 & 7304 & 7747 & 2 & 0,00543 & 0,03731 & 350 & \\
\hline 100 & 7304 & 9180 & 1 & 0,00671 & 0,05258 & 350 & $\checkmark$ \\
\hline
\end{tabular}

(continua) 
(continuação Tabela B.2)

\begin{tabular}{|c|c|c|c|c|c|c|c|}
\hline $\mathbf{N}^{\circ}$ & DE & PARA & $\begin{array}{c}\text { ID do } \\
\text { circuito } \\
\text { no ramo }\end{array}$ & $\begin{array}{c}\boldsymbol{R}_{i j} \\
\text { (p.u.) }\end{array}$ & $\begin{array}{c}X_{i j} \\
\text { (p.u.) }\end{array}$ & $\begin{array}{l}f_{i j}^{\max } \\
\text { (MW) }\end{array}$ & $\begin{array}{l}\text { Contingência } \\
\text { no "N-1" }\end{array}$ \\
\hline 101 & 7306 & 7826 & 1 & 0,00649 & 0,04799 & 395 & $\checkmark$ \\
\hline 102 & 7306 & 7826 & 2 & 0,00649 & 0,04799 & 395 & \\
\hline 103 & 7306 & 9130 & 1 & 0,01066 & 0,06729 & 260 & $\checkmark$ \\
\hline 104 & 7306 & 46851 & 1 & 0,00639 & 0,03739 & 284 & \\
\hline 105 & 7306 & 46851 & 2 & 0,00639 & 0,03739 & 284 & \\
\hline 106 & 7307 & 7782 & 1 & 0,00559 & 0,03040 & 232 & $\checkmark$ \\
\hline 107 & 7307 & 7782 & 2 & 0,00559 & 0,03040 & 232 & \\
\hline 108 & 7307 & 9195 & 1 & 0,00629 & 0,03168 & 160 & $\checkmark$ \\
\hline 109 & 7307 & 9195 & 2 & 0,00629 & 0,03168 & 160 & \\
\hline 110 & 7308 & 7307 & 1 & 0,00021 & 0,00095 & 270 & \\
\hline 111 & 7310 & 7307 & 1 & 0,00169 & 0,00760 & 270 & \\
\hline 112 & 7312 & 7307 & 1 & 0,00370 & 0,01663 & 270 & \\
\hline 113 & 7711 & 7713 & 1 & 0,00065 & 0,00825 & 2214 & $\checkmark$ \\
\hline 114 & 7711 & 7732 & 1 & 0,00146 & 0,01839 & 2214 & $\checkmark$ \\
\hline 115 & 7711 & 7733 & 1 & 0,00054 & 0,00687 & 2214 & $\checkmark$ \\
\hline 116 & 7719 & 7722 & 1 & 0,00073 & 0,00917 & 2363 & $\checkmark$ \\
\hline 117 & 7719 & 7736 & 1 & 0,00047 & 0,00586 & 2363 & $\checkmark$ \\
\hline 118 & 7719 & 7736 & 2 & 0,00035 & 0,00590 & 2187 & \\
\hline 119 & 7722 & 7752 & 1 & 0,00289 & 0,03648 & 2282 & $\checkmark$ \\
\hline 120 & 7722 & 7752 & 2 & 0,00289 & 0,03648 & 2108 & \\
\hline 121 & 7722 & 7766 & 1 & 0,00172 & 0,02348 & 2363 & $\checkmark$ \\
\hline 122 & 7722 & 7766 & 2 & 0,00172 & 0,02170 & 2362 & \\
\hline 123 & 7722 & 8952 & 1 & 0,00000 & 0,00050 & 2350 & \\
\hline 124 & 7722 & 8952 & 2 & 0,00000 & 0,00050 & 2350 & \\
\hline 125 & 7723 & 7779 & 1 & 0,01419 & 0,06720 & 350 & \\
\hline 126 & 7723 & 7779 & 2 & 0,01419 & 0,06720 & 350 & \\
\hline 127 & 7724 & $\begin{array}{l}7758 \\
\end{array}$ & 1 & 0,01692 & 0,13278 & 212 & \\
\hline 128 & 7725 & 7790 & 1 & 0,01187 & 0,08966 & 350 & $\checkmark$ \\
\hline 129 & 7725 & 7790 & 2 & 0,01187 & 0,08966 & 350 & \\
\hline 130 & 7732 & 6628 & 1 & 0,00040 & 0,00385 & 2363 & $\checkmark$ \\
\hline 131 & 7732 & 6628 & 2 & 0,00045 & 0,00437 & 2189 & \\
\hline 132 & 7732 & 7300 & 1 & 0,00031 & 0,00410 & 2189 & $\checkmark$ \\
\hline 133 & 7732 & 7748 & 1 & 0,00200 & 0,02693 & 2363 & $\checkmark$ \\
\hline 134 & 7733 & 7713 & 1 & 0,00015 & 0,00257 & 2655 & $\checkmark$ \\
\hline 135 & 7733 & 7713 & 2 & 0,00019 & 0,00242 & 2214 & \\
\hline 136 & 7733 & 7736 & 1 & 0,00255 & 0,02922 & 2036 & $\checkmark$ \\
\hline 137 & 7734 & 7731 & 1 & 0,00600 & 0,02844 & 350 & \\
\hline 138 & 7734 & 7731 & 2 & 0,00601 & 0,02841 & 350 & $\checkmark$ \\
\hline 139 & 7734 & 7990 & 1 & 0,01588 & 0,06939 & 243 & $\checkmark$ \\
\hline 140 & 7734 & 7990 & 2 & 0,01588 & 0,06939 & 243 & \\
\hline 141 & 7734 & 46942 & 1 & 0,00245 & 0,01267 & 243 & $\checkmark$ \\
\hline 142 & 7734 & 46942 & 2 & 0,00290 & 0,01540 & 243 & \\
\hline 143 & 7736 & 7744 & 1 & 0,00031 & 0,00509 & 2654 & $\checkmark$ \\
\hline 144 & 7736 & 7744 & 2 & 0,00031 & 0,00509 & 2654 & \\
\hline 145 & 7736 & 7748 & 1 & 0,00162 & 0,02048 & 2363 & $\checkmark$ \\
\hline 146 & 7736 & 7752 & 1 & 0,00164 & 0,02769 & 2655 & $\checkmark$ \\
\hline 147 & 7739 & 7794 & 1 & 0,01894 & 0,09774 & 350 & $\checkmark$ \\
\hline 148 & 7739 & 7982 & 1 & 0,01730 & 0,08841 & 350 & $\checkmark$ \\
\hline 149 & 7739 & 7982 & 2 & 0,01730 & 0,08841 & 350 & \\
\hline 150 & 7740 & 7808 & 1 & 0,00235 & 0,01327 & 328 & $\checkmark$ \\
\hline
\end{tabular}

(continua) 
(continuação Tabela B.2)

\begin{tabular}{|c|c|c|c|c|c|c|c|}
\hline $\mathbf{N}^{\circ}$ & DE & PARA & $\begin{array}{c}\text { ID do } \\
\text { circuito } \\
\text { no ramo }\end{array}$ & $\begin{array}{c}\boldsymbol{R}_{i j} \\
\text { (p.u.) }\end{array}$ & $\begin{array}{c}X_{i j} \\
\text { (p.u.) }\end{array}$ & $\begin{array}{l}f_{i j}^{\max } \\
(\mathbf{M W})\end{array}$ & $\begin{array}{l}\text { Contingência } \\
\text { no "N-1" }\end{array}$ \\
\hline 151 & 7740 & 7745 & 1 & 0,00537 & 0,03449 & 311 & \\
\hline 152 & 7740 & 7926 & 1 & 0,00133 & 0,00873 & 327 & $\checkmark$ \\
\hline 153 & 7740 & 7928 & 1 & 0,00133 & 0,00873 & 327 & $\checkmark$ \\
\hline 154 & 7741 & 7713 & 1 & 0,00058 & 0,01009 & 2655 & $\checkmark$ \\
\hline 155 & 7743 & 7823 & 1 & 0,00524 & 0,02704 & 300 & $\checkmark$ \\
\hline 156 & 7743 & 7824 & 1 & 0,00533 & 0,02744 & 300 & $\checkmark$ \\
\hline 157 & 7743 & 51693 & 1 & 0,01190 & 0,06615 & 354 & $\checkmark$ \\
\hline 158 & 7744 & 7741 & 1 & 0,00148 & 0,02426 & 2654 & $\checkmark$ \\
\hline 159 & 7744 & 7759 & 1 & 0,00160 & 0,02680 & 3096 & $\checkmark$ \\
\hline 160 & 7744 & 7759 & 2 & 0,00160 & 0,02680 & 3096 & \\
\hline 161 & 7747 & 7725 & 1 & 0,01097 & 0,07542 & 350 & $\checkmark$ \\
\hline 162 & 7747 & 7725 & 2 & 0,01097 & 0,07542 & 350 & \\
\hline 163 & 7747 & 7744 & 1 & 0,00000 & 0,01488 & 672 & $\checkmark$ \\
\hline 164 & 7747 & 7744 & 2 & 0,00000 & 0,01488 & 672 & \\
\hline 165 & 7748 & 6628 & 1 & 0,00212 & 0,02556 & 2363 & $\checkmark$ \\
\hline 166 & 7748 & 6758 & 1 & 0,00052 & 0,00654 & 2363 & $\checkmark$ \\
\hline 167 & 7748 & 7760 & 1 & 0,00159 & 0,02012 & 2162 & $\checkmark$ \\
\hline 168 & 7749 & 7021 & 1 & 0,01930 & 0,09990 & 259 & $\checkmark$ \\
\hline 169 & 7749 & 7820 & 1 & 0,03045 & 0,15738 & 259 & \\
\hline 170 & 7749 & 7820 & 2 & 0,03041 & 0,15718 & 259 & $\checkmark$ \\
\hline 171 & 7750 & 50212 & 1 & 0,00064 & 0,00805 & 3921 & $\checkmark$ \\
\hline 172 & 7750 & 50213 & 1 & 0,00106 & 0,01334 & 3921 & $\checkmark$ \\
\hline 173 & 7751 & 7722 & 1 & 0,00164 & 0,03034 & 2937 & $\checkmark$ \\
\hline 174 & 7751 & 7736 & 1 & 0,00188 & 0,02325 & 2120 & $\checkmark$ \\
\hline 175 & 7751 & 7750 & 1 & 0,00073 & 0,00916 & 2120 & $\checkmark$ \\
\hline 176 & 7752 & 7750 & 1 & 0,00027 & 0,00343 & 2120 & $\checkmark$ \\
\hline 177 & 7755 & 38857 & 1 & 0,01140 & 0,09730 & 669 & $\checkmark$ \\
\hline 178 & 7755 & 39850 & 1 & 0,00300 & 0,02570 & 669 & $\checkmark$ \\
\hline 179 & 7757 & 7724 & 1 & 0,00844 & 0,06618 & 212 & \\
\hline 180 & 7759 & 7823 & 1 & 0,00000 & 0,01500 & 672 & $\checkmark$ \\
\hline 181 & 7759 & 7823 & 2 & 0,00000 & 0,01500 & 672 & \\
\hline 182 & 7759 & 7823 & 3 & 0,00000 & 0,01500 & 672 & \\
\hline 183 & 7760 & 7762 & 1 & 0,00086 & 0,01455 & 2546 & $\checkmark$ \\
\hline 184 & 7760 & 7762 & 2 & 0,00086 & 0,01455 & 2546 & \\
\hline 185 & 7760 & 7766 & 1 & 0,00154 & 0,01940 & 2162 & \\
\hline 186 & 7760 & 7766 & 2 & 0,00114 & 0,02020 & 3184 & $\checkmark$ \\
\hline 187 & 7763 & 6651 & 1 & 0,01896 & 0,09870 & 288 & \\
\hline 188 & 7763 & 6651 & 2 & 0,01740 & 0,08690 & 288 & $\checkmark$ \\
\hline 189 & 7763 & 6708 & 1 & 0,01569 & 0,08142 & 238 & $\checkmark$ \\
\hline 190 & 7765 & 7722 & 1 & 0,00200 & 0,02760 & 1227 & $\checkmark$ \\
\hline 191 & 7765 & 7722 & 2 & 0,00245 & 0,02973 & 1227 & \\
\hline 192 & 7766 & 6755 & 1 & 0,00076 & 0,01171 & 1636 & $\checkmark$ \\
\hline 193 & 7766 & $\begin{array}{l}6758 \\
\end{array}$ & 1 & 0,00056 & 0,00697 & 2363 & $\checkmark$ \\
\hline 194 & 7770 & 7982 & 1 & 0,00188 & 0,00961 & 350 & $\checkmark$ \\
\hline 195 & 7770 & 7982 & 2 & 0,00188 & 0,00961 & 350 & \\
\hline 196 & 7771 & $\begin{array}{l}7757 \\
\end{array}$ & 1 & 0,00396 & 0,03366 & 669 & $\checkmark$ \\
\hline 197 & 7771 & 38858 & 1 & 0,00934 & 0,07932 & 669 & $\checkmark$ \\
\hline 198 & 7776 & 7820 & 1 & 0,05052 & 0,17774 & 350 & $\checkmark$ \\
\hline 199 & 7776 & 7820 & 2 & 0,04668 & 0,17780 & 350 & \\
\hline 200 & 7780 & 9276 & 1 & 0,01670 & 0,06200 & 179 & $\checkmark$ \\
\hline
\end{tabular}

(continua) 
(continuação Tabela B.2)

\begin{tabular}{|c|c|c|c|c|c|c|c|}
\hline $\mathbf{N}^{\circ}$ & DE & PARA & $\begin{array}{c}\text { ID do } \\
\text { circuito } \\
\text { no ramo }\end{array}$ & $\begin{array}{c}\boldsymbol{R}_{i j} \\
\text { (p.u.) }\end{array}$ & $\begin{array}{c}X_{i j} \\
\text { (p.u.) }\end{array}$ & $\begin{array}{l}f_{i j}^{\max } \\
\text { (MW) }\end{array}$ & $\begin{array}{c}\text { Contingência } \\
\text { no "N-1" }\end{array}$ \\
\hline 201 & 7781 & 8780 & 1 & 0,00406 & 0,02098 & 213 & \\
\hline 202 & 7782 & 9065 & 1 & 0,00338 & 0,01746 & 232 & $\checkmark$ \\
\hline 203 & 7782 & 9276 & 1 & 0,01700 & 0,06300 & 179 & $\checkmark$ \\
\hline 204 & 7785 & 7743 & 1 & 0,02123 & 0,10955 & 232 & $\checkmark$ \\
\hline 205 & 7785 & 7781 & 1 & 0,00094 & 0,00485 & 232 & $\checkmark$ \\
\hline 206 & 7794 & 6190 & 1 & 0,00836 & 0,04143 & 309 & \\
\hline 207 & 7794 & 6190 & 2 & 0,00836 & 0,04143 & 309 & \\
\hline 208 & 7800 & 7802 & 1 & 0,00014 & 0,00074 & 430 & \\
\hline 209 & 7800 & 7802 & 2 & 0,00014 & 0,00074 & 268 & \\
\hline 210 & 7802 & 7740 & 1 & 0,02306 & 0,11923 & 243 & $\checkmark$ \\
\hline 211 & 7802 & 7808 & 1 & 0,02314 & 0,11882 & 243 & $\checkmark$ \\
\hline 212 & 7802 & 7824 & 1 & 0,00939 & 0,04840 & 243 & \\
\hline 213 & 7802 & 7824 & 2 & 0,00901 & 0,04631 & 243 & $\checkmark$ \\
\hline 214 & 7812 & 7826 & 1 & 0,01505 & 0,07776 & 259 & \\
\hline 215 & 7812 & 7826 & 2 & 0,01503 & 0,07766 & 259 & $\checkmark$ \\
\hline 216 & 7812 & 8321 & 1 & 0,02584 & 0,13090 & 160 & $\checkmark$ \\
\hline 217 & 7812 & 8321 & 2 & 0,02584 & 0,13090 & 160 & \\
\hline 218 & 7820 & 6730 & 1 & 0,01327 & 0,08355 & 417 & $\checkmark$ \\
\hline 219 & 7820 & 7826 & 1 & 0,02493 & 0,15740 & 417 & $\checkmark$ \\
\hline 220 & 7824 & 7823 & 1 & 0,00019 & 0,00097 & 547 & $\checkmark$ \\
\hline 221 & 7824 & 7823 & 2 & 0,00019 & 0,00097 & 547 & \\
\hline 222 & 7830 & 7802 & 1 & 0,00345 & 0,02362 & 300 & $\checkmark$ \\
\hline 223 & 7830 & 7824 & 1 & 0,00509 & 0,03484 & 300 & $\checkmark$ \\
\hline 224 & 7850 & 9170 & 1 & 0,00238 & 0,01160 & 518 & $\checkmark$ \\
\hline 225 & 7904 & 7790 & 1 & 0,00649 & 0,05091 & 350 & $\checkmark$ \\
\hline 226 & 7904 & 7790 & 2 & 0,00649 & 0,05091 & 350 & \\
\hline 227 & 7921 & 9020 & 1 & 0,00400 & 0,02090 & 290 & $\checkmark$ \\
\hline 228 & 7921 & 9020 & 2 & 0,00400 & 0,02140 & 290 & \\
\hline 229 & 7921 & 9020 & 3 & 0,00420 & 0,02270 & 225 & \\
\hline 230 & 7921 & 9165 & 1 & 0,01670 & 0,09160 & 225 & $\checkmark$ \\
\hline 231 & 7921 & 9209 & 1 & 0,00280 & 0,01350 & 470 & $\checkmark$ \\
\hline 232 & 7921 & 9245 & 1 & 0,00100 & 0,00530 & 540 & $\checkmark$ \\
\hline 233 & 7921 & 9276 & 1 & 0,00393 & 0,02173 & 359 & $\checkmark$ \\
\hline 234 & 7921 & 9276 & 2 & 0,00393 & 0,02173 & 359 & \\
\hline 235 & 7921 & 51457 & 1 & 0,01246 & 0,08428 & 494 & $\checkmark$ \\
\hline 236 & 7922 & 9188 & 1 & 0,01440 & 0,07240 & 340 & $\checkmark$ \\
\hline 237 & 7922 & 9265 & 1 & 0,00050 & 0,00400 & 335 & $\checkmark$ \\
\hline 238 & 7922 & 9304 & 1 & 0,00950 & 0,04770 & 329 & \\
\hline 239 & 7922 & 9304 & 2 & 0,00804 & 0,04383 & 359 & $\checkmark$ \\
\hline 240 & 7924 & 7923 & 1 & 0,01951 & 0,09565 & 260 & $\checkmark$ \\
\hline 241 & 7924 & 8333 & 1 & 0,00180 & 0,00920 & 329 & \\
\hline 242 & 7924 & 9095 & 1 & 0,00554 & 0,02766 & 270 & $\checkmark$ \\
\hline 243 & 7926 & 7927 & 1 & 0,00080 & 0,00214 & 311 & $\checkmark$ \\
\hline 244 & 7927 & 7900 & 1 & 0,00118 & 0,00776 & 327 & $\checkmark$ \\
\hline 245 & 7928 & 7929 & 1 & 0,00080 & 0,00214 & 311 & $\checkmark$ \\
\hline 246 & 7929 & 7900 & 1 & 0,00118 & 0,00776 & 327 & $\checkmark$ \\
\hline 247 & 7980 & 7770 & 1 & 0,00564 & 0,02883 & 350 & $\checkmark$ \\
\hline 248 & 7980 & 7770 & 2 & 0,00564 & 0,02883 & 350 & \\
\hline 249 & 7990 & 7980 & 1 & 0,01369 & 0,05980 & 243 & $\checkmark$ \\
\hline 250 & 7990 & 7980 & 2 & 0,01369 & 0,05980 & 243 & \\
\hline
\end{tabular}


(continuação Tabela B.2)

\begin{tabular}{|c|c|c|c|c|c|c|c|}
\hline $\mathbf{N}^{\circ}$ & DE & PARA & $\begin{array}{c}\text { ID do } \\
\text { circuito } \\
\text { no ramo }\end{array}$ & $\begin{array}{c}\underset{(\text { p.u. }}{\boldsymbol{R}_{i j}} \\
\text { (p. }\end{array}$ & $\begin{array}{c}X_{i j} \\
\text { (p.u.) }\end{array}$ & $\begin{array}{l}f_{i j}^{\max } \\
\text { (MW) }\end{array}$ & $\begin{array}{l}\text { Contingência } \\
\text { no "N-1" }\end{array}$ \\
\hline 251 & 8135 & 9314 & 1 & 0,00698 & 0,03901 & 365 & $\checkmark$ \\
\hline 252 & 8321 & 9195 & 1 & 0,01148 & 0,05818 & 160 & $\checkmark$ \\
\hline 253 & 8321 & 9195 & 2 & 0,01148 & 0,05818 & 160 & \\
\hline 254 & 8720 & 7765 & 1 & 0,00120 & 0,01580 & 1227 & $\checkmark$ \\
\hline 255 & 8721 & 7765 & 1 & 0,00145 & 0,01736 & 1227 & $\checkmark$ \\
\hline 256 & 8721 & 8720 & 1 & 0,00000 & 0,00010 & 9999 & $\checkmark$ \\
\hline 257 & 8731 & 7747 & 1 & 0,00236 & 0,01177 & 243 & \\
\hline 258 & 8736 & 7747 & 1 & 0,00394 & 0,01962 & 243 & \\
\hline 259 & 8741 & 7722 & 1 & 0,00494 & 0,02350 & 800 & \\
\hline 260 & 8771 & 8772 & 1 & 0,00034 & 0,00598 & 3305 & \\
\hline 261 & 8771 & 8772 & 2 & 0,00034 & 0,00598 & 3305 & \\
\hline 262 & 9002 & 9170 & 1 & 0,02450 & 0,12240 & 270 & $\checkmark$ \\
\hline 263 & 9002 & 9184 & 1 & 0,01580 & 0,07900 & 270 & $\checkmark$ \\
\hline 264 & 9002 & 9306 & 1 & 0,01730 & 0,09630 & 290 & $\checkmark$ \\
\hline 265 & 9002 & 9330 & 1 & 0,02420 & 0,12130 & 270 & $\checkmark$ \\
\hline 266 & 9002 & 9340 & 1 & 0,02496 & 0,12366 & 270 & $\checkmark$ \\
\hline 267 & 9002 & 9340 & 2 & 0,02496 & 0,12366 & 270 & \\
\hline 268 & 9010 & 9040 & 1 & 0,00670 & 0,03808 & 290 & $\checkmark$ \\
\hline 269 & 9010 & 9040 & 2 & 0,00670 & 0,03808 & 290 & \\
\hline 270 & 9010 & 9170 & 1 & 0,02890 & 0,14440 & 270 & $\checkmark$ \\
\hline 271 & 9015 & 9110 & 1 & 0,00450 & 0,02310 & 210 & $\checkmark$ \\
\hline 272 & 9015 & 9110 & 2 & 0,00450 & 0,02310 & 210 & \\
\hline 273 & 9015 & 9314 & 1 & 0,00549 & 0,02586 & 235 & $\checkmark$ \\
\hline 274 & 9020 & 7584 & 1 & 0,00260 & 0,01290 & 270 & \\
\hline 275 & 9020 & 7780 & 1 & 0,00830 & 0,04320 & 210 & $\checkmark$ \\
\hline 276 & 9020 & 9045 & 1 & 0,00270 & 0,01260 & 270 & $\checkmark$ \\
\hline 277 & 9020 & 9050 & 1 & 0,00130 & 0,00700 & 290 & $\checkmark$ \\
\hline 278 & 9020 & 9051 & 1 & 0,00222 & 0,01228 & 290 & $\checkmark$ \\
\hline 279 & 9020 & 9110 & 1 & 0,00210 & 0,01120 & 290 & $\checkmark$ \\
\hline 280 & 9020 & 9110 & 2 & 0,00210 & 0,01120 & 290 & \\
\hline 281 & 9020 & 9110 & 3 & 0,00210 & 0,01120 & 290 & \\
\hline 282 & 9020 & 9209 & 1 & 0,00283 & 0,01320 & 270 & $\checkmark$ \\
\hline 283 & 9020 & 9245 & 1 & 0,00410 & 0,02250 & 290 & $\checkmark$ \\
\hline 284 & 9020 & 9345 & 1 & 0,02580 & 0,09830 & 179 & $\checkmark$ \\
\hline 285 & 9030 & 9120 & 1 & 0,01710 & 0,08550 & 270 & $\checkmark$ \\
\hline 286 & 9040 & 7753 & 1 & 0,00044 & 0,01250 & 672 & $\checkmark$ \\
\hline 287 & 9040 & 7753 & 2 & 0,00044 & 0,01250 & 672 & \\
\hline 288 & 9045 & 9209 & 1 & 0,00070 & 0,00300 & 270 & $\checkmark$ \\
\hline 289 & 9050 & 9110 & 1 & 0,00192 & 0,01010 & 290 & $\checkmark$ \\
\hline 290 & 9060 & 7782 & 1 & 0,00040 & 0,01940 & 210 & $\checkmark$ \\
\hline 291 & 9060 & 7782 & 2 & 0,00040 & 0,01940 & 210 & \\
\hline 292 & 9060 & 8135 & 1 & 0,00385 & 0,02152 & 365 & $\checkmark$ \\
\hline 293 & 9060 & 9015 & 1 & 0,01270 & 0,05920 & 350 & $\checkmark$ \\
\hline 294 & 9060 & 9015 & 2 & 0,01270 & 0,05920 & 350 & \\
\hline 295 & 9060 & 9065 & 1 & 0,00385 & 0,02121 & 276 & $\checkmark$ \\
\hline 296 & 9060 & 9066 & 1 & 0,00387 & 0,01936 & 365 & $\checkmark$ \\
\hline 297 & 9062 & 7782 & 1 & 0,00390 & 0,02130 & 290 & $\checkmark$ \\
\hline 298 & 9062 & 51704 & 1 & 0,00030 & 0,00170 & 365 & $\checkmark$ \\
\hline 299 & 9065 & 7781 & 1 & 0,01247 & 0,06435 & 232 & $\checkmark$ \\
\hline 300 & 9066 & 51704 & 1 & 0,00094 & 0,00422 & 365 & $\checkmark$ \\
\hline
\end{tabular}

(continua) 
(continuação Tabela B.2)

\begin{tabular}{|c|c|c|c|c|c|c|c|}
\hline $\mathbf{N}^{\circ}$ & DE & PARA & $\begin{array}{c}\text { ID do } \\
\text { circuito } \\
\text { no ramo }\end{array}$ & $\begin{array}{c}\boldsymbol{R}_{i j} \\
\text { (p.u.) }\end{array}$ & $\begin{array}{c}X_{i j} \\
\text { (p.u.) }\end{array}$ & $\begin{array}{l}f_{i j}^{\max } \\
\text { (MW) }\end{array}$ & $\begin{array}{l}\text { Contingência } \\
\text { no "N-1" }\end{array}$ \\
\hline 301 & 9090 & 9140 & 1 & 0,00390 & 0,02140 & 290 & \\
\hline 302 & 9090 & 9140 & 2 & 0,00390 & 0,02140 & 365 & $\checkmark$ \\
\hline 303 & 9090 & 9286 & 1 & 0,01200 & 0,06640 & 290 & $\checkmark$ \\
\hline 304 & 9090 & 9286 & 2 & 0,01195 & 0,06643 & 290 & \\
\hline 305 & 9095 & 9192 & 1 & 0,00890 & 0,04450 & 270 & $\checkmark$ \\
\hline 306 & 9097 & 9209 & 1 & 0,00470 & 0,02300 & 270 & $\checkmark$ \\
\hline 307 & 9100 & 7782 & 1 & 0,00400 & 0,02000 & 329 & $\checkmark$ \\
\hline 308 & 9100 & 51020 & 1 & 0,00841 & 0,04490 & 265 & $\checkmark$ \\
\hline 309 & 9110 & 7924 & 1 & 0,00224 & 0,01250 & 290 & $\checkmark$ \\
\hline 310 & 9110 & 7924 & 2 & 0,00250 & 0,01250 & 290 & \\
\hline 311 & 9110 & 9051 & 1 & 0,00043 & 0,00236 & 290 & $\checkmark$ \\
\hline 312 & 9110 & 9206 & 1 & 0,00560 & 0,02600 & 210 & \\
\hline 313 & 9110 & 9206 & 2 & 0,00520 & 0,02690 & 340 & $\checkmark$ \\
\hline 314 & 9110 & 9208 & 1 & 0,00328 & 0,01542 & 270 & $\checkmark$ \\
\hline 315 & 9110 & 9350 & 1 & 0,00386 & 0,01790 & 210 & $\checkmark$ \\
\hline 316 & 9110 & 51002 & 1 & 0,00623 & 0,03032 & 336 & $\checkmark$ \\
\hline 317 & 9120 & 9020 & 1 & 0,00739 & 0,03689 & 270 & $\checkmark$ \\
\hline 318 & 9120 & 9097 & 1 & 0,00283 & 0,01410 & 270 & $\checkmark$ \\
\hline 319 & 9120 & 51457 & 1 & 0,01761 & 0,08726 & 270 & $\checkmark$ \\
\hline 320 & 9130 & 7812 & 1 & 0,02210 & 0,08750 & 179 & $\checkmark$ \\
\hline 321 & 9130 & 9304 & 1 & 0,01770 & 0,08870 & 270 & $\checkmark$ \\
\hline 322 & 9140 & 9245 & 1 & 0,03340 & 0,18560 & 290 & $\checkmark$ \\
\hline 323 & 9140 & 9250 & 1 & 0,00510 & 0,02860 & 290 & $\checkmark$ \\
\hline 324 & 9140 & 9280 & 1 & 0,02190 & 0,12260 & 290 & $\checkmark$ \\
\hline 325 & 9140 & 9283 & 1 & 0,01231 & 0,06804 & 365 & $\checkmark$ \\
\hline 326 & 9165 & 51020 & 1 & 0,00168 & 0,00898 & 265 & $\checkmark$ \\
\hline 327 & 9184 & 9272 & 1 & 0,01920 & 0,09630 & 340 & $\checkmark$ \\
\hline 328 & 9192 & 7923 & 1 & 0,00682 & 0,03290 & 260 & $\checkmark$ \\
\hline 329 & 9195 & 51703 & 1 & 0,00000 & 0,00002 & 80 & \\
\hline 330 & 9204 & 9206 & 1 & 0,00140 & 0,00860 & 336 & $\checkmark$ \\
\hline 331 & 9204 & 9210 & 1 & 0,00040 & 0,00260 & 336 & $\checkmark$ \\
\hline 332 & 9206 & 9213 & 1 & 0,00160 & 0,00780 & 270 & $\checkmark$ \\
\hline 333 & 9208 & 9209 & 1 & 0,00116 & 0,00567 & 315 & $\checkmark$ \\
\hline 334 & 9209 & 9204 & 1 & 0,00007 & 0,00499 & 362 & $\checkmark$ \\
\hline 335 & 9213 & 51001 & 1 & 0,00249 & 0,01158 & 319 & $\checkmark$ \\
\hline 336 & 9230 & 9233 & 1 & 0,01370 & 0,11610 & 365 & $\checkmark$ \\
\hline 337 & 9230 & 9261 & 1 & 0,00840 & 0,04180 & 270 & $\checkmark$ \\
\hline 338 & 9233 & 9030 & 1 & 0,03740 & 0,18710 & 270 & $\checkmark$ \\
\hline 339 & 9233 & 9040 & 1 & 0,00027 & 0,00179 & 540 & $\checkmark$ \\
\hline 340 & 9233 & 9261 & 1 & 0,02920 & 0,14590 & 270 & $\checkmark$ \\
\hline 341 & 9233 & 9280 & 1 & 0,04033 & 0,21966 & 265 & $\checkmark$ \\
\hline 342 & 9245 & 7624 & 1 & 0,00120 & 0,00620 & 270 & \\
\hline 343 & 9250 & 9165 & 1 & 0,02450 & 0,13540 & 225 & $\checkmark$ \\
\hline 344 & 9250 & 9264 & 1 & 0,01984 & 0,10082 & 319 & $\checkmark$ \\
\hline 345 & 9250 & 9310 & 1 & 0,01459 & 0,05554 & 250 & $\checkmark$ \\
\hline 346 & 9250 & 9345 & 1 & 0,03370 & 0,12550 & 179 & $\checkmark$ \\
\hline 347 & 9265 & 9264 & 1 & 0,00826 & 0,04198 & 319 & $\checkmark$ \\
\hline 348 & 9272 & 9188 & 1 & 0,01920 & 0,09630 & 340 & $\checkmark$ \\
\hline 349 & 9280 & 7780 & 1 & 0,01710 & 0,09310 & 290 & $\checkmark$ \\
\hline 350 & 9283 & 7921 & 1 & 0,02729 & 0,15080 & 365 & $\checkmark$ \\
\hline
\end{tabular}

(continua) 
(continuação Tabela B.2)

\begin{tabular}{|c|c|c|c|c|c|c|c|}
\hline $\mathbf{N}^{\circ}$ & DE & PARA & $\begin{array}{c}\text { ID do } \\
\text { circuito } \\
\text { no ramo }\end{array}$ & $\begin{array}{c}\boldsymbol{R}_{i j} \\
\text { (p.u.) }\end{array}$ & $\begin{array}{c}X_{i j} \\
\text { (p.u.) }\end{array}$ & $\begin{array}{l}f_{i j}^{\max } \\
\text { (MW) }\end{array}$ & $\begin{array}{l}\text { Contingência } \\
\text { no "N-1" }\end{array}$ \\
\hline 351 & 9286 & 9265 & 1 & 0,01720 & 0,08390 & 817 & $\checkmark$ \\
\hline 352 & 9286 & 9306 & 1 & 0,01380 & 0,07660 & 290 & $\checkmark$ \\
\hline 353 & 9286 & 50211 & 1 & 0,02300 & 0,11200 & 817 & $\checkmark$ \\
\hline 354 & 9290 & 7812 & 1 & 0,01830 & 0,09150 & 210 & $\checkmark$ \\
\hline 355 & 9290 & 9180 & 1 & 0,01688 & 0,08864 & 239 & $\checkmark$ \\
\hline 356 & 9290 & 9310 & 1 & 0,01550 & 0,05910 & 179 & $\checkmark$ \\
\hline 357 & 9314 & 9192 & 1 & 0,00980 & 0,05510 & 365 & $\checkmark$ \\
\hline 358 & 9340 & 9184 & 1 & 0,01264 & 0,10269 & 441 & $\checkmark$ \\
\hline 359 & 9340 & 9330 & 1 & 0,00085 & 0,00477 & 354 & $\checkmark$ \\
\hline 360 & 9350 & 9206 & 1 & 0,00161 & 0,00835 & 340 & $\checkmark$ \\
\hline 361 & 38853 & 39841 & 1 & 0,00361 & 0,02998 & 669 & $\checkmark$ \\
\hline 362 & 38853 & 39841 & 2 & 0,00361 & 0,02998 & 669 & \\
\hline 363 & 38857 & 4290 & 1 & 0,01080 & 0,09150 & 699 & $\checkmark$ \\
\hline 364 & 38858 & 4290 & 1 & 0,00520 & 0,04400 & 699 & $\checkmark$ \\
\hline 365 & 39841 & 39850 & 1 & 0,01961 & 0,16270 & 669 & $\checkmark$ \\
\hline 366 & 39841 & 39850 & 2 & 0,01961 & 0,16270 & 669 & \\
\hline 367 & 44651 & 44652 & 1 & 0,00010 & 0,00020 & 220 & \\
\hline 368 & 44651 & 44653 & 1 & 0,00010 & 0,00010 & 220 & \\
\hline 369 & 44655 & 6618 & 1 & 0,00369 & 0,01845 & 298 & $\checkmark$ \\
\hline 370 & 44655 & 6623 & 1 & 0,00041 & 0,00205 & 103 & \\
\hline 371 & 44841 & 6619 & 1 & 0,00470 & 0,02400 & 276 & $\checkmark$ \\
\hline 372 & 44900 & 6625 & 1 & 0,00310 & 0,01858 & 318 & $\checkmark$ \\
\hline 373 & 44900 & 6625 & 2 & 0,00465 & 0,02787 & 318 & \\
\hline 374 & 44900 & 44914 & 1 & 0,01426 & 0,08558 & 318 & $\checkmark$ \\
\hline 375 & 44925 & 6652 & 1 & 0,00920 & 0,05750 & 383 & \\
\hline 376 & 44925 & 6652 & 2 & 0,01000 & 0,06000 & 284 & \\
\hline 377 & 46942 & 7740 & 1 & 0,02030 & 0,10519 & 243 & $\checkmark$ \\
\hline 378 & 46942 & 7808 & 1 & 0,02160 & 0,11520 & 243 & $\checkmark$ \\
\hline 379 & 46942 & 7904 & 1 & 0,00625 & 0,04903 & 350 & $\checkmark$ \\
\hline 380 & 46942 & 7904 & 2 & 0,00625 & 0,04903 & 350 & \\
\hline 381 & 47120 & 9261 & 1 & 0,00210 & 0,01045 & 270 & $\checkmark$ \\
\hline 382 & 47121 & 8771 & 1 & 0,00099 & 0,01757 & 3305 & \\
\hline 383 & 47121 & 8771 & 2 & 0,00099 & 0,01757 & 3305 & \\
\hline 384 & 47121 & 47120 & 1 & 0,00000 & 0,01430 & 700 & $\checkmark$ \\
\hline 385 & 47121 & 47120 & 2 & 0,00000 & 0,01430 & 700 & \\
\hline 386 & 47121 & 50213 & 1 & 0,00225 & 0,02829 & 3921 & $\checkmark$ \\
\hline 387 & 47121 & 50213 & 2 & 0,00225 & 0,02829 & 3921 & \\
\hline 388 & 50211 & 7850 & 1 & 0,00000 & 0,00010 & 817 & $\checkmark$ \\
\hline 389 & 50211 & 9002 & 1 & 0,01150 & 0,05590 & 817 & $\checkmark$ \\
\hline 390 & 50211 & 50220 & 1 & 0,02140 & 0,10020 & 817 & $\checkmark$ \\
\hline 391 & 50212 & 50215 & 1 & 0,00000 & 0,01430 & 672 & $\checkmark$ \\
\hline 392 & 50212 & 50215 & 2 & 0,00000 & 0,01430 & 672 & \\
\hline 393 & 50213 & 7752 & 1 & 0,00036 & 0,00460 & 3921 & $\checkmark$ \\
\hline 394 & 50213 & 7752 & 2 & 0,00036 & 0,00460 & 3921 & \\
\hline 395 & 50213 & 7753 & 1 & 0,00256 & 0,03220 & 3921 & $\checkmark$ \\
\hline 396 & 50213 & 7753 & 2 & 0,00256 & 0,03220 & 3921 & \\
\hline 397 & 50213 & 50212 & 1 & 0,00159 & 0,02000 & 3921 & $\checkmark$ \\
\hline 398 & 50213 & 50214 & 1 & 0,00000 & 0,01430 & 672 & $\checkmark$ \\
\hline 399 & 50213 & 50214 & 2 & 0,00000 & 0,01430 & 672 & \\
\hline 400 & 50214 & 7921 & 1 & 0,00383 & 0,01860 & 528 & $\checkmark$ \\
\hline
\end{tabular}

(continua) 
(continuação Tabela B.2)

\begin{tabular}{|c|c|c|c|c|c|c|c|}
\hline $\mathbf{N}^{\circ}$ & DE & PARA & $\begin{array}{c}\text { ID do } \\
\text { circuito } \\
\text { no ramo }\end{array}$ & $\begin{array}{c}\boldsymbol{R}_{i j} \\
\text { (p.u.) }\end{array}$ & $\begin{array}{c}X_{i j} \\
\text { (p.u.) }\end{array}$ & $\begin{array}{l}f_{i j}^{\max } \\
(\mathbf{M W})\end{array}$ & $\begin{array}{l}\text { Contingência } \\
\text { no "N-1" }\end{array}$ \\
\hline 401 & 50214 & 9120 & 1 & 0,00134 & 0,01211 & 687 & $\checkmark$ \\
\hline 402 & 50214 & 9120 & 2 & 0,00134 & 0,01211 & 687 & \\
\hline 403 & 50215 & 9350 & 1 & 0,00575 & 0,02800 & 817 & $\checkmark$ \\
\hline 404 & 50216 & 7924 & 1 & 0,00752 & 0,03650 & 817 & $\checkmark$ \\
\hline 405 & 50216 & 9098 & 1 & 0,00090 & 0,00447 & 400 & \\
\hline 406 & 50216 & 9192 & 1 & 0,00090 & 0,00447 & 400 & $\checkmark$ \\
\hline 407 & 50220 & 7922 & 1 & 0,02205 & 0,17910 & 441 & $\checkmark$ \\
\hline 408 & 50220 & 7922 & 2 & 0,02205 & 0,17910 & 441 & \\
\hline 409 & 50220 & 9184 & 1 & 0,00055 & 0,00448 & 441 & $\checkmark$ \\
\hline 410 & 50220 & 9184 & 2 & 0,00055 & 0,00448 & 441 & \\
\hline 411 & 51001 & 9350 & 1 & 0,00355 & 0,01647 & 319 & $\checkmark$ \\
\hline 412 & 51002 & 51004 & 1 & 0,00012 & 0,00028 & 362 & $\checkmark$ \\
\hline 413 & 51003 & 9210 & 1 & 0,00037 & 0,00178 & 336 & $\checkmark$ \\
\hline 414 & 51004 & 51003 & 1 & 0,00012 & 0,00028 & 362 & $\checkmark$ \\
\hline 415 & 51457 & 9230 & 1 & 0,02349 & 0,11634 & 270 & $\checkmark$ \\
\hline 416 & 51457 & 47120 & 1 & 0,01514 & 0,10270 & 494 & $\checkmark$ \\
\hline 417 & 51693 & 7923 & 1 & 0,01020 & 0,05670 & 354 & $\checkmark$ \\
\hline 418 & 6710 & 6754 & 1 & 0,00000 & 0,01200 & 672 & $\checkmark$ \\
\hline 419 & 6710 & 6754 & 2 & 0,00000 & 0,01200 & 672 & \\
\hline 420 & 6710 & 6754 & 3 & 0,00000 & 0,01200 & 672 & \\
\hline 421 & 6627 & 6628 & 1 & 0,00000 & 0,01210 & 600 & $\checkmark$ \\
\hline 422 & 6627 & 6628 & 2 & 0,00000 & 0,01210 & 600 & \\
\hline 423 & 6627 & 6628 & 3 & 0,00000 & 0,01210 & 600 & \\
\hline 424 & 6625 & 6626 & 1 & 0,00000 & 0,01270 & 600 & $\checkmark$ \\
\hline 425 & 6625 & 6626 & 2 & 0,00000 & 0,01230 & 600 & \\
\hline 426 & 6625 & 6626 & 3 & 0,00000 & 0,01230 & 600 & \\
\hline 427 & 7299 & 7300 & 1 & 0,00000 & 0,01210 & 672 & $\checkmark$ \\
\hline 428 & 7015 & 7020 & 1 & 0,00032 & 0,01260 & 672 & $\checkmark$ \\
\hline 429 & 7015 & 7020 & 2 & 0,00032 & 0,01260 & 672 & \\
\hline 430 & 7015 & 7020 & 3 & 0,00032 & 0,01260 & 672 & \\
\hline 431 & 7733 & 7734 & 1 & 0,00032 & 0,01259 & 672 & $\checkmark$ \\
\hline 432 & 7733 & 7734 & 2 & 0,00032 & 0,01260 & 672 & \\
\hline 433 & 7733 & 7734 & 3 & 0,00024 & 0,01272 & 672 & \\
\hline 434 & 7723 & 7736 & 1 & 0,00015 & 0,01238 & 672 & \\
\hline 435 & 7723 & 7736 & 2 & 0,00042 & 0,01232 & 672 & \\
\hline 436 & 7723 & 7736 & 3 & 0,00042 & 0,01228 & 672 & $\checkmark$ \\
\hline 437 & 7751 & 9060 & 1 & 0,00018 & 0,01211 & 672 & $\checkmark$ \\
\hline 438 & 7751 & 9060 & 2 & 0,00024 & 0,01236 & 672 & \\
\hline 439 & 7751 & 9060 & 3 & 0,00031 & 0,01291 & 672 & \\
\hline 440 & 7732 & 7739 & 1 & 0,00032 & 0,01282 & 672 & $\checkmark$ \\
\hline 441 & 7732 & 7739 & 2 & 0,00031 & 0,01285 & 672 & \\
\hline 442 & 7732 & 7739 & 3 & 0,00031 & 0,01285 & 672 & \\
\hline 443 & 7750 & 9110 & 1 & 0,00030 & 0,01345 & 672 & \\
\hline 444 & 7750 & 9110 & 2 & 0,00039 & 0,01255 & 672 & \\
\hline 445 & 7750 & 9110 & 3 & 0,00036 & 0,01341 & 672 & \\
\hline 446 & 7750 & 9110 & 4 & 0,00020 & 0,01168 & 672 & $\checkmark$ \\
\hline 447 & 7740 & 7741 & 1 & 0,00044 & 0,01987 & 672 & \\
\hline 448 & 7740 & 7741 & 2 & 0,00044 & 0,01898 & 672 & $\checkmark$ \\
\hline 449 & 7740 & 7741 & 3 & 0,00044 & 0,01898 & 672 & \\
\hline 450 & 7752 & 7921 & 1 & 0,00020 & 0,01234 & 672 & \\
\hline
\end{tabular}

(continua) 
(continuação Tabela B.2)

\begin{tabular}{|l|c|c|c|c|c|c|c|}
\hline $\mathbf{N}^{\circ}$ & DE & PARA & $\begin{array}{c}\text { ID do } \\
\text { circuito } \\
\text { no ramo }\end{array}$ & $\begin{array}{c}\boldsymbol{R}_{i j} \\
\text { (p.u.) }\end{array}$ & $\begin{array}{c}\boldsymbol{X}_{i j} \\
\text { (p.u.) }\end{array}$ & $\begin{array}{c}f_{i j}^{\max } \\
(\mathbf{M W})\end{array}$ & $\begin{array}{c}\text { Contingência } \\
\text { no “N-1" }\end{array}$ \\
\hline 451 & 7752 & 7921 & 2 & 0,00044 & 0,01174 & 672 & $\checkmark$ \\
\hline 452 & 7752 & 7921 & 3 & 0,00020 & 0,01235 & 672 & \\
\hline 453 & 7752 & 7921 & 4 & 0,00020 & 0,01234 & 672 & \\
\hline 454 & 7765 & 7922 & 1 & 0,00016 & 0,01212 & 672 & $\checkmark$ \\
\hline 455 & 7765 & 7922 & 2 & 0,00016 & 0,01212 & 672 & \\
\hline 456 & 7765 & 7922 & 3 & 0,00023 & 0,01294 & 672 & \\
\hline 457 & 7762 & 7763 & 1 & 0,00039 & 0,01271 & 672 & \\
\hline 458 & 7762 & 7763 & 2 & 0,00016 & 0,01219 & 672 & $\checkmark$ \\
\hline 459 & 7762 & 7763 & 3 & 0,00039 & 0,01271 & 672 & \\
\hline 460 & 7748 & 7749 & 1 & 0,00031 & 0,01266 & 672 & $\checkmark$ \\
\hline 461 & 7713 & 46942 & 1 & 0,00032 & 0,01260 & 672 & $\checkmark$ \\
\hline 462 & 7713 & 46942 & 2 & 0,00032 & 0,01260 & 672 & \\
\hline 463 & 7712 & 7903 & 1 & 0,00032 & 0,01260 & 672 & $\checkmark$ \\
\hline 464 & 7712 & 7903 & 2 & 0,00032 & 0,01260 & 672 & \\
\hline 465 & 7711 & 7980 & 1 & 0,00032 & 0,01260 & 672 & $\checkmark$ \\
\hline 466 & 7711 & 7980 & 2 & 0,00032 & 0,01260 & 672 & \\
\hline 467 & 7711 & 7980 & 3 & 0,00032 & 0,01260 & 672 & \\
\hline
\end{tabular}


Tabela B.3 - Lista de ramos candidatos - SGSB.

\begin{tabular}{|c|c|c|c|c|c|c|c|}
\hline $\mathbf{N}^{\circ}$ & DE & PARA & $\begin{array}{c}\boldsymbol{R}_{i j} \\
\text { (p.u.) }\end{array}$ & $\begin{array}{c}X_{i j} \\
\text { (p.u.) }\end{array}$ & $\begin{array}{l}f_{i j}^{\max } \\
(\mathbf{M W})\end{array}$ & $\begin{array}{c}c_{i j}^{1} \\
\text { (milhões de } \mathbf{R} \$ \text { ) }\end{array}$ & $\begin{array}{c}c_{i j}^{2} \\
\text { (milhões de } \mathbf{R} \$ \text { ) }\end{array}$ \\
\hline 1 & 6710 & 7762 & 0,00080 & 0,00840 & 1660 & 113,96297 & 182,34075 \\
\hline 2 & 6754 & 6602 & 0,01300 & 0,07760 & 320 & 41,98290 & 67,17264 \\
\hline 3 & 7741 & 7759 & 0,00100 & 0,01710 & 3096 & 236,92797 & 473,85594 \\
\hline 4 & 6630 & 6649 & 0,00109 & 0,01822 & 3096 & 228,07140 & 364,91424 \\
\hline 5 & 6630 & 6710 & 0,00176 & 0,02948 & 3096 & 386,46143 & 618,33829 \\
\hline 6 & 7712 & 7741 & 0,00043 & 0,00617 & 2616 & 102,01768 & 204,03536 \\
\hline 7 & 7760 & 7015 & 0,00093 & 0,01295 & 3684 & 246,37184 & 492,74368 \\
\hline 8 & 7711 & 7748 & 0,00220 & 0,03146 & 2616 & 383,29021 & 766,58042 \\
\hline 9 & 7711 & 7712 & 0,00057 & 0,00815 & 2616 & 96,83091 & 193,66182 \\
\hline 10 & 6628 & 7015 & 0,00054 & 0,00751 & 3684 & 139,59451 & 279,18902 \\
\hline 11 & 7749 & 7021 & 0,00622 & 0,03031 & 408 & 39,19598 & 78,39196 \\
\hline 12 & 7749 & 7024 & 0,00662 & 0,05205 & 408 & 50,50493 & 101,00986 \\
\hline 13 & 7771 & 7757 & 0,00338 & 0,02857 & 669 & 33,05678 & 66,11356 \\
\hline 14 & 7000 & 6665 & 0,00760 & 0,06480 & 319 & 56,01057 & 112,02114 \\
\hline 15 & 7755 & 39850 & 0,00300 & 0,02570 & 669 & 19,16355 & 38,32710 \\
\hline 16 & 7020 & 7022 & 0,01190 & 0,06130 & 259 & 36,18301 & 72,36602 \\
\hline 17 & 7903 & 7731 & 0,00096 & 0,00754 & 408 & 14,00449 & 28,00897 \\
\hline 18 & 38858 & 4290 & 0,00520 & 0,04400 & 669 & 45,90389 & 91,80778 \\
\hline 19 & 7980 & 7794 & 0,00168 & 0,01320 & 408 & 19,98944 & 31,98311 \\
\hline 20 & 7785 & 7743 & 0,02123 & 0,10955 & 232 & 27,13762 & 54,27524 \\
\hline 21 & 7020 & 6733 & 0,00407 & 0,01982 & 300 & 24,46486 & 48,92972 \\
\hline 22 & 7020 & 6763 & 0,00814 & 0,03964 & 320 & 47,78913 & 95,57826 \\
\hline 23 & 38857 & 39850 & 0,01188 & 0,10048 & 669 & 94,86244 & 189,72488 \\
\hline 24 & 38857 & 7771 & 0,01110 & 0,09391 & 669 & 70,97594 & 141,95188 \\
\hline 25 & 38857 & 4290 & 0,01096 & 0,09310 & 669 & 90,52966 & 181,05932 \\
\hline 26 & 7024 & 6763 & 0,00855 & 0,04162 & 408 & 51,47191 & 102,94382 \\
\hline 27 & 50212 & 7759 & 0,00227 & 0,02864 & 2937 & 308,37761 & 616,75522 \\
\hline 28 & 47121 & 50213 & 0,00225 & 0,02829 & 2728 & 313,37551 & 626,75102 \\
\hline 29 & 9286 & 50211 & 0,02300 & 0,11200 & 408 & 158,94587 & 317,89174 \\
\hline 30 & 39841 & 39850 & 0,01811 & 0,15403 & 645 & 142,17421 & 284,34842 \\
\hline 31 & 38853 & 39841 & 0,00469 & 0,03897 & 645 & 45,50100 & 91,00200 \\
\hline 32 & 7740 & 7900 & 0,00447 & 0,02618 & 284 & 100,93139 & 201,86278 \\
\hline 33 & 7790 & 46942 & 0,01178 & 0,08982 & 338 & 60,70629 & 97,13006 \\
\hline 34 & 6628 & 7300 & 0,00069 & 0,00827 & 2148 & 81,87943 & 163,75886 \\
\hline 35 & 7000 & 7776 & 0,00596 & 0,07137 & 284 & 58,27996 & 116,55992 \\
\hline 36 & 7760 & 6710 & 0,00095 & 0,01660 & 2716 & 158,02832 & 316,05664 \\
\hline 37 & 47121 & 7753 & 0,00115 & 0,02020 & 2716 & 187,86033 & 375,72066 \\
\hline 38 & 7739 & 7794 & 0,01894 & 0,09774 & 350 & 50,75068 & 101,50136 \\
\hline 39 & 47120 & 9261 & 0,00210 & 0,01045 & 270 & 17,60548 & 35,21096 \\
\hline 40 & 6763 & 7749 & 0,02474 & 0,12624 & 359 & 62,61748 & 125,23496 \\
\hline 41 & 7922 & 9265 & 0,00050 & 0,00400 & 335 & 11,79484 & 23,58968 \\
\hline 42 & 7748 & 6758 & 0,00052 & 0,00654 & 2363 & 80,56796 & 161,13593 \\
\hline 43 & 7306 & 9130 & 0,01066 & 0,06729 & 260 & 40,72528 & 81,45056 \\
\hline 44 & 9290 & 7812 & 0,01830 & 0,09150 & 210 & 52,51024 & 105,02048 \\
\hline 45 & 7766 & 6755 & 0,00076 & 0,01171 & 1636 & 118,93810 & 237,87620 \\
\hline 46 & 7763 & 6651 & 0,01740 & 0,08690 & 288 & 52,26472 & 104,52944 \\
\hline 47 & 9110 & 9208 & 0,00328 & 0,01542 & 270 & 16,82800 & 33,65600 \\
\hline 48 & 7749 & 7820 & 0,03041 & 0,15718 & 259 & 75,38452 & 150,76904 \\
\hline 49 & 7299 & 6616 & 0,00350 & 0,01710 & 164 & 17,76916 & 35,53832 \\
\hline 50 & 7762 & 7763 & 0,00039 & 0,01271 & 672 & 66,06618 & 132,13236 \\
\hline
\end{tabular}


(continuação Tabela B.3)

\begin{tabular}{|c|c|c|c|c|c|c|c|}
\hline $\mathbf{N}^{\circ}$ & DE & PARA & $\begin{array}{c}\boldsymbol{R}_{i j} \\
\text { (p.u.) }\end{array}$ & $\begin{array}{c}X_{i j} \\
\text { (p.u.) }\end{array}$ & $\begin{array}{l}f_{i j}^{\max } \\
\text { (MW) }\end{array}$ & $\underset{\text { (milhões de R\$) }}{c_{i j}^{1}}$ & $\begin{array}{c}c_{i j}^{2} \\
\text { (milhões de } \mathbf{R} \$)\end{array}$ \\
\hline 51 & 7748 & 6628 & 0,00212 & 0,02556 & 2363 & 248,86165 & 497,72329 \\
\hline 52 & 7021 & 7022 & 0,01720 & 0,08910 & 259 & 54,59716 & 109,19432 \\
\hline 53 & 6754 & 6601 & 0,00780 & 0,03980 & 182 & 26,52604 & 53,05208 \\
\hline 54 & 7732 & 7748 & 0,00200 & 0,02693 & 2363 & 264,18913 & 528,37826 \\
\hline 55 & 6615 & 44841 & 0,00200 & 0,00980 & 276 & 13,67716 & 27,35432 \\
\hline 56 & 6715 & 6688 & 0,01100 & 0,08890 & 280 & 53,49232 & 106,98464 \\
\hline 57 & 7732 & 7739 & 0,00031 & 0,01285 & 672 & 66,07000 & 132,14000 \\
\hline 58 & 6651 & 6688 & 0,01590 & 0,08090 & 350 & 43,46692 & 86,93384 \\
\hline 59 & 6608 & 44920 & 0,00458 & 0,03240 & 350 & 24,15268 & 48,30536 \\
\hline 60 & 6754 & 7763 & 0,01440 & 0,07270 & 237 & 39,70228 & 79,40456 \\
\hline 61 & 7921 & 9209 & 0,00280 & 0,01350 & 470 & 18,34204 & 36,68408 \\
\hline 62 & 7747 & 7725 & 0,01097 & 0,07542 & 350 & 46,29040 & 92,58080 \\
\hline 63 & 7299 & 7300 & 0,00000 & 0,01210 & 672 & 66,07000 & 132,14000 \\
\hline 64 & 6603 & 7763 & 0,00141 & 0,00834 & 390 & 25,70764 & 51,41528 \\
\hline 65 & 9192 & 7923 & 0,00682 & 0,03290 & 260 & 24,19360 & 48,38720 \\
\hline 66 & 7802 & 7808 & 0,02314 & 0,11882 & 243 & 59,54848 & 119,09696 \\
\hline 67 & 9208 & 9209 & 0,00116 & 0,00567 & 315 & 13,75900 & 27,51800 \\
\hline 68 & 6665 & 7757 & 0,02629 & 0,19266 & 338 & 102,22804 & 204,45608 \\
\hline 69 & 7734 & 7731 & 0,00601 & 0,02841 & 350 & 25,05292 & 50,10584 \\
\hline 70 & 7299 & 6761 & 0,00080 & 0,00460 & 342 & 13,06336 & 26,12672 \\
\hline 71 & 6627 & 6615 & 0,00340 & 0,01700 & 325 & 16,86892 & 33,73784 \\
\hline 72 & 7921 & 9245 & 0,00100 & 0,00530 & 540 & 14,12728 & 28,25456 \\
\hline 73 & 7740 & 7808 & 0,00235 & 0,01327 & 328 & 18,01468 & 36,02936 \\
\hline 74 & 6651 & 7042 & 0,01442 & 0,08049 & 160 & 25,95316 & 51,90632 \\
\hline 75 & 6627 & 6618 & 0,00610 & 0,03250 & 243 & 22,63864 & 45,27728 \\
\hline 76 & 7304 & 7747 & 0,00543 & 0,03731 & 350 & 26,19868 & 52,39736 \\
\hline 77 & 6715 & 7042 & 0,00363 & 0,02654 & 350 & 21,86116 & 43,72232 \\
\hline 78 & 7812 & 8321 & 0,02584 & 0,13090 & 160 & 65,23636 & 130,47272 \\
\hline 79 & 9110 & 9051 & 0,00043 & 0,00236 & 290 & 14,49556 & 28,99112 \\
\hline 80 & 6619 & 7739 & 0,00011 & 0,00010 & 684 & 9,74884 & 19,49768 \\
\hline 81 & 7763 & 6708 & 0,01569 & 0,08142 & 238 & 48,33640 & 96,67280 \\
\hline 82 & 7824 & 7823 & 0,00019 & 0,00097 & 547 & 12,04036 & 24,08072 \\
\hline 83 & 6763 & 7739 & 0,02210 & 0,11475 & 259 & 57,58432 & 115,16864 \\
\hline 84 & 6627 & 6733 & 0,01600 & 0,08070 & 175 & 43,67152 & 87,34304 \\
\hline 85 & 6649 & 6626 & 0,00069 & 0,01294 & 3455 & 142,70084 & 285,40168 \\
\hline 86 & 7755 & 38857 & 0,01140 & 0,09730 & 669 & 70,88332 & 141,76664 \\
\hline 87 & 7722 & 7752 & 0,00289 & 0,03648 & 2108 & 338,56342 & 677,12683 \\
\hline 88 & 7719 & 7722 & 0,00073 & 0,00917 & 2363 & 103,61062 & 207,22124 \\
\hline 89 & 7751 & 7722 & 0,00164 & 0,03034 & 2937 & 285,79162 & 571,58324 \\
\hline 90 & 9272 & 9188 & 0,01920 & 0,09630 & 340 & 55,29280 & 110,58560 \\
\hline 91 & 50220 & 7922 & 0,02205 & 0,17910 & 441 & 92,65276 & 185,30552 \\
\hline 92 & 9233 & 9040 & 0,00027 & 0,00179 & 540 & 9,99436 & 19,98872 \\
\hline 93 & 9209 & 9204 & 0,00007 & 0,00499 & 362 & 13,26796 & 26,53592 \\
\hline 94 & 7304 & 9180 & 0,00671 & 0,05258 & 350 & 23,82532 & 47,65064 \\
\hline 95 & 9100 & 7782 & 0,00400 & 0,02000 & 329 & 56,72500 & 113,45000 \\
\hline 96 & 7743 & 7823 & 0,00524 & 0,02704 & 300 & 21,12460 & 42,24920 \\
\hline 97 & 9110 & 9350 & 0,00386 & 0,01790 & 210 & 17,76916 & 35,53832 \\
\hline 98 & 7743 & 7824 & 0,00533 & 0,02744 & 300 & 20,92000 & 41,84000 \\
\hline 99 & 6627 & 6628 & 0,00000 & 0,01210 & 600 & 66,07000 & 132,14000 \\
\hline 100 & 6625 & 6626 & 0,00000 & 0,01230 & 600 & 66,07000 & 132,14000 \\
\hline
\end{tabular}


(continuação Tabela B.3)

\begin{tabular}{||c|c|c|c|c|c|c|c||}
\hline $\mathbf{N}^{\circ}$ & $\mathbf{D E}$ & $\mathbf{P A R A}$ & $\begin{array}{c}\boldsymbol{R}_{i j} \\
\text { (p.u.) }\end{array}$ & $\begin{array}{c}\boldsymbol{X}_{i j} \\
\text { (p.u.) }\end{array}$ & $\begin{array}{c}f_{i j}^{\max } \\
(\mathbf{M W})\end{array}$ & $\begin{array}{c}c_{i j}^{1} \\
\text { (milhões de R\$) }\end{array}$ & $\begin{array}{c}c_{i j}^{2} \\
\text { (milhões de R\$) }\end{array}$ \\
\hline 101 & 7820 & 6730 & 0,01327 & 0,08355 & 417 & 44,81728 & 89,63456 \\
\hline 102 & 6624 & 6625 & 0,00220 & 0,01090 & 357 & 14,25004 & 28,50008 \\
\hline 103 & 7736 & 7752 & 0,00164 & 0,02769 & 2655 & 287,43752 & 574,87504 \\
\hline 104 & 7922 & 9188 & 0,01440 & 0,07240 & 340 & 35,89672 & 71,79344 \\
\hline 105 & 9290 & 9310 & 0,01550 & 0,05910 & 179 & 34,34176 & 68,68352 \\
\hline 106 & 7736 & 7748 & 0,00162 & 0,02048 & 2363 & 203,70216 & 407,40431 \\
\hline 107 & 7751 & 7736 & 0,00188 & 0,02325 & 2120 & 231,47679 & 462,95357 \\
\hline 108 & 7751 & 7750 & 0,00073 & 0,00916 & 2120 & 102,58193 & 205,16386 \\
\hline \hline
\end{tabular}




\section{Apêndice C. \\ Caso tutorial - Sistema Garver}

Neste apêndice é apresentado um estudo de caso tutorial para o emprego do algoritmo metaheurístico construtivo (AMC-PET) proposto nesta tese, onde é realizada a solução e análise do problema de planejamento da transmissão para um sistema teste de pequeno porte, o Sistema Garver [23]. Este estudo visa facilitar o entendimento do funcionamento da ferramenta proposta. Incialmente, são apresentados os dados do sistema teste utilizado e uma análise da topologia base de sua rede. Em seguida, são ilustradas as etapas do AMC-PET realizadas para solução do problema.

\section{C.1.}

\section{Sistema Garver}

O Sistema Garver, proposto em [23] e apresentado no diagrama da Figura C.1, é formado por um total de 6 barras, das quais 5 estão inicialmente conectadas à rede da topologia base (barras de 1 a 5). A barra isolada (6) é uma barra de geração. Os dados de barra do Sistema Garver estão presentes na Tabela C.1.

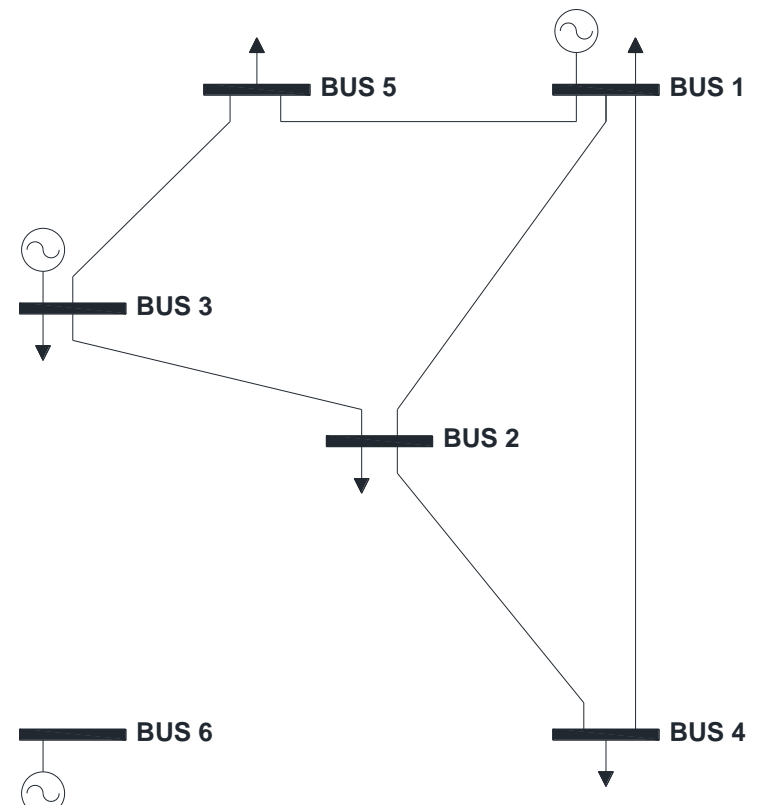

Figura C.1 - Diagrama do Sistema Garver [23]. 
Tabela C.1 - Dados de barra - Sistema Garver.

\begin{tabular}{|c|c|c|c||}
\hline Barra & $\begin{array}{c}\text { Carga } \\
\text { (MW) }\end{array}$ & $\begin{array}{c}\text { Geração } \\
\text { Máxima } \\
\text { (MW) }\end{array}$ & $\begin{array}{c}\text { Prioridade } \\
\text { no Despacho } \\
\text { da Geração }\end{array}$ \\
\hline 1 & 80 & 150 & 3 \\
\hline 2 & 240 & 0 & - \\
\hline 3 & 40 & 360 & 2 \\
\hline 4 & 160 & 0 & - \\
\hline 5 & 240 & 0 & - \\
\hline 6 & 0 & 600 & 1 \\
\hline TOTAL: & 760 & 1110 & \multicolumn{2}{|l}{} \\
\hline
\end{tabular}

Verifica-se, a partir de uma simples análise dos montantes de geração e de carga do sistema, que é necessária a conexão da barra de geração isolada à rede para que a carga possa ser atendida em sua totalidade. Sem essa barra, o montante de carga excede a capacidade máxima de geração em 250 MW. Além disso, considerando-se as restrições de capacidade dos circuitos e os montantes de perdas ôhmicas, espera-se que sejam necessários novos reforços, além daquele(s) de conexão da barra de geração isolada. Isso, para garantir a operação do sistema sem cortes de carga na condição de rede intacta e, ainda, sem sobrecargas dos equipamentos e/ou cortes por ilhamento em caso de contingência na transmissão.

Estão presentes na topologia base do Sistema Garver 6 circuitos, distribuídos em 6 ramos, conforme Figura C.1. Estes ramos, mais 9 ramos novos, são considerados como candidatos a receberem reforços na expansão da transmissão. As informações relativas a esses ramos estão apresentadas na Tabela C.2.

Tabela C.2 - Dados de ramos candidatos - Sistema Garver.

\begin{tabular}{||c|c|c|c|c|c|c|c||}
\hline \hline $\mathbf{N}^{\circ}$ & $\mathbf{D E}$ & PARA & $\begin{array}{c}\text { Circuitos } \\
\text { existentes }\end{array}$ & $\begin{array}{c}\boldsymbol{R}_{\boldsymbol{i j}} \\
(\mathbf{p . u .})\end{array}$ & $\begin{array}{c}\boldsymbol{X}_{\boldsymbol{i j}} \\
(\mathbf{p . u .})\end{array}$ & $\begin{array}{c}f_{i j}^{\max } \\
(\mathbf{M W})\end{array}$ & $\begin{array}{c}\boldsymbol{c}_{\boldsymbol{i j}} \\
\left(\mathbf{1 0} \mathbf{3}^{\mathbf{2}} \times \mathbf{\$}\right)\end{array}$ \\
\hline 01 & 1 & 2 & 1 & 0,10 & 0,40 & 100 & 40 \\
\hline 02 & 1 & 4 & 1 & 0,15 & 0,60 & 80 & 60 \\
\hline 03 & 1 & 5 & 1 & 0,05 & 0,20 & 100 & 20 \\
\hline 04 & 2 & 3 & 1 & 0,05 & 0,20 & 100 & 20 \\
\hline 05 & 2 & 4 & 1 & 0,10 & 0,40 & 100 & 40 \\
\hline 06 & 3 & 5 & 1 & 0,05 & 0,20 & 100 & 20 \\
\hline 07 & 1 & 3 & 0 & 0,09 & 0,38 & 100 & 38 \\
\hline 08 & 1 & 6 & 0 & 0,17 & 0,68 & 70 & 68 \\
\hline 09 & 2 & 5 & 0 & 0,08 & 0,31 & 100 & 31 \\
\hline 10 & 2 & 6 & 0 & 0,08 & 0,30 & 100 & 30 \\
\hline 11 & 3 & 4 & 0 & 0,15 & 0,59 & 82 & 59 \\
\hline 12 & 3 & 6 & 0 & 0,12 & 0,48 & 100 & 48 \\
\hline 13 & 4 & 5 & 0 & 0,16 & 0,63 & 75 & 63 \\
\hline 14 & 4 & 6 & 0 & 0,08 & 0,30 & 100 & 30 \\
\hline 15 & 5 & 6 & 0 & 0,15 & 0,61 & 78 & 61 \\
\hline
\end{tabular}


Após solução do subproblema de operação, conforme problema de otimização (3.5) apresentado na Subseção 3.7.2, quando é considerada a topologia base do sistema, verifica-se um corte de carga de 391,67 MW e perdas ôhmicas de 26,67 MW. Nesta condição, os ramos do Sistema Garver apresentam os fluxos dispostos na Tabela C.3. Nesta tabela, a última coluna representa os valores calculados para o índice de carregamento hipotético $\left(I n d_{c h-i j}\right)$, conforme equação (3.1) apresentada na Subseção 3.3.1. Cabe salientar que os índices de sensibilidade não são aplicados à topologia base (primeiro nível construtivo). No entanto, esta seção visa apenas descrever o comportamento/utilização destes índices, o que pode ser realizado, sem qualquer prejuízo para seu entendimento, com o emprego da configuração inicial do sistema.

Tabela C.3 - Fluxos de potência - Topologia base - Sistema Garver.

\begin{tabular}{||c|c|r|r|r|r||}
\hline $\mathbf{N}^{\circ}$ & $\mathbf{D E}$ & $\mathbf{P A R A}$ & $\begin{array}{c}\boldsymbol{f}_{i j} \\
(\mathbf{M W})\end{array}$ & $\begin{array}{c}f_{i j}^{\max } \\
(\mathbf{M W})\end{array}$ & $\begin{array}{c}\text { Ind }_{c h-i j} \\
(\mathbf{p . u} .)\end{array}$ \\
\hline 01 & 1 & 2 & 0 & 100 & 0 \\
\hline 02 & 1 & 4 & 66,67 & 80 & 0,83 \\
\hline 03 & 1 & 5 & 0 & 100 & 0 \\
\hline 04 & 2 & 3 & 100,00 & 100 & 1,00 \\
\hline 05 & 2 & 4 & 100,00 & 100 & 1,00 \\
\hline 06 & 3 & 5 & 100,00 & 100 & 1,00 \\
\hline 07 & 1 & 3 & 0 & 100 & 0,53 \\
\hline 08 & 1 & 6 & 0 & 70 & - \\
\hline 09 & 2 & 5 & 0 & 100 & 0 \\
\hline 10 & 2 & 6 & 0 & 100 & - \\
\hline 11 & 3 & 4 & 0 & 82 & 1,24 \\
\hline 12 & 3 & 6 & 0 & 100 & - \\
\hline 13 & 4 & 5 & 0 & 75 & 0,85 \\
\hline 14 & 4 & 6 & 0 & 100 & - \\
\hline 15 & 5 & 6 & 0 & 78 & - \\
\hline
\end{tabular}

Verifica-se que mesmo para os ramos 7, 9, 11 e 13, os quais são inativos na topologia base, são apresentados valores para o índice $I n d_{c h-i j}$. Já para os ramos inativos $8,10,12,14$ e 15, responsáveis pela interligação da barra de geração isolada (6) à rede, não é possível calcular um valor para o índice de carregamento hipotético. Isto se deve ao fato de que o ângulo de tensão da barra $6\left(\theta_{6}\right)$ não é definido/obtido após solução do problema (3.5). Dessa forma, se o mecanismo de adição (MA) do AMC-PET fosse empregado à topologia base do Sistema Garver para classificação dos ramos candidatos mais atrativos, estes últimos ramos inati- 
vos só poderiam ser selecionados a partir da taxa de adição definida pelo planejador, conforme apresentado na Subseção 3.3.2.

$\mathrm{Na}$ análise de contingência simples da rede de transmissão (critério "N-1"), para a qual é mantido o despacho obtido para rede intacta, verifica-se um montante de 183,00 MW de sobrecarga. Nenhum corte de carga por ilhamento é verificado no estudo de contingências. Na Tabela C.4, a seguir, são apresentados os valores de sobrecargas resultantes da perda de circuitos nos ramos ativos da rede de transmissão. As linhas nesta tabela estão associadas a cada ramo contingenciado. Nas colunas, são apresentadas as eventuais sobrecargas em cada um dos ramos remanescentes.

Tabela C.4 - Sobrecargas resultantes do estudo de contingências - Sistema Garver.

\begin{tabular}{|c|c|c|c|c|c|c|c|c|}
\hline \multicolumn{2}{|c|}{$\begin{array}{c}\text { Ramo da } \\
\text { Contingência } c\end{array}$} & \multicolumn{6}{|c|}{ Sobrecarga no Ramo $i-j$ (MW) } & \multirow{2}{*}{$\begin{array}{r}\text { Ind } d_{s c-i j}^{\text {outro }} \\
\text { (MW) }\end{array}$} \\
\hline DE & PARA & $1-2$ & $1-4$ & $1-5$ & $2-3$ & $2-4$ & $3-5$ & \\
\hline 1 & 2 & - & 3,33 & 0 & 0 & 0 & 0 & 3,33 \\
\hline 1 & 4 & 0 & - & & 11,11 & 66,66 & & 77,77 \\
\hline 1 & 5 & 0 & 0 & - & 0 & 0 & 0 & 0 \\
\hline 2 & 3 & 0 & 15,24 & 0 & - & 0 & 0 & 15,24 \\
\hline 2 & 4 & 0 & 86,66 & 0 & 0 & - & 0 & 86,66 \\
\hline 3 & 5 & 0 & 0 & 0 & 0 & 0 & - & 0 \\
\hline \multicolumn{2}{|c|}{$\begin{array}{c}\text { Ind } \\
\text { próprio } \\
\text { (MW) }\end{array}$} & 0 & 105,23 & 0 & 11,11 & 66,66 & 0 & - \\
\hline
\end{tabular}

Os índices de sobrecarga $\operatorname{Ind}_{s c-i j}^{\text {próprio }}$ e $\operatorname{Ind}_{s c-i j}^{\text {outros }}$ são calculados para os ramos da Tabela C.4 conforme equações (3.2) e (3.3), respectivamente. Tais índices são apresentados na última linha ( $\left.I n d_{s c-i j}^{\text {próprio }}\right)$ e última coluna ( $\left.I n d_{s c-i j}^{\text {outros }}\right)$ desta mesma tabela. Percebe-se que o ramo entre as barras 1 e 4 (ramo 1-4) apresenta o maior valor do $\operatorname{Ind}_{s c-i j}^{\text {próprio }}(105,23 \mathrm{MW})$. Já o índice $\operatorname{Ind} d_{s c-i j}^{\text {outros }}$ tem seu maior valor encontrado para o ramo 2-4 (86,66 MW).

A partir dessas informações, é possível avaliar, em termos de aptidão, a topologia base da rede para o Sistema Garver, conforme função objetivo (3.4a) do subproblema de investimento. Neste caso, a topologia base é representada por uma plano de expansão $n$, em que todos os componentes $n_{i j}$ são preenchidos com valor 0 (zero), ou seja, o plano não possui qualquer reforço previsto. Sendo assim, 
o investimento apresentado para esse plano é nulo $\left(\sum_{(i j) \in \Omega_{r}} c_{i j} n_{i j}=0\right)$. Considerando a penalidade $\alpha_{i n v}$ do subproblema de investimento igual a $10^{3} \$ / \mathrm{MW}$, a função objetivo $f(n)$ apresentaria o valor de $574,67 \times 10^{3} \$$, sendo $c c(n)=391,67 \mathrm{MW}$ e $\sum_{c=1}^{n c}\left[c c i(n)_{c}+s c(n)_{c}\right]=183,00 \mathrm{MW}$.

\section{C.2.}

\section{Execução do AMC-PET}

Para realização e análise de uma execução do AMC-PET, quando empregado na solução do problema de planejamento da transmissão para o Sistema Garver, são definidos os seguintes valores para os parâmetros da ferramenta:

- $n_{\mathrm{MA}}=n_{\mathrm{MCM}}=5$ (tamanhos dos conjuntos $\Omega_{\mathrm{MA}}$ e $\left.\Omega_{\mathrm{MCM}}\right) ;$

- $n_{\mathrm{V}}=10\left(\right.$ tamanho do conjunto $\left.\Omega_{\mathrm{V}}\right)$;

- $n_{r}=3$ no emprego do MA, sendo um ramo selecionado a partir de cada um dos três índices de atratividade apresentados na Subseção 3.3.1 $\left(\operatorname{Ind}_{c h-i j}, \operatorname{Ind}_{s c-i j}^{\text {próprio }}\right.$ e $\left.\operatorname{Ind} d_{s c-i j}^{\text {outros }}\right)$;

- Taxa de adição igual a 50\% no MA;

- Taxas de cruzamento e de mutação dos mecanismos MC e MM iguais, respectivamente, a $65 \%$ e $8 \%$;

- $n_{p}=3$ (critério de convergência: estagnação da melhor solução viável).

Para realização deste estudo, é utilizado o AMC-PET apresentado no Capítulo 3 considerando os ajustes descritos nas Seções 4.6 e 5.3.

\section{C.2.1.}

\section{Primeiro Nível Construtivo}

Para cumprir o primeiro nível construtivo do AMC-PET, conforme apresentado na Seção 3.4, são criados 15 novos indivíduos a partir da topologia base da rede, sendo cada indivíduo formado pela adição de um reforço em cada ramo candidato do problema.

Cada um dos 15 indivíduos criados é avaliado, assim como apresentado na Seção C.1 para a topologia base. Dos 15 indivíduos, os 5 ( $\left.n_{\mathrm{MA}}\right)$ que apresentam as 
melhores aptidões são selecionados e armazenados no conjunto $\Omega_{\mathrm{MA}}$. Os indivíduos selecionados possuem um reforço nos ramos candidatos 2, 5, 9, 11 e 13, com aptidões, respectivamente, de $452,86 \times 10^{3} \$, 459,66 \times 10^{3} \$, 585,02 \times 10^{3} \$$, $421,19 \times 10^{3} \$$ e $468,47 \times 10^{3} \$$.

Os conjuntos $\Omega_{\mathrm{MCM}}, \Omega_{\mathrm{MD}}$ e $\Omega_{\mathrm{V}}$ permanecem vazios no primeiro nível construtivo.

\section{C.2.2.}

\section{Demais Níveis Construtivos}

A partir do segundo nível construtivo, os mecanismos de adição (MA), de cruzamento (MC), de mutação (MM), de seleção (MS) e de depuração (MD) passam a ser empregados às soluções em construção, conforme dinâmica do processo construtivo apresentada na Seção 3.6. O mecanismo de refinamento (MR) relaxado é também empregado às soluções viáveis durante o processo construtivo, de acordo com o ajuste do AMC-PET proposto na Seção 5.3.

$\mathrm{Na}$ Tabela C.5 a seguir, estão presentes os números de indivíduos gerados e avaliados nos passos (i), (ii) e (iv) do processo dentro de cada nível construtivo, a partir do segundo, conforme algoritmo apresentado na Seção 3.4. Estão também presentes nesta tabela, para cada nível, o número de indivíduos viáveis do conjunto $\Omega_{\mathrm{V}}$ e informações relativas ao melhor indivíduo em construção.

Tabela C.5 - Evolução do processo construtivo - AMC-PET - Sistema Garver.

\begin{tabular}{|c|c|c|c|c|c|c|}
\hline \multirow{2}{*}{$\begin{array}{l}\text { Nível } \\
\text { Const. }\end{array}$} & \multicolumn{3}{|c|}{ Número de indivíduos avaliados } & \multirow{2}{*}{$\begin{array}{c}\text { Indivíduos } \\
\text { no conjunto } \\
\Omega_{\mathrm{V}}\end{array}$} & \multicolumn{2}{|c|}{ Melhor indivíduo } \\
\hline & $\begin{array}{c}\text { Passo (i) } \\
\text { MA }\end{array}$ & $\begin{array}{l}\text { Passo (ii) } \\
\text { MC e MM }\end{array}$ & $\begin{array}{c}\text { Passo (iv) } \\
\text { MD }\end{array}$ & & $\begin{array}{l}\text { Aptidão } \\
\left(10^{3} \times \$\right)\end{array}$ & $\begin{array}{c}\text { Invest. } \\
\left(10^{3} \times \$\right)\end{array}$ \\
\hline 2 & 29 & 5 & 8 & 0 & 376,43 & 99,00 \\
\hline 3 & 89 & 18 & 9 & 0 & 376,43 & 99,00 \\
\hline 4 & 100 & 19 & 9 & 0 & 371,30 & 80,00 \\
\hline 5 & 111 & 19 & 10 & 0 & 363,61 & 100,00 \\
\hline 6 & 94 & 20 & 9 & 0 & 325,67 & 131,00 \\
\hline 7 & 85 & 19 & 10 & 0 & 260,06 & 161,00 \\
\hline 8 & 82 & 20 & 9 & 0 & 188,09 & 150,00 \\
\hline 9 & 61 & 19 & 10 & 0 & 188,09 & 150,00 \\
\hline 10 & 66 & 20 & 10 & 4 & 210,00 & 210,00 \\
\hline 11 & 58 & 24 & 8 & 9 & 210,00 & 210,00 \\
\hline 12 & 50 & 28 & 10 & 10 & 190,00 & 190,00 \\
\hline 13 & 51 & 30 & 7 & 10 & 170,00 & 170,00 \\
\hline 14 & 39 & 26 & 8 & 10 & 170,00 & 170,00 \\
\hline 15 & 47 & 29 & 7 & 10 & 170,00 & 170,00 \\
\hline
\end{tabular}


De acordo com a execução analisada, são necessários 15 níveis construtivos para atendimento do critério de convergência adotado $\left(n_{p}=3\right)$. Isto significa que novos indivíduos viáveis de melhor qualidade são identificados até o décimo terceiro nível construtivo.

De forma geral, verifica-se que o maior número de avaliações de indivíduos acontece no passo (i) do AMC-PET, com o emprego do MA. Para cada indivíduo apresentado ao mecanismo, é gerado um total de indivíduos igual a $n_{r}$ (i.e., 3) mais o número de ramos selecionados a partir da taxa de adição considerada (aproximadamente $50 \%$ dos 5 ramos para conexão da barra isolada), conforme apresentado na Subseção 3.3.2. Desses, apenas um indivíduo segue no processo construtivo, aquele que apresenta a melhor aptidão. No segundo nível construtivo da execução analisada, o MA é empregado aos 5 indivíduos do conjunto $\Omega_{\mathrm{MA}}$, provenientes do primeiro nível, gerando outros 5 indivíduos com mais um reforço, os quais formarão o novo $\Omega_{\mathrm{MA}}$. A partir do terceiro nível construtivo, este mecanismo é empregado em até 20 indivíduos $\left(n_{\mathrm{MA}}+n_{\mathrm{MCM}}+n_{\mathrm{MD}}=5+5+10\right)$, pertencentes aos conjuntos $\Omega_{\mathrm{MA}}, \Omega_{\mathrm{MCM}}$ e $\Omega_{\mathrm{MD}}$.

Verifica-se a partir do terceiro nível construtivo na Tabela C.5 que o número de indivíduos gerados e avaliados no MA decresce com a evolução do processo construtivo. Isso ocorre uma vez que os indivíduos em construção passam a apresentar reforços nos ramos de interligação da barra isolada. Dessa forma, esses ramos deixam de ser selecionados a partir da taxa de adição, podendo também ser avaliados e selecionados por meio dos índices de atratividade, participando, assim, dos $n_{r}$ ramos selecionados. Além do mais, existe a possibilidade de geração de indivíduos repetidos, os quais são avaliados apenas uma vez.

No emprego dos mecanismos MC e MM, cumprindo o passo (ii) do AMCPET, é gerado um número de indivíduos igual ao número de indivíduos criados no passo (i) mais o de indivíduos viáveis presentes no conjunto $\Omega_{\mathrm{V}}$. No segundo nível construtivo, quando apenas os 5 indivíduos gerados no passo (i) são progenitores, 5 indivíduos são gerados e avaliados. A partir do terceiro e até décimo nível construtivo (o qual recebe $\Omega_{\mathrm{V}}$ vazio), são gerados até 20 indivíduos, a depender do número de indivíduos resultantes do emprego do MA no passo (i). Do décimo primeiro nível ( $\Omega_{\mathrm{V}}$ inicial não mais vazio) até a convergência do processo construtivo, um número maior que 20 indivíduos pode ser gerado, o que é verificado nos resultados apresentados na Tabela C.5. 
No passo (iv), é realizado o emprego do MD aos indivíduos dos conjuntos $\Omega_{\mathrm{MA}}$ e $\Omega_{\mathrm{MCM}}$ e eventuais indivíduos viáveis identificados no nível construtivo corrente. Dessa forma, do segundo ao nono nível construtivo, quando indivíduos viáveis ainda não haviam sido identificados, foram gerados e avaliados até 10 $\left(n_{\mathrm{MA}}+n_{\mathrm{MCM}}\right)$ indivíduos. Cabe destacar que indivíduos repetidos podem ser gerados a partir da depuração, o que justifica um número de indivíduos menor que 10 para alguns dos níveis construtivos. Já a partir do décimo nível, era de se esperar um número maior que 10 indivíduos fosse gerado pelo MD, uma vez que indivíduos viáveis identificados também passam pela depuração. Contudo, mesmo com a utilização da estratégia de diversidade exposta na Seção 4.6, os indivíduos em construção passam a apresentar subconjuntos de reforços parecidos, o que aumenta as chances de se gerar indivíduos repetidos com a depuração.

Verifica-se na Tabela C.5, que o conjunto $\Omega_{\mathrm{V}}$ termina o processo com 10 indivíduos, conforme limite estabelecido pelo parâmetro $n_{\mathrm{V}}$. As informações desses 10 indivíduos, obtidos após a convergência do processo construtivo, estão presentes na Tabela C.6 a seguir.

Tabela C.6 - Melhores soluções com execução única do AMC-PET - Sistema Garver.

\begin{tabular}{|c|c|c|c|}
\hline Plano & $\begin{array}{c}\text { Investimento } \\
\left(\mathbf{1 0}^{\mathbf{3}} \times \mathbf{\$}\right)\end{array}$ & $\begin{array}{c}\text { Total de } \\
\text { Ramos }\end{array}$ & $\begin{array}{c}\text { Total de } \\
\text { Reforços }\end{array}$ \\
\hline E1-G.1 & 170,00 & 5 & 7 \\
\hline E1-G.2 & 190,00 & 3 & 7 \\
\hline E1-G.3 & 200,00 & 4 & 8 \\
\hline E1-G.4 & 211,00 & 5 & 8 \\
\hline E1-G.5 & 218,00 & 5 & 8 \\
\hline E1-G.6 & 231,00 & 5 & 8 \\
\hline E1-G.7 & 239,00 & 5 & 8 \\
\hline E1-G.8 & 240,00 & 5 & 9 \\
\hline E1-G.9 & 260,00 & 5 & 9 \\
\hline E1-G.10 & 270,00 & 6 & 8 \\
\hline
\end{tabular}

\section{C.2.3.}

\section{Refinamento das Soluções Finais}

Após convergência do processo construtivo, é empregado o mecanismo de refinamento (MR) às soluções do conjunto $\Omega_{\mathrm{V}}$, conforme descrito na Subseção 3.3.7. Contudo, uma vez que a versão relaxada deste mecanismo foi sendo aplicado a cada solução viável identificada durante o processo construtivo, e dadas as 
dimensões reduzidas deste problema, nenhum reforço foi eliminado das soluções viáveis finais após convergência do processo. Portanto, as melhores soluções apresentadas na Tabela C.6 correspondem também às melhores soluções identificadas em apenas uma execução do AMC-PET para solução do problema com o Sistema Garver.

\section{C.3.}

\section{Considerações Finais}

A fim de verificar estatisticamente o desempenho do AMC-PET na solução do problema de planejamento para o Sistema Garver, foram realizadas 100 execuções do algoritmo considerando os parâmetros ajustados para a execução única apresentada na Seção C.2. As 10 melhores soluções identificadas em todas as execuções são apresentadas na Tabela C.7 a seguir.

Tabela C.7 - Melhores soluções identificadas - Sistema Garver.

\begin{tabular}{|c|c|c|c|}
\hline Plano & $\begin{array}{c}\text { Investimento } \\
(\mathbf{1 0} \mathbf{3} \times \mathbf{\$})\end{array}$ & $\begin{array}{c}\text { Total de } \\
\text { Ramos }\end{array}$ & $\begin{array}{c}\text { Total de } \\
\text { Reforços }\end{array}$ \\
\hline AMC-G.1 & 170,00 & 5 & 7 \\
\hline AMC-G.2 & 190,00 & 3 & 7 \\
\hline AMC-G.3 & 190,00 & 4 & 8 \\
\hline AMC-G.4 & 200,00 & 4 & 8 \\
\hline AMC-G.5 & 201,00 & 5 & 8 \\
\hline AMC-G.6 & 208,00 & 5 & 8 \\
\hline AMC-G.7 & 210,00 & 4 & 9 \\
\hline AMC-G.8 & 210,00 & 5 & 9 \\
\hline AMC-G.9 & 210,00 & 4 & 8 \\
\hline AMC-G.10 & 210,00 & 5 & 8 \\
\hline
\end{tabular}

Os índices de desempenho apresentados na Seção 4.2 foram calculados para as 100 execuções realizadas. A taxa de sucesso $\mathrm{T}_{\mathrm{S}}$ obtida foi de $100 \%$, ou seja, em todas as execuções foi identificada pelo menos uma das 10 melhores soluções da Tabela C.7. Em média, foram gastos $3,68 \times 10^{-3}$ segundos para realização de cada execução $\left(\mathrm{T}_{\mathrm{M}}=3,68 \times 10^{-3} \mathrm{~s}\right)$. Os índices $\mathrm{D}_{\text {Best }}$ e $\mathrm{D}_{10 \text { Best }}$ foram calculados com base na melhor solução da Tabela C.7 e apresentaram, respectivamente, 0,24\% e 28,54\%. A partir dos valores obtidos para estes índices, pode-se dizer que o AMC-PET demonstrou um bom desempenho, mesmo para o índice $\mathrm{D}_{10 \mathrm{Best}}$, cujo limite mínimo é de $17,59 \%$, valor obtido aplicando-se o cálculo de $\mathrm{D}_{10 \text { Best }}$ às soluções da Tabela C.7. 
A melhor solução identificada, a qual foi também encontrada na execução única apresentada na Seção C.2, está representada no diagrama da Figura C.2. No diagrama, os circuitos em vermelho com linha tracejada representam os reforços previstos nesta solução. Um montante de 33,22 MW de perdas ôhmicas é obtido para esta configuração.

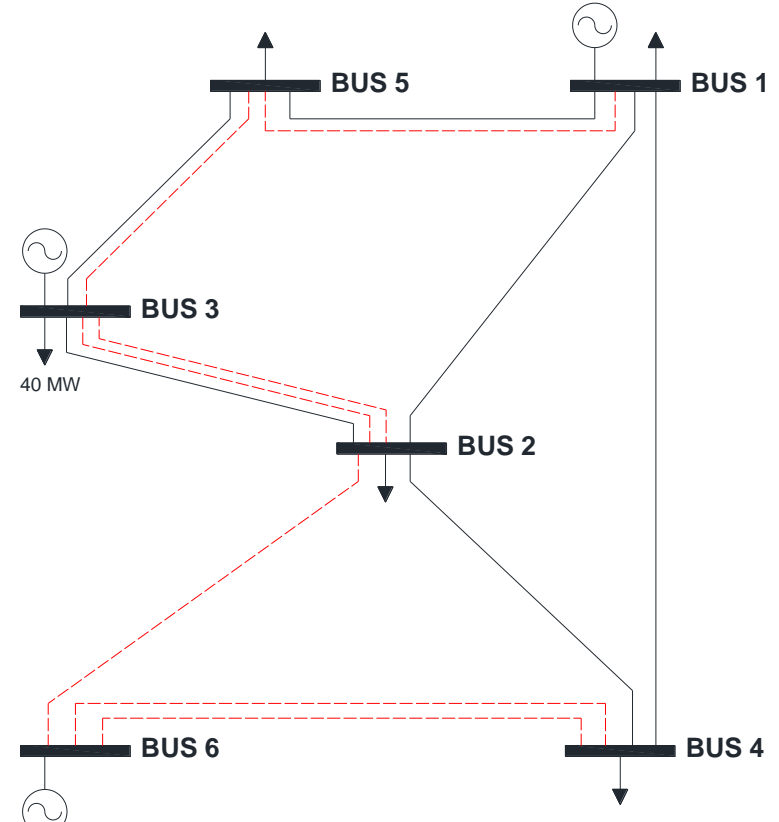

Figura C.2 - Diagrama do Sistema Garver com plano AMC-G.1.

No diagrama da Figura C.2 é possível verificar que dos 15 ramos candidatos ao reforço, apenas 5 recebem novos circuitos. Nesta solução, a barra 6 , que na topologia base do sistema se encontra isolada, é interligada à rede por meio de 3 reforços, em 2 ramos candidatos. 